Gas Separations Using Ceramic Membranes

Final Report

September 1988 - February 1993

C.L. Lin

J.C.S. Wu

G.R. Gallaher

G.W. Smith

D.L. Flowers

T.E. Gerdes

P.K.T. Liu

Work Performed Under Contract No.: DE-AC21-88MC25135

For

U.S. Department of Energy

Office of Fossil Energy

Morgantown Energy Technology Center

P.0. Box 880

Morgantown, West Virginia 26507-0880

\author{
By \\ Aluminum Company of America \\ Alcoa Technical Center \\ 100 Technical Drive \\ Alcoa Center, Pennsylvania 15069
}

February 1993 


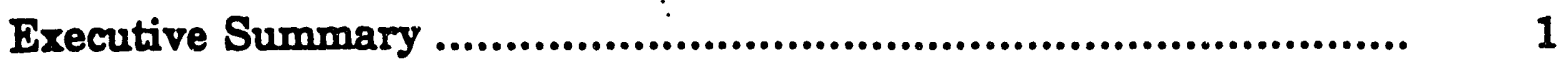

1. Introduction ............................................................ 2

2. Characterization of Existing Membranes ............................. 4

2.1 Morphology ............................................................... 4

2.2 Pore Size Distribution ................................................... 6

2.2.1 Methodology ................................................................. 6

2.2.2 Results and Discussion .............................................

2.3 Pure Component Gas Permeability................................. 11

2.3.1 Methodology ........................................................ 11

2.3.2 Results and Discussion .............................................. 15

2.4 Thermal and Hydrothermal Stability ................................ 22

2.4.1 Thermal Stability ................................................ 22

2.4.1.1 Methodology .............................................. 22

2.4.1.2 Results and Discussion ....................... 25

2.4.2 Hydrothermal Stability ......................................... 34

2.4.2.1 Methodology ........................................ 34

2.4.2.2 Results and Discussion .......................... 34

2.5 Chemical Stability ......................................................... 40

2.5.1 Methodology ........................................................... 40

2.5.2 Results and Discussion ...................................... 40

3. G\&s Separations with Existing Membranes .......................... 45

3.1 Introduction ............................................................ 45

3.2 Literature Review............................................................ 46

3.3 Experiment (.................................................................. 48

3.4 Mathematical Model............................................................ 48

3.4.1 Basic Assumptions ................................................. 48

3.4.2 Mass Transport Through Porous Membrane ........ 52

3.5 Results and Discussion ............................................... 55

3.5.1 Permeation with Single Components ...................... 55

3.5.2 Separations of Binary Mixtures.............................

3.5.3 Error Analysis ................................................. 64

3.5.4 Effect of Pressure Ratio and Feed Pressure............ 64

3.5.5 Effect of Temperature ............................................... 6

3.5.6 Effect of Concentration ................................................. 6

3.5.7 Effect of Pore Size ..................................................

3.5.8 Effect of Stage Cut ............................................. 70

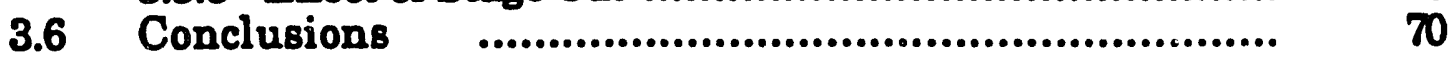

4. Modifications of Commercial Ceramic Membranes................. 73

4.1 Introduction .......................................................... 73

4.2 Literature Review...................................................... 73

4.3 Deposition Chemistry and Methodology …..................... 73 
4.4 Morphological Characterization with SEM/EDAX ......... 74

4.5 Characterization of Microporous Structure with Pore Size Distribution Analyzer .............................. 81

4.6 Characterization with Gaseous Molecules as Probes ..... 92

4.6.1 Porous Membranes .......................................... 92

4.6.2 Dense Phase Membranes ............................... 92

4.7 Reproducibility and Scale-up of Chemical Vapor Deposition $\quad$....................................................... 94

4.8 Thermal Stability of Silica Modified Membranes ............ 101

4.9 Hydrothermal Stability of Silica Modified Membranes ... 109

4.10 Thermal/Hydrothermal Stabilities of $\mathrm{La}_{2} \mathrm{O}_{3}$ Modified Membranes .................................................. 114

4.11 Zirconia Modified Membranes ......................................... 115

5. Membrane Modification by In-situ Zeolite Crystallization ....... 120

5.1 Pretreatment ....................................................... 120

5.2 Synthesis Procedures ......................................................... 121

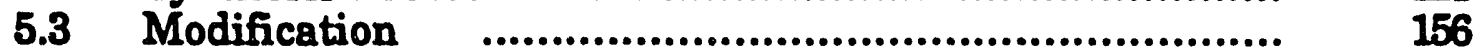

6. Gas Separations Using Modified Membranes ......................... 158

6.1 Introduction ........................................................... 158

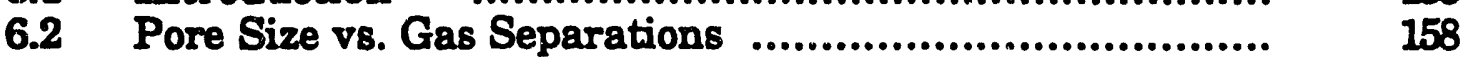

6.3 Literature Review on Si-Modified Membranes ................ 160

6.4 Separations of Gas Mixtures using Si-Modified Membranes (.......................................................... 162

6.4.1 Single Gas Permeation .................................... 163

6.4.2 Mixture Separation ........................................... 163

6.5 Removal of Trace Contaminants ................................ 167

Conclusion $\quad$.......................................................................... 173

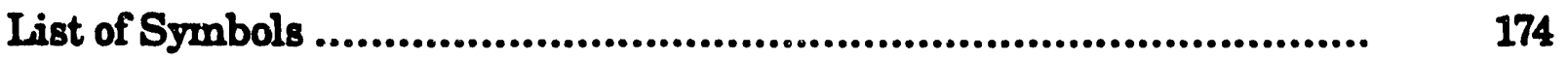

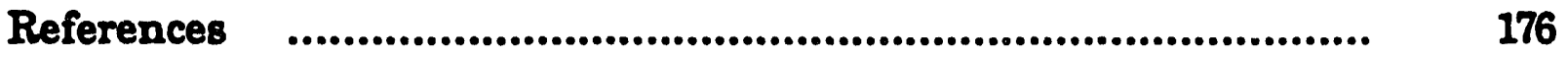

Appendix Fortran Program: Binary Mixture Separation ............. 180 


\section{LIST OF TABLIES}

Table 2.1 Average Pure Component Permeabilities as a Function of

Temperature ..... ....................................................

Table 2.2 Ideal Separation Factors Based on Pure Component

Permeabilities Referenced to $\mathrm{H}_{2}$

Table 2.3 $\mathrm{N}_{2}$ Permeabilities of As-Received Membranes at $25^{\circ} \mathrm{C} . . .$.

Table 2.4 Characteristics of $\gamma-\mathrm{Al}_{2} \mathrm{O}_{3}$ Membrane as a Function of Thermal Treatment at $640^{\circ} \mathrm{C}$

Table 2.5 Characteristics of $\gamma_{-} \mathrm{Al}_{2} \mathrm{O}_{3}$ Membranes as a Function of Hydrothermal Treatment at $640^{\circ} \mathrm{C}$

Table 3.1 Experimental Values of $N_{k}$ and $\beta$

Table $3.2 \quad \mathrm{H}_{2} / \mathrm{N}_{2}$ Mixture Separation .....................................

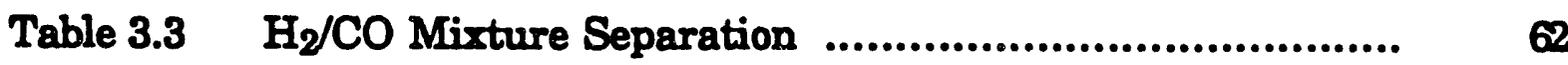

Table $3.4 \quad \mathrm{He}_{2} \mathrm{O}_{2}$ Mixture Separation .......................................

Table 4.1 Pore Size v8. He/N2 Separation of Silica Modified Porous Membranes at Room Temperature

Table 4.2 Separations of Silica Modified Porous Membranes with Pore Size of $15-6 \AA$

Tahle 4.3 $\mathrm{He}, \mathrm{N}_{2}$ and $\mathrm{H}_{2}$ Permeabilities of Modified Dense

Membranes at Various Temperatures

Table 4.4 $\mathrm{He}, \mathrm{N}_{2}$ Permeabilities of Dense Silica Membranes with Improved Deposition.

Table 4.5 $\quad \mathrm{N}_{2}$ Permeability of Various Starting Materials for CVD

Table 4.6 $\mathrm{He}, \mathrm{N}_{2}$ Permeabilities of $10^{n}$ Modified Porous Silica Membranes

Table 4.7 He, $\mathrm{N}_{2}$ Permeabilities of $10^{n}$ Modified Silica Membrane at Three Different Positions 
Table 4.8 He, $\mathrm{N}_{2}$ Permeabilities of Existing and Modified During Thermal and Hydrothermal Treatment

Table 4.9 The He and $\mathrm{N}_{2}$ Permeabilities of Silica Modified Dense Membranes Si418 During Thermal Treatment

Table 4.10 The He and $\mathrm{N}_{2}$ Permeabilities of Silica Modified Dense Membranes Si421 During Thermal Treatment .............

Table 4.11 The He and $\mathrm{N}_{2}$ Permeabilities of Silica Modified Dense Membranes Si428 During Thermal Treatment 106

Table 4.12 The $\mathrm{He}$ and $\mathrm{N}_{2}$ Permeabilities of Silica Modified Dense Membranes Si432 During Thermal/Hydrothermals Treatment

Table 4.13 The He and $\mathrm{N}_{2}$ Permeabilities of Stainless Steel Tube as Control for Thermal/Hydrothermal Treatment

Table 4.14 The He and $\mathrm{N}_{2}$ Permeabilities of Silica Modified Dense Membranes Si438 During Thermal/Hydrothermal Treatment

Table 4.15 The Deposition Condition for $\mathrm{ZrO}_{2}$ on Existing Alumina Membranes

Table 5.1 The Concentration of the Pretreatment Sol-gel of Zeolitic Membranes

Table 5.2 The Nitrogen and Helium Permeabilities of Various Pretreated Zeolitic Membranes on $0.2 \mathrm{~mm}$ Support.

Table 5.3 The Nitrogen and Helium Permeabilities of Pretreated Zeolitic Membranes on $500 \AA$ Support

Table 5.4 The Nitrogen and Helium Permeabilities of Pretreated Membranes on $100 \AA$ Support

Table 5.5 The Nitrogen Permeabilities of Zeolitic Membranes on Supports Before and After In-situ Synthesis

Table 5.6 Synthesis Conditions for ZS104-ZS110

Table 5.7 The Synthesis Conditions for Zeolitic Membrane ZS122-ZS124

Table 5.8 He and $\mathrm{N}_{2}$ Permeabilities of Zeolitic Membranes 
Table 5.9 He and $\mathrm{N}_{2}$ Permeabilities of Zeolitic Membranes Before and After Silica CVD Modification

Table 5.10 The Nitrogen and Helium Permeabilities of Zeolitic Membranes ZS139 After Pretreatment and In-situ Synthesis.

Table 5.11 He and $\mathrm{N}_{2}$ Permeability of Various Zeolitic Membranes After Pretreatment, In-situ Synthesis and/or CVD.........

Table 6.1 Permeabilities Comparison of High Selectivity Membranes

Table 6.2 $\quad \mathrm{H}_{2} / \mathrm{N}_{2}$ Separation in Modified Membrane-AS195

Table 6.3 $\mathrm{H}_{2} / \mathrm{N}_{2}$ Separation Selectivity of Silica Modified

Table 6.4 The Simulated Decomposition of $\mathrm{NH}_{3}$ and $\mathrm{H}_{2} \mathrm{~S}$ in 


\section{IIST OF FIGURES}

Figure 2.1 SEM Micrograph of a Cross Section of a Nominal $40 \AA$ Asymmetric Alumina Membrane

Figure 2.2 SEM Micrograph of the Inner Surface of a Nominal $40 \AA$ Asymmetric Alumina Membrane

Figure 2.3 Pore Size Distribution of a Nominal 40A Asymmetric Alumina Membrane by $\mathrm{Hg}$ Intrusion Porosimetry .........

Figure 2.4 Schematic of a Flow-weighted Dynamic Pore Size Distribution Analyzer

Figure 2.5 Pore Size Distribution using the Flow-weighted Dynamic Pore Size Distribution Apparatus of Three Nominal 40A Asymmetric Membranes as Received from the Manufacturer

Figure 2.6 Repeat Pore Size Distribution Runs on the Same Membrane to Establish the Reproducibility of the Dynamic Pore Size Distribution Apparatus ..................................................

Figure 2.7 Schematic of the High Temperature, High Pressure

Gas Permeation Test Apparatus ..............................

Figure 2.8 Membrane Permeability vs. Transmembrane Pressure for $\mathrm{H}_{2}, \mathrm{He}, \mathrm{N}_{2}, \mathrm{CO}$ and $\mathrm{CH}_{4}$ at $25^{\circ} \mathrm{C} \ldots \ldots \ldots \ldots \ldots \ldots \ldots . . . \ldots . .$.

Figure 2.9 Membrane Permeability v8. Transmembrane Pressure for $\mathrm{H}_{2}, \mathrm{He}, \mathrm{N}_{2}, \mathrm{CO}_{2}, \mathrm{CO}$ and $\mathrm{CH}_{4}$ at $538^{\circ} \mathrm{C}$

Figure 2.10 Membrane Permeability v8. Transmembrane Pressure for $\mathrm{H}_{2}, \mathrm{He}, \mathrm{N}_{2}, \mathrm{CO}_{2}, \mathrm{CO}$ and $\mathrm{CH}_{4}$ at $650^{\circ} \mathrm{C}$

Figure 2.11 Nembrane Permeability v8. Transmembrane Pressure for $\mathrm{H}_{2}, \mathrm{He}, \mathrm{N}_{2}, \mathrm{CO}_{2}, \mathrm{CO}$ and $\mathrm{CH}_{4}$ at $815^{\circ} \mathrm{C}$

Figure 2.12 $\mathrm{N}_{2}$ Permeability at $25^{\circ} \mathrm{C}$ of a Nominal $40 \AA$ Membrane Before and After Treatment with $10 \% \mathrm{O}_{2} /$ Balance $\mathrm{He}$ at $538^{\circ} \mathrm{C}$ for 16 Hours Following Exposure to $\mathrm{CO}$ and $\mathrm{CH}_{4}$ at High Temperature $\left(538-815^{\circ} \mathrm{C}\right)$.

Figure 2.13 Schematic of Thermal and Hydrothermal Stability Test Unit with On-Line Gas Permeation Characterization 
Figure 2.14 Permeability Growth as a Function of Treatment Temperature in Flowing $\mathrm{N}_{2}$ for a Nominal $40 \AA$

Membrane

Figure 2.15 Permeability Change as a Function of Treatment Time for a Nominal $40 \AA$ Membrane Exposed to Flowing $\mathrm{N}_{2}$ for 100 Hours at $640^{\circ} \mathrm{C}$

Figure 2.16 Pore Size Distribution of a Nominal $40 \AA$ Membrane Before and After Thermal Treatment at $640^{\circ} \mathrm{C}$

for 100 Hours

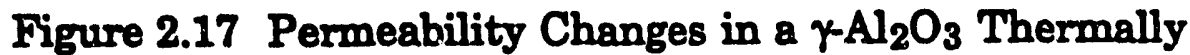
Treated at $640^{\circ} \mathrm{C}$ for 36 Hours the Stored at Ambient Conditions for 6 Months

Figure 2.18 Model of Pore Structure Changes in a $\gamma-\mathrm{Al}_{2} \mathrm{O}_{3}$ Membrane Subjected to Thermal Treatment at Temperature up to $640^{\circ} \mathrm{C}$

Figure 2.19 Permeability Growth in a Nominal $40 \AA \gamma-\mathrm{Al}_{2} \mathrm{O}_{3}$ as a Function of Treatment Time at $640^{\circ} \mathrm{C}$ in a Feed Stream of 5\% Steam

Figure 2.20 Changes in Pore Size Distribution of a Nominal $40 \AA$ $\gamma-\mathrm{Al}_{2} \mathrm{O}_{3}$ as a Function of Treatment Time at $640^{\circ} \mathrm{C}$ in a Feed Stream of $5 \%$ Steam

Figure 2.21 Changes in Pore Size Distribution of a Nominal $40 \AA$ $\gamma-\mathrm{Al}_{2} \mathrm{O}_{3}$ as a Function of Treatment Time at $640^{\circ} \mathrm{C}$ in a Feed Stream of $90 \%$ Steam.

Figure 2.22 Pore Size Distribution of a Nominal $40 \AA \gamma \mathrm{Al}_{2} \mathrm{O}_{3}$ After Hydrothermal Treatment at $640^{\circ} \mathrm{C}$ in a Feed Stream of $90 \%$ Steam and in the Presence of Alkali Species

Figure 2.23 Wide View SEM Micrograph of the Membrane Surface After Hydrothermal Treatment at $640^{\circ} \mathrm{C}$ in a Feed Stream of $90 \%$ Steam and in the Presence of Alkali Species

Figure 2.24 Magnified View of the Membrane Surface After Hydrothermal Treatment at $640^{\circ} \mathrm{C}$ in a Feed Stream of 90\% Steam and in the Presence of Alkali Species

Figure 2.25 EDAX Spectrum of the Membrane Surface After Hydrothermal Treatment at $640^{\circ} \mathrm{C}$ in a Feed Stream of 
90\% Steam and in the Presence of Alkali Species

Figure 3.1 Molecular Diffusion Through Capillary for a Mixture of Nitrogen and Hydrogen ........................................... 47

Figure 3.2 SEM Micrograph of Alumina Membrane Structure ....... 49

Figure 3.3 Schematic Diagram of Experimental Facility for Gas Separations Through Membrane ............................... $\quad 50$

Figure 3.4 A Perfect Mixing Model for Gas Separation.................. 51

Figure 3.5 Gas Permeabilities vs. Average Pressures at $20^{\circ} \mathrm{C}$......... 56

Figure 3.6 Gas Permeabilities vs. Average Pressures at $538^{\circ} \mathrm{C}$....... 57

Figure 3.7 Gas Permeabilities vs. Average Pressure at $815^{\circ} \mathrm{C} . . . . . . . . \quad 58$

Figure 3.8 Feed Pressure Effect on Separation of $\mathrm{H}_{2} / \mathrm{N}_{2}$ Mixture ..... $\quad 65$

Figure 3.9 Influence of Feed Pressures on Separation Efficiency of $\mathrm{H}_{2} / \mathrm{N}_{2}$ Mixture ..............................................

Figure 3.10 Temperature Effect on Separation of $\mathrm{H}_{2} / \mathrm{N}_{2}$ Mixture ....... 68

Figure 3.11 Feed Concentration Effect on Separation of $\mathrm{H}_{2} / \mathrm{N}_{2}$ Mixture.................................................................

Figure 3.12 Pore Size Effect on Separation of $\mathrm{H}_{2} \mathrm{~N}_{2}$ Mixture ............ 71

Figure 3.13 Stage Cut Effect on Separation of $\mathrm{H}_{2} / \mathrm{N}_{2}$ Mixture $\ldots . . . . . . . . \quad 72$

Figure 4.1 The Schematic of Chemical Vapor Deposition Apparatus ................................................................ T5

Figure 4.2 SEM of Inner Surface of Silica Modified Membrane Si005

Figure 4.3 SEM of Cross-Section of Silica Modified Membrane Si001

Figure 4.4 SEM of Cross-Section of Silica Modified Membrane Si004

Figure 4.5 SEM of Cross-Section of Silica Modified Membrane Si005 
Figure 4.6 SEM of Cross-Section of Silica Modified Membrane Si009

Figure 4.7 EDAX of the Inside. Surface of Silica Modified Membrane Si001

Figure 4.8 EDAX of Inner Surface of Silica Modified Membrane Si004

Figure 4.9 EDAX of Top Surface of Silica Modified Membrane Si009

Figure 4.10 EDAX of Cross-Section of Silica Modified Membrane Si0n9 at $1.5 \mu \mathrm{m}$ Position from Top

Figure 4.11 Pore Size Distribution of Silica Modified Membrane Si211

Figure 4.12 Pore Size Distribution of Silica Modified Membrane Si409

Figure 4.13 Pore Size Distribution of Silica Modified Membrane Si415

Figure 4.14 Pore Size Distribution of Silica Modified Membrane Si416

Figure 4.15 Pore Size Distribution of Silica Modified Membrane Si416

91

Figure 4.16 Thermal Treatment of Silica Porous Modified Membranes Si071

Figure 4.17 He and N2 Permeabilities of Modified Membrane Si421 during Thermal Treatment.

Figure 4.18 He and N2 Permeabilities of Modified Membrane Si438 during Thermal/Hydrothermal Treatment

Figure 4.19 Pore Size Distribution of Zirconia Modified Membranes $\mathrm{Zr} 008$

Figure 4.20 Pore Size Distribution of Zirconia Modified Membranes $\mathrm{Zr} 012$

Figure 5.1 SEM of Inner Surface of Zeolitic Modified Membrane ZS133 
Figure 5.2 SEM of Inner Surface of Zeolitic Modified Membrane ZS133

Figure 5.3 SEM of Inner Surface of Zeolitic Modified Membrane ZS136

Figure 5.4 SEM of Inner Surface of Zeolitic Modified Membrane ZS136

Figure 5.5 SEM of Cross-Section of Zeolitic Modified Membrane ZS136

130

Figure 5.6 SEM of Inner Surface of Zeolitic Modified Membrane ZS117

132

Figure 5.7 SEM of Cross-Section of Zeolitic Modified Membrane ZS014

Figure 5.8 SEM of Cross-Section of Zeolitic Modified Membrane ZSO23

134

Figure 5.9 SEM of Cross-Section of Zeolitic Modified Membrane ZSO76

Figure 5.10 SEM of Cross-Section of Zeolitic Modified Membrane ZS133

Figure 5.11 EDAX of the Inside Surface of ZSO05 Developmental Zeolitic Membrane

Figure 5.12 SEM of Outside Surface of Zeolitic Modified Membrane ZSOO5

Figure 5.13 EDAX of Inner Surface of Zeolitic Membrane ZS106 141

Figure 5.14 EDAX of Inner Surface of Zeolitic Membrane ZS107 142

Figure 5.15 EDAX of Inner Surface of Zeolitic Membrane ZS110 143

Figure 5.16 Pore Size Distribution of Zeolitic Membrane ZS122 147

Figure 5.17 Pore Size Distribution of Zeolitic Membrane ZS123 ......... 148

Figure 5.18 Pore Size Distribution of Zeolitic Membrane ZS124 ......... $\quad 149$

Figure 5.19 Pore Size Distribution of Zeolitic Membrane ZS139 ......... 152

Figure 5.20 Pore Size Distribution of Zeolitic Membrane ZS143 ......... 153 
Figure 5.21 Pore Size Distribution of Zeolitic Membrane ZS148 ......... 154

Figure 6.1 The $\mathrm{H}_{2} / \mathrm{N}_{2}$ Separation Selectivity vs. Pore Size .............. 159

Figure 6.2 Temperature Effect on Permeability - AS195 ................. 164

Figure 6.3 Simulation Conditions of Catalytic Membrane Reactor ... 168

Figure 6.4 Summary of the $\mathrm{NH}_{3}$ and $\mathrm{H}_{2} \mathrm{~S}$ Conversion.................... 170

Figure 6.5 Summary of the $\mathrm{NH}_{3}$ and $\mathrm{H}_{2} \mathrm{~S}$ Conversion................... 172 


\section{Erecutive Summary}

This study covers a comprehensive evaluation of existing ceramic membranes for high temperature gas separations. Methodology has been established for microporous characterization stability and gas separation efficiency. A mathematical model was developed to predict gas separations with existing membranes. Silica and zeolitic modifications of existing membranes were pursued to enhance its separation efficiency. Some of which demonstrates unique separations properties. Use of the dense-silica membranes for hydrogen enrichment was identified as a promising candidate for future development. In addition, the decomposition of trace ammonia contaminant via a catalytic membrane reactor appears feasible. A further economic analysis is required to assess its commercial viability. 


\section{Introduction}

About one-eighth of world's cosl production is used to generate electricity in the United States (Schmitt, 1980). Pressure to reduce the cost and environmental impact of producing electricity from coal has stimulated interest in the improvement of advanced power generation systems, such as integrated gasification combined cycle (IGCC) and direct coal-fuel turbine (DCFT) systems.

The advantage of IGCC systems is to allow the most stringent environmental standard to be met economically (Schmitt, 1980). To achieve this clean-up with conventional technology, however, the efficiency loss associated with heat recovery and wet scrubbing is unavoidable (Reed, 1985). Thus it is desirable to perform the clean-up at high temperature and high pressure (HTHP). Hot gas stream clean-up also provides a higher inlet temperature of gas to the combustion turbine, which is critical to the efficiency and electricity cost of IGCC systems (Larson, 1981; Schmitt, 1980). The similar advantages of hot gas clean-up are also applicable to DCFT systems. The ceramic membrane is capable of operating at this condition and could achieve clean-up without a cooling-heating cycle. They have good structure statility and generally can withstand more harsh chemical environments. In addition, the developed HTHP gas separation technology, such as separation of $\mathrm{H}_{2}$, can be particularly beneficial in the petrochemical as well as synthetic fuel industries.

Selection of membrane materials was crucial for applications in HTHP conditions. Presently the support of commercial inorganic membranes include carbon, glass and alumina. A commercially available alumina membrane with $40 \AA$ pore diameter was identified as one of the potential candidates for HTHP gas separations. It had an excellent stability and acceptable hydrothermal stability at $650^{\circ} \mathrm{C}$. The thin membrane layer provided high permeability, which was essential for processing high volume streams involved in IGCC and DCFT systems. Gas separation with such a membrane can perform Knudsen diffusion, i.e. based on molecular weight.

An improved separation efficiency is also highly desirable for applications involving hydrogen separation and catalytic decomposition of contaminants, $\mathrm{NH}_{3}$ and $\mathrm{H}_{2} \mathrm{~S}$. One of the effective avenues is to narrow its pore size through surface modification. Thus, gas separation can be accomplished through molecular sieving. One step further, a dense film membrane can even provide a near infinite selectivity of certain gas, such as $\mathrm{H}_{2}$. Both small pore and dense-phase membranes can be readily available through minor modification of existing commercial membranes.

In this project, investigation was focused on: (1) hardware establishment, i.e., membrane modules including housing and end seals for conducting gas separations at HTHP; (2) evaluation of existing alumina membranes with particular emphasis on material characteristics, stability, and gas permeation/separation; (3) study of gas transport phenomenon and development of a mathematical model to verify the results with experimental data using existing membranes, and to simulate gas separation for a range of conditions 
encountered in coal-gas cleanup operations; (4) synthesis and characterization of highly selective membranes with small pore and dense film for high temperature gas separations. 
The commercial application of microporous ceramic membranes began in the late 1970's and focused primarily on liquid phase micofiltration and ultrafiltration. As a result of the superior mechanical, thermal, and chemical properties of ceramic membranes compared to their polymeric counterparts, considerable interest has been focused on high temperature gas phase applications including filtration, gas separations, and ceramic membrane reactors. Details of membrane synthesis and application have been recently reviewed (Bhave, 1991). Critical to the success of these emerging applications is an understanding of the characteristics of microporous ceramic membranes.

The mechanisms for gas transport through a porous membrane vary primarily with pore size and to some extent with chemical interaction between the diffusing species and the membrane material. At the largest pore size, transport is governed by Poiseuille flow and no separation occurs for multicomponent streams. When the pore size is approximately less than $1 / 10$ that of the mean free path of the diffusing species, collisions between the gas molecules and the pore wall control the transport of species through the membrane. This is known as Knudsen diffusion and separation between species is inversely proportional to the inverse square root of their molecular weights. When pore dimensions approach those of the diffusing species, separations can occur by size exclusion or molecular sieving. In this regime nearly infinite separation factors are theoretically attainable. Under circumstances where adsorption of a species occurs onto the surface of the membrane, transport can be enhanced due to surface diffusion. Finally, for condensable vapor species, capillary condensation can occur in the pores of the membrane and transport through the membrane is governed by pseudo-liquid phase diffusion.

Important parameters for characterizing the performance of a membrane include membrane structure or morphology, gas permeability, multicomponent gas separation factors, and pore size distribution of the separating layer. For applications involving high temperatures and/or severe environments, thermal stability, hydrothermal stability, and chemical stability of the membrane are also critically important.

\subsection{Marphologs}

The membranes investigated in this study are asymmetric, composite ceramic membranes, commercially available as tubular elements under the trade name Membralor(B. A cross section of this configuration is shown in the SEM micrograph in Figure 2.1.

The support shown in Figure 2.1 is an extruded $\alpha$-alumina with a average pore diameter of approximately $10 \mu \mathrm{m}$ and a porosity of approximately $45 \%$. the support layer is approximately $2 \mathrm{~mm}$ thick. A second layer, approximately $50 \mu \mathrm{m}$ thick, is slip-cast onto this support and fired to yield an $\alpha-\mathrm{Al}_{2} \mathrm{O}_{3}$ layer with an average pore diameter of $0.8 \mu \mathrm{m}$ and a porosity of 
Figure 2.1 SEMM Micrograph of a Cross Section of a Nominal $40 \AA$ Asymmetric Alumina Membrane

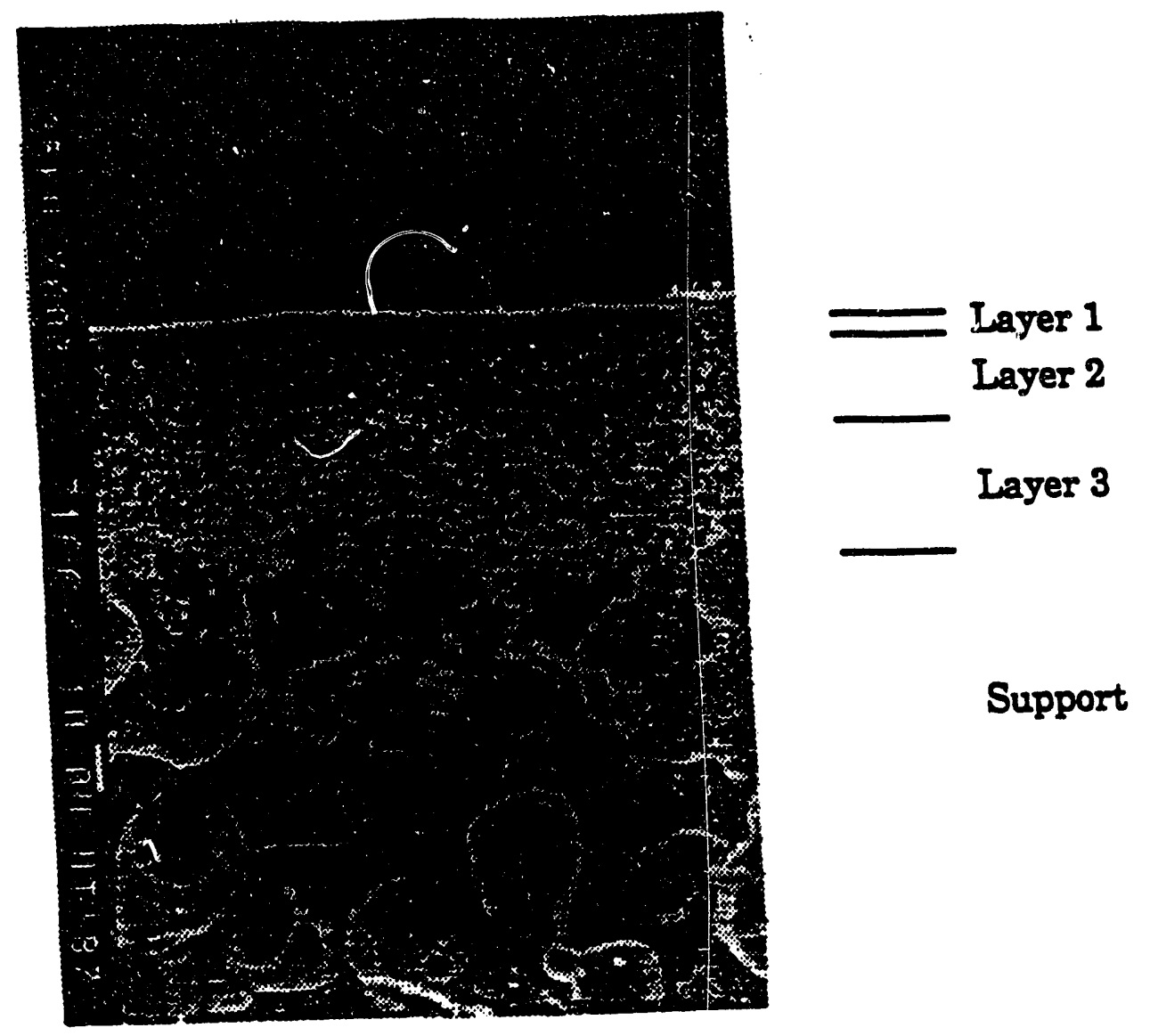

Layer 1: Pore Diameter $=40 \AA ;$ Thickness $=3-5 \mu \mathrm{m} ;$ Porosity $=50 \%$

Layer 2 : Pore Diameter $=0.2 \mu \mathrm{m}$; Thickness $=15-30 \mu \mathrm{m} ;$ Porosity $=35 \%$

Layer 3: Pore Diameter $=0.8 \mu \mathrm{m} ;$ Thickness $=30-50 \mu \mathrm{m} ;$ Porosity $=40 \%$

Support : Pore Diameter $=10-15 \mu \mathrm{m} ;$ Thickness $=1.5-2.0 \mathrm{~mm} ;$ Porosity $=40-45 \%$ 
40\%. Similarly, a third $\alpha-\mathrm{Al}_{2} \mathrm{O}_{3}$ layer, approximately $30 \mu \mathrm{m}$ thick, with an average pore diameter of $0.2 \mu \mathrm{m}$ and a porosity of $35 \%$ is deposited. The final top layer is slip-cast and fired to yield a $5 \mu \mathrm{m}$ thick, transitional $\gamma-\mathrm{Al}_{2} \mathrm{O}_{3}$ layer with a nominal pore size of $40 \AA$ and a porosity of $50 \%$. An SEM micrograph of the top surface of this inner layer is shown in Figure 2.2. From there it can be seen that the top layer is defect-free (ie. no pinholes or cracks) This top layer provides a separating barrier capable of Knudsen separation for most gas separations encountered. The asymmetric support structure permits high permeability combined with mechanical strength.

\section{Pare Sive Distribution}

\subsubsection{Methodalogy}

For microporous membranes, pore diameter is one of the most critical factors in determining membrane performance. For the commercially available, asymmetric $40 \AA \gamma-\mathrm{Al}_{2} \mathrm{O}_{3}$ membrane however, the separating layer constitutes less than $0.2 \%$ by weight of the total sample. As a result, traditional techniques such as nitrogen adsorption or mercury intrusion do not have sufficient resolution to determine the pore size in this small layer. A typical pore size distribution from Hg porosimetry is given in Figure 2.3. From there the $10 \mu \mathrm{m}$ support as well as the $0.8 \mu \mathrm{m}$ and $0.2 \mu \mathrm{m}$ sub-layers can be readily seen. However, the distribution for the nominal $40 \AA$ separating layer is broad and diffuse with pores from $30 \AA$ to $110 \AA$ indicated.

A flow weighted pore size distribution analyzer has been developed which is capable of characterizing this thin layer. A schematic of the apparatus is shown in Figure 2.4. The details of the technique were originally developed from work performed at the Oak Ridge Gaseous Diffusion Plant and described by Fain (1989).

The technique is based on the principle of condensation of a vapor in a capillary as described by the Kelvin Equation:

$$
\operatorname{Ln}\left(P_{0} / P\right)=2 \gamma /(r R T)
$$

where: $\quad P_{0}=$ vapor pressure of condensable vapor

$\mathrm{P}=$ partial pressure of condensable vapor

$\gamma=$ liquid surface tension of condensed vapor

$V=$ molar volume of condensed vapor

$r=$ pore radius where vapor is condensed

$\mathrm{R}=$ gas constant

$\mathrm{T}=$ temperature in the pore

A gas mixture which contains a condensable as well as a 

Figure 22 SEM Micrograph of the Inner Surface of a Nominal 40A Asymmetric
Alumina Membrane

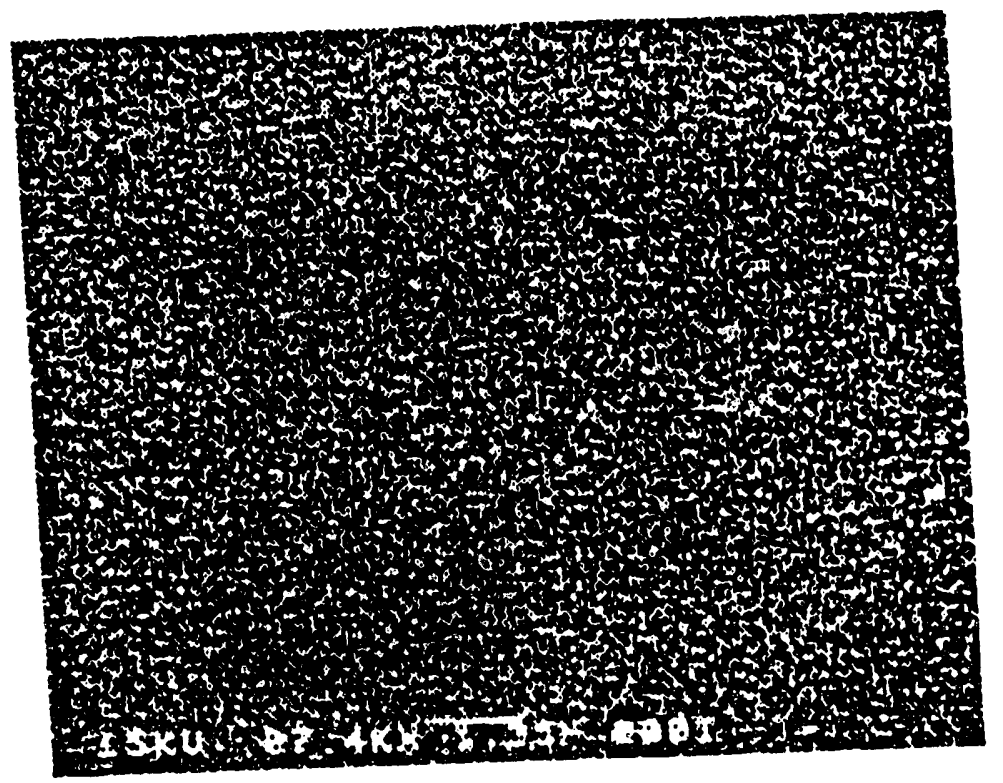




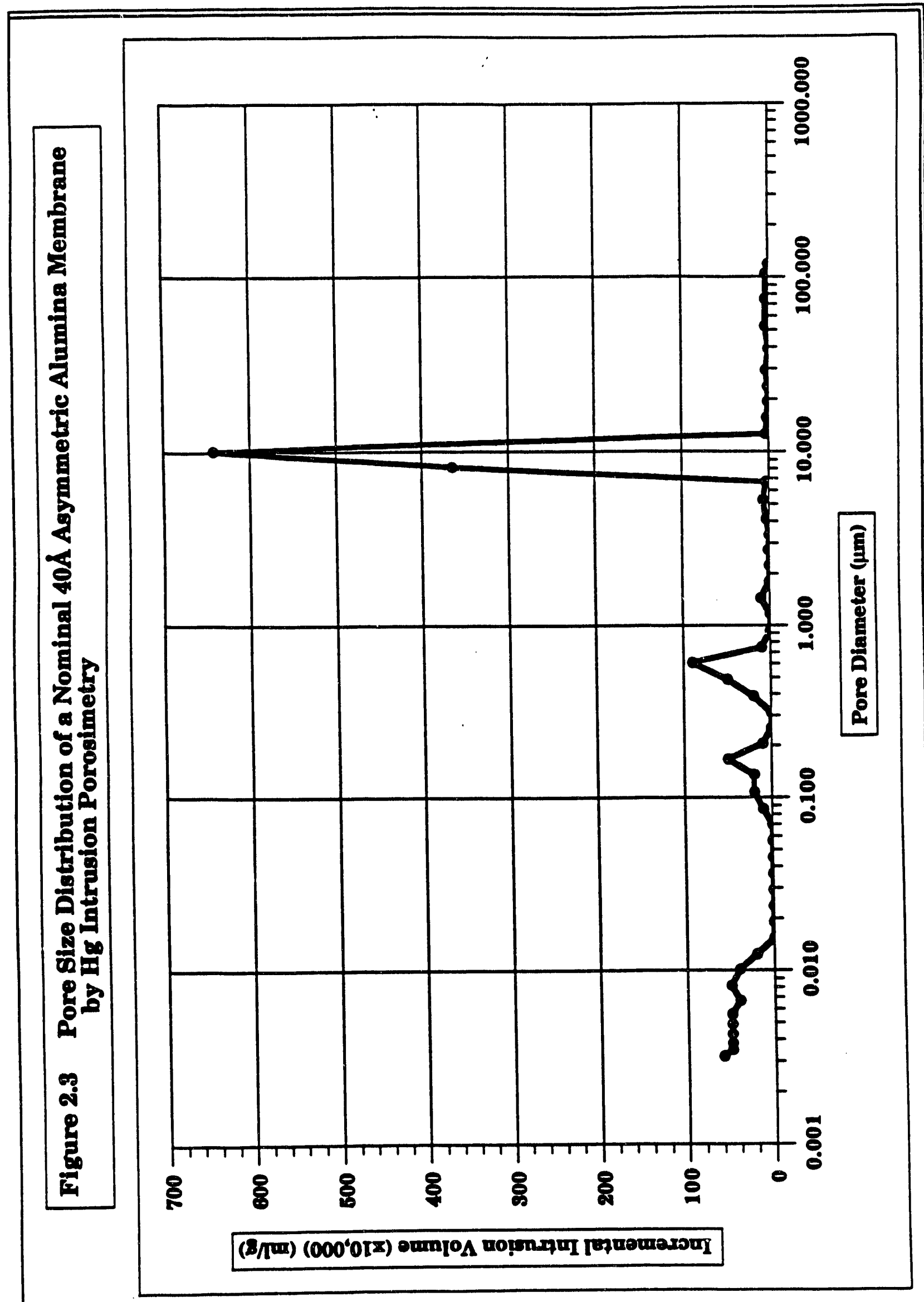




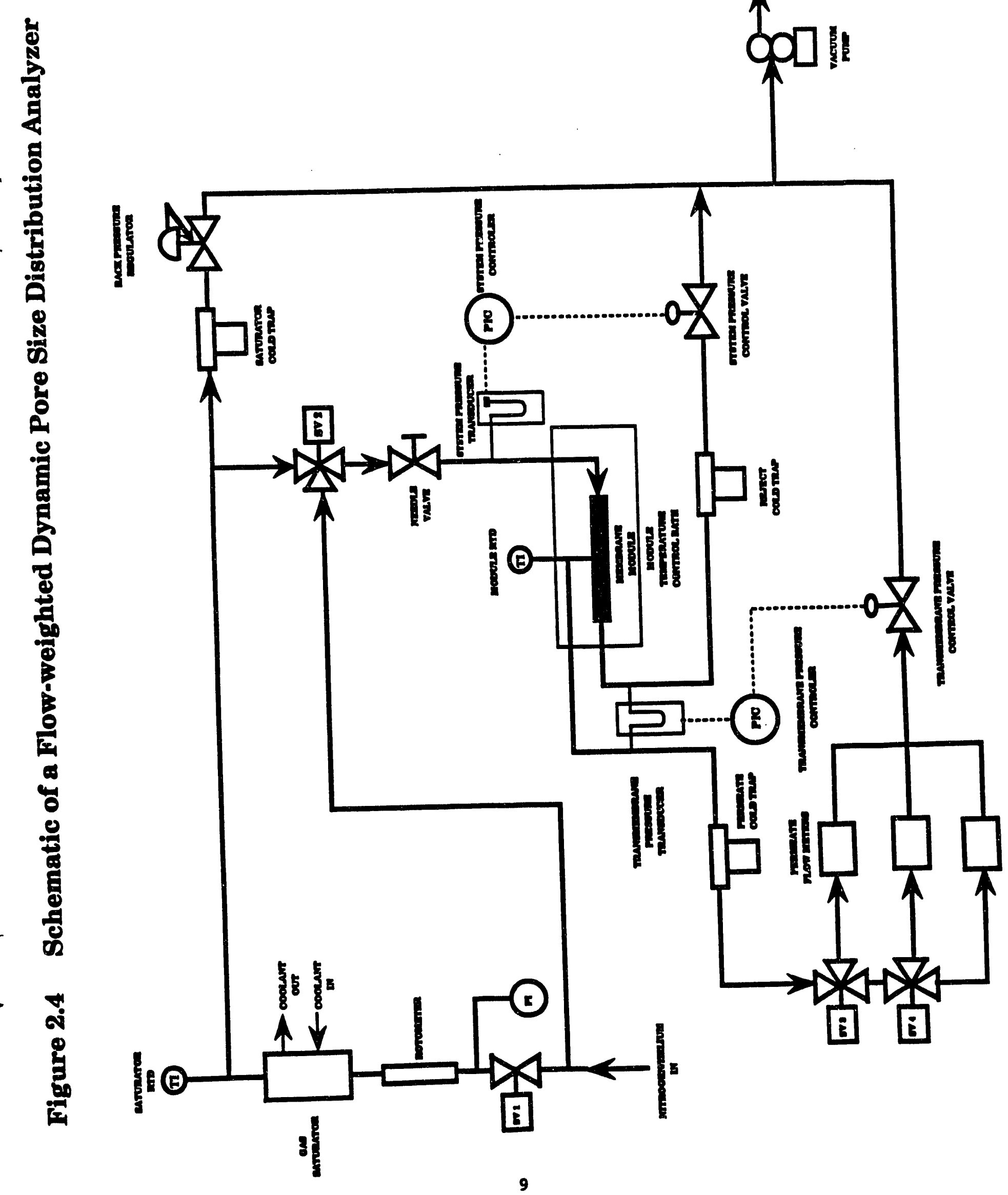


noncondensable gas is fed into the membrane tube and permeates through the membrane layer. When the partial pressure of the condensable gas is raised so as to satisfy Eqn. (1), vapor will condense in pores of radius $r$, thereby blocking them and resulting in a dropoff in flow. At a pressure approaching the saturated vapor pressure of the vapor, all pores in the membrane can be blocked and no permeate flow is observed. As the system pressure is stepwise lowered, pores are evacuated starting from the largest radius to the smallest. This change in flow can be monitored relative to partial pressure to give a flow weighted pore size distribution.

As shown in Figure 2.4, a stream of nitrogen or helium is saturated with cyclohexane by sparging through the temperature controlled saturator which is maintained so as to generate a 5\% cyclohexane mixture. The membrane housing is immersed in a constant temperature bath and fed with a side stream from this flow. Total membrane pressure is varied by varying the reject flow while transmembrane gressure is maintained at a constant 15 Torr by controlling the permeate flow. Permeate and reject flows are monitored with mass flowmeters. Vacuum is drawn on the system with a vacuum pump. This system is interfaced with a Macintosh II computer for process control, data logging, and real time data analysis. Labview software from National Instruments is used for these purposes.

In a typical experiment, full vacuum is drawn on the membrane to evacuate any condensed impurities while gas flow (either $\mathrm{N}_{2}$ or $\mathrm{He}$ ) is initiated to the saturator and allowed to equilibrate. The $\mathrm{N}_{2}$ /cyclohexane mixture is then introduced into the membrane. The total pressure is raised to a sufficient level to fully condense the cycloherane in the pores completely blocking permeate flow. The system pressure is then stepwise lowered. When a pressure equivalent, to a pore radius as determined by Eqn. 1 is reached, those pores are evacuated and flow is initiated. Permeate flow is monitored for each increment and a distribution of incremental permeate flow versus system pressure results. This data is then analyzed via Eqn. 1 taking into account the thickness of the adsorbed monolayer of cyclohezane on the pore wall. The result is a distribution of permeate flow versus pore radius and a flow weighted average pore radius can be calculated.

The primary advantage of this system is that it allows accurate pore size distribution measurement of the thin separating top layer of the asymmetric membranes. In addition, the distribution is based on incremental flow through the membrane rather than incremental volume desorbed (as in $\mathrm{N}_{2}$ porosimetry) or incremental volume intruded (as in $\mathrm{Hg}$ porosimetry). This incremental flow relates directly to membrane performance in gas separation applications. Also, no assumptions are required regarding porosity or tortuosity. 
The technique is limited by the constraints of the Kelvin equation. As a result, the lower limit of pore diameter accessible with this technique is approximately $15 \AA$. Below this diameter, surface interactions with the adsorbate become significant, and the assumptions under which the Kelvin equation is derived breakdown. Theoretically, there is no upper limit to the application of the Kelvin equation. However, as noted by Gregg and Sing (Gregg, et al., 1982), the relative pressures for given pore sizes at the upper end of the mesopnrous regime are grouped so closely together that experimental error renders the results highly questionable. Therefore, this technique is only used for pore sizes up to approximately $500 \AA$ or less.

\subsection{Results and Discussion}

The pore size distribution for several nominal $40 \AA$ membranes as received from the manufacturer are shown in Figure 2.5. From there it can be seen that the average flow-weighted pore size is essentially 40A. The distribution for the as-received membranes ranges from approximately $20 \AA$ minimum pore diameter to approximately $55 \AA$ maximum pore diameter. These results are in excellent agreement with those reported by Fain (1989) for similar inembranes. Figure 2.6 shows the results of an experiment where multiple runs where made on a single membrane. From there it can be seen that reproducibility of the technique is quite good. The average pore diameter was $40.6 \AA \pm$ $1.8 \AA$ within $95 \%$ confidence limits $(\sigma=0.74 \AA)$. The resulting reproducibility is $\pm 4.5 \%$.

\section{Pure Companent Gas Permeability}

\subsubsection{Methodologs}

In gas permeation, the flux of gas through the membrane layer is measured as a function of total pressure, transmembrane pressure, and stage cut (ie., the fraction of gas fed to the membrane that permeates through it). Permeability results are reported as gas flow per unit transmembrane pressure per unit membrane surface area (ie., $\mathrm{m}^{3} / \mathrm{hr} / \mathrm{atm} / \mathrm{m}^{2}$ ).

Figure 2.7 shows a schematic of the high temperature, high pressure gas permeation apparatus used in this study. Gas feed rates into the membrane are controlled by mass flow controllers. Total pressure, transmembrane pressure and stage cut are controlled by

backpressure regulators on the exit permeate and reject lines. Feed, reject and permeate pressures are read by precision pressure transducers, and permeate and reject flowrates are measured by calibrated mass flowmeters. The temperature of the membrane module can be varied via an electric tube furnace with a maximum operating temperature of $1000^{\circ} \mathrm{C}$. The furnace and module are 


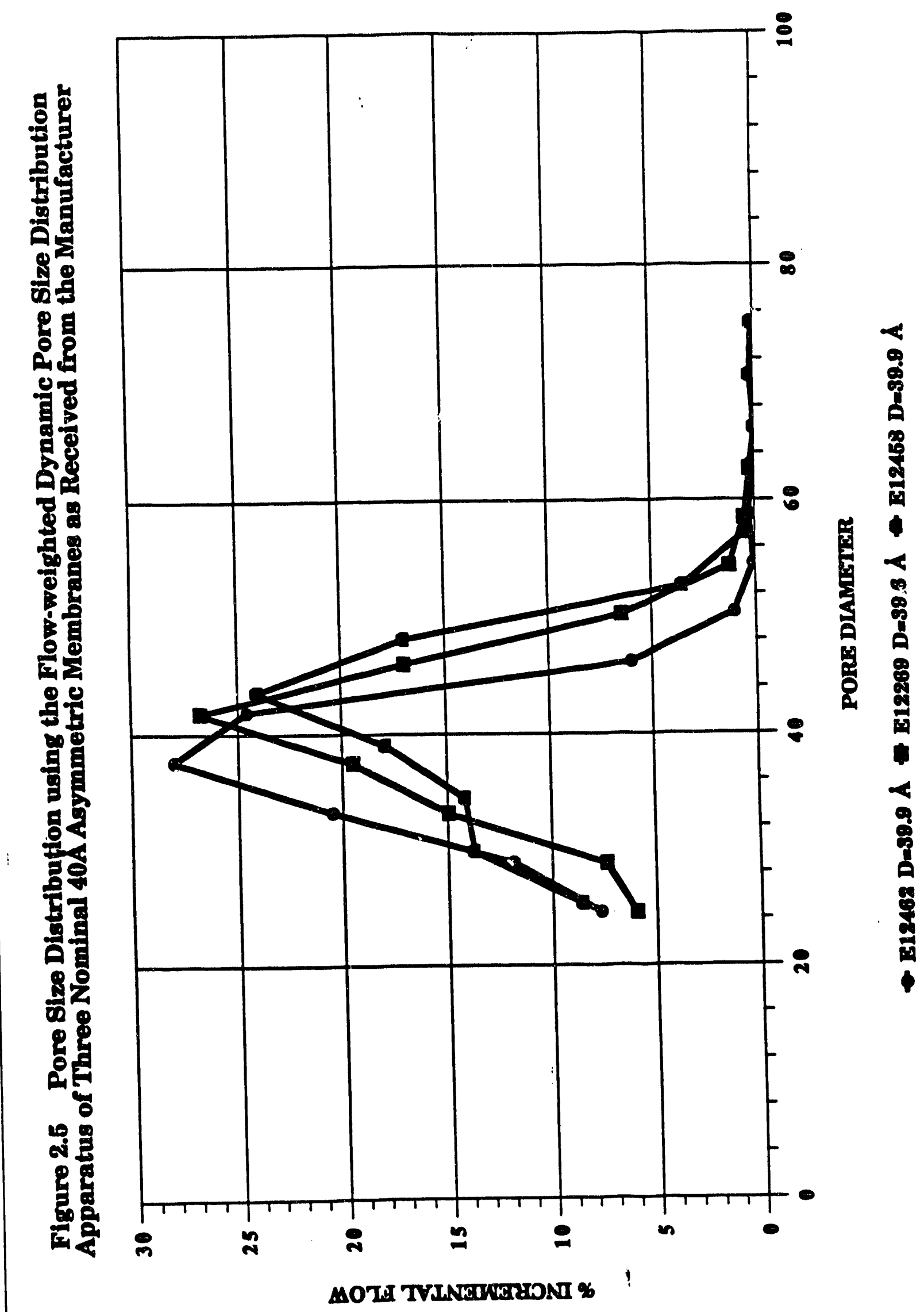




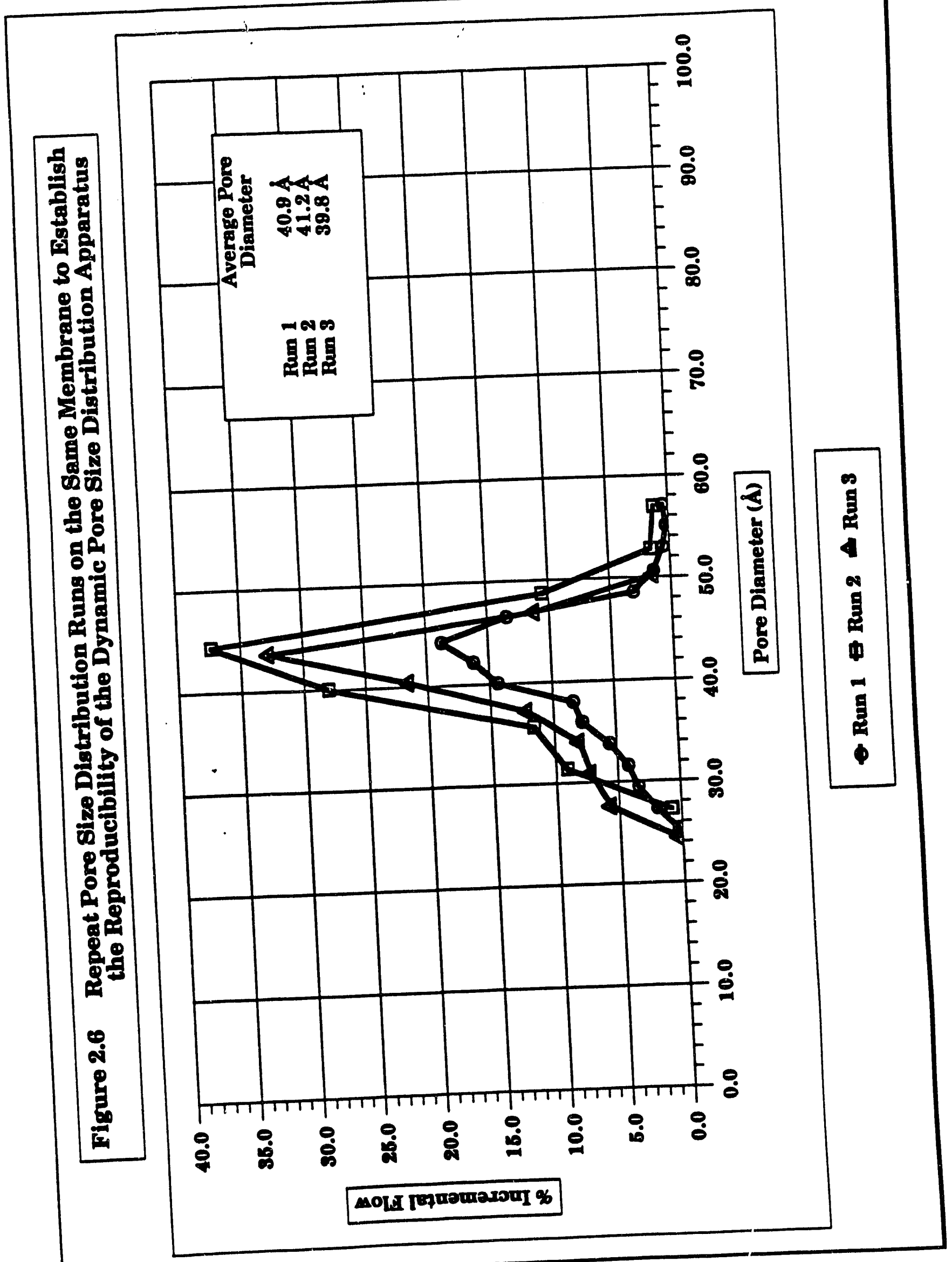



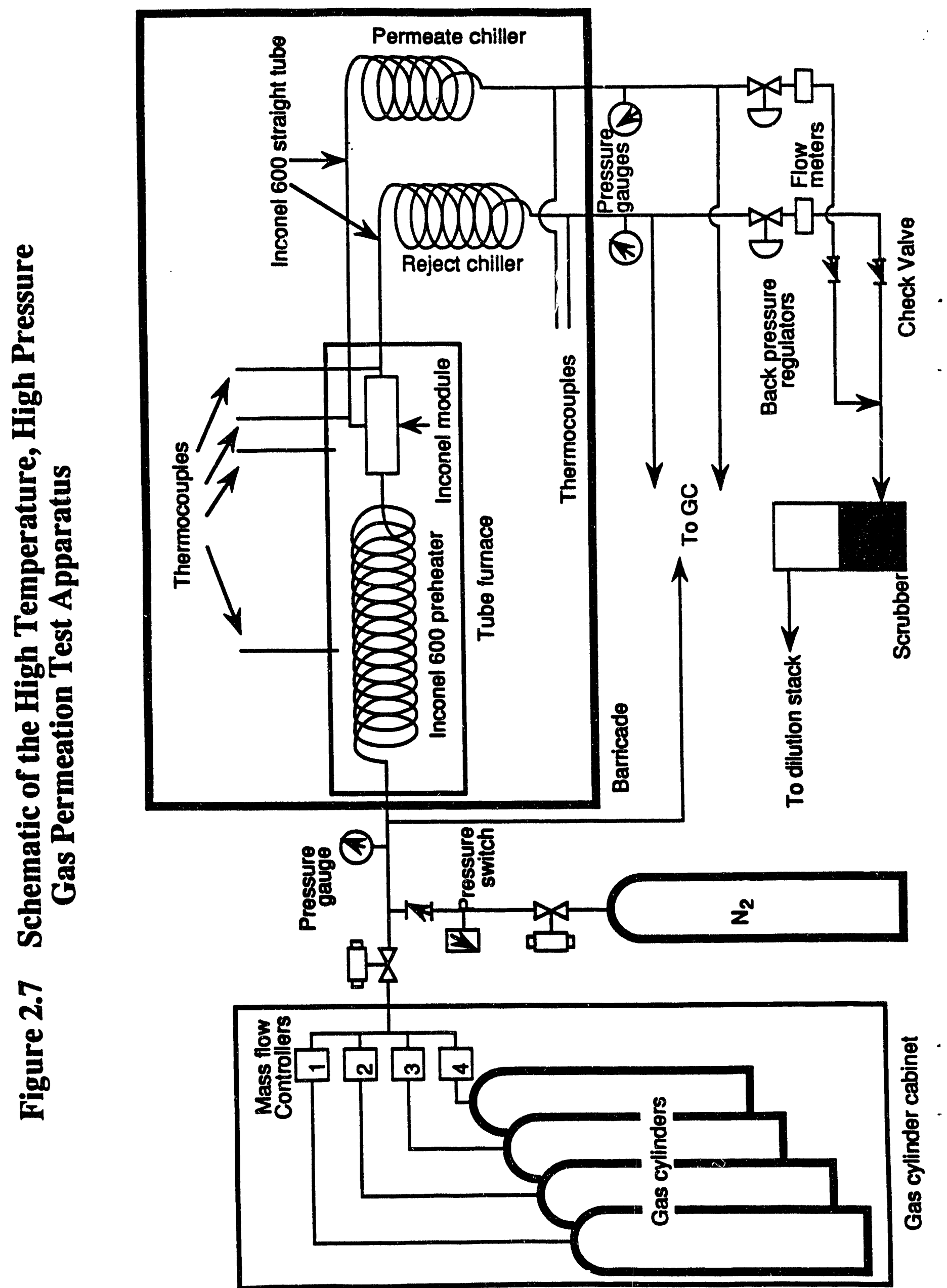
housed in a steel enclosure which is purged with $\mathrm{N}_{2}$ in order to maintain an inert atmosphere allowing the investigation of flammable gases (ie. $\mathrm{H}_{2}, \mathrm{CH}_{4}$ ). This inert atmosphere is monitored for $\mathrm{O}_{2}$ and combustibles, and the furnace and flow controllers are interlocked to shutdown in the event of a leak. The reject and permeate flows are fed to a caustic scrubber allowing for the handling of acid gases such as $\mathrm{H}_{2} \mathrm{~S}$ and $\mathrm{SO}_{2}$. After the scrubber, the effluents are fed to a dilution stack and discharged.

\section{Results and Discussion}

Permeability vs. transmembrane pressure drop results for $\mathrm{H}_{2}, \mathrm{He}$, $\mathrm{N}_{2}, \mathrm{CO}_{2}, \mathrm{CO}$, and $\mathrm{CH}_{4}$ at $25^{\circ} \mathrm{C}, 538^{\circ} \mathrm{C}, 650^{\circ} \mathrm{C}$, and $815^{\circ} \mathrm{C}$ are given in Figures 2.8, 2.9, 2.10, and 2.11 respectively. Pure component permeabilities are summarized in Table 2.1 and ideal separation factors based on these permeabilities are summarized in Table 2.2.

The permeubility of pure gases through a porous solid will be governed by Knudsen diffusion when the Knudsen number:

where:

$$
\mathbf{K}_{\mathbf{n}}=\lambda \mathbf{r} \quad \text { Eqn. } 2
$$

$$
\begin{aligned}
& \lambda=\text { mean free path } \\
& r=p \text {.re radius }
\end{aligned}
$$

is very much greater than 1 . Under these conditions, the permeability through the membrane can be described by:

$$
P=2 / 3 \cdot r \cdot(8 R T / \pi M)^{1 / 2} \bullet(\varepsilon / \tau) \bullet(1 / R T L) \quad \text { Eqn. } 3
$$

where:

$$
\begin{aligned}
& \text { P=permeability } \\
& \text { r=pore radius } \\
& \mathrm{R}=\mathrm{gas} \text { constant } \\
& \text { T=absolute temperature } \\
& \text { M=molecular weight } \\
& \text { e=porosity } \\
& \text { L=tortuosity } \\
& \text { L=membrane layer thickness }
\end{aligned}
$$

From this it can be seen that in the Knudsen regime, permeability is independent of transmembrane pressure drop and inversely proportional to the square root of molecular weight.

From Figures 2.8-2.11 it can be seen that the permeabilities of all of the compounds studied are essentially independent of transmembrane pressure at all temperatures. The slight deviation 
Table 2.1: Average Pure Component Permeabilities as a Function of Temperature

\begin{tabular}{|l|c|c|c|c|}
\hline \multirow{2}{*}{ Gas } & \multicolumn{4}{|c|}{$\begin{array}{c}\text { Permeability } \\
\left(\mathrm{m}^{3} / \mathrm{m}^{2} / \mathrm{hr} / \mathrm{atm}\right)\end{array}$} \\
\hline & $25^{\circ} \mathrm{C}$ & $538^{\circ} \mathrm{C}$ & $650^{\circ} \mathrm{C}$ & $815^{\circ} \mathrm{C}$ \\
\cline { 2 - 5 } $\mathrm{H}_{2}$ & 245.4 & 292.0 & 297.0 & 313.2 \\
$\mathrm{He}$ & 173.0 & 216.4 & 220.9 & 234.0 \\
$\mathrm{~N}_{2}$ & 70.0 & 86.1 & 85.7 & 96.9 \\
$\mathrm{CO}_{2}$ & N/A & 61.8 & 62.2 & 72.2 \\
$\mathrm{CO}$ & 73.0 & 47.3 & 46.3 & 42.7 \\
$\mathrm{CH}$ & 86.0 & 54.5 & 50.5 & 26.1 \\
\hline
\end{tabular}


Table 2.2: Ideal Separation Factors Based on Pure Component Permeabilities Referenced to $\mathrm{H}_{2}$

\begin{tabular}{|c|c|c|c|c|c|}
\hline Gas B & $25^{\circ} \mathrm{C}$ & $\begin{array}{l}\text { Perm } \\
538^{\circ} \mathrm{C}\end{array}$ & $\begin{array}{l}\text { el } \\
650^{\circ} \mathrm{C}\end{array}$ & $815^{\circ} \mathrm{C}$ & $\begin{array}{l}\text { Theoretical Ideal } \\
\text { Separation Factor } \\
\left(M_{B} / M_{H 2}\right)\end{array}$ \\
\hline $\mathrm{He}$ & 1.42 & 1.35 & 1.34 & 1.34 & 1.41 \\
\hline $\mathbf{N}_{2}$ & 3.51 & 3.39 & 3.46 & 3.23 & 3.74 \\
\hline $\mathrm{CO}_{2}$ & N/A & 4.73 & 4.78 & 4.34 & 4.69 \\
\hline $\mathrm{CO}^{*}$ & 3.36 & 6.17 & 6.42 & 7.34 & 3.74 \\
\hline $\mathrm{CH}_{4}{ }^{*}$ & 2.85 & 5.36 & 5.88 & 12.0 & 2.83 \\
\hline
\end{tabular}

- Coke formation postulated on membrane surface. 

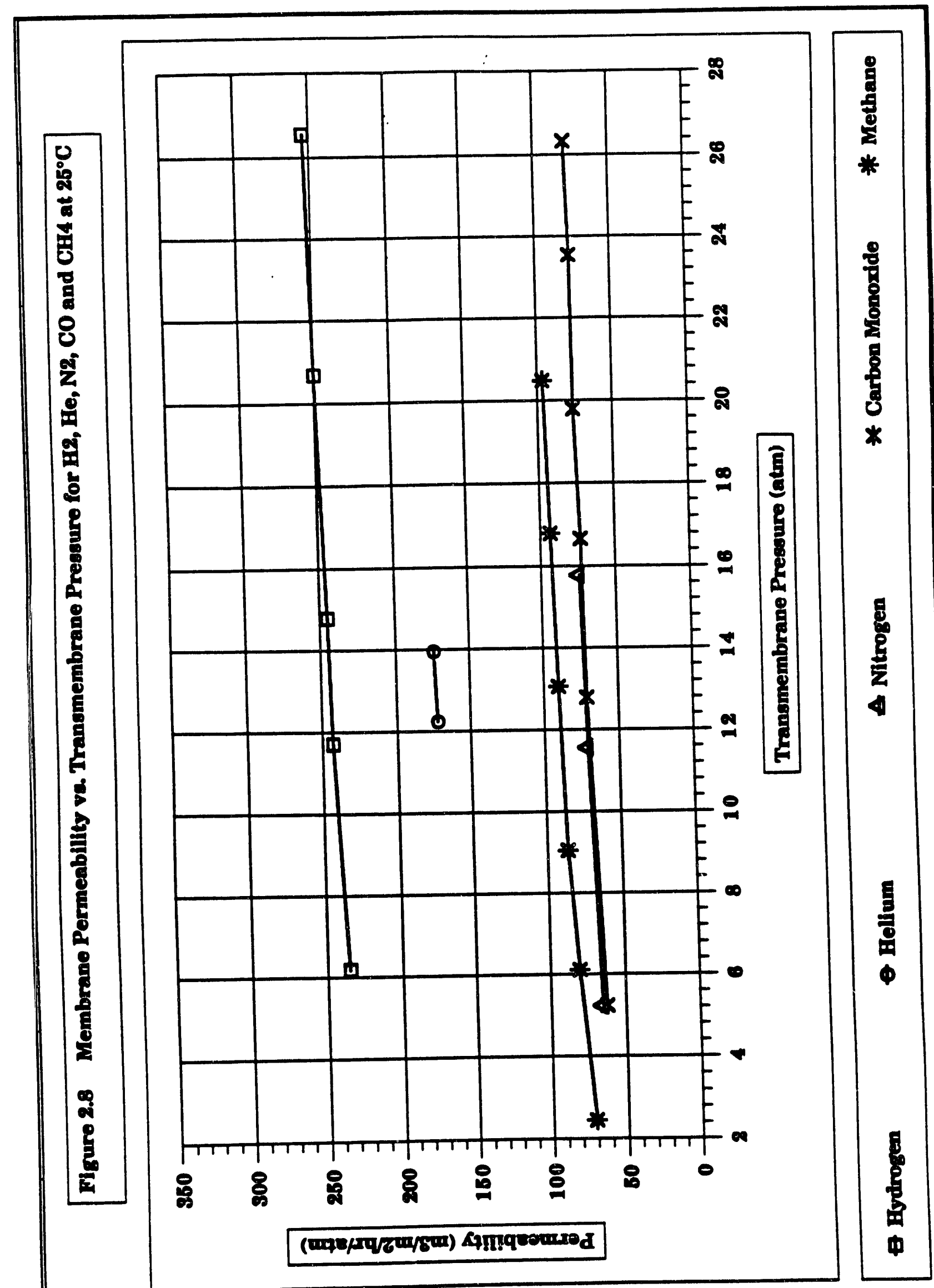


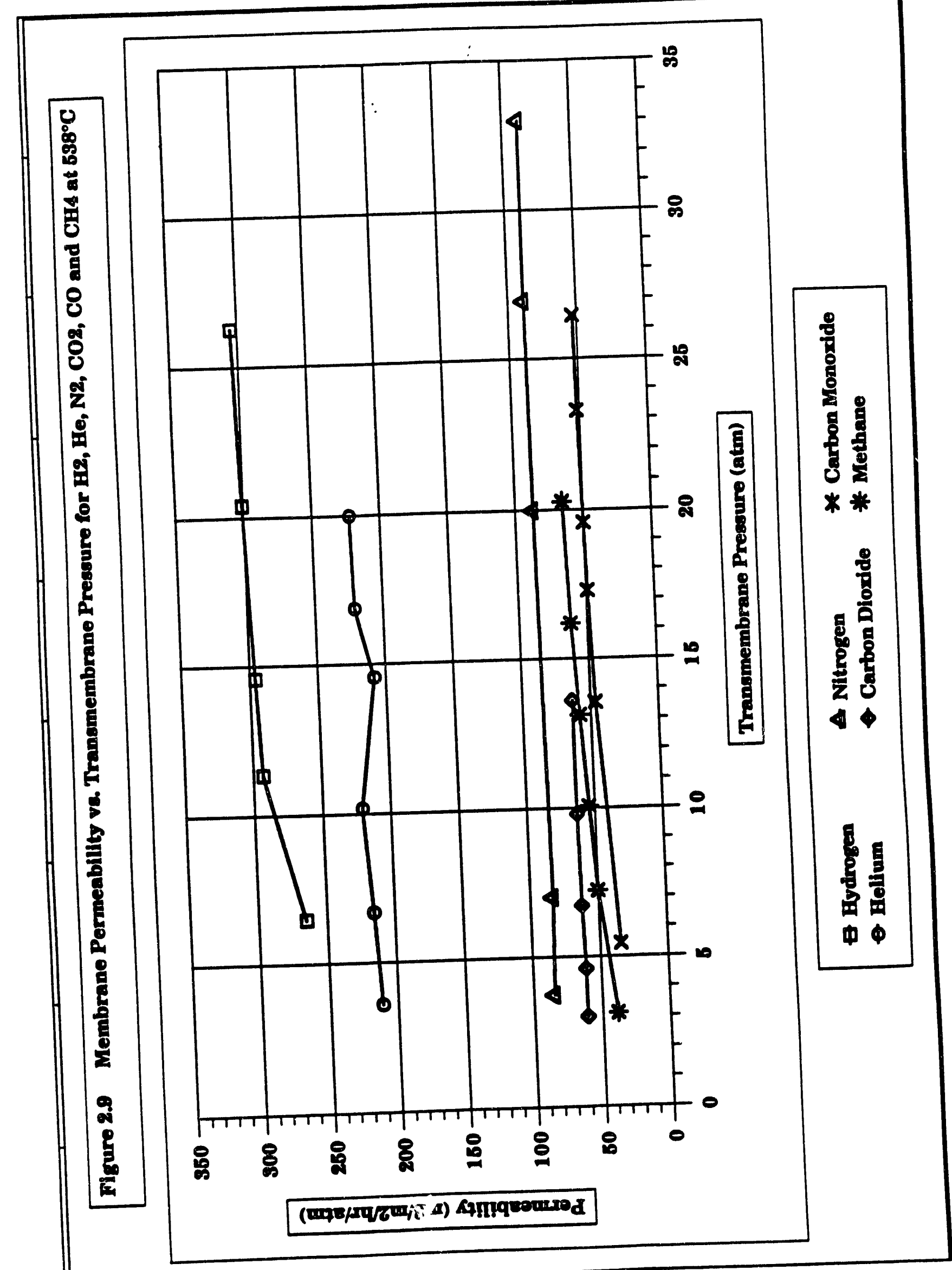




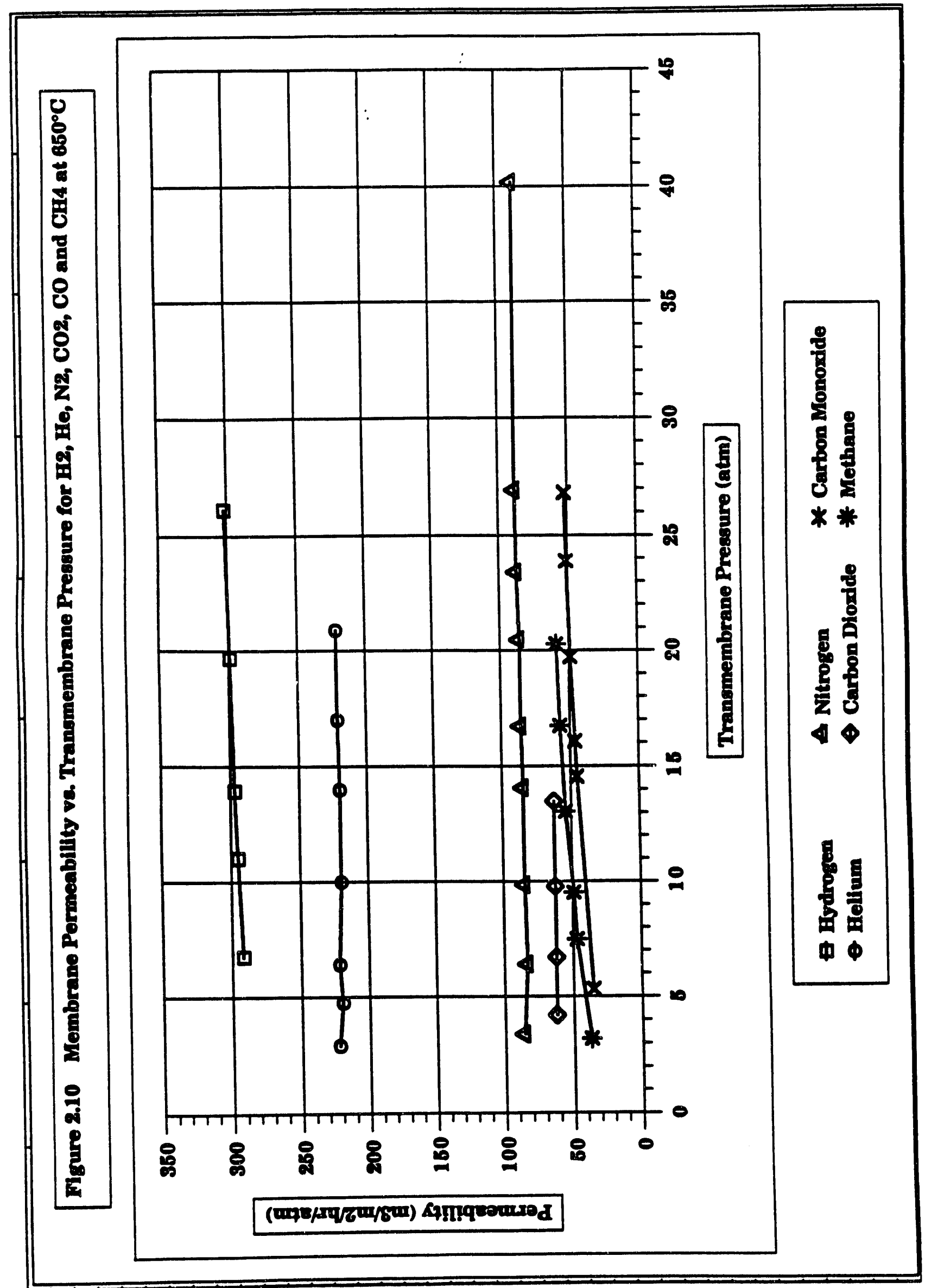




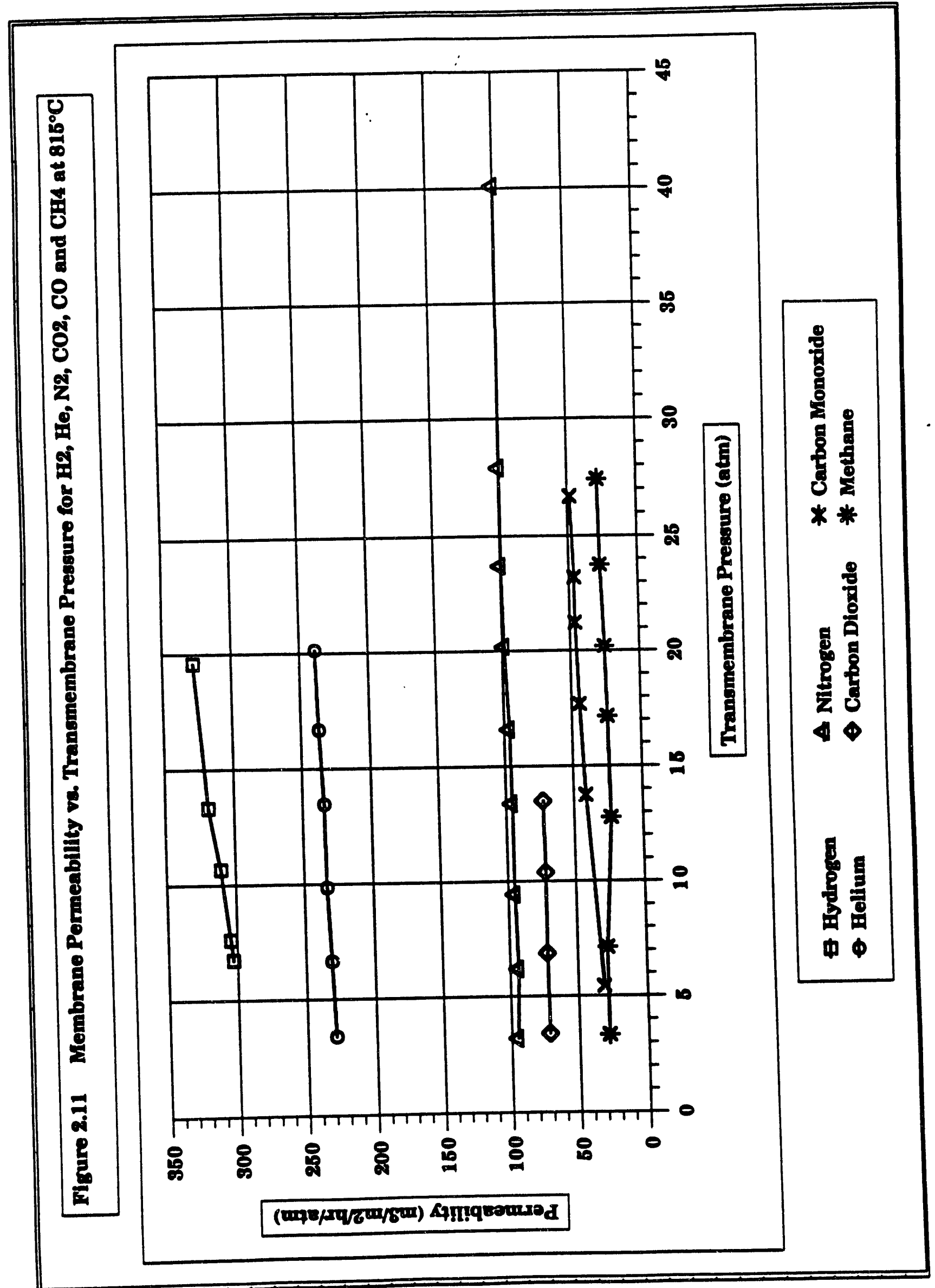


with transmembrane pressure has been shown by Leenaars, et al. (Leenaars, et al., 1984) to be a contribution of Poiseuille flow resistance in the support layers of the asymmetric membrane. Table 2.2 shows the separation factors based on the pure cornponent permeabilities and referenced to $\mathrm{H}_{2}$. From Eqn. 3, if Knudsen diffusion is the controlling mechanism of transport, the ratio of permeabilities of any two compounds under otherwise similar conditions should be given by:

$$
P_{A} / P_{B}=\left(M_{B} / M_{A}\right)^{1 / 2}
$$

Eqn. 4

From Table 2.2 it can be seen that this is in fact the case for all compounds studied at $25^{\circ} \mathrm{C}$. At elevated temperatures $\mathrm{H}_{2}, \mathrm{He}, \mathrm{N}_{2}$, and $\mathrm{CO}_{2}$ continue to follow this trend. For $\mathrm{CO}$ and $\mathrm{CH}_{4}$, however, the separation factors appear to be increasing well in excess of the ideal values. From Table 2.1, it seems that this deviation is due to a decline in $\mathrm{CO}$ and $\mathrm{CH}_{4}$ permeability relative to the other compounds.

For both gases, coking was hypothesized as the reason for the permeability decline at high temperatures. This is supported by the results of Figure 2.12. There the room temperature $\mathrm{N}_{2}$ permeability of the presumably coked membrane and also the room temperature $\mathrm{N}_{2}$ permeability of the same membrane after treatment in a $10 \%$ $\mathrm{O}_{2} /$ balance $\mathrm{He}$ at $538^{\circ} \mathrm{C}$ for 16 hours is shown. The average $\mathrm{N}_{2}$ permeability increased from $49.7 \mathrm{~m}^{3} / \mathrm{m}^{2} / \mathrm{hr} / \mathrm{atm}$ to 122.5 $\mathrm{m}^{3} / \mathrm{m}^{2} / \mathrm{hr} / \mathrm{atm}$ after this treatment. The final permeability value is consistent with that reported above for $\mathrm{N}_{2}$. The source of this carbon deposition appears to be $\mathrm{CO}$ disproportionation and $\mathrm{CH}_{4}$ decomposition on the acidic sites of the transitional $\gamma-\mathrm{Al}_{2} \mathrm{O}_{3}$ layer. As a result, the high temperature permeabilities reported for $\mathrm{CO}$ and $\mathrm{CH}_{4}$ are likely not accurate.

\section{Thermal and Hydrothermal Stability}

\subsubsection{Thermal Stability}

Many of the emerging applications for microporous ceramic membranes hope to capitalize on the thermal stability of ceramics in comparison to polymeric membranes. However, no assessment of the thermal stability of commercially available, asymmetric membranes has been reported.

\subsubsection{Methodology}

In this study, the thermal and hydrothermal stability of the nominal $40 A$ membranes were assessed in the apparatus shown in Figure 2.13. Under thermal conditions, an inert gas 


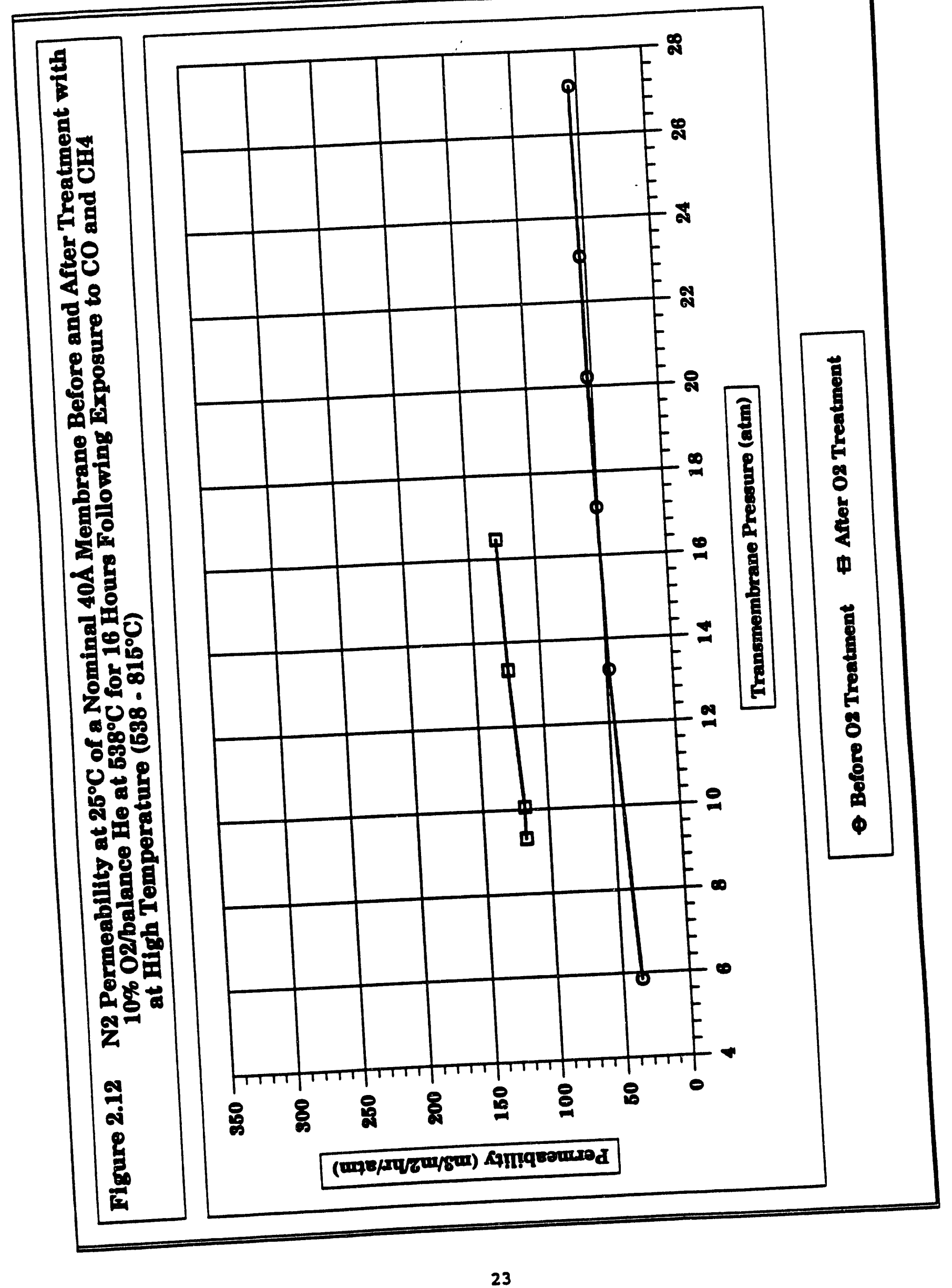




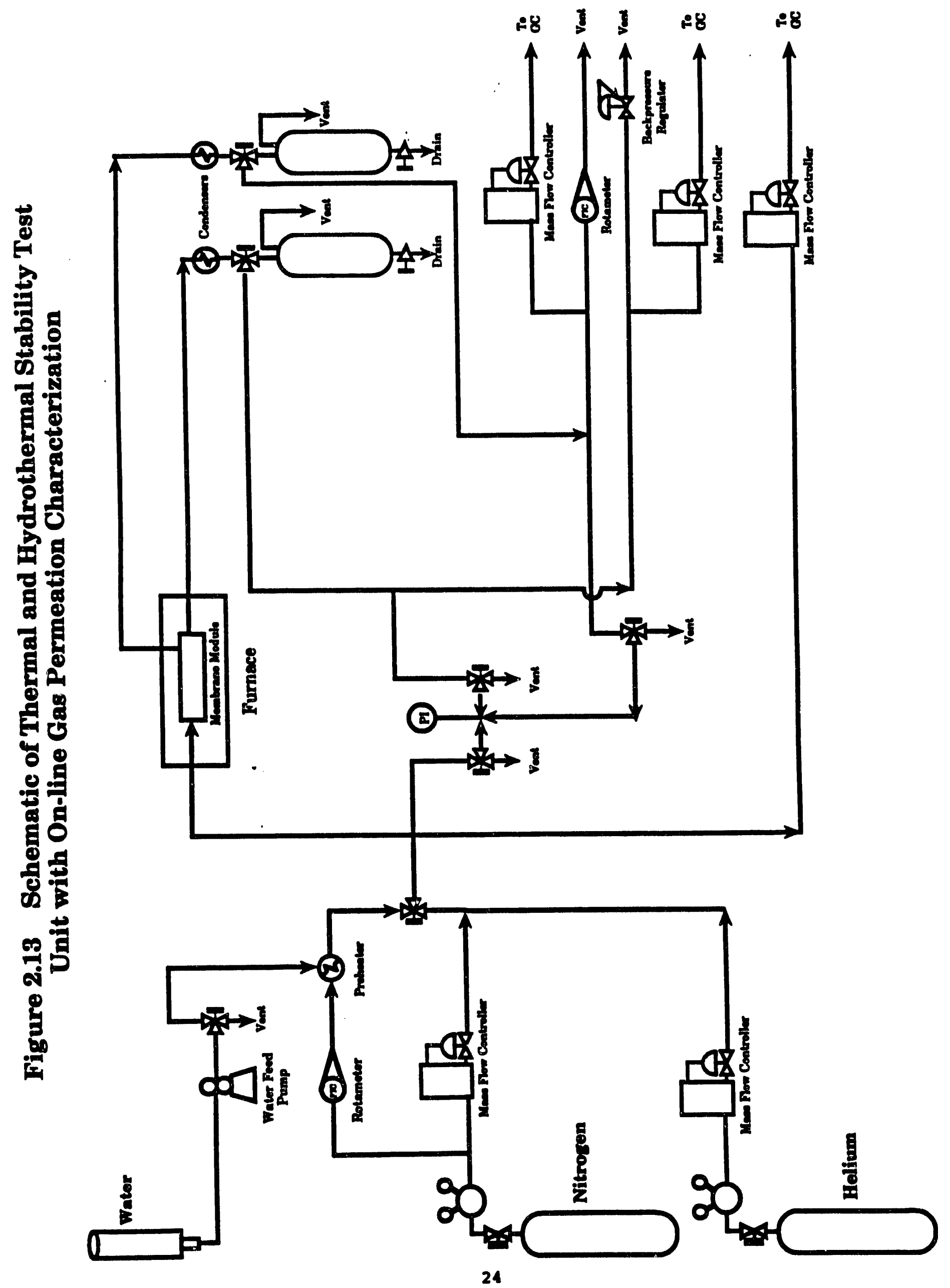


such as $\mathrm{He}$ or $\mathrm{N}_{2}$ is introduced to the membrane module via mass flow controllers. The module is housed in a tube furnace which allows the membrane to be heated up to $650^{\circ} \mathrm{C}$. After the furnace, the permeate and reject effluents are cooled in condensers. During thermal treatment, these effluents are vented to a hood. The permeability of the membrane can be measured periodically via the on-line test gauge and flow measuring set up. Here, reject flow is diverted from the vent through a back pressure regulator in order to vary transmembrane pressure. The permeate stream is diverted from the vent through a calibrated rotameter to monitor permeate flow. Feed, reject, and permeate pressures are monitored with a precision test gauge. This unit is also interfaced with an on-line gas chromatograph in order to assess $\mathrm{N}_{2} / \mathrm{He}$ mixed gas separation factors.

\subsubsection{Results and Discussion}

The room temperature $\mathrm{N}_{2}$ permeabilities of several membranes as received from the manufacturer are given in Table 2.3. There reported values range from $51 \mathrm{~m}^{3} / \mathrm{m}^{2} / \mathrm{hr} / \mathrm{atm}$ to $70 \mathrm{~m}^{3} / \mathrm{m}^{2} / \mathrm{hr} / \mathrm{atm}$. However, values as low as 40 $\mathrm{m}^{3 /} \mathrm{m}^{2} / \mathrm{hr} / \mathrm{atm}$ have been observed. In addition to this wide range of as received permeabilities, the fresh permeability also seemed to vary with time of year, with higher values observed in the less humid winter months and lower values observed in the more humid summer months.

The effect of thermal treatment on the fresh as received membranes are summarized in Figures 2.14, 2.15, and 2.16. Figure 2.14 shows the effect of treatment temperature on $\mathrm{N}_{2}$ permeability measured at room temperature. Here the membrane was treated in $500 \mathrm{cc} / \mathrm{min}$ of flowing $\mathrm{N}_{2}$ for three hours each at $25^{\circ} \mathrm{C}, 200^{\circ} \mathrm{C}, 400^{\circ} \mathrm{C}, 500^{\circ} \mathrm{C}$, and $640^{\circ} \mathrm{C}$. Thermal treatment had negligible effect on permeability at temperatures up to $400^{\circ} \mathrm{C}$. However, treatment at $500^{\circ} \mathrm{C}$ and $600^{\circ} \mathrm{C}$ resulted in a near doubling of the permeability of the membrane.

Figure 2.15 shows the effect of thermal treatment on $\mathrm{N}_{2}$ permeability measured at room temperature as a function of treatment time and Figure 2.16 shows the effect of this treatment on the pore size distribution of the membrane. Treatment was carried out at $640^{\circ} \mathrm{C}$ with a $500 \mathrm{cc} / \mathrm{min}$ flow of $\mathrm{N}_{2}$ fed to the membrane module. The permeability of the fresh membrane was approximately $40 \mathrm{~m}^{3} / \mathrm{hr} / \mathrm{m}^{2} / \mathrm{atm}$ and the flow weighted average pore size was $39.6 \AA$. As can be seen from Figure 2.14, the permeability rose to a value of approximately 
Table 2.3: $\mathrm{N}_{2}$ Permeabilities of As-Received Membranes at $25^{\circ} \mathrm{C}$

\begin{tabular}{|l|c|}
\hline Membrane & $\begin{array}{c}\text { Permeability } \\
\left(\mathrm{m}^{3 / m} / \mathrm{m} / \mathrm{hr} / \mathrm{atm}\right)\end{array}$ \\
\hline E11831 & 70 \\
E11835 & 6 \\
E12269 & 53 \\
E12458 & 53 \\
E12462 & 51 \\
\hline
\end{tabular}




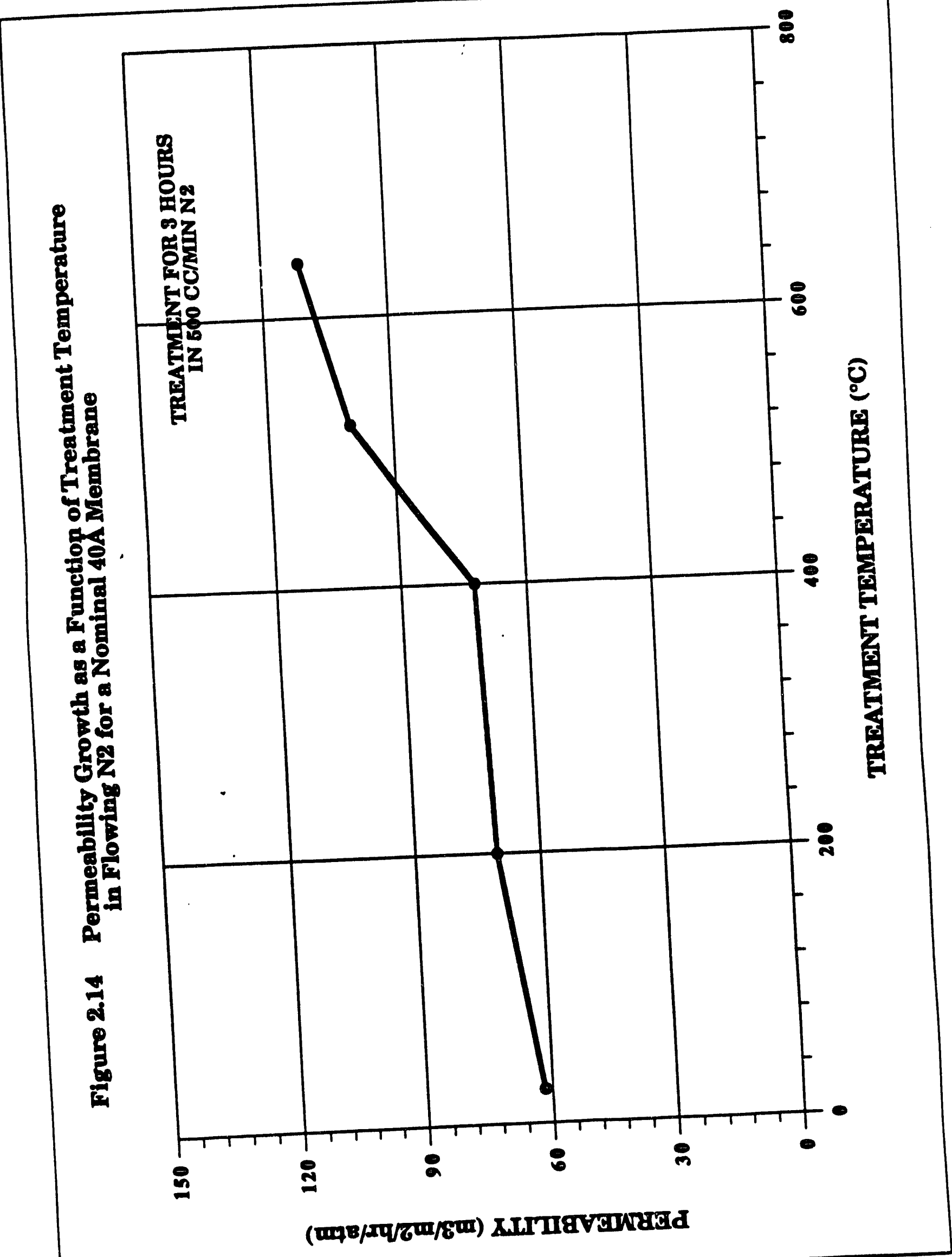




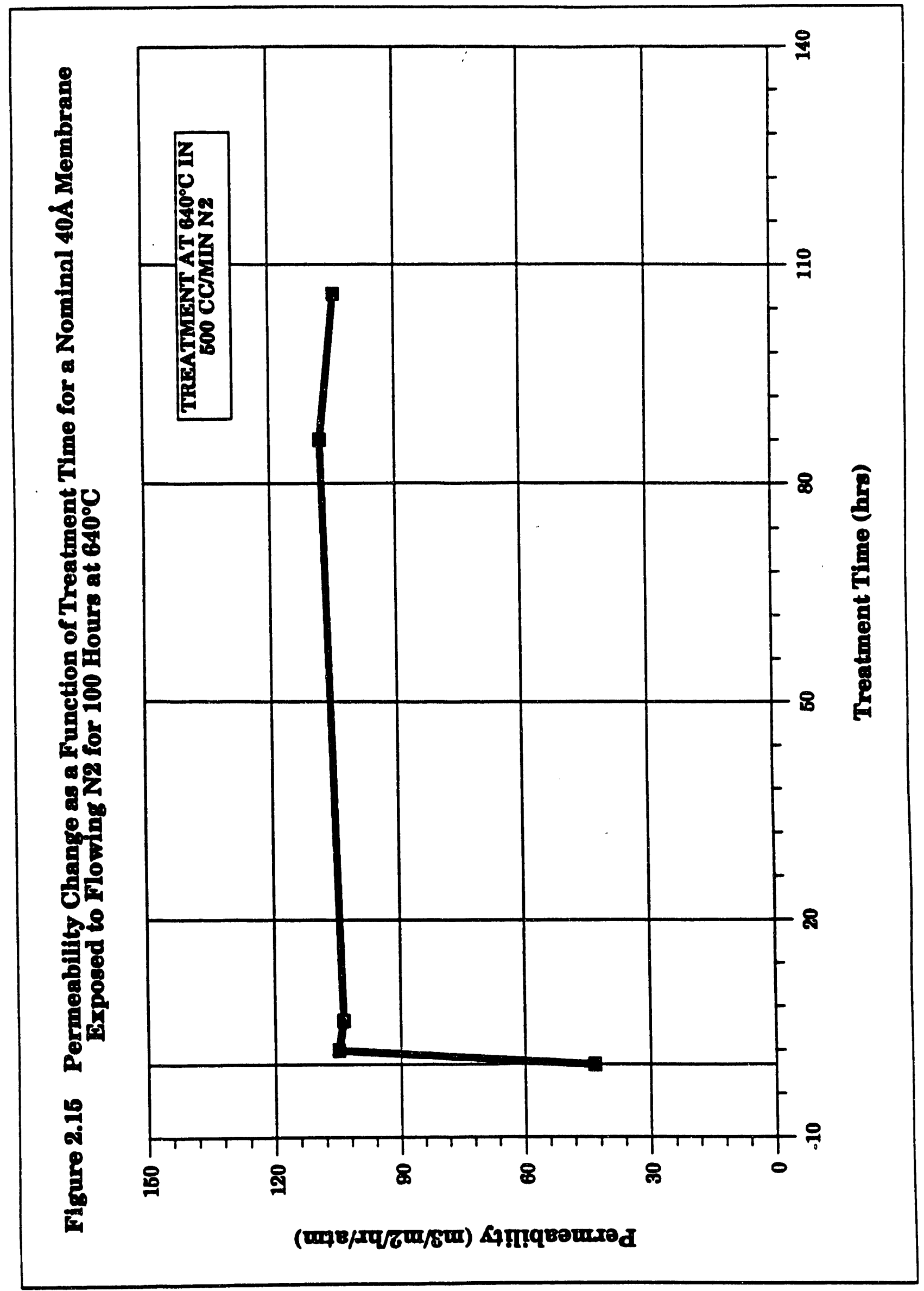




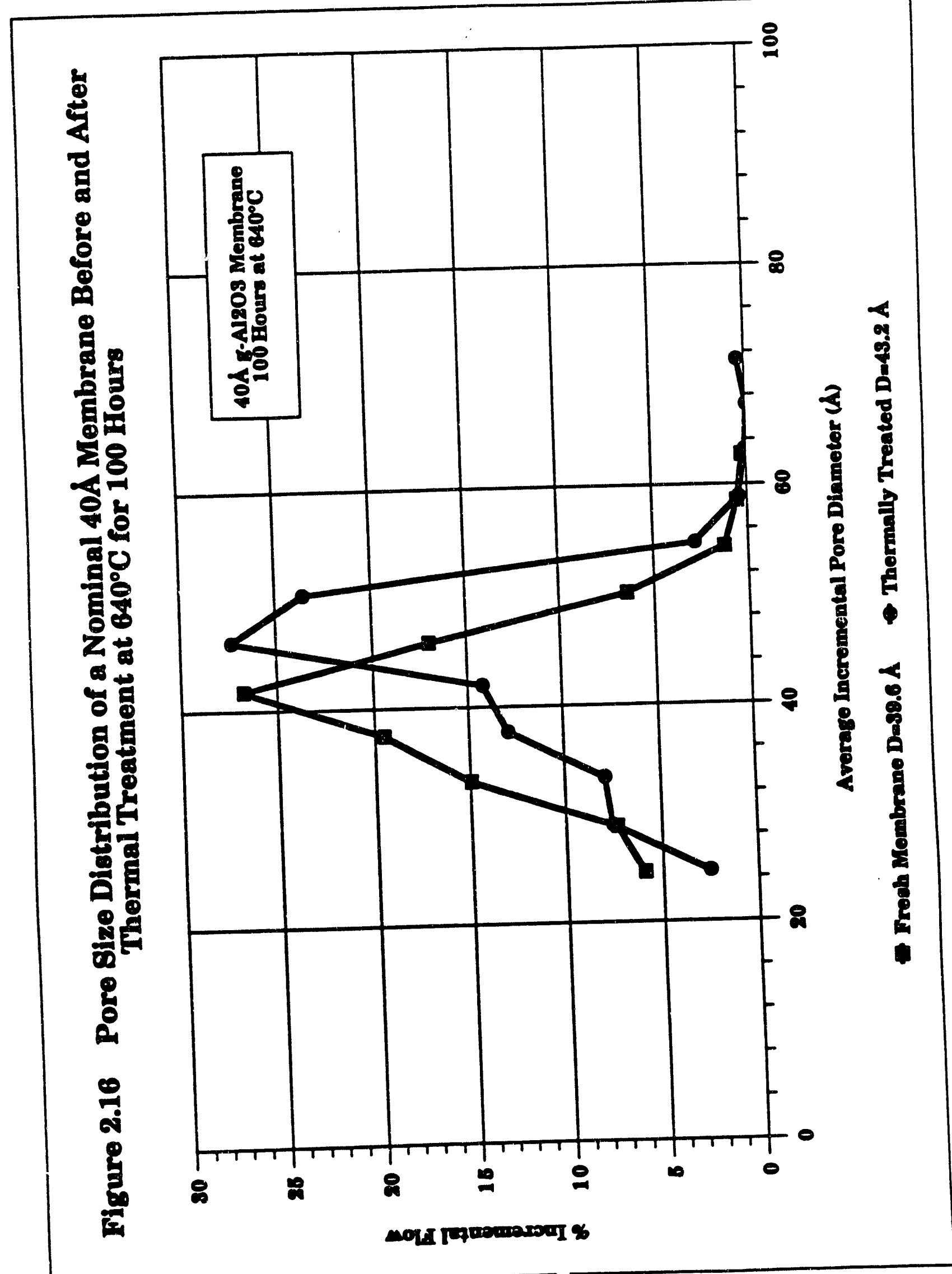


$110 \mathrm{~m}^{3} / \mathrm{hr} / \mathrm{m}^{2} / \mathrm{atm}$ after two hours of exposure and remained unchanged after 100 hours of treatment. While the permeability of the membrane more than doubled with thermal treatment, the pore size grew only slightly to $43.2 \AA$ as shown in Figure 2.15. This thermally treated membrane was then stored in the laboratory, exposed to room air. After six months, it was resubjected to thermal treatment. The changes in permeability throughout this process are summarized in Figure 2.17. There it can be seen that after six months storage, the permeability of the membrane reverted to its original, asreceived value. Subsequent thermal treatment as before caused a near doubling of the permeability, suggesting that the process is reversible.

Transport through membranes in this pore size range is by Knudsen diffusion and permeability is proportional to pore diameter. Table 2.4 summarizes the predicted pore size change based on the observed permeability increase along with the ratios of porosity to tortuosity $(\varepsilon / \tau)$ calculated using Eqn. 3 and the observed permeabilities and pore sizes. For pore sizs changes to account for the increased permeability, a pore radius of nearly $42 \AA$ should have been observed. Obviously the increase in permeability is far in excess of that accountable by the modest increase in pore size suggesting that some other change in the structure of the membrane layer is taking place. A near doubling of the porosity to tortuosity $(\varepsilon / \tau)$ ratio seems to explain the observations. The problem then becomes one of how to explain this change.

Two possible scenarios are presented in Figure 2.18. The pore structure of $\gamma-\mathrm{Al}_{2} \mathrm{O}_{3}$ membranes is thought to be slit shaped (Wefers et al., 1987; Leenaars et al., 1984). In Scenario 1, these slit shaped pores are partially filled with adsorbed moisture leaving a capillary of diameter $\mathrm{d}_{\mathrm{p}}$. This moisture is evacuated during thermal treatment at high temperatures, but readsorbs during subsequent exposure to room air. In each step of this process, the pore size distribution analysis, which is based on capillary condensation, measures the width of the slit, $d_{p}$ (Gregg et al., 1982). The adsorbed water must be strongly adsorbed since short term exposure to 10 torr vacuum during pore size distribution analysis does not change the observed permeability of these membranes. The high temperature required to observe permeability changes during thermal treatment also supports this statement.

The second scenario in Figure 2.18 involves lateral movement of the stacked plates which form the pore structure. Again, with only lateral movement, pore size analysis would detect the 


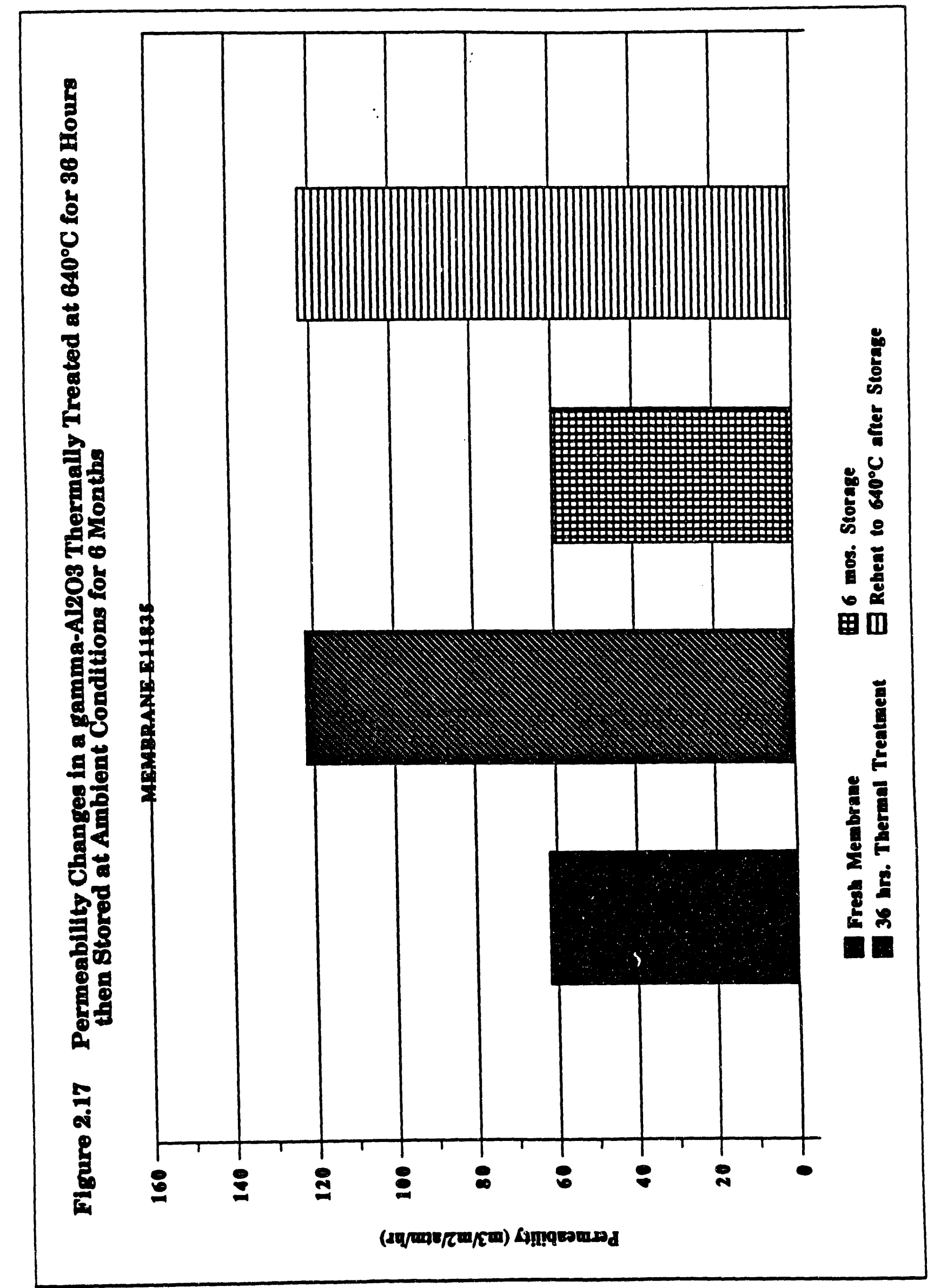


Table 2.4: Characteristics of $\gamma-\mathrm{Al}_{2} \mathrm{O}_{3}$ Membrane as a Function of Thermal Treatment at $640^{\circ} \mathrm{C}$

\begin{tabular}{|c|c|c|c|c|c|}
\hline & & $\begin{array}{c}N_{2} \text { Permeability } \\
\left(\mathrm{m}^{3} / \mathrm{m}^{2} / \mathrm{hr} / \mathrm{atm}\right)\end{array}$ & $\begin{array}{c}\mathrm{N}_{2} \text { Permeability } \\
\left(\mathrm{mol} / \mathrm{m}^{2} / \mathrm{hr} / \mathrm{atm}\right)\end{array}$ & Predicted $\mathrm{r}(\AA)$ & $\varepsilon / \tau$ \\
\cline { 2 - 6 } Fresh & 19.8 & 52.3 & 2335 & - & 0.127 \\
$100 \mathrm{hrs}$ & 21.6 & 110.0 & 4910 & 41.7 & 0.244 \\
\hline
\end{tabular}


Figure 2.18 Model of Pore Structure Changes in a $\gamma-\mathrm{Al}_{2} \mathrm{O}_{3}$ Membrane Subjected to Thermal Treatment at Temperature up to $640^{\circ} \mathrm{C}$

Scenario 1:

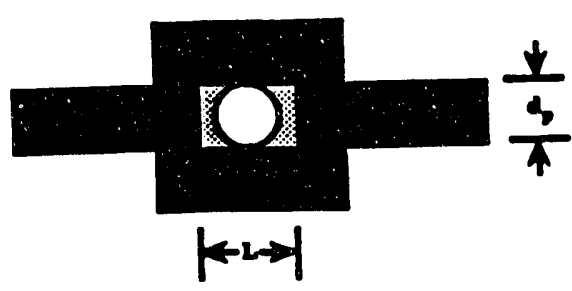

Adsorbed moisture partially blocks as-received pore.

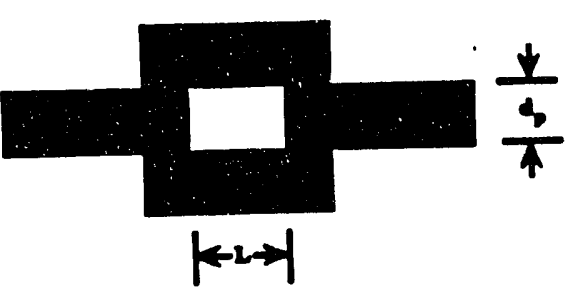

Adsorbed moisture evacuated during thermal treatment.

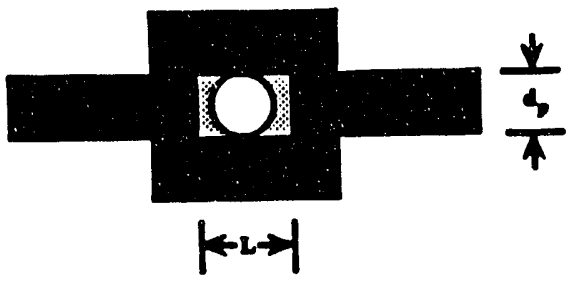

Moisture readsorbs during storage partially refilling pore.

Scenario 2:

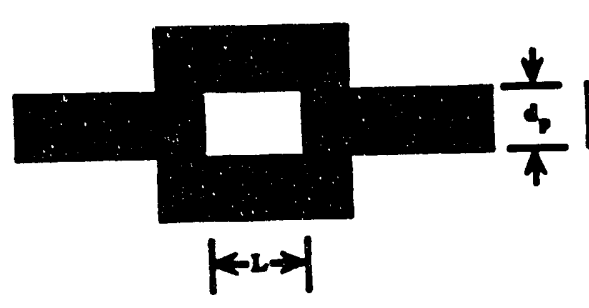

As-received pore has dimensions dp and $L$.

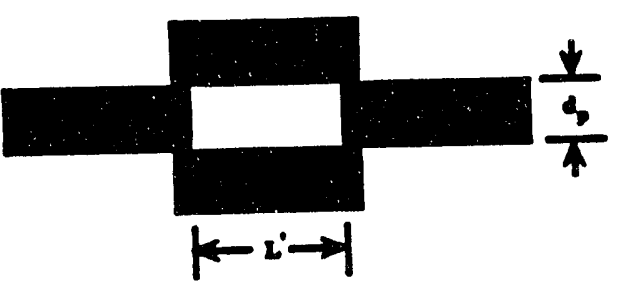

During thermal treatment $\mathrm{Al}_{2} \mathrm{O}_{3}$ plates shift increasing $\mathrm{L}$ to $\mathrm{L}$.

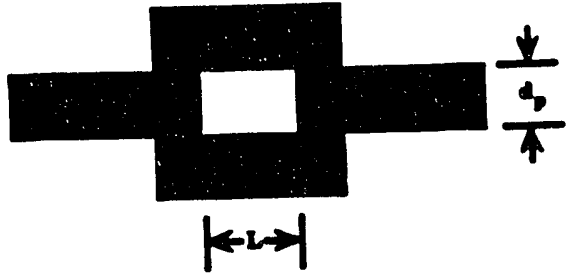

During storage, plates shift back to original position. 
slit width, $d_{p}$. This scenario would require that the plates shift back during exposure to room air. For this scenario to be valid, the length of the slit would have to double in order to account for the observed permeability change. It seems probable that dimensional changes of this magnitude would inevitably induce defects such as cracks in the membrane structure. As a result, Scenario 1 most likely occurs.

These results suggest that the $\gamma-\mathrm{Al}_{2} \mathrm{O}_{3}$ membranes are thermally stable at temperatures up to $640^{\circ} \mathrm{C}$. All permeability measurements were made at room temperature following incremental periods of thermal treatment. This shows that the membranes are also stable to controlled thermal cycling. The observed changes in permeability appear to be due to desorption of water and other contaminants adsorbed onto the membrane during storage. This also explains the variation in permeability of the as received membranes and suggests that an initial thermal treatment is necessary in order to characterize the true gas permeability of these membranes.

\subsubsection{Hydrothermal Stability}

\subsubsection{Methodology}

The effect of hydrothermal stability was also assessed using the apparatus in Figure 2.13. For one membrane, however, 24 $\mu \mathrm{L}$ of liquid water was fed to a vaporizer which was purged with $2 \mathrm{~L} / \mathrm{min}$ of flowing $\mathrm{N}_{2}$. This resulted in a stream of approximately $5 \%$ by volume water vapor in $\mathrm{N}_{2}$ at the treatment temperature. For a second membrane, a stream of approximately $90 \%$ steam was used. These $\mathrm{N}_{2} /$ steam streams were fed to the heated module. The water was condensed and collected from both the reject and permeate streams. Before permeabilities were measured, the water flow was halted and the membrane was purged overnight in flowing $\mathrm{N}_{2}$.

\subsubsection{Results and Discussion}

The effect of hydrothermal treatment with a $5 \%$ steam stream on the first membrane is shown in Figures 2.19 and 2.20. From Figure 2.19, the permeability through the membrane rose rapidly to a value of approximately $110 \mathrm{~m}^{3} / \mathrm{hr} / \mathrm{m}^{2} / \mathrm{atm}$, as with thermal treatment. Under hydrothermal conditions however, the permeability rose further, plateauing at a value of nearly $145 \mathrm{~m}^{3} / \mathrm{m}^{2} / \mathrm{hr} / \mathrm{atm}$. The pore size distribution of the fresh membrane and after 95 and 117.5 hours of exposure are shown in Figure 2.20. There it is evident that the flow weighted average size has grown from approximately $40 \AA$ for the fresh 


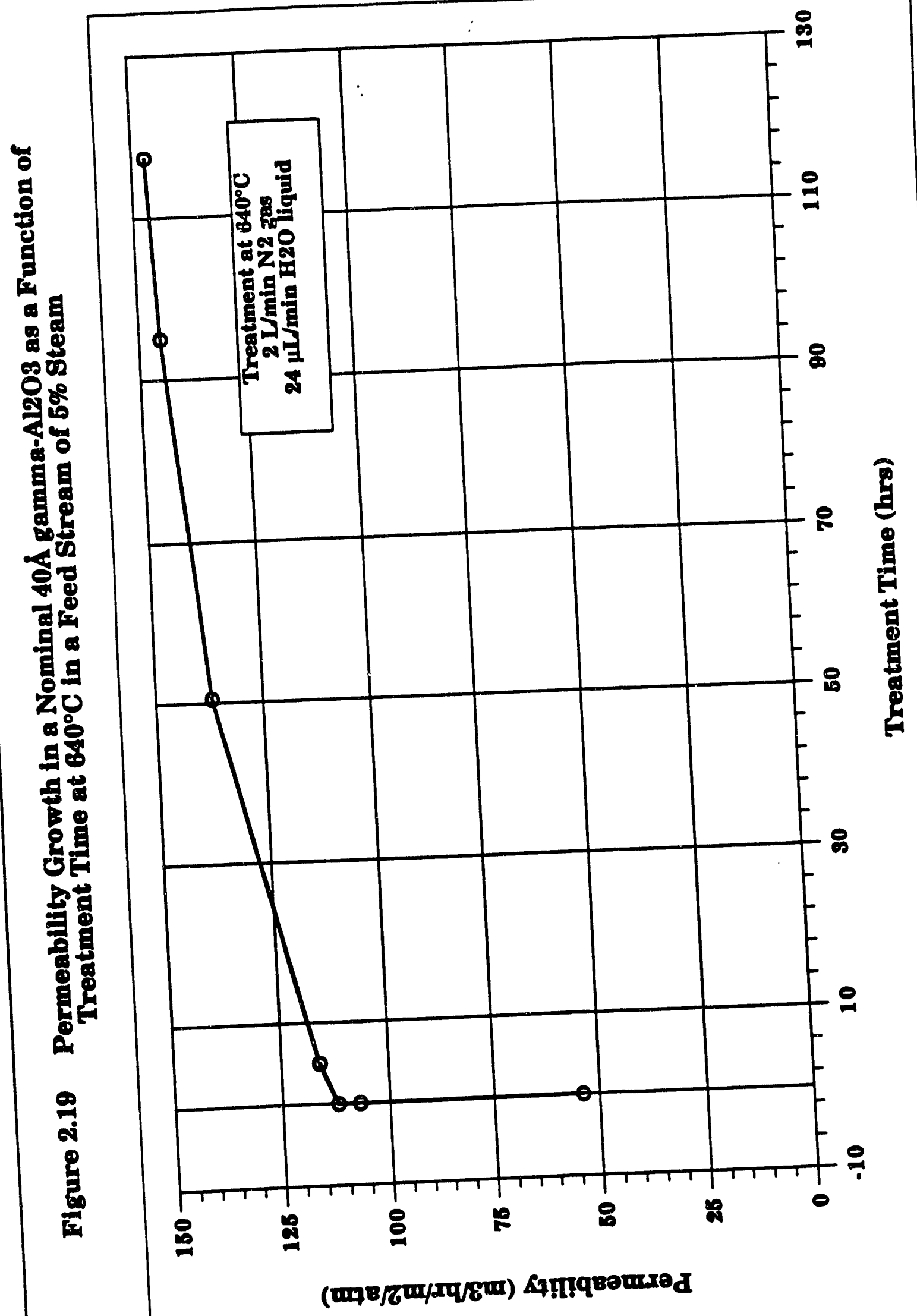




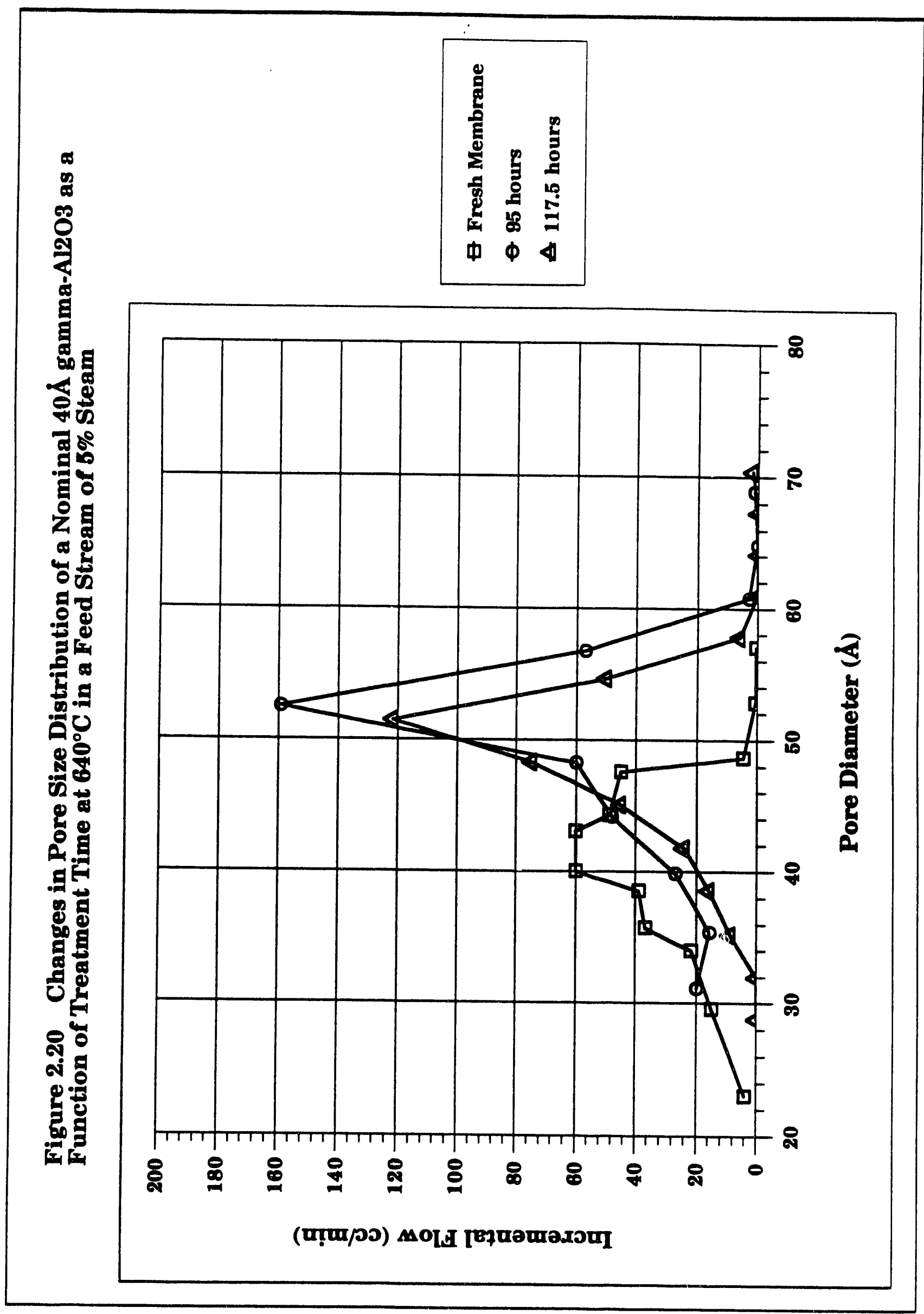


membrane to $52 \AA$ after 95 hours of treatment. No additional pore enlargement is observed after 117.5 hours of cumulative treatment. The results for the second membrane subjected to 90\% steam are shown in Figure 2.21. After 198 hours in 90\% steam, the permeability of the membrane grew to 188 $\mathrm{m}^{3} / \mathrm{m}^{2} / \mathrm{hr} / \mathrm{atm}$ and the average pore size grew to $65.0 \AA$.

The transitional $\gamma-\mathrm{Al}_{2} \mathrm{O}_{3}$ is known to undergo transformation through other transitional forms of alumina towards the thermodynamically stable $\alpha-\mathrm{Al}_{2} \mathrm{O}_{3}$ form at elevated temperatures (T $900^{\circ} \mathrm{C}$ ) (Wefers et al., 1987). Water is known to accelerate this process as well as to lower the temperature at which it takes place. The results here suggest that such a transformation is taking place resulting in pore growth.

Permeability, pore size, predicted pore size based on observed permeability change, and porosity to tortuosity ratio changes throughout treatment are summarized in Table 2.5 for both membranes. For the membrane subjected to $5 \%$ steam treatment, the increase in permeability after hydrothermal treatment can be completely accounted for by pore enlargement:

$109 \mathrm{~m}^{3} / \mathrm{hr} / \mathrm{m}^{2} / \mathrm{atm} X(24.5 \AA / 18.5 \AA)=144 \mathrm{~m}^{3} / \mathrm{hr} / \mathrm{m}^{2} / \mathrm{atm}$

Likewise for the membrane subjected to $90 \%$ steam:

$109 \mathrm{~m}^{3} / \mathrm{hr} / \mathrm{m}^{2} / \mathrm{atm} X(32.3 \AA / 18.8 \AA)=187 \mathrm{~m}^{3} / \mathrm{hr} / \mathrm{m}^{2} / \mathrm{atmo}$

In addition, the porosity to tortuosity ratios $(\varepsilon / \tau)$ are slightly higher than those observed after thermal treatment, suggesting that these pore size increases are accompanied by a slight increase in porosity.

These results suggest that the largest changes in membrane structure occur within the first few hours of treatment. The membrane appears to be relatively stable thereafter. This is consistent with a transformation from $\gamma-\mathrm{Al}_{2} \mathrm{O}_{3}$ to another intermediate transitional alumina phase. The higher concentration of steam appears to have an increased mineralizing effect. It is not clear, however, if a truly stable plateau has been reached under these conditions or if the kinetics of the transformation have only slowed to the point where much longer exposure times are necessary to observe significant changes in the membrane structure. 


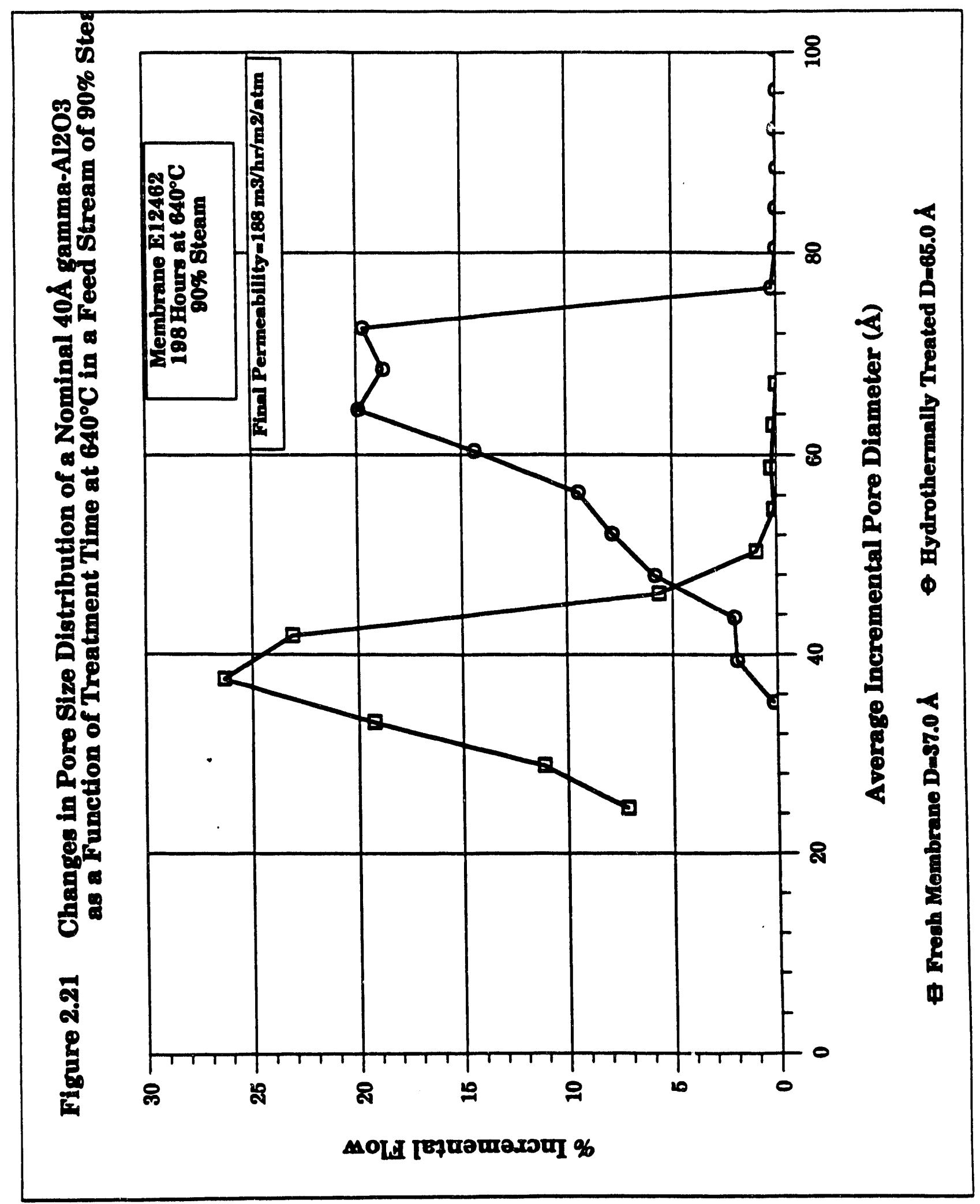


Table 2.5: Characteristics of $\gamma-\mathrm{Al}_{2} \mathrm{O}_{3}$ Membranes as a Function of Hydrothermal Treatment at $640^{\circ} \mathrm{C}$

\begin{tabular}{|c|c|c|c|c|c|}
\hline $\begin{array}{l}\text { Hydro } 1 \\
5 \% \text { steam }\end{array}$ & 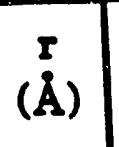 & $\begin{array}{l}\mathrm{N}_{2} \text { Permeability } \\
\left(\mathrm{m}^{\left.3 / \mathrm{m}^{2 / \mathrm{hr}} / \mathrm{atm}\right)}\right.\end{array}$ & $\begin{array}{l}\mathrm{N}_{2} \text { Permeability } \\
(\mathrm{mol} / \mathrm{m} 2 / \mathrm{hr} / \mathrm{atm})\end{array}$ & $\begin{array}{c}\text { Predicted } \mathrm{r} \\
(\AA)\end{array}$ & $\varepsilon / \tau$ \\
\hline $\begin{array}{l}\text { Fresh } \\
\text { (after thermal) }\end{array}$ & 18.5 & & 4866 & - & 0.282 \\
\hline 95 hours & 24.6 & 148.4 & 6625 & 25.2 & 0.289 \\
\hline 117.5 hours & 24.5 & 1525 & 6808 & 25.9 & 0.298 \\
\hline \multicolumn{6}{|l|}{$\begin{array}{l}\text { Hydro } 2 \\
90 \% \text { steam }\end{array}$} \\
\hline $\begin{array}{l}\text { Fresh } \\
\text { (after thermal) }\end{array}$ & 18.8 & 109.0 & 4866 & - & 0.278 \\
\hline 198 hours & 32.3 & 188.0 & 8392 & 32.4 & 0.279 \\
\hline
\end{tabular}




\subsection{Chemical Stability}

Many of the process streams where high temperature membrane processes may be applied contain compounds which may react with the ceramic membrane. Alkali species are an important class of such compounds which would be present in coal gasifier streams as well as in high temperature petrochemical streams where alkali-promoted catalysts are in use.

\subsubsection{Methodology}

To assess the potential effect of alkali exposure, a ceramic membrane was packed with a crushed, commercially available $\mathrm{K}^{+}$-promoted $\mathrm{Fe}_{2} \mathrm{O}_{3}$ catalyst then exposed to hydrothermal treatment. The feed to the membrane module consisted of $200 \mathrm{cc} / \mathrm{min}$ of $\mathrm{N}_{2}$ into which was evaporated $1.2 \mathrm{ml} / \mathrm{min}$ of liquid water. Exposure was for four hours at $640^{\circ} \mathrm{C}$.

\subsection{Results and Discussion}

Results are sumamarized in Figures 2.22, 2.23, 2.24, and 2.25. As a result of this treatment the $\mathrm{K}^{+}$content of the catalyst fell from $8.24 \%$ to $7.55 \%$ on a $\mathrm{K}_{2} \mathrm{O}$ basis. The equivalent alkali flowrate was $2.4 \times 10^{-6}$ $\mathrm{mol} / \mathrm{min}$. Following this exposure, the $\mathrm{N}_{2}$ permeability of this membrane was observed to be approximately $15 \mathrm{~m}^{3} / \mathrm{hr} / \mathrm{m}^{2} / \mathrm{atm}$. This is in contrast to a value of approximately $150 \mathrm{~m}^{2} / \mathrm{hr} / \mathrm{m}^{2} / \mathrm{atm}$ found for membranes undergoing the same hydrothermal treatment in the absence of alkali species. The pore size distribution of the membrane can be seen in Figure 2.22. Approximately 20\% of the flow through the membrane after exposure to alkali is attributable to pores with diameters in excess of $100 \AA$.

Figures 2.23 and 2.24 show SEM micrographs of the inner membrane surface following this treatment. The inner surface is decorated with crystallites not seen on the fresh inner surface (see Figure 2). In addition, defects are now evident on the alkali exposed surface. From Figure 2.25, EDAX of the membrane surface showed peaks attributable to both Al and to $\mathrm{K}$.

These results are consistent with the formation of alkali aluminates and possibly $\beta$-aluminas (Wefers et al., 1987). They also indicate that alkali species may have a severe effect on the integrity of $\gamma-\mathrm{Al}_{2} \mathrm{O}_{3}$ membranes. The loss in permeability with increasing pore size suggests a loss in porosity in the membrane layer. This could be due to blocking of pores by deposited alkali species or to morphological changes associated with compound formation between alkali and alumina. 


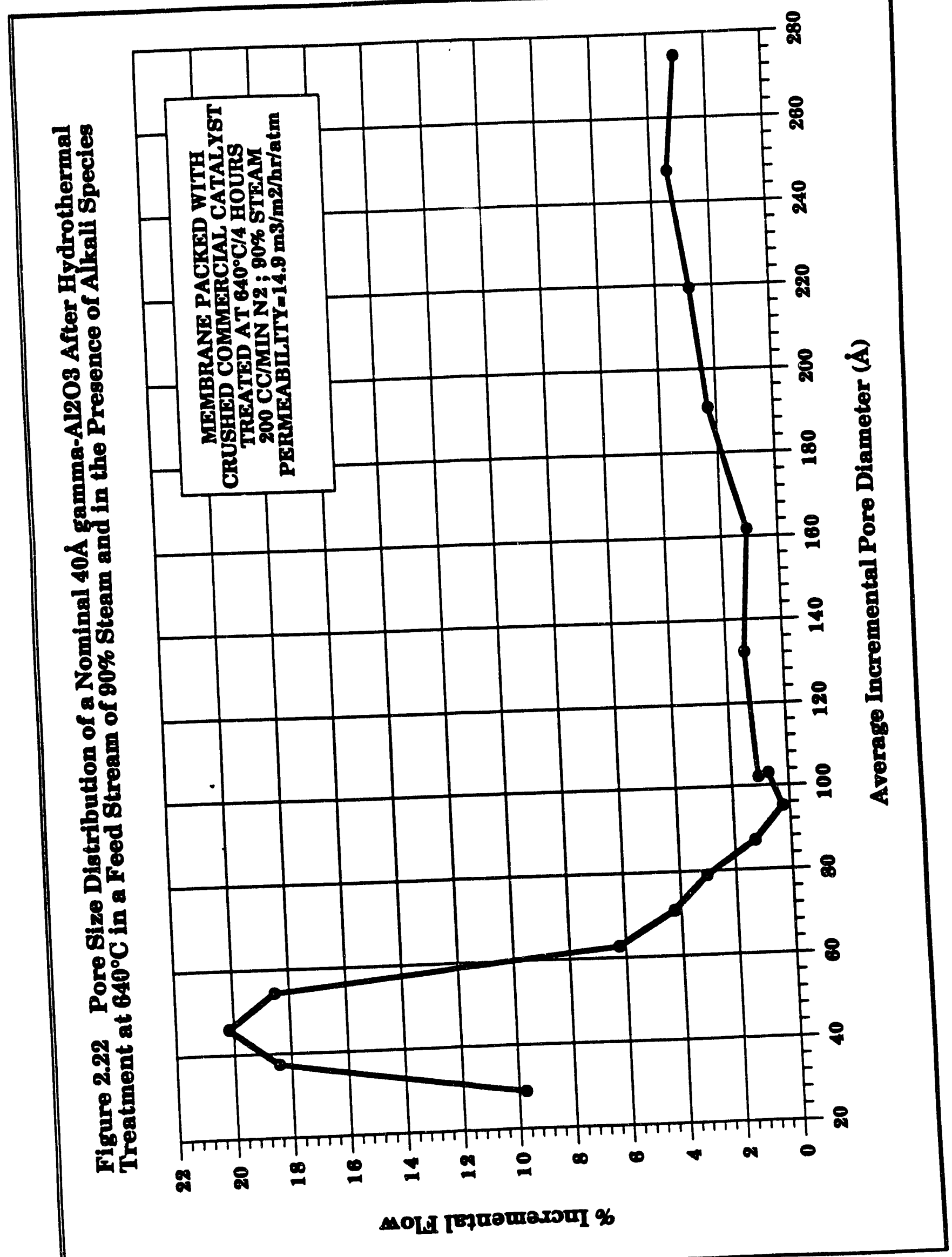


Figure 2.23 Wide View SEM Micrograph of the Membrane Surface After Hydrothermal Treatment at $640^{\circ} \mathrm{C}$ in a Feed Stream of $90 \%$ Steam and in the Presence of Alkali Species

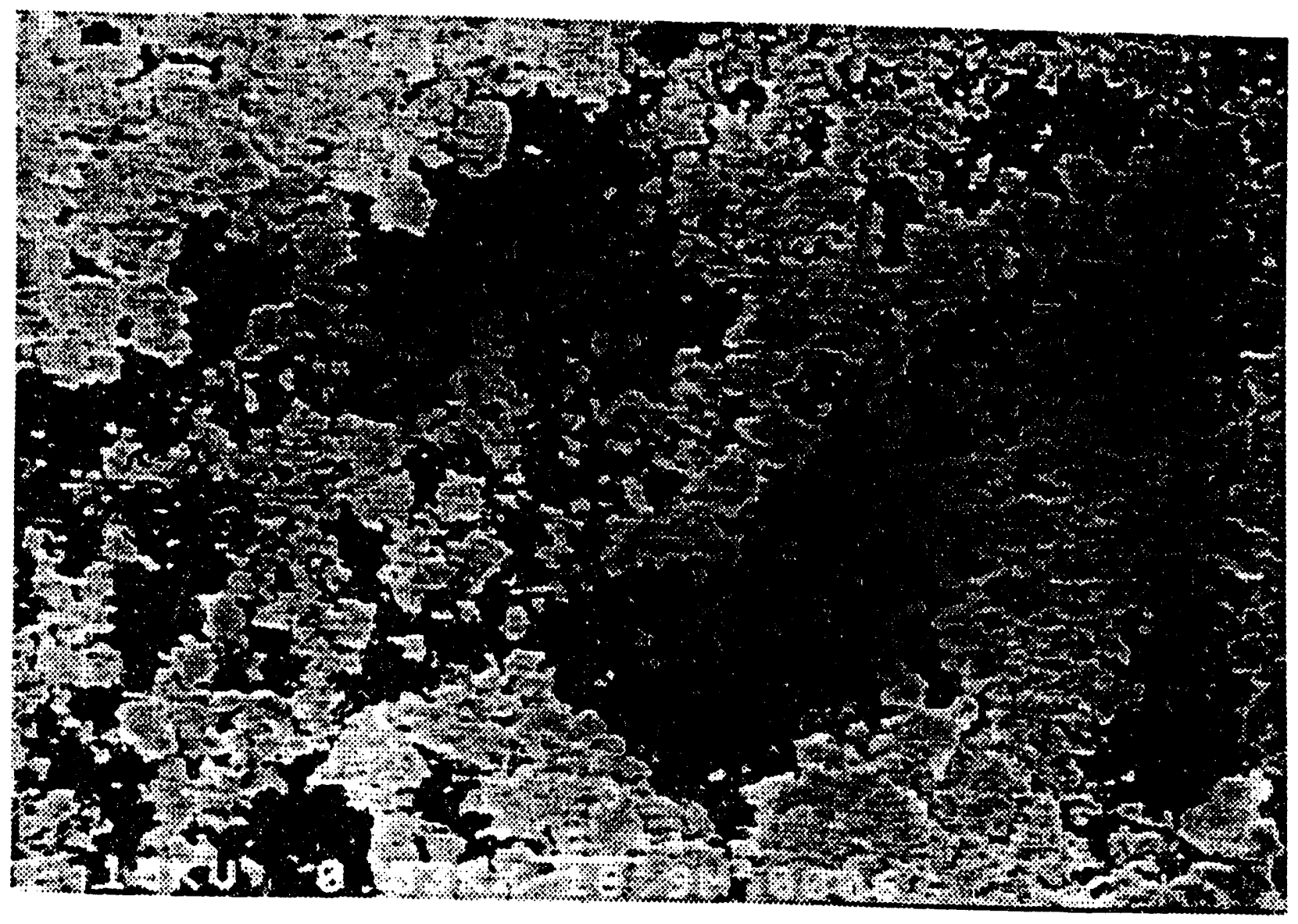


Figure 224 Magnified View of the Membrane Surface After Hydrothermal Treatment at $640^{\circ} \mathrm{C}$ in a Feed Stream of $90 \%$ Steam and in the

\section{Presence of Alloali Species}

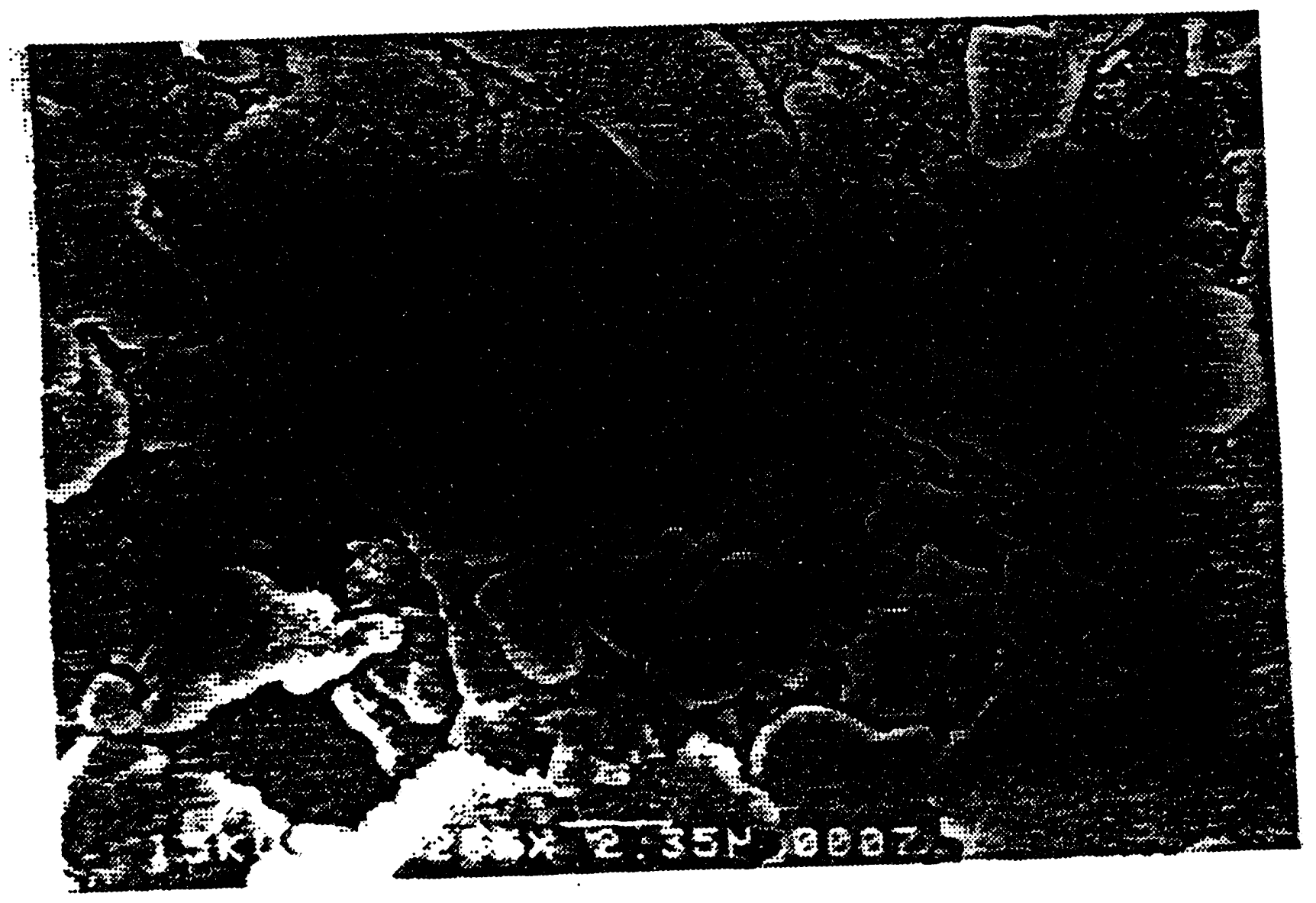




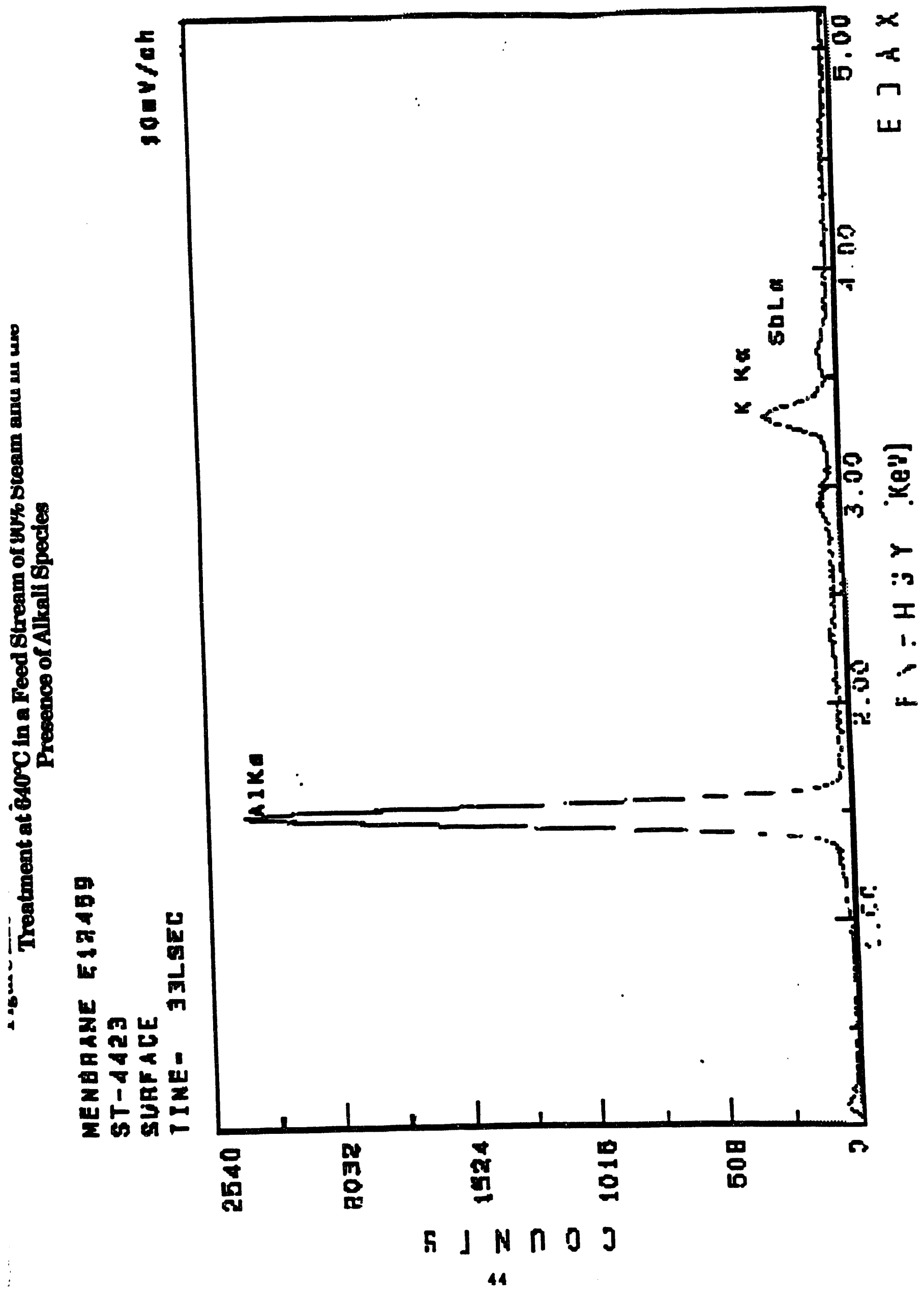




\section{Ges Separations with Fristing Membranes}

Gas separations using commercial ceramic membranes with $40 \AA$ pore diameter were performed for three binary mixtures: $\mathrm{H}_{2} / \mathrm{CO}, \mathrm{H}_{2} / \mathrm{N}_{2}$ and $\mathrm{He}_{2} \mathrm{O}_{2}$. The experimental conditions covered a wide range of temperature $\left(25\right.$ to $815^{\circ} \mathrm{C}$ ) and pressure (3 to $38 \mathrm{~atm})$. A mathematical model based upon Knudsen diffusion and intermolecular momentum transfer was developed to predict gas separation efficiency. The experimental results agreed well with the model prediction. The permeability of $\mathrm{CO}$ was substantially lower than the value expected from Knudsen diffusion. Nevertheless, the model developed was able to account for this phenomenon and predicted equally well for a binary mixture containing $\mathrm{CO}$. The effect of key operating parameters on separation behaviors was studied with the model developed.

\subsection{Introduction}

Gas separations via permselective membranes have been developed in the past few years. Several membrane-based processes have been commercialized using polymeric membranes. Microporous inorganic membranes have also boen actively explored due to their better material stability than the polymeric counterparts for high temperature and/or high pressure (HTHP) applications. Materials discussed in the literature include vycor glass, aluminum oxide and others with pore size ranging from several microns to $-40 \AA$. Several existing and emerging separations at HTHP could be streamlined with the use of these membranes. For example, separation of $\mathrm{H}_{2} \mathrm{~S}$ from a high pressure natural gas stream, and recovery of hydrogen from coal gasification products.

Gas separations via microporous membranes involve four mechanisms: Knudsen diffusion, surface diffusion, capillary condensation with liquid flow and molecular sieving. In general, when the mean free path of a molecule is ten times larger than the pore diameter, Knudsen diffusion is predominant (Yang, 1987). At an elevated temperature, capillary condensation unlikely exists in commercial microporous membranes with $240 \AA$ of pore diameter. Molecular sieving does not take place because the smallest pore size commercially available, i.e., 40A, is much larger than gaseous molecules. Surface diffusion is possible; but could be negligible for most gases at an elevated temperature. Hwang and Kammermeyer indicated that surface diffusion on microporous yycor glass quickly approached zero with increasing temperature (Hwang and Kammermeyer, 1966). At high temperature $\left(337^{\circ} \mathrm{C}\right)$, the total flow approaches Knudsen diffusion at a low pressure range $(<2 \mathrm{~atm})$. Shindo, et al. also showed that surface diffusion could be negligible at high temperatures (Shindo et al., 1983). In summary, Knudsen diffusion is a dominant mechanism to be considered in gas separation with commercial ceramic membranes under HTHP environment. Viscous flow, resulted from pressure difference across the pore, is not considered as one of the separation mechanisms. 
Many models were developed to describe gas separation using microporous membranes (Shindo et al., 1984, 1989; Pan and Habgood, 1974, 1978; Kao et al. 1989; Li et al., 1990; Huckins and Kammermeyer, 1953; Tranchino, 1989; Haraya et al., 1987; Tock and Kammermeyer, 1969; Uhlhorn et al., 1989). These models were all based on ideal Knudsen separation. The individual permeability in a multi-component gas mixture was assumed the same as that in a single component, and was independent of pressure. This assumption was valid only at a low pressure range. Practically, membranebased processes required a transmembrane pressure drop to achieve effective gas separations. Under this circumstance, interaction between components in a mixture could become significant.

Interaction between molecules was first incorporated into a gas kinetic model by Present and deBethune (P-D model) more than 40 years ago (Present and Debethune, 1949). A theoretical model including Knudsen diffusion, inter-molecular momentum transfer and viscous flow was developed to describe the gas flow through a single capillary. Figure 3.1 illustrates the concept of the inter-molecular momentum transfer. In a binary mixture each molecule has three possible collision patterns: one type of molecule collides with the other type, the same type, or the wall. The average momentum remains constant in the collision with the same type of molecules. However, a net momentum transfer occurs for collision between different molecules.

Most literature studies since then have based upon the P-D model. Fain and Brown separated neon isotopes under vacuum in capillary and parallelplate systems with well-defined geometry (Fain and Brown, 1974). The P-D model was modified empirically to improve the prediction. Haraya et. al., presented the separation of $\mathrm{H}_{2}-\mathrm{CO}$ in porous glass membranes with pore diameter ranging from 31 to $200 \AA$ at 5-50 atms and $100^{\circ} \mathrm{C}$ (Haraya et al., 1986 a, b). They applied the P-D model to the observed Knudsen permeabilities with the assistance of a fitting parameter. Eickmann and Werner incorporated 2 parameters to the P-D model to account for membrane morphology and the reflection of gas molecules (Eickmann and Werner, 1985).

In this paper, a mathematical model has been developed following the approach by Eickmann and Werner for a commercial caramic membrane unit. Predicted gas separation behaviors have been compared with experimental results at HIHP. This model has then been utilized to analyze the effects of key operating parameters, such as stage cut, feed pressure, pressure ratio of permeate to feed sides and molar composition of the feed. 
Figure 3.1 : Molecular Diffusion Through Capillary for a Mixture of Nitrogen and Hydrogen

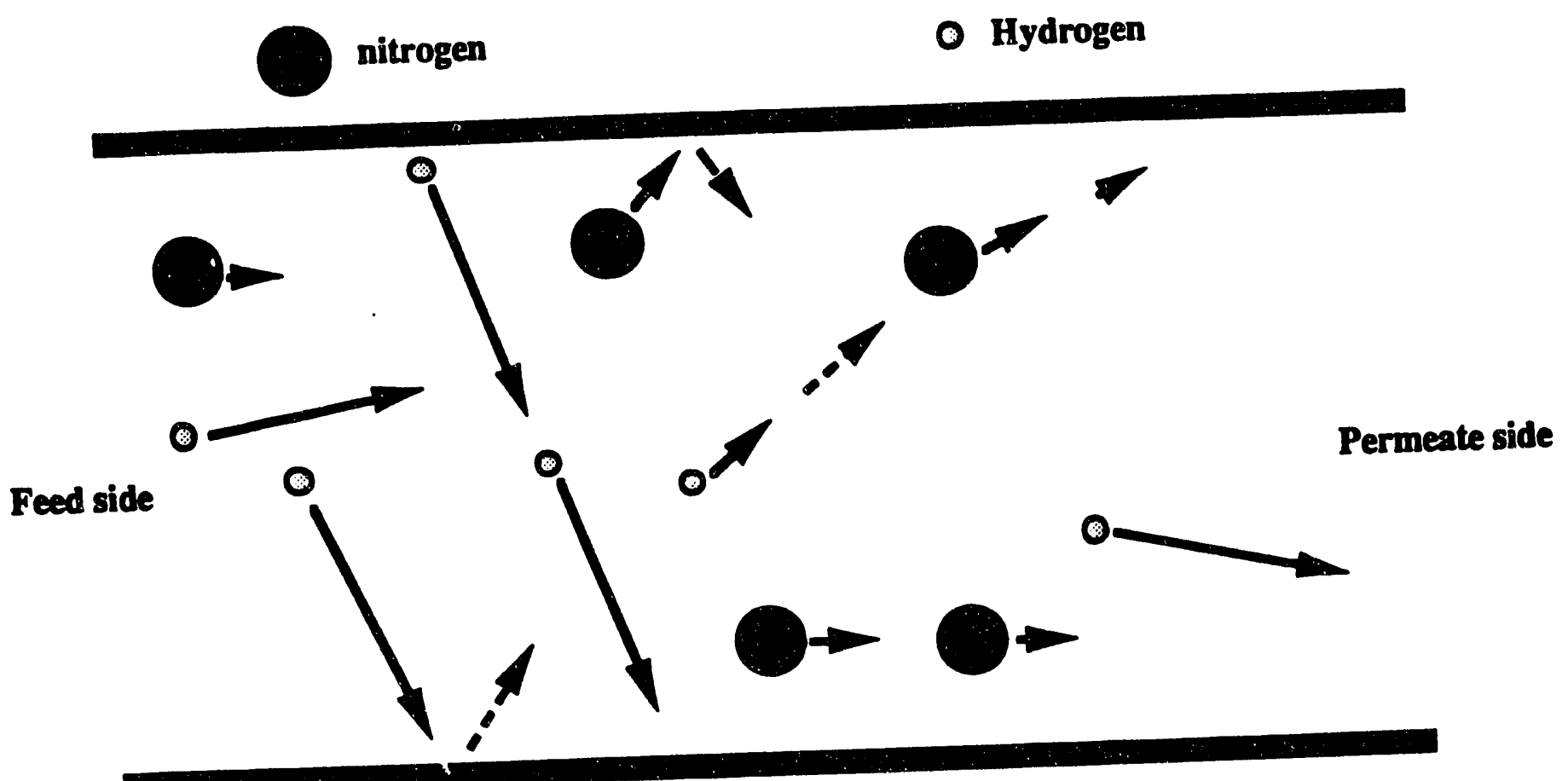


The material used in this study was a multiple layer microporous asymmetric membrane offered from Alcoa Separations under the trade name Membralox. The individual layer structure is shown in a crosssectional SEM micrograph in Figure 3.2. The permselective layer is confined in the top layer with $3-5$ micron thickness. The nominal pore diameter is $40 \AA$ with porosity of -0.5 . The detailed characteristics of this membrane was reported elsewhere (Wu and Liu, 1992). The membrane module contains a tubular membrane with 1 "length, which was housed in a stainless steel module and sealed by Grafoil ribbon (graphite based packing material) between the tube and the housing.

Figure 3.3 shows the schematic diagram of the facility used for gas separations at high temperatures. Binary gas mixtures were prepared from single gas components including $\mathrm{H}_{2}, \mathrm{O}_{2}, \mathrm{He}, \mathrm{N}_{2}$, and $\mathrm{CO}$. Each mixture was preheated before entering the membrane module. After separation by a membrane, permeate and reject streams were then cooled down and measured by mass flow meters before the compositional analysis by a GC. A thermocouple was inserted into the center of the membrane to measure the temperature. The operating temperature studied ranged from $20^{\circ} \mathrm{C}$ to $815^{\circ} \mathrm{C}$. Pressure was controlled by regulators installed in the reject and permeate lines. Feed pressure varied from 3 to 38 atm, and permeate pressure from 1.3 to 27 atm. Stage cut was operated from 0.01 to 0.36 by adjusting the feed flows ranging from 10 to $100 \mathrm{Vmin}$. The permeability of the single gas components, i.e., $\mathrm{H}_{2}, \mathrm{He}, \mathrm{N}_{2}$, and $\mathrm{CO}$, was also measured with the same unit. The permeability of orygen was not measured because of potential oxidation of graphite packing at a high temperature. Separation of $\mathrm{O}_{2} / \mathrm{He}$ mixtures was carried out at a dilute oxygen environment (11\%) for a short period to avoid the oxidation.

\section{Mathematical Model}

\subsubsection{Basic Assumptions}

The model developed for gas separation using microporous membranes is based on the following assumptions: (1) ideal gas behavior, (2) a well-mired flow in both the reject and permeate streams; (3) no pressure drops throughout the reject and permeate sides respectively; and (4) negligible surface diffusion. The collisions between molecules, and between molecule and pore wall are assumed completely elastic. Perfect miring as shown in Figure 3.4 is justified because the tube length is very short, i.e. $2.54 \mathrm{~cm}$. Two equations derived from material balance for the separator can thus be established as follows:

$$
\begin{aligned}
& Q_{F}=Q_{P}+Q_{R} \\
& X_{0} \cdot Q_{F}=Y \cdot Q_{P}+X \cdot Q_{R}
\end{aligned}
$$


Figure 3.2 : SEM Micrograph of Alumina Membrane Structure

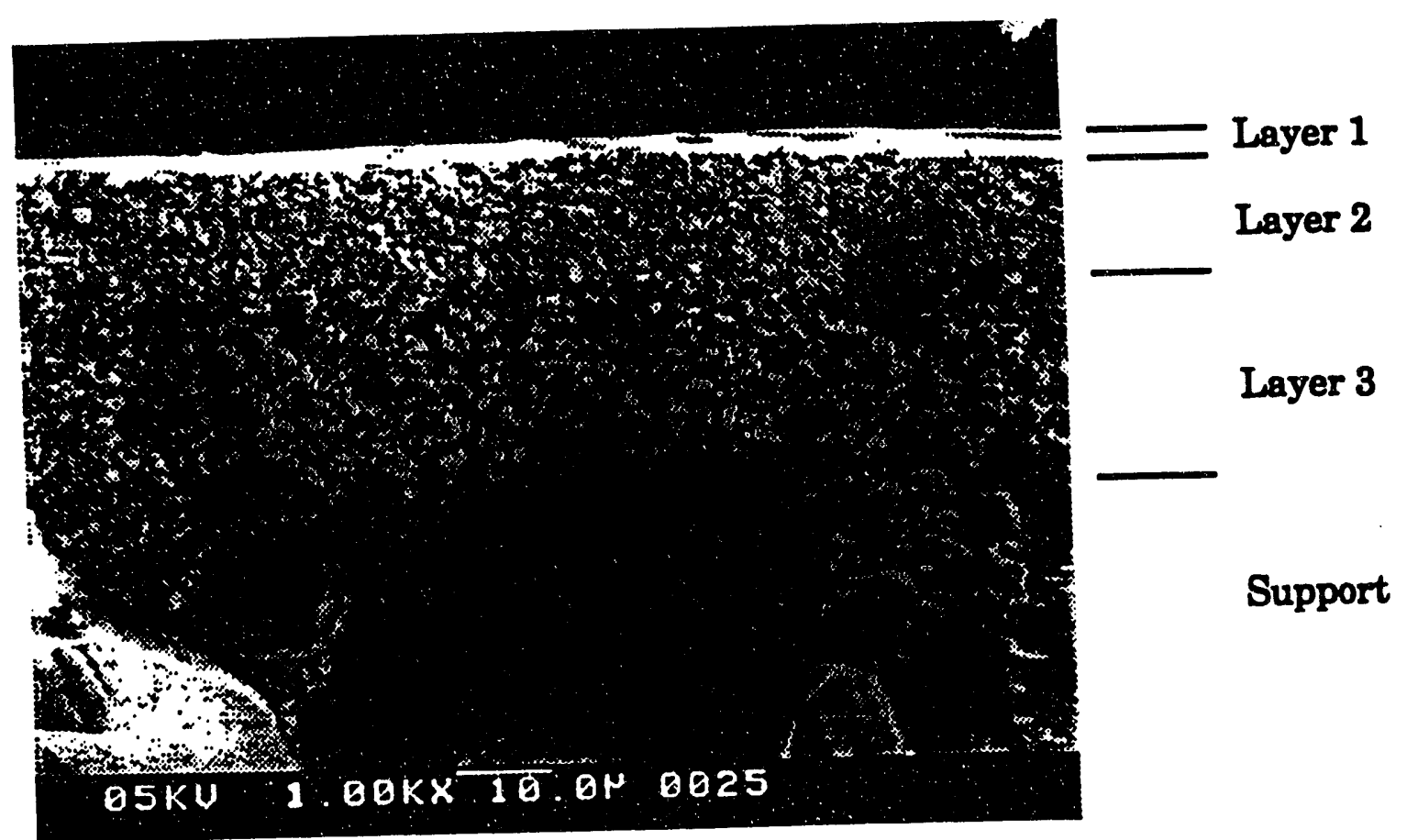

Layer 1: Pore Diameter $=40 \AA ;$ Thickness $=3-5 \mu \mathrm{m} ;$ Porosity $=50 \%$

Layer 2 : Pore Diameter $=0.2 \mu \mathrm{m} ;$ Thickness $=15-30 \mu \mathrm{m} ;$ Porosity $=35 \%$

Layer 3 : Pore Diameter $=0.8 \mu \mathrm{m}$; Thickness $=30$ - $50 \mu \mathrm{m} ;$ Porosity $=40 \%$

Support : Pore Diameter $=10-15 \mu \mathrm{m} ;$ Thickness $=1.5-2.0 \mathrm{~mm} ;$ Porosity $=4.0-45 \%$ 

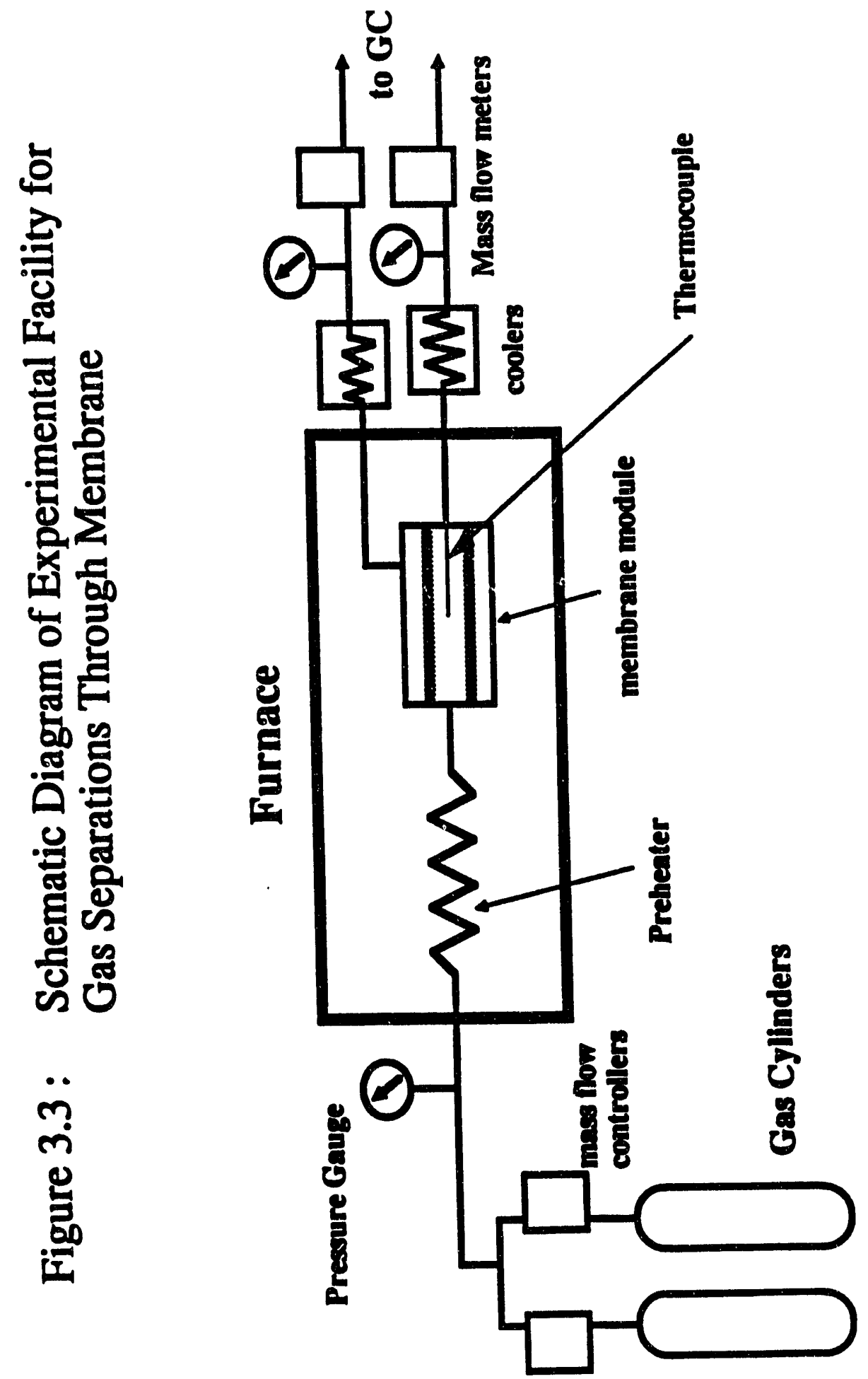
Figure 3.4 : A Perfect Mixing Model for Gas Separation

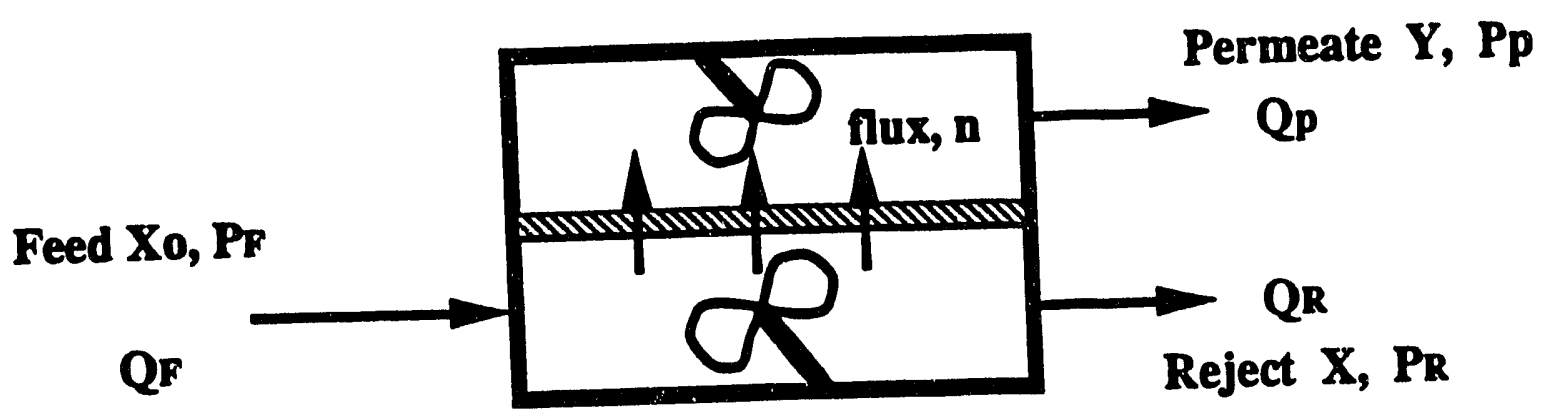


From Equations 1 and 2, the mole fraction of the permeate side stream can be derived in terms of the stage cut $\theta$ :

$$
Y=\frac{X_{0}-X(1-\theta)}{\theta}
$$

where:

$$
\theta=\frac{Q_{P}}{Q_{F}}
$$

\subsubsection{Mass Transport Through Porous Membrane}

Molar fluxes permeated through the membrane can be calculated according to Eickmann and Werner's model (Eickmann and Werner, 1985).

$$
\begin{aligned}
& n_{1}=-\frac{g^{\prime}}{L}\left[\frac{\alpha_{0}}{1+B^{\prime} p} \frac{d(x p)}{d z}+\frac{f_{0} B^{\prime} x p}{1+B^{\prime} p} \frac{d p}{d z}+x A^{\prime} p \frac{d p}{d z}\right] \\
& n_{2}=-\frac{g^{\prime}}{L}\left[\frac{1}{1+B^{\prime} p} \frac{d(1-x) p_{1} f_{0} B^{\prime} p(1-x)}{1+B^{\prime} p} \frac{d p}{d z}+(1-x) A^{\prime} p \frac{d p}{d z}\right] \\
& g=\frac{8 r_{k}}{3 \pi}\left[\frac{\pi}{2 k T m_{2}}\right]^{1 / 2} \\
& A=\frac{3 r_{k}}{16 \eta v_{2}} \\
& f_{0}=\frac{m_{2}^{1 / 2}}{m_{x}^{1 / 2}} \\
& \alpha_{0}=\left(m_{2} / m_{1}\right)^{1 / 2} \\
& B=\frac{8 r_{k}}{3 \pi}\left[\frac{\pi k T}{2 m^{+}}\right]^{1 / 2} \frac{m_{x}^{1 / 2}}{\left(m_{1}+m_{2}\right)^{1 / 2}} \frac{1}{p_{12}} \\
& m_{x}^{1 / 2}=x m_{1}^{1 / 2}+(1-x) m_{2}^{1 / 2}
\end{aligned}
$$




$$
\begin{aligned}
m^{+} & =\frac{m_{1} m_{2}}{m_{1}+m_{2}} \\
v_{2} & =\left[\frac{8 k T}{\pi m_{2}}\right]^{1 / 2} \\
g^{\prime} & =n_{k} \pi \pi k^{2} \beta g \\
A^{\prime} & =\frac{A}{\beta} \\
B^{\prime} & =B \beta
\end{aligned}
$$

The diffusion coefficient, $D_{12}$, can be calculated (Bird et al, 1960) as,

$$
D_{12}=\frac{1}{3} v \lambda
$$

with the mean molecular velocity

$$
v=\left(\frac{4 k T}{\pi m^{+}}\right)^{1 / 2}
$$

and the mean free path of molecule

$$
\lambda=\frac{k T}{\sqrt{2} \pi \sigma^{2} p}
$$

The average collision diameter $\sigma^{*}$ of the different molecules is defined as,

$$
\sigma^{*}=\frac{\sigma_{1}+\sigma_{2}}{2}
$$

The viscosity $(\eta)$ of the gas mixture for a binary system is estimated with the corresponding state method using the Lucas mixing rule (Reid et al, 1987).

The molar fluxes, $n_{1}$ and $n_{2}$, represent the flux of the light and heavy components, respectively. The first two terms in Eqs. 5 \& 6 calculate the flows contributed by Knudsen diffusion and momentum transfer between molecules respectively. The third term calculates the contribution of the viscous flow. The Knudsen term accounts for separation, while the second and third terms dilute the separation 
efficiency achieved by the first term.

Eqs. 5 and 6 were originally derived from the momentum balance in a single capillary (Present and DeBethune, 1949). In order to apply these equations to a membrane, two parameters, $n_{k}$ and $B$, were introduced by Eickmann and Werner. The former accounts for the theoretical number of capillaries per unit membrane area. The latter accounts for the reflection condition of a molecule on the pore wall. These parameters can be determined from single gas permeability via Eq. 22.

$$
C p=\frac{n s}{\Delta p}=\left(\frac{8}{3} n_{k} \beta r_{k}^{3}\left(\frac{\pi}{2 k T m}\right)^{1 / 2}+\frac{n_{k} r_{k}^{4}}{2 \eta v}\left(\frac{\pi}{2 k T m}\right)^{1 / 2} \bar{p}\right]_{L}^{1}
$$

From permeability, $C_{p}$, vs. average pressure, $\bar{p}$, across the membrane, $n_{k}$ and $B$ can be obtained from the slope and intercept, respectively.

Mathematically, $n_{k}$ and $B$ are analogous to porosity $(\varepsilon)$ and tortuosity ( $\tau$ ), adopted in the literature study (Keizer et al., 1988) for gas permeation dominant by the Knudsen diffusion behavior. Similarly, $\varepsilon$ and $\tau$ can be determined from the linear relationship of permeability v8. transmembrane pressure drop. According to the definition and the mathematical derivation, $n_{\mathrm{k}}$ accounts for the morphology of the membrane, including $\varepsilon$ and $\tau$. $B$ is used to correct behaviors that deviate from Knudsen diffusion. $n_{k}$ and $B$ thus defined offer expanded meaning and have been successfully applied to a mixture involving $\mathrm{CO}$ which deviated away from Knudsen diffusion significantly. This system is discussed later in the paper. Once the values of $n_{k}$ and $B$ are known, the molar flures of a binary mixture through a given membrane can be determined. A given membrane separation system can be described completely by feed composition, temperature, stage cut, and feed and permeate pressures. Mole fractions of reject and permeate as well as its separation factor can then be calculated from the above equations. A trial and error approach is required in this calculation. An initial mole fraction of permeate $\left(Y_{0}\right)$ is given to initiate the iteration. The molar fluxes are calculated according to the initial $Y_{0}$ value, then confirmed with the material balance. The trial-and-error is iterated until a correct $Y$ is found to satisfy the material balance. This model is solved by a FORTRAN program. The program list and the method to run this program are in the Appendix. 


\subsection{Results and Discussion}

\subsubsection{Permeation with Single Components}

Figures 3.5 to 3.7 show gas permeability vs. average pressure at $20^{\circ} \mathrm{C}$, $538^{\circ} \mathrm{C}$ and $815^{\circ} \mathrm{C}$, respectively, for $\mathrm{H}_{2}, \mathrm{He}, \mathrm{CO}$ and $\mathrm{N}_{2}$. The permeability is relatively independent of the pressure, indicating Knudsen diffusion dominates under these operating conditions. The slight increase in permeabilities along with the pressure increase is attributed to the viscous flow, which becomes significant at a higher pressure. This observation is consistent with our assumption that defect of the membranes is negligible.

$n_{k}$ and $B$ were obtained according to Eq. 22. Data on permeability vs. average pressure fit well with the curve generated from the linear regression. Since $n_{k}$ is the characteristic of a given membrane reflecting its porous structure (e.g., porosity, tortuosity, etc.), it should be a constant for a given membrane. To determine $n_{k}$ from

the slope of Cp vs. $\tilde{p}$, pore diameter, $2 r_{k}$, is required. The $n_{k}$ was determined from the $\mathrm{N}_{2}$ permeability at $20^{\circ} \mathrm{C}$, where the nominal pore diameter of $40 \AA$ quoted by the manufacturer was used. The average $n_{k}$ thus determined, $3.52 \pm 1.09 \mathrm{E} 16\left(1 / \mathrm{m}^{2}\right)$, was used to estimate the pore size of the membranes exposed at a higher temperature. According to our previous experience, the pore diameter of the membrane grew from 40 to $-80 \AA$ during the thermal treatment at $850^{\circ} \mathrm{C}$ as a result of phase transition of $\gamma$-alumina (Gallaher et al. 1990). The enlargement is highly dependent upon its treatment temperature and is irreversible. A similar result on pore enlargement was reported in the literature (Leenaars et al. 1984). The pore diameter thus derived is listed in Table 3.1, ranging from 44 to $78 \AA$, consistent with the experience reported previously. The pore diameter ranges from 45 to $66 \AA$ at $538^{\circ} \mathrm{C}$ and 61 to $78 \AA$ at $815^{\circ} \mathrm{C}$. This range of pore diameter, instead of a single number, at a given temperature was resulted from the maximum temperature a membrane was exposed to previously. This approach tacitly assumes a constant $\varepsilon / \tau$ throughout the pore enlargement during thermal treatment. A similar assumption on $\varepsilon$ was verified in the literature (Leenaars et al., 1984). The uncertainty of the pore diameter estimation and its impact on separation efficiency prediction is discussed in the next section.

$B$ represents the reflection condition of molecules after colliding with the pore wall. If the collision between the wall and gas molecules is completely elastic, and the tortuosity of the membrane is one (i.e. straight capillary tube in the membrane layer), the theoretical value of $B$ is 1 . $B$, however, is usually less than one because (a) the tortuosity of most membranes is larger than one; (b) possible nonideal reflection of some gases from the pore wall due to the 


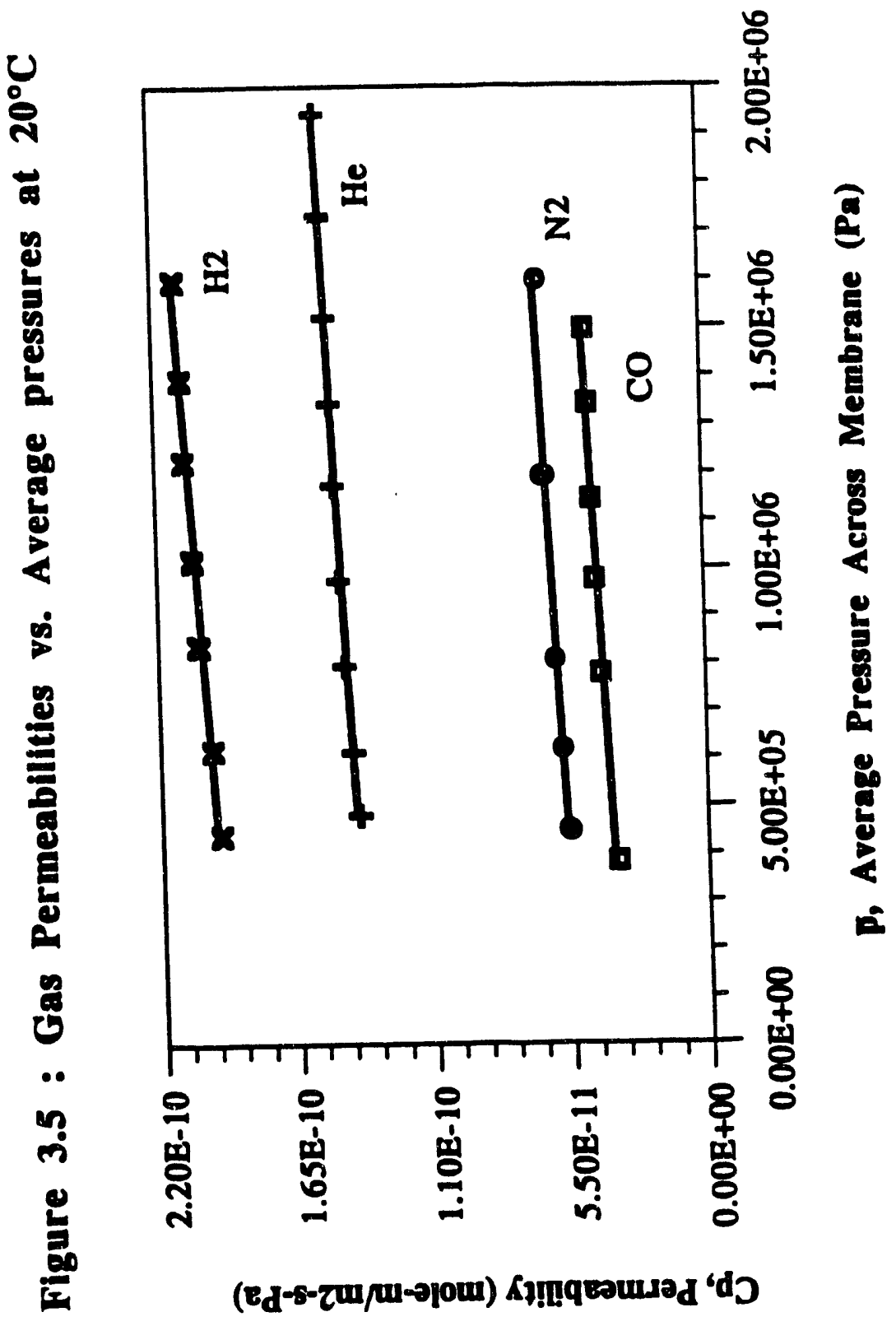




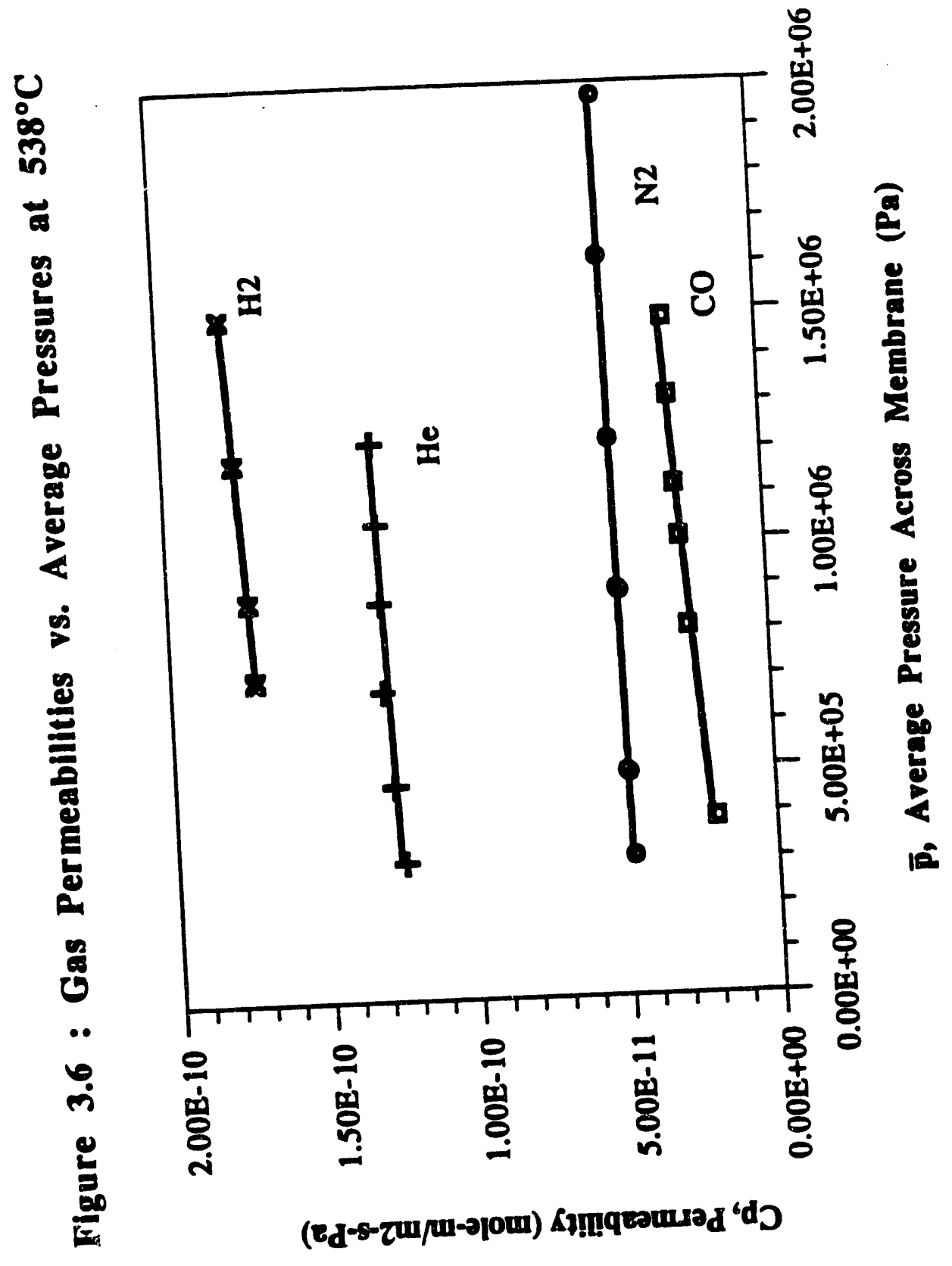




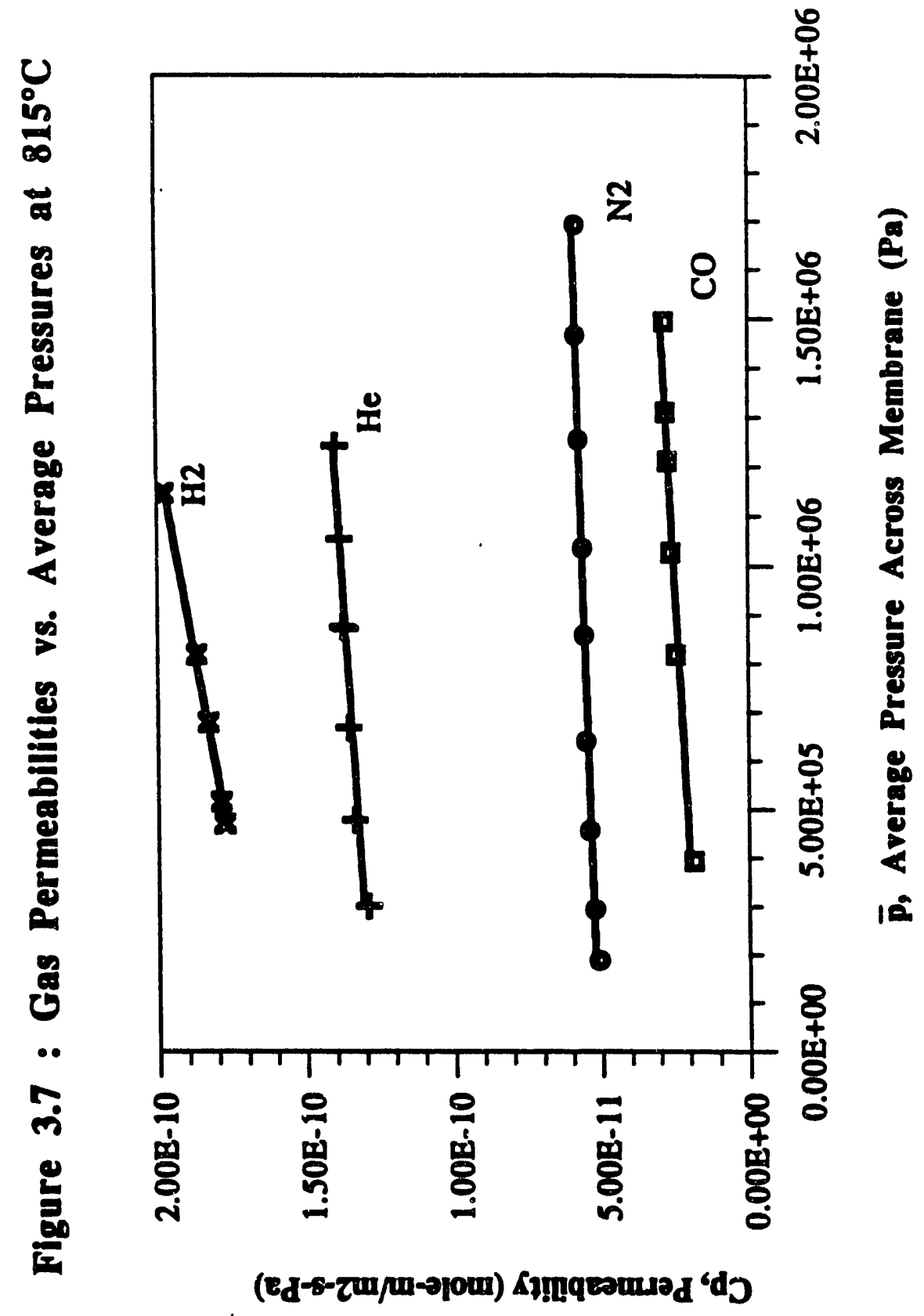


Table 3.1 : Experimental Values of $\mathrm{N}_{k}$ and $\beta$

\begin{tabular}{lccll} 
& $\begin{array}{c}\text { Temp } \\
\left({ }^{\circ} \mathrm{C}\right)\end{array}$ & $\begin{array}{c}\text { Nominal Pore Diameter* } \\
(\AA)\end{array}$ & $\begin{array}{c}\mathrm{N}_{\mathbf{k}} \\
\left(1 / \mathrm{m}^{2}\right)\end{array}$ & $\beta$ \\
\hline $\mathrm{He}$ & 25 & 40 & $3.36 \mathrm{E} 16$ & 0.48 \\
& 538 & 53 & & 0.29 \\
& 815 & 70 & & 0.15 \\
$\mathrm{~N} 2$ & 25 & 40 & $4.30 \mathrm{E} 16$ & 0.40 \\
& 538 & 45 & & 0.50 \\
& 815 & 61 & & 0.24 \\
$\mathrm{H} 2$ & & 40 & & 0.66 \\
& 25 & 51 & & 0.32 \\
& 538 & 78 & & 0.10 \\
$\mathrm{CO}$ & 815 & & & 0.27 \\
& 25 & 40 & & 0.06 \\
& 538 & 66 & & 0.05 \\
& 650 & 68 & & \\
& 815 & & & \\
\end{tabular}

* Pore diameters at higher temperatures estimated from the average $\mathrm{N}_{k}$ at $20^{\circ} \mathrm{C}$ 
interaction between molecules and membrane material, and (c) other factors. The factor (b) implies that $B$ could be a function of temperature and gas components. B listed in Table 3.1 varies from 0.05 to 0.66 . Due to the limited data available here, no correlation was attempted for each gas. B was treated as a constant in Eickmann and Werner's study in contrary to the observation here.

Compared with the permeability of $\mathrm{H}_{2}, \mathrm{He}$, and $\mathrm{N}_{2}$, the permeability of $\mathrm{CO}$ is much lower than the theoretical value based upon Knudsen diffusion. It should locate in the neighborhood of $\mathrm{N}_{2}$ 's according to the molecular weight. A similar observation was reported in the literature (Haraya et al. 1986a). The unexpected behavior of $\mathrm{CO}$ may be attributed to the interaction of $\mathrm{CO}$ with aluminum oxide surface. This effect is described adequately by Eq. 22 via the correction of $B$. Another factor, surface diffusion, is possible but negligible because the permeability in this case was reduced not enhanced by this effect.

\subsubsection{Separations of Binary Mixtures}

Tables 3.2 to 3.4 list the separation results of binary mixtures involving $\mathrm{H}_{2} / \mathrm{CO}, \mathrm{H}_{2} / \mathrm{N}_{2}$, and $\mathrm{O}_{2} / \mathrm{He}$ systems. Pressure ratio $(\mathrm{Pr})$ and selectivity $(\alpha)$ are defined in Eqs. 23 and 24, respectively.

$$
\begin{aligned}
& P_{Y}=\frac{P_{1}}{P_{h}} \\
& \alpha=\left(\frac{Y}{1-Y}\right)\left(\frac{X}{1-X}\right)
\end{aligned}
$$

The experiments were carried out at a wide range of feed composition, stage cut, temperature, feed pressure and pressure ratio. Experimental results are presented in terms of the mole fraction of the permeate which is compared with the predicted values from the model. The simulation is generally in good agreement with the experimental results generated from a wide range of operating conditions: $20^{\circ} \mathrm{C}$ to $815^{\circ} \mathrm{C}, 1$ to $34 \mathrm{~atm}, .01$ to .36 for stage cut, and .1 to .8 for pressure ratio. Most of the deviations between the predicted and experimental mole fraction are within 10\%. The model, however, consistently overestimates the mole fraction of the light component in the permeate for the $\mathrm{H}_{2} / \mathrm{CO}$ and $\mathrm{H}_{2} / \mathrm{N}_{2}$.

B for oxygen was not available experimentally. It was assumed similar to nitrogen for predicting the mixture of $\mathrm{O}_{2} / \mathrm{He}$. The deviation, $\triangle Y \%$, for $\mathrm{He}$ in $\mathrm{O}_{2}$ is much less than those for $\mathrm{H}_{2} / \mathrm{CO}$ and $\mathrm{H}_{2} / \mathrm{N}_{2}$. This may be misleading because only one molar fraction was tested here, i.e., 0.89 for He. Deviation in terms of oxygen is also listed in Table 3.4 for comparison. Deviations for the $\mathrm{O}_{2} / \mathrm{He}$ mixtures at high temperatures (i.e., observations 2 and 5 in Table 3.4) are 


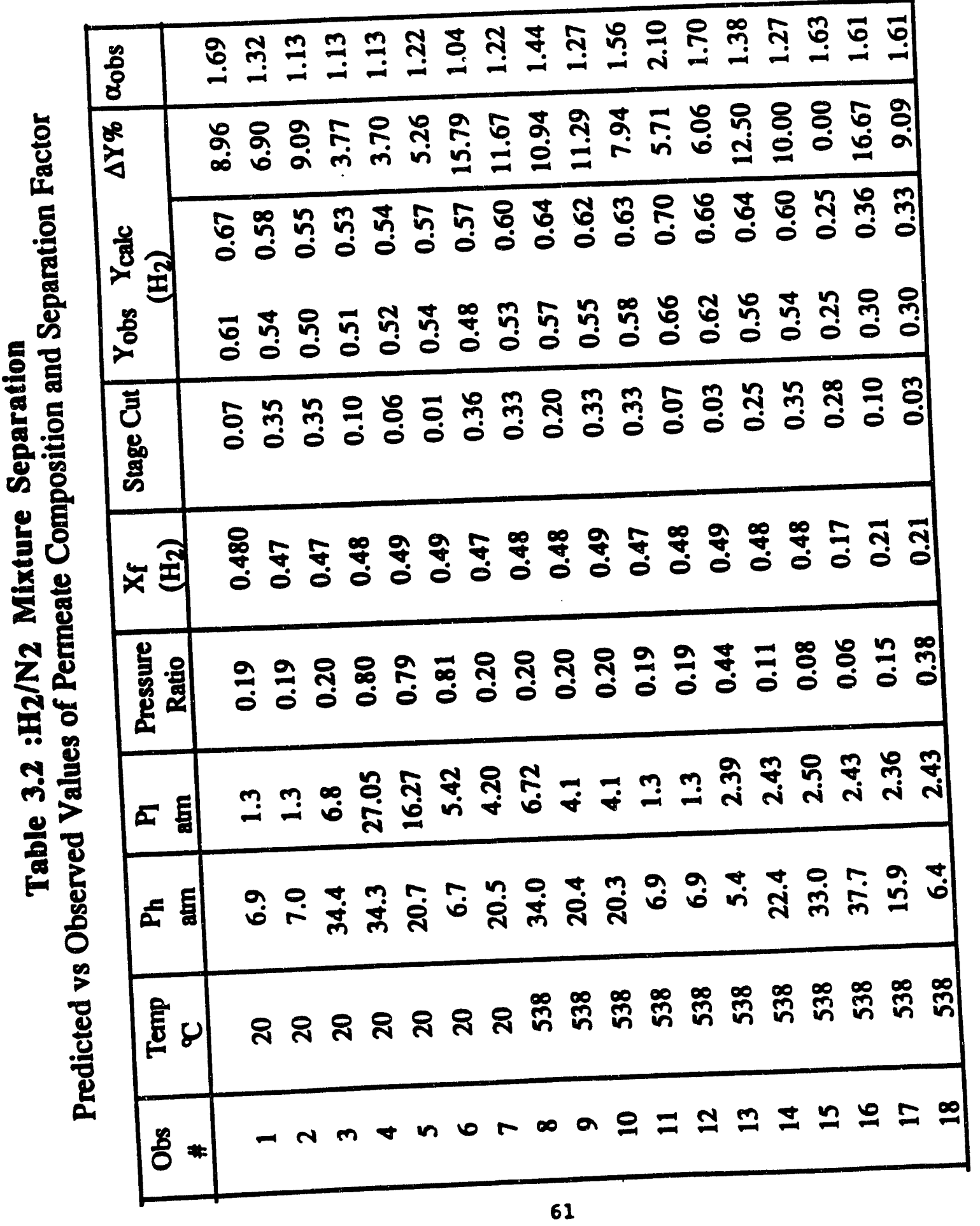




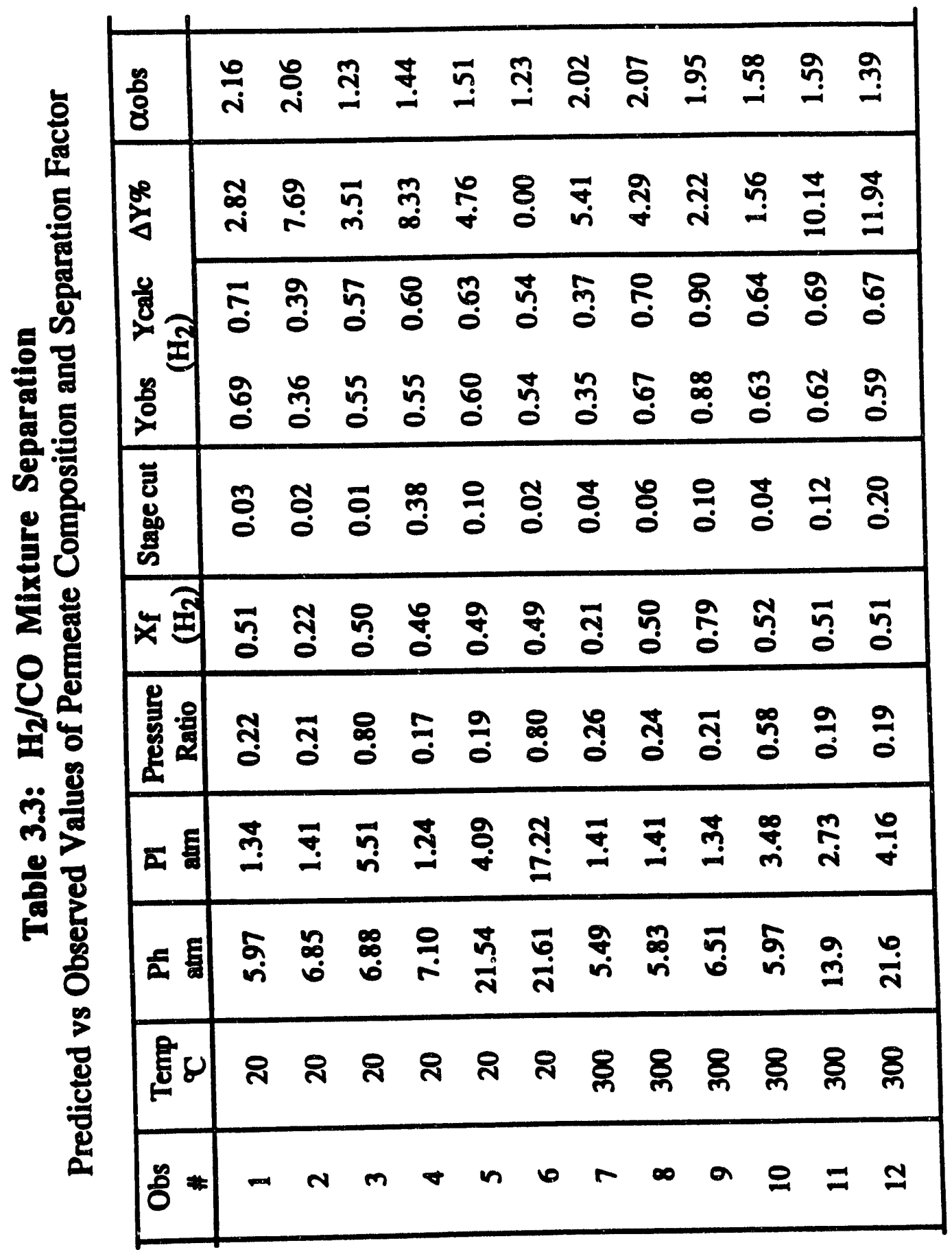




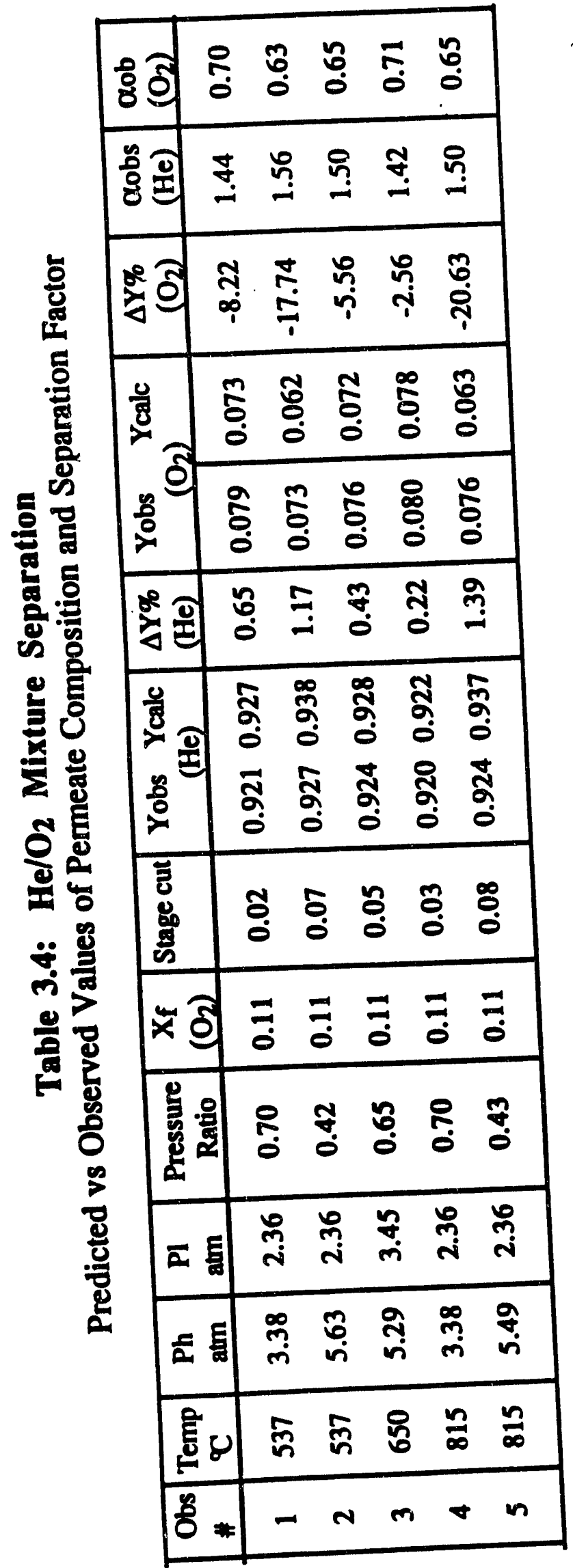


much higher than the rest. The graphite-based end seals could be oxidized under these conditions, causing bypass of the retentate to the permeate through the damaged seal. Experimental values of $B$ for $\mathrm{H}_{2}$ and $\mathrm{CO}$ at $300^{\circ} \mathrm{C}$ were not available. They were estimated by linear interpolation with $\beta$ at 20 and $538^{\circ} \mathrm{C}$.

\subsubsection{Error Analysis}

Determination of $n_{k}$ from the slope of the single component permeation data inevitably involves some uncertainty. The slope should be very gradual intrinsically for the microporous membrane unless the contribution of the viscous flow becomes significant. Sensitivity analysis of $\mathrm{n}_{\mathrm{k}}$ was performed for $\mathrm{H}_{2} / \mathrm{N}_{2}$ mixtures at $538^{\circ} \mathrm{C}$ (obs \# 8.18 listed in Table 3.1). If $n_{k}$ varies $\pm 30 \%$ of the average value used in this study, i.e., 3.52E16, the associated pore diameter change is $45 \pm 4 \AA$. This degree of variation in $n_{k}$ and pore diameter resulted in a maximum change of $0.88 \%$ of the permeate composition. This range of uncertainty is acceptable, and is much less than the deviation between observed and predicted values.

Based upon the experimental and simulation study, the parameters involved in separation were identified as feed pressure, temperature, stage cut, pressure ratio, pore size and concentration. Effects of these parameters on selectivity are discussed in the following with the model developed.

\subsubsection{Effect of Pressure Ratio and Feed Pressure}

A binary mixture, $\mathrm{H}_{2} / \mathrm{N}_{2}$, was used as a case studying the effect of pressure ratio and feed pressure. Figure 3.8 presents the simulation results in terms of separation factor $(\alpha)$ vs. pressure ratio $(\mathrm{Pr})$ with feed pressure as a parameter. The operating condition is detailed in the figure. Under the selected condition, the lower the pressure ratio, the higher the separation factor is. This is attributed to higher separative driving force at a lower $\operatorname{Pr}$. When the feed pressure is low and $\operatorname{Pr}$ approaches zero, the separation approaches the prediction by the ideal Knudsen separation. When the pressure ratio approaches one, no separation is expected.

For a given pressure ratio, the higher the feed pressure, the lower the separation efficiency is as shown in Figure 3.8. The mean free path of a molecule is shorter at a higher pressure (Eq. 20). The frequency of molecular collision thus increases and the intermolecular momentum transfer becomes more significant. The light component (i.e. $\mathrm{H}_{2}$ ) loses its momentum during diffusing through the membrane; meanwhile, the heavy component (e.g. $\mathrm{N}_{2}$ ) gains the momentum. The average velocity of the light component thus decreases and that of heavy component increases. The enrichment of 


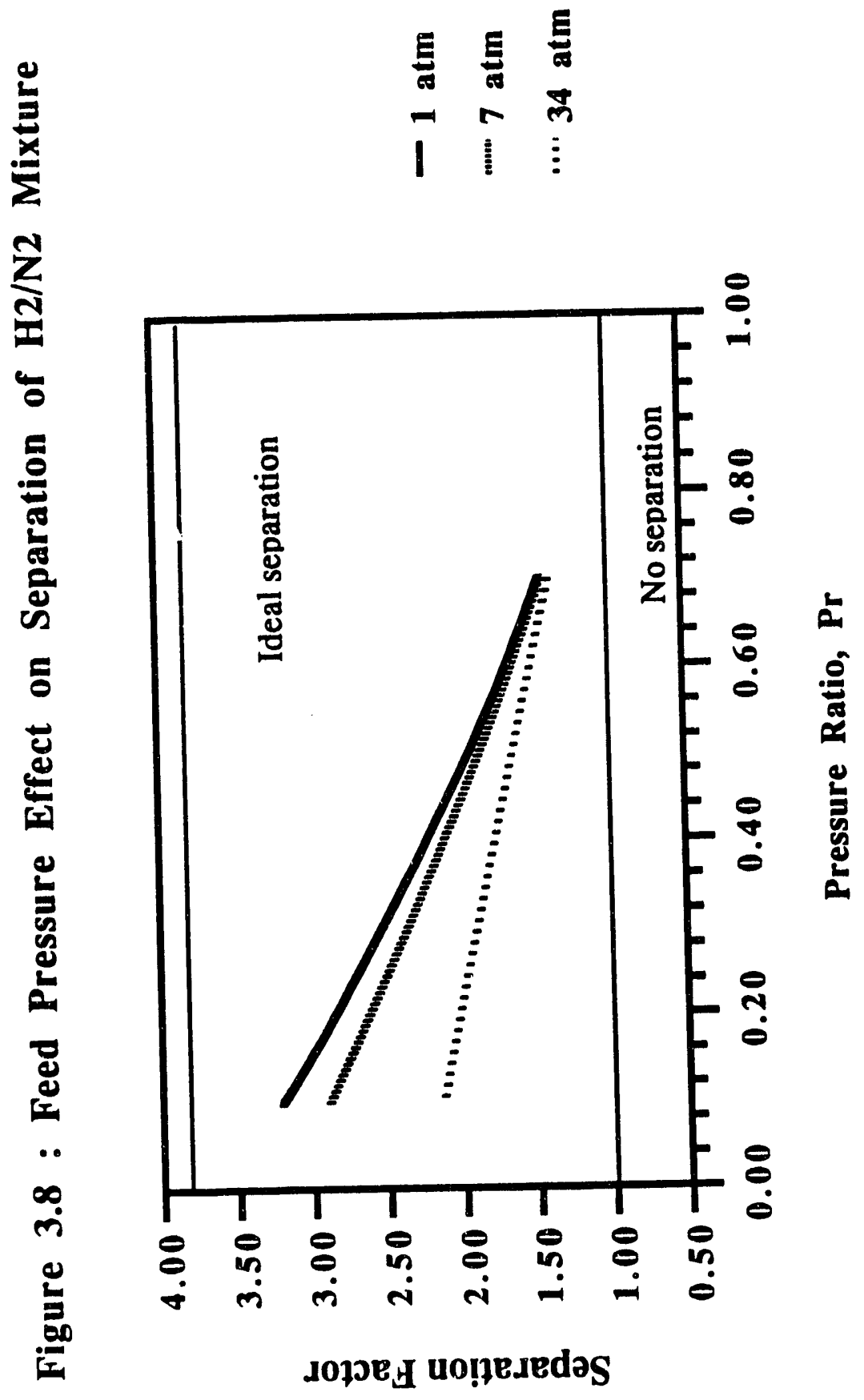


the light component is discounted away from the ideal Knudsen diffusion, so does the separation factor.

The pressure effect is illustrated in Figure 3.9. It displays the distribution of the individual $\mathrm{H}_{2}$ molar flux through the membrane for the $\mathrm{H}_{2} / \mathrm{N}_{2}$ separation. Again, Knudsen represents the separative part of the flow; momentum and viscous represent the nonseparative part. The inter-molecular momentum transfer has a significant impact on separation when the feed pressure increases. Furthermore, it shows that the viscous flow is not a major dilution factor even at a very high feed pressure because the pore size is small $(56 \AA)$ and still within the Knudsen regime. The analysis clearly indicates the importance of intermolecular momentum transfer for gas separations within the Knudsen regime.

\subsubsection{Effect of Temperature}

It has been commonly accepted that temperature does not affect gas separations based upon Knudsen diffusion because the ideal separation factor is independent of temperature as shown in Eq. 10. The intermolecular momentum transfer, however, is partially dependent upon the mean free path, which is a function of temperature. Figure 3.10 shows the temperature effect on separation factor from room temperature to $815^{\circ} \mathrm{C}$. The higher the temperature, the better the separation is. The mean free path is longer at a higher temperature for a given pressure ratio. Thus, less momentum loss is expected for $\mathrm{H}_{2}$, which enhances the separation factor. The degree of improvement, nevertheless, is less than the effect of pressure.

\subsubsection{Effect of Concentration}

Effect of feed concentration on the separation factor is illustrated in Figure 3.11. As the $\mathrm{H}_{2}$ concentration decreases, the separation factor also decreases under the selected operating condition. When the feed contains less $\mathrm{H}_{2}$ and more $\mathrm{N}_{2}$, the collision frequency of $\mathrm{H}_{2}$ to $\mathrm{N}_{2}$ is greater than that of $\mathrm{H}_{2}$ to $\mathrm{H}_{2}$. Therefore, more $\mathrm{H}_{2}$ momentum is lost at a low $\mathrm{H}_{2}$ concentration. The separation efficiency of $\mathrm{H}_{2}$ decreases through this effect. However, the concentration effect is weak compared with those of feed pressure and temperature because the molecule collision on pore wall is much more frequent than collision between molecules.

\subsubsection{Effect of Pore Sive}

Effect of pore size can be described with the intermolecular momentum transfer. As a rule of thumb, Knudsen diffusion would dominate if the mean free path is at least 10 times larger than the pore diameter. It has widely prevailed that the separation factor is 


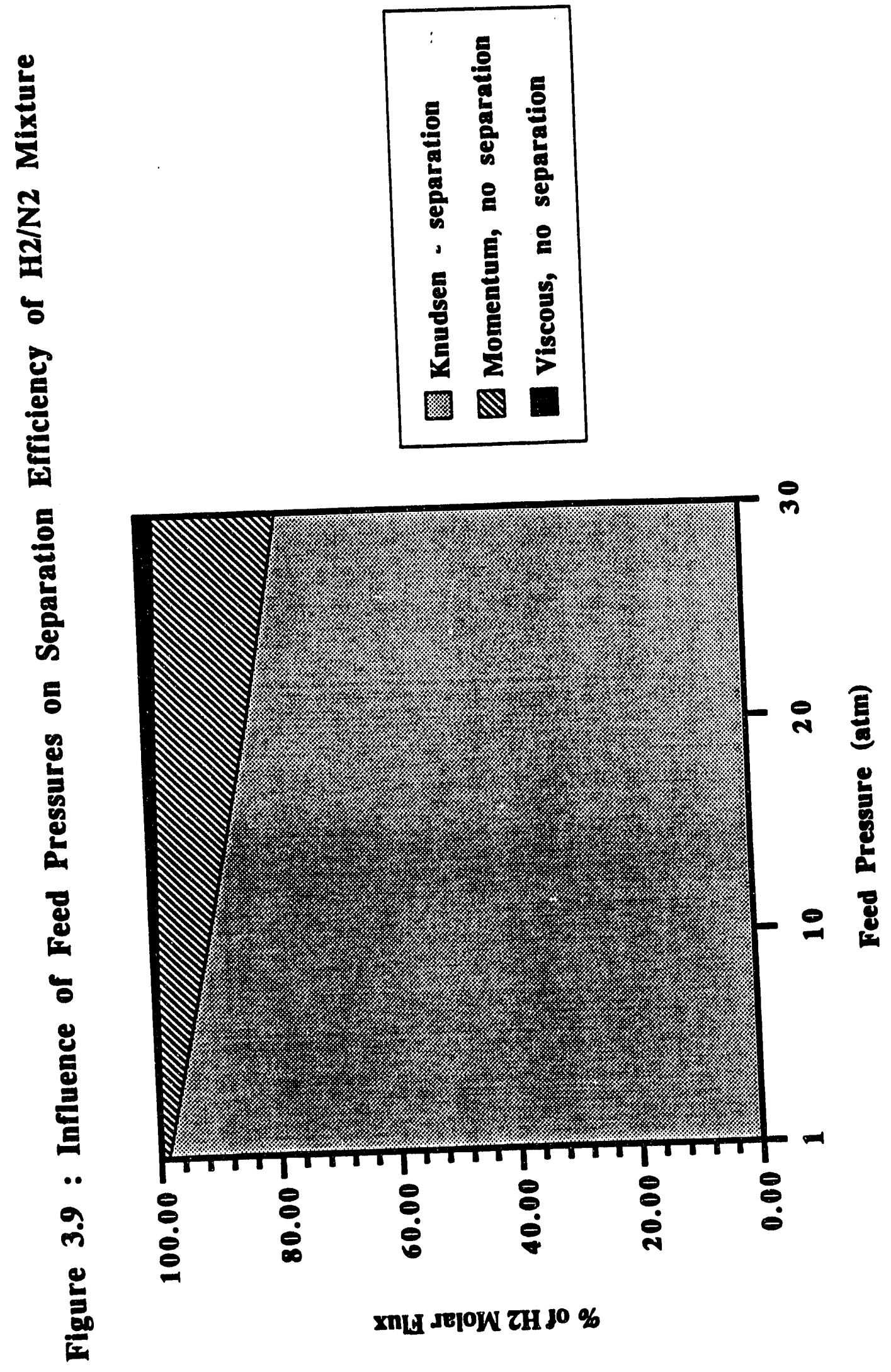




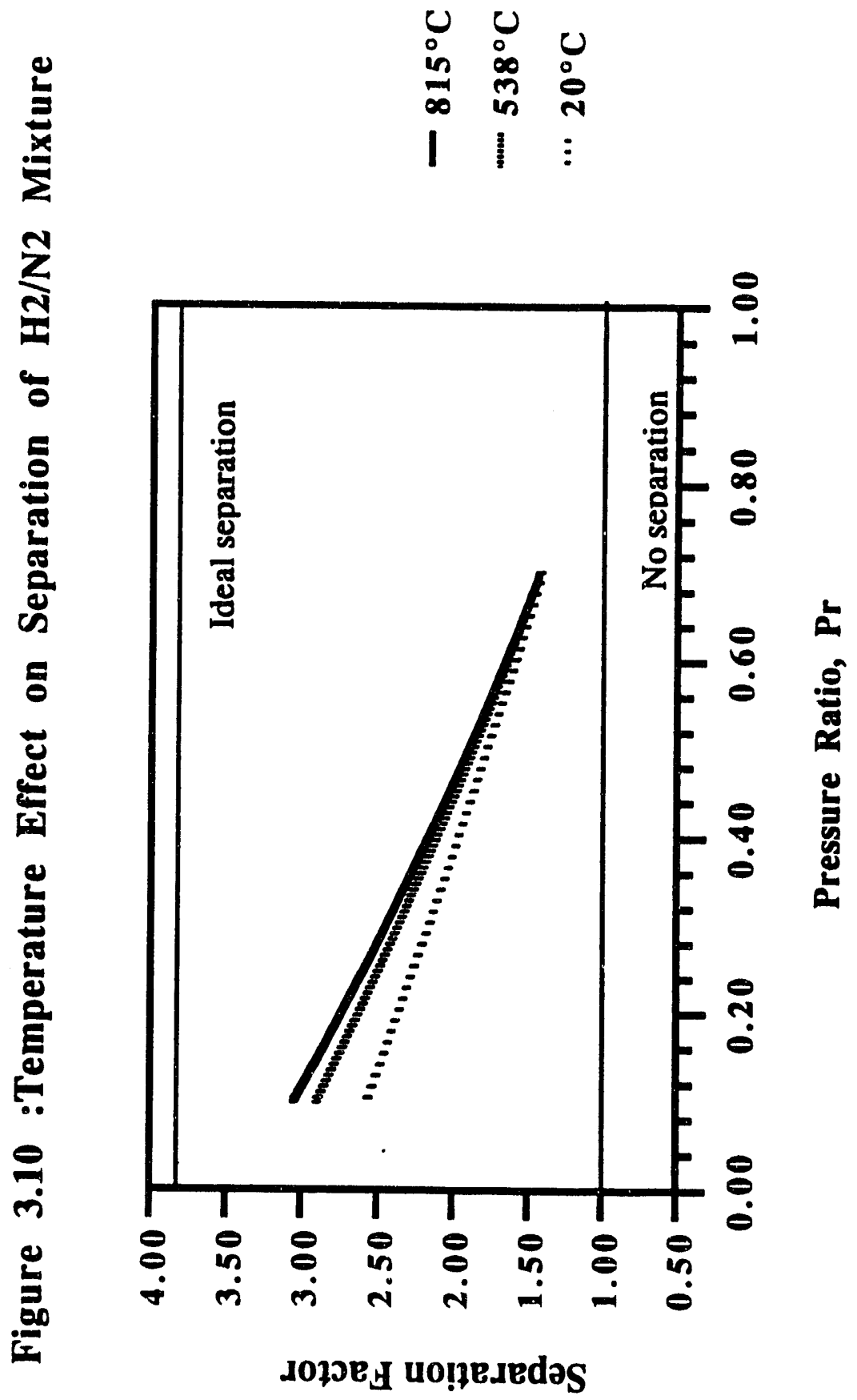




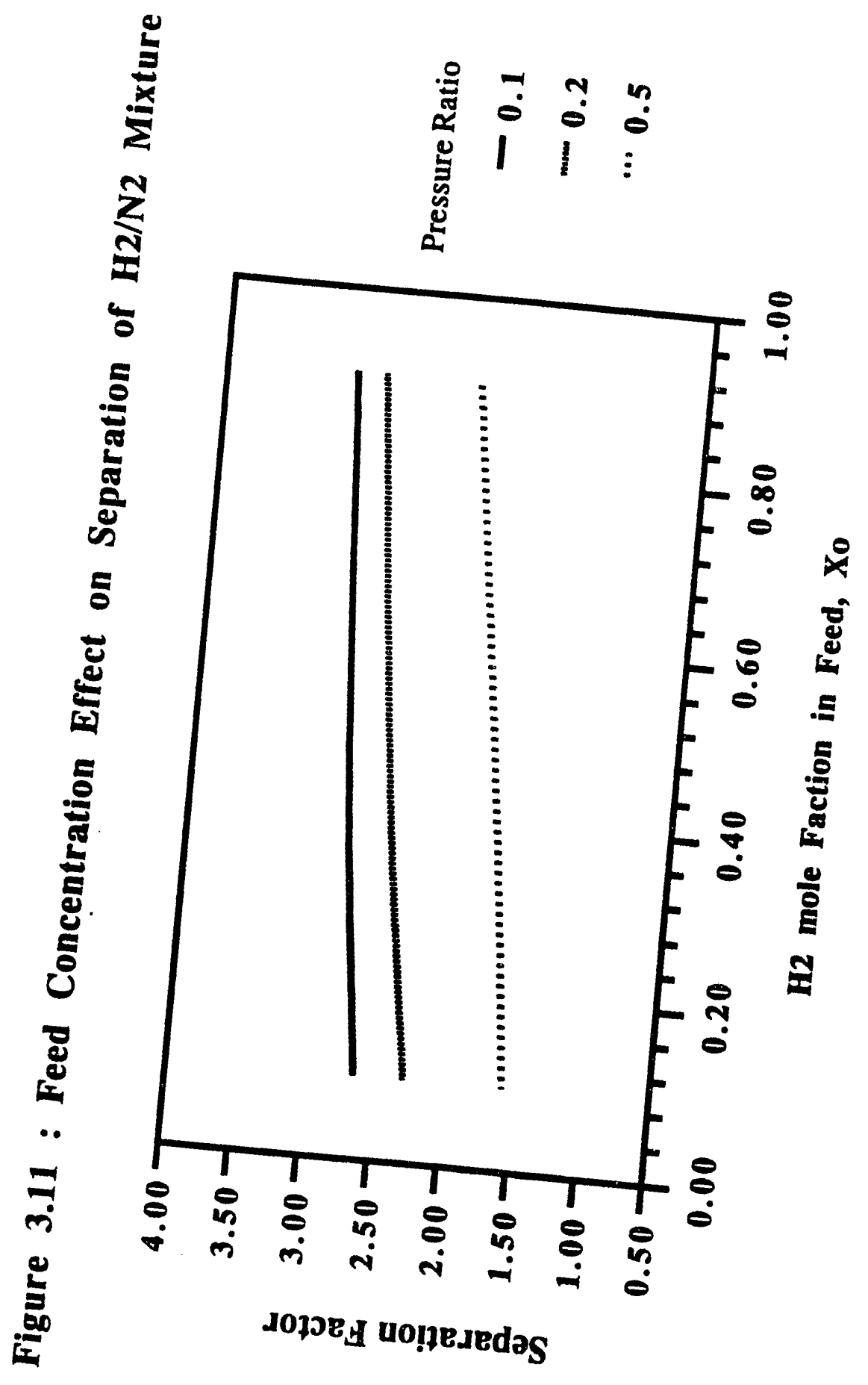


constant once the diffusion through a pore diameter is within the Knudsen regime. A pore diameter $<100 \AA$ would comfortably provide gas separations according to Knudsen diffusion. A smaller pore diameter, however, means more collision to wall than to another molecule. As a result, the contribution of the inter-molecular momentum transfer is reduced. Figure 3.12 shows the separation factor slightly increases with the pore size decrease from 100 to $20 \AA$. The effect of pore size is less than that of pressure, temperature and concentration and becomes negligible at a high pressure ratio. The effect of pore size discussed here should be treated as theoretical prediction because the experimental study covered in this paper was generated from the membranes with pore size $\geq 40 \AA$.

\subsubsection{Effect of Stage Cut}

The influence of stage cut on separation factor is simply governed by the material balance. As shown in Figure 3.13, the higher the stage cut, the worse the separation. At a high stage cut, the driving force for gas separation in terms of partial pressure difference is reduced to maintain the material balance. Evidently, a small stage cut is required in order to achieve the enrichment of the light component in the permeate side to the level determined by the ideal Knudsen separation.

\subsection{Conclusions}

A mathematical model was established for gas separations in a microporous membrane at high temperature, and was verified by experimental data. This model requires the permeability of the single component to determine two parameters, $n_{k}$ and $B$, which relate to the morphology of microporous membranes and the reflection behavior of gas molecules, respectively. Gas separations for a binary mixture can then be predicted with the model developed. Gas permeation of $\mathrm{CO}$ deviated substantially from the values expected from Knudsen diffusion. This behavior was corrected with the model, which then predicted the gas separation involving $\mathrm{CO}$ adequately.

The effect of the key operating parameters is described through the simulation study. Feed side pressure and pressure ratio have much more significant effect on the separation factor than others under the condition studied. A lower feed-side pressure and pressure ratio is required to achieve maximum separation efficiency. 


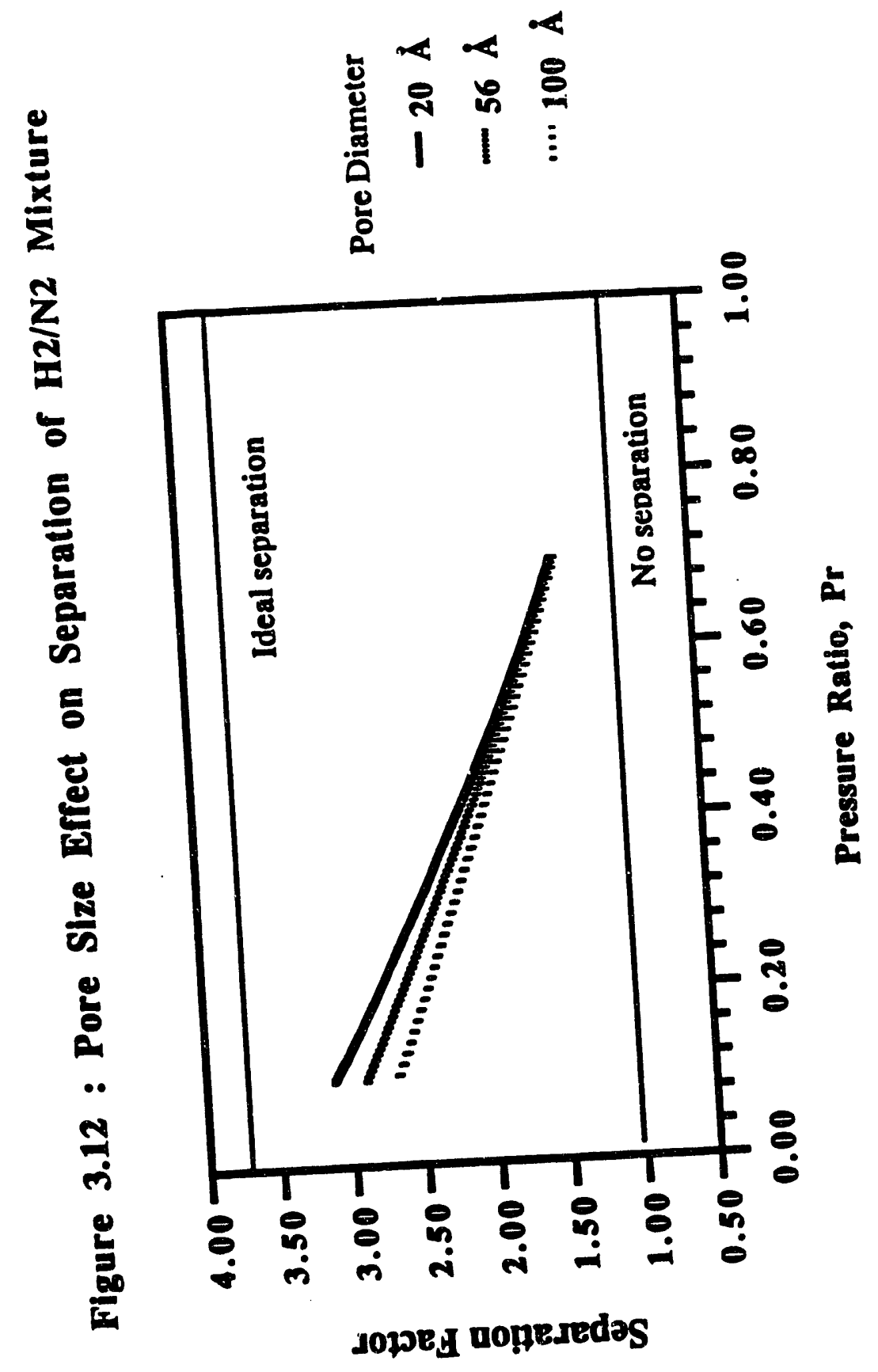




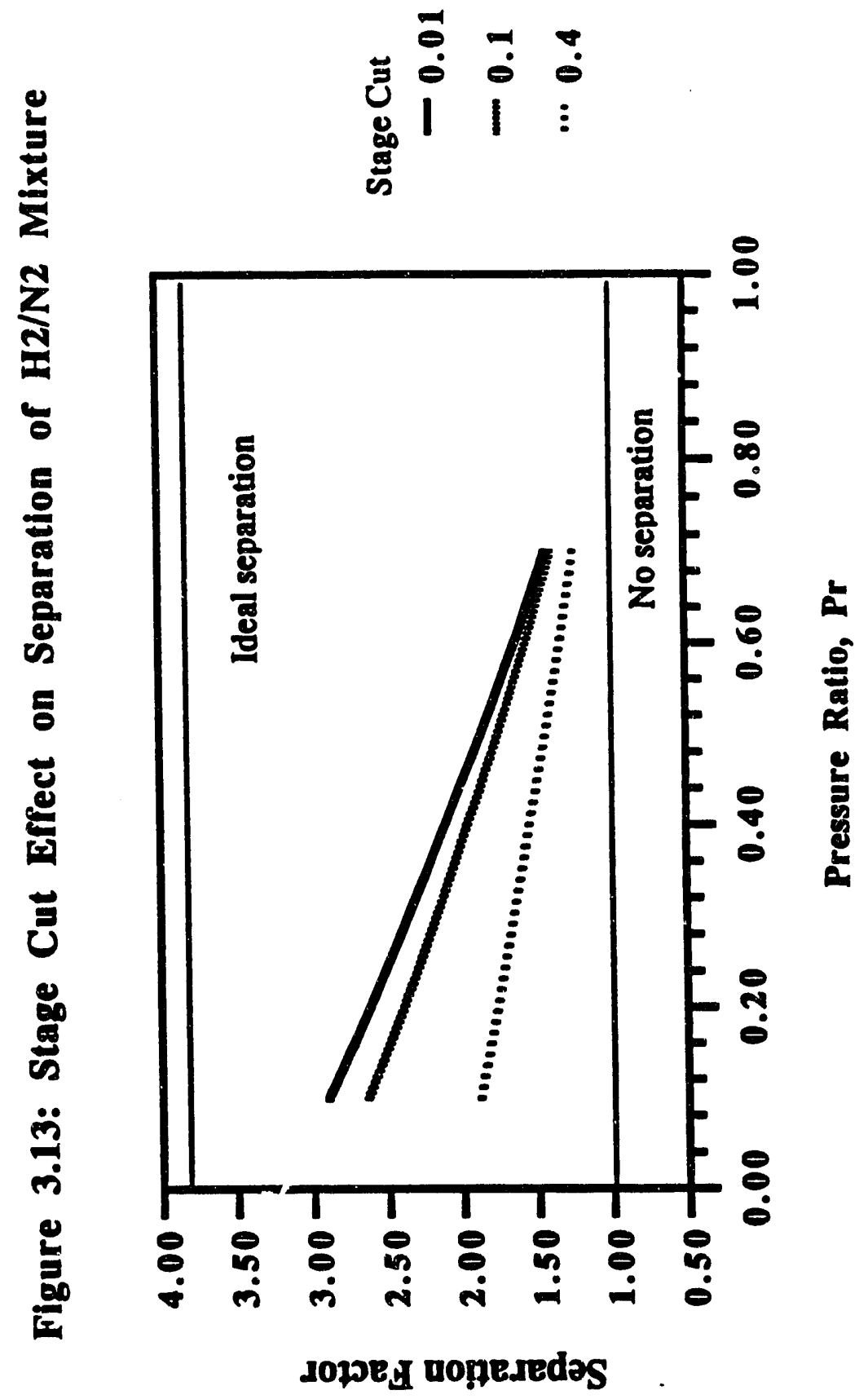




\section{Modifications of Commercial Ceramic Membranes}

\subsection{Introduction}

Currently, the applications of inorganic membranes are limited to UF and MF, because the minimum pore diameter of inorganic membranes available is in the range of $30-40 \AA$. These membranes can separate gas mixtures based on Knudsen diffusion, which is inversely proportional to the square root of molecular mass (Present, 1949). Membranes with a smaller pore size or with a specific surface property can achieve a higher separation selectivity via other separation mechanisms (e.g. surface diffusion, molecular sieving, etc.). The modification selected in this study is to deposit thin films of metal oxides within the wall of porous supports. Deposition of silica oxide via chemical vapor deposition (CVD) has been studied extensively in this project. Deposition of zirconium oxide via CVD and lanthanium oxide via impregnation was also explored to some extent. The deposition methodology, characterization results, gas separation performance and thermal/hydrothermal stabilities of the modified membranes are discussed in detail in this section.

\subsection{Literature Review}

Modifications of inorganic membranes by chemical vapor deposition have been documented in the literature, specifically on the use of silica and zirconia. Silica modification has several advantages. Niwa et. al. reported that the silica modification of zeolite did reduce the size of the pore opening (Niewa, 1984, 1987, 1989). Silica modification of porous Vycor glass tubes was performed to improve the selectivity for gas separation (Gavalas, 1989; Nam, 1989; Gavalas, 1990; Okubo, 1989). Murrel and Dispenziere (Murrel, 1988) reported that the addition of $5 \%$ silica to alumina led to distinct stabilization of alumina under the calcination at $950^{\circ} \mathrm{C}$ and steam at $870^{\circ} \mathrm{C}$.

Zirconia is another candidate as a modifier. Somiya and Yoshimura reported that the addition of $\mathrm{ZrO}_{2}$ to $\gamma$-alumina retarded the phase change of alumina under thermal and hydrothermal treatments and improved its stability (Somiya, 1985). Krishnamoorthy reported that Mg partially stabilized $\mathrm{ZrO}_{2}$ (PSZ) and $\mathrm{Mg}$-Ti-PSZ showed better corrosion resistance toward coal ash attack than existing $\gamma$-alumina (Kirshnamorthy, 1990). Deposition of $\mathrm{ZrO}_{2}$ on existing alumina membranes evidently is another promising step in improving the thermal/hydrothermal stabilities and chemical resistance of existing alumina membranes.

\subsection{Deposition Chemistry and Methodology}

Two types of silica modified membranes were obtained by chemical vapor deposition: porous and dense membranes. The resultant porous silica membrane demonstrates a pore size ranging from $65 \AA$ to $-4 \AA$. The dense silica modified membrane exhibited an exceptional hydrogen separation 
selectivity at an elevated temperature. Typically, membranes were modified with silica by introducing tetraethyl orthosilicate (TEOS) into the pores of porous alumina membranes and decomposing on the wall of the pores (CVD). The experimental apparatus for the CVD process is shown in Figure 4.1. Existing tubular membranes with " $40 \AA$ pore diameter and 1" and $10^{\prime \prime}$ lengths (US Filter) were used as precursors in these experiments. TEOS was introduced on the inner surface of the membrane. Helium containing 10 to $20 \%$ of oxygen was chosen as a carrier gas. The temperature of the furnace varied from 200 to $600^{\circ} \mathrm{C}$ and the vaporizer was set at $21-150^{\circ} \mathrm{C}$. The feed and reject rates were controlled by mass flow meters. The permeate rate was monitored and determined with a soap-film meter. The feed pressure varied from 0 to $60 \mathrm{psi}$. The deposition process lasted for 15 to 300 minutes.

Thickness and pore size of the modified membrane was controlled through the following parameters: vaporizer temperature, feed, reject and permeate flow rates and deposition temperature, time and pressure. Deposition mechanism of silica on alumina membranes is complex and has not been well understood. The reaction involving TEOS as the source for the deposition of $\mathrm{SiO}_{2}$ on the membranes is suggested as follows:

$$
\mathrm{Si}\left(\mathrm{OC}_{2} \mathrm{H}_{5}\right)_{4}+\mathrm{O}_{2} \rightarrow \mathrm{SiO}_{2}+\mathrm{C}_{2} \mathrm{H}_{5} \mathrm{OH}+\mathrm{C}_{2} \mathrm{H}_{4}+\mathrm{CO}_{2}+\mathrm{H}_{2} \mathrm{O}
$$

$\mathrm{C}_{2} \mathrm{H}_{5} \mathrm{OH}$ could further react with $\mathrm{O}_{2}$ to form $\mathrm{CO}_{2}$ and $\mathrm{H}_{2} \mathrm{O}$. The final gaseous products depend on the ratio of oxygen to other components and the decomposition temperature.

\subsection{Morphological Characterization with SEM/EDAX}

Scanning electron microscope (SEM) (WB-6, International Scientific Instruments, Inc.) with energy dispersive spectroscopy (EDAX) (PV9900, EDAX International, Inc.) was used to examine the location and morphology of the modified layer. However, the resolution of the SEM (25 $\mathrm{KX}$ ) was not sufficient to identify the pore size of the modified layer. If the material of the modifier is different from the support's, the combination of SEM and EDAX can provide the information on the thickness and the location of the modified layer. Typically, the modification of the existing membranes may take place within and/or on the top of the membranes. The former generates ass mechanical stress than the latter and is desirable from the material stability standpoint. However, its porosity is further reduced from the precursor's, resulting in the reduction of the permeate.

The SEM image of the inner surface of the modified membrane demonstrates a uniform layer with no pinholes or cracks as shown in Figure 4.2. Figures 2.1, and 4.3-4.6 present the SEM image of the cross-section of the existing and modified membranes, Si001, Si004, Si005 and Si009, respectively. No visible difference was observed between the existing and the modified membrane in each layer along the cross section, 


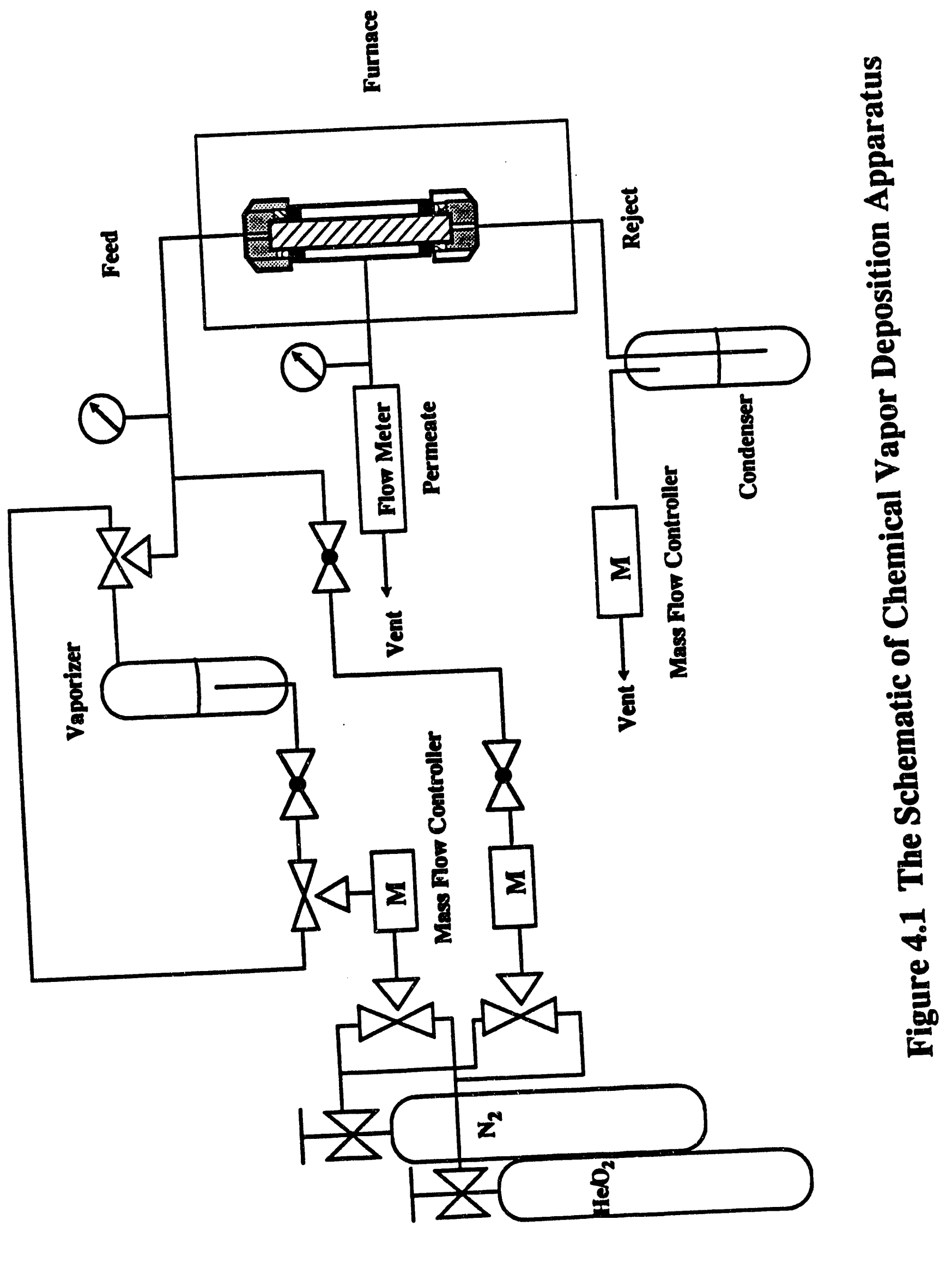




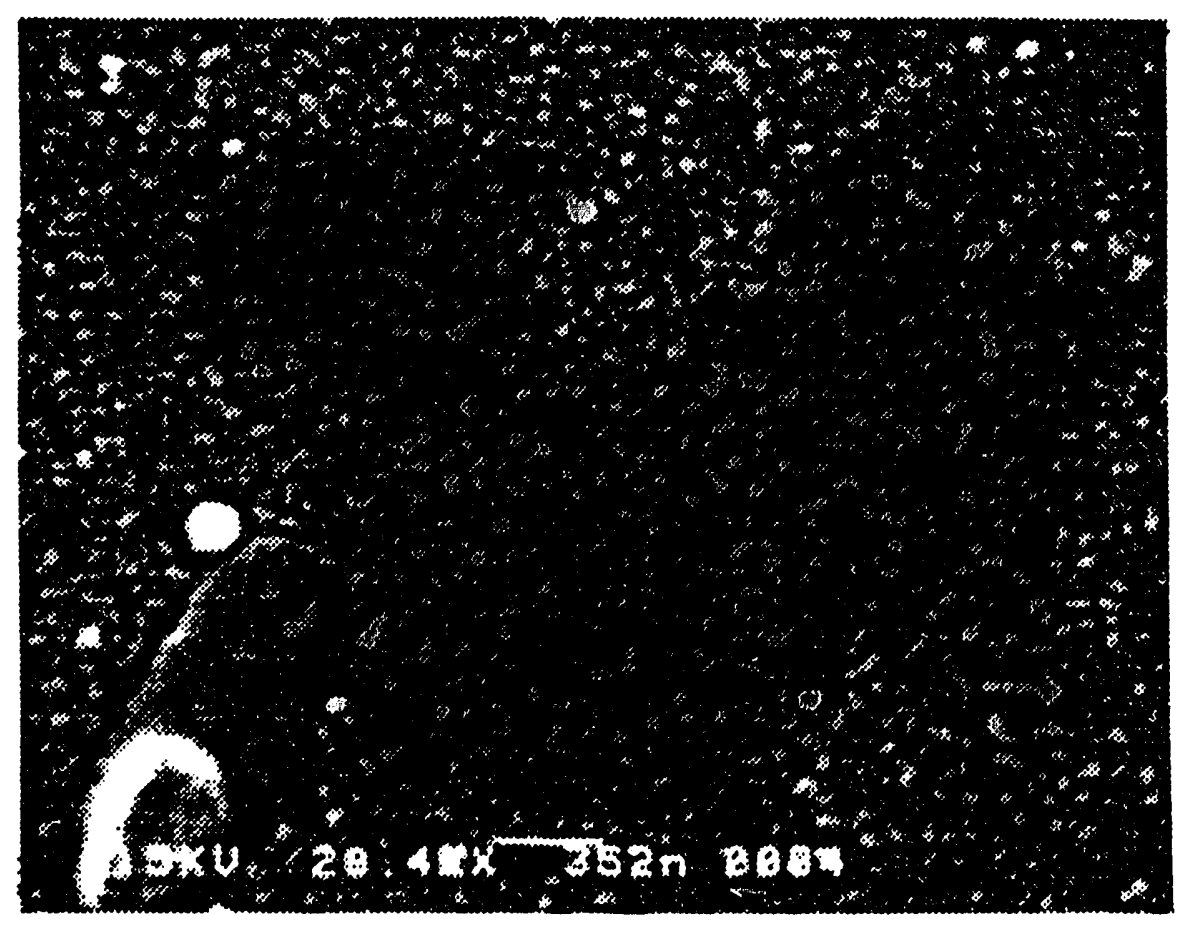

Figare 42

SEM of Inner Surface of Silica Modified Membrane Si005 


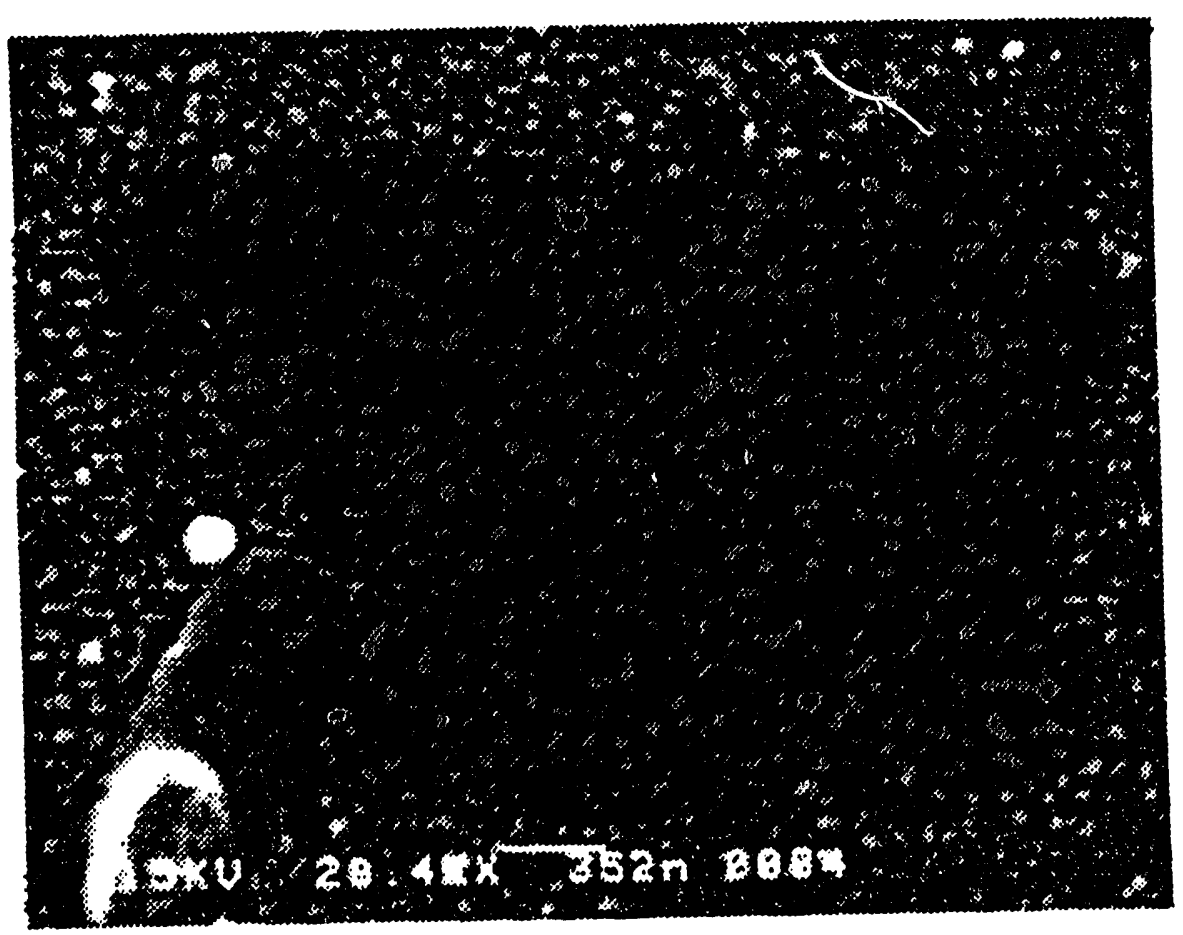

Figure 4.3

SEM of Crosesection of Silica Modified Membrane Si001 


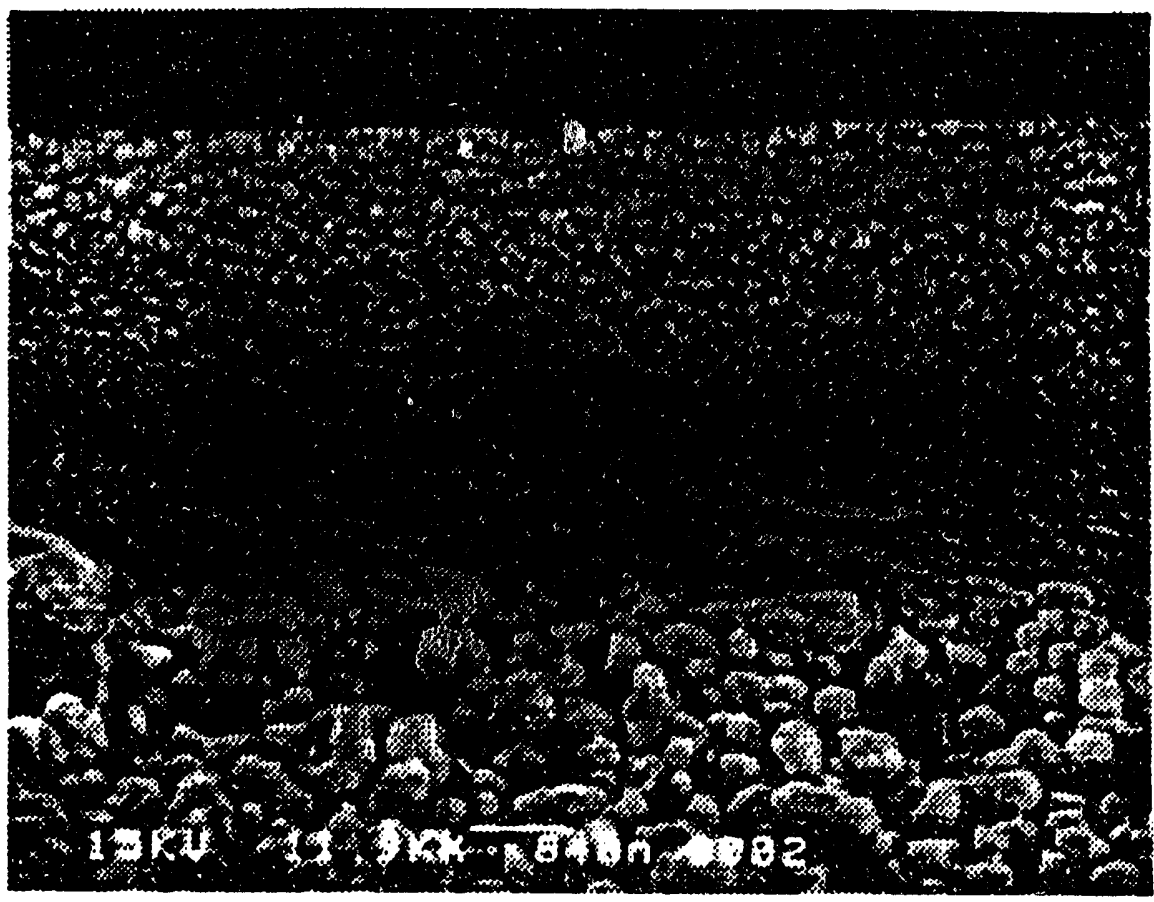

Figure 4.4

SDM of Crow-Section of Silica Modified Membrane SiOO4 


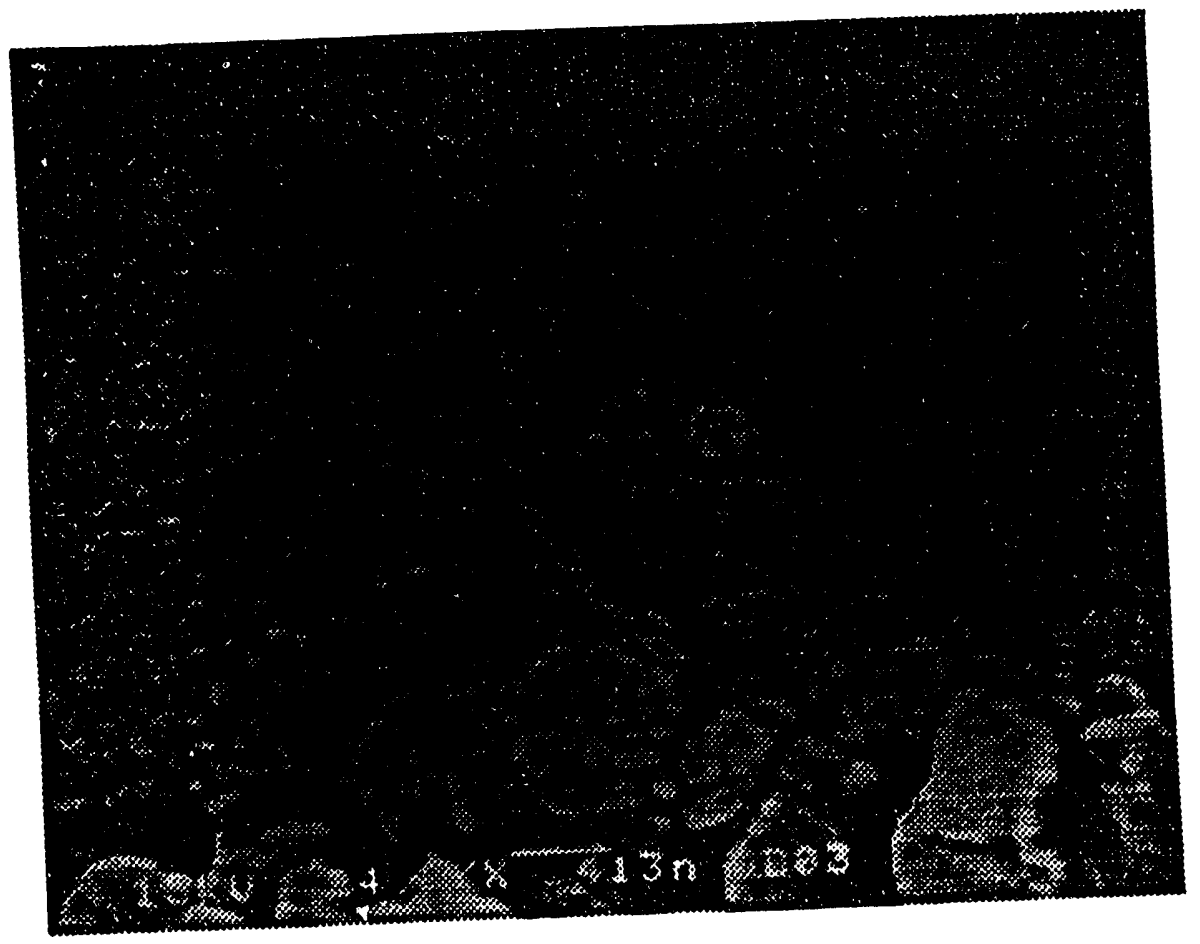

Figure 4.5

SEM of Crosof ection of Silica. Modified Membrane Si005 


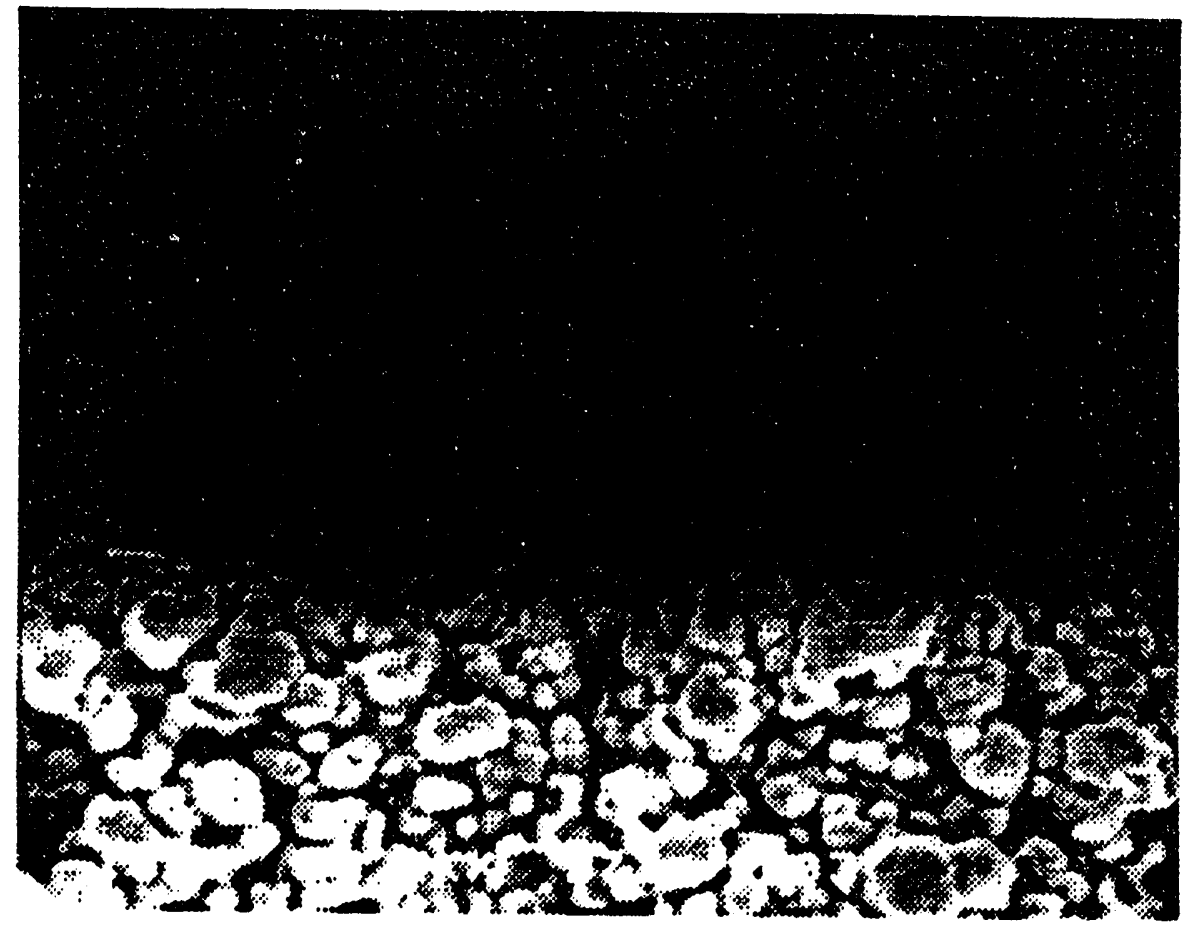

Figure 46

SEM of Crow-Section of Siliea Modified Membrane Si009 
nor any significant increase in the membrane layer thickness. Further EDAX showed a significant silica content on the top surface of the membrane (Figures $4.7 \& 4.8$ ). Evidently silica was primarily deposited within the existing porous structure; no additional membrane layer was produced as a result of deposition.

EDAX examination throughout the membrane layer offers information on the thickmess of the modified layer. A significant silica content ( -1250 counts) was detected on the top surface of SiO09 (Figure 4.9). However, the silica content decreased along the depth of the membrane. The silica content at $1.5 \mu \mathrm{m}$ below the top surface was 250 counts (Figure 4.10). No significant silica content was detected at the position below $1.5 \mu \mathrm{m}$ depth. This concludes that the thickness of the modified layer is about $1.5 \mu \mathrm{m}$. Most of the membranes generated from this method were found to have a similar layer thickness. The EDAX can also provide the information on metal oxide loading of the modified membranes. For example, Si001 showed a higher amount of silica content at its inner surface than SiO04 (Figures 4.7 v8. 4.8).

\subsection{Characterization of Microporous Structure with Pore Size Distribution Analyzer}

A pore size distribution analyzer can be used to identify the average pore size of a membrane and its pore size distribution. However, this instrument is not suitable for a pore size smaller than $-15 \AA$ because of the complication of the pore size estimation based upon the Kelvin equation. For membranes with $<15 \AA$, however, a pore size analyzer is useful for confirming the non-existence of the pore size larger than $15 \AA$.

A series of modified membranes were produced with a pore size ranging from 31 - <15 $\AA$, listed in Table 4.1. For example, the modified membrane, Si211, exhibited a sharp pore size distribution with an average pore size around 23A (Figure 4.11). The analysis of the modified membranes Si207 and Si209, on the other hand, showed that no significant flow was contributed from a pore size larger than $15 \AA$.

This characterization technique is very informative in directing the synthesis process. For example, a wide pore size distribution (24-65 $\AA$ ) of the modified membrane, Si409, indicated a nonuniform deposition ( Figure

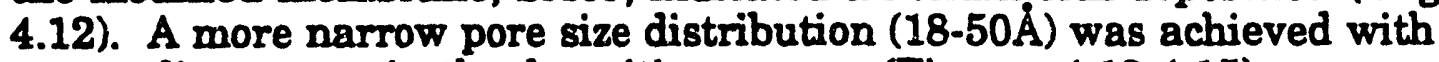
some adjustments in the deposition process (Figures 4.13-4.15).

Porous modified membranes with pore size ranging from $40-5 \AA$ can also be characterized by gas separations. Relative pore size among modified membranes can be determined by the separation selectivity for $\mathrm{N}_{2}$ /neopentane, $\mathrm{He} / \mathrm{SF}_{6}$ and $\mathrm{He} / \mathrm{N}_{2}$ mixtures. Gas separations with these modified membranes are discussed in the following sections. 


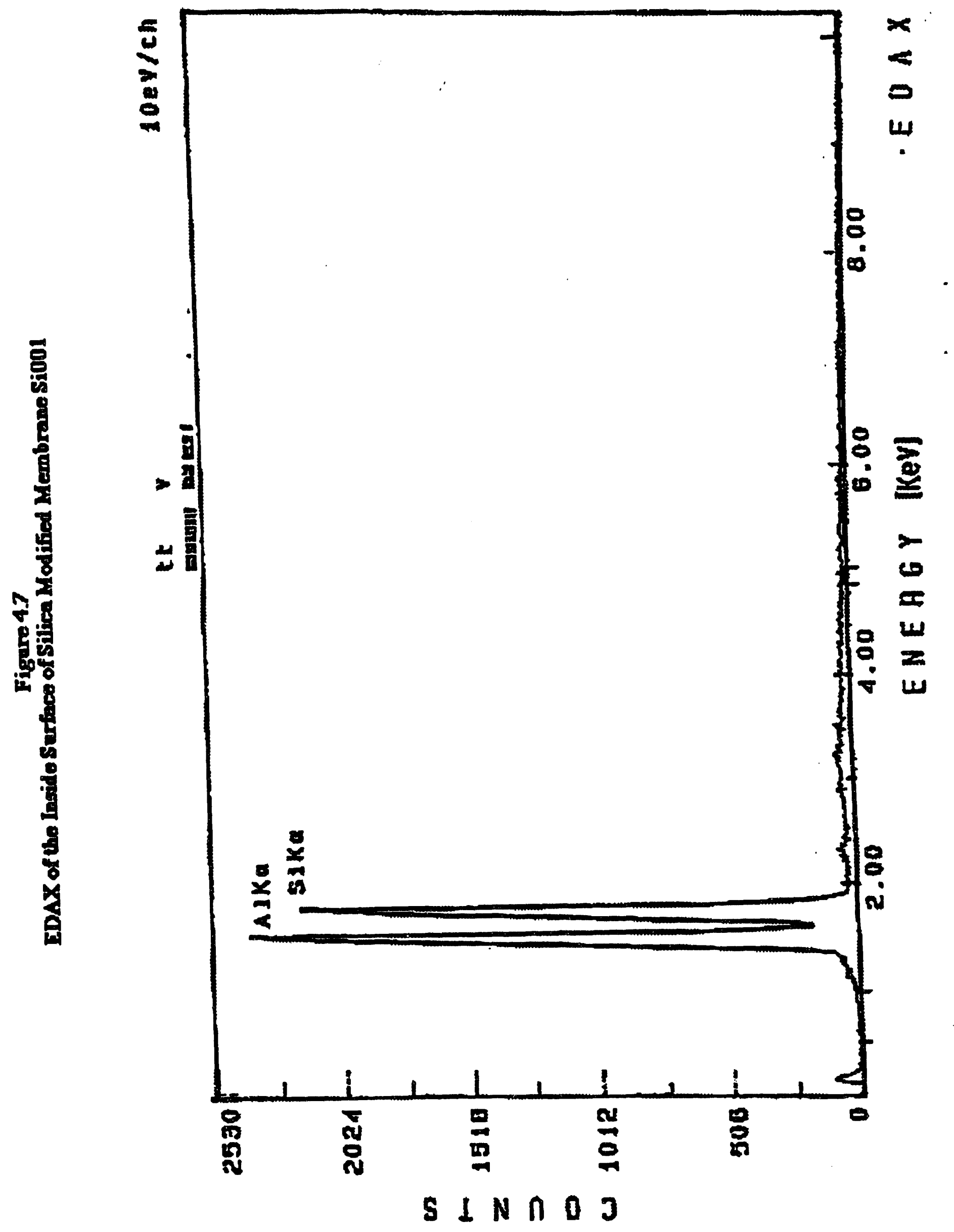




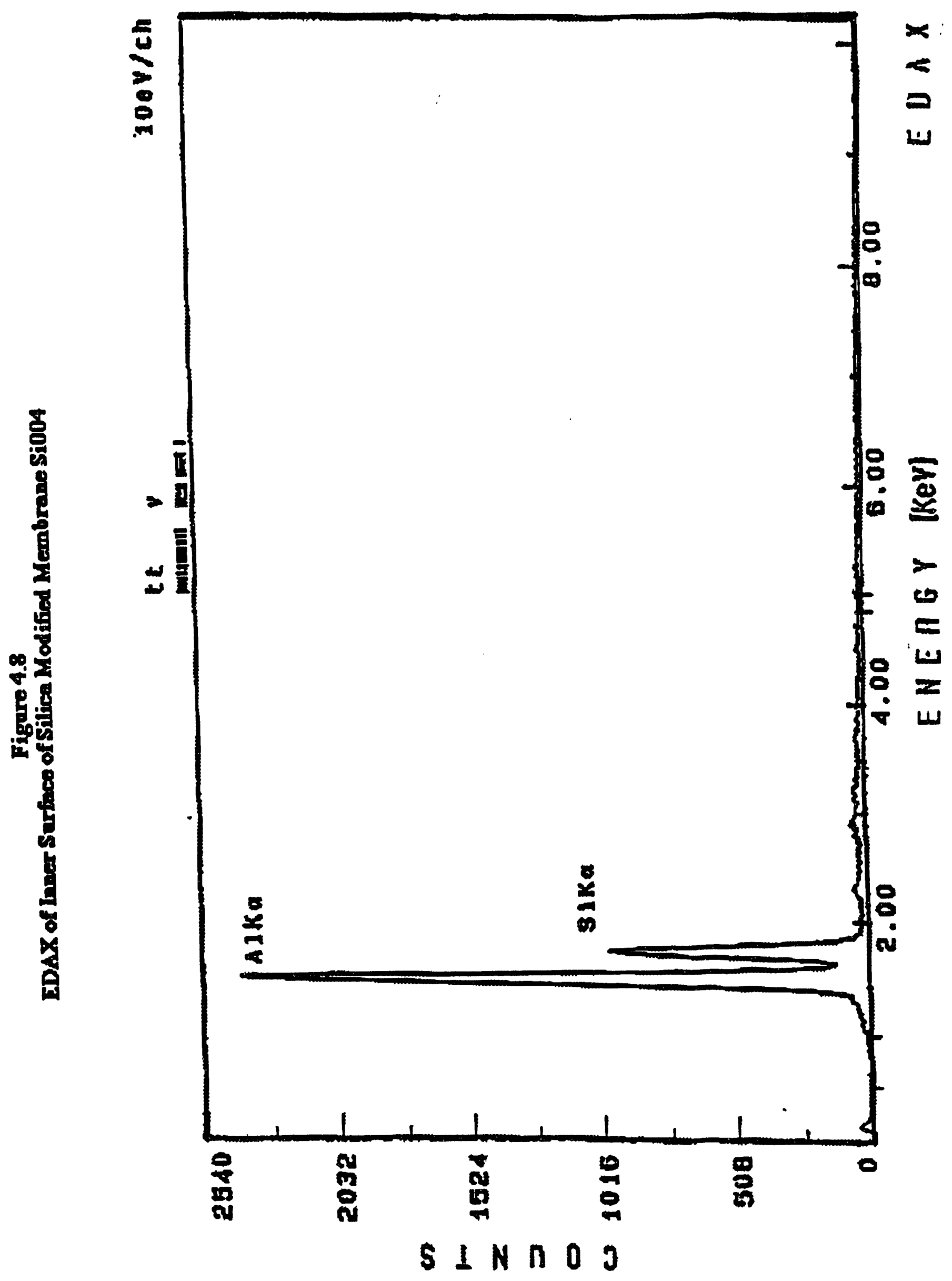




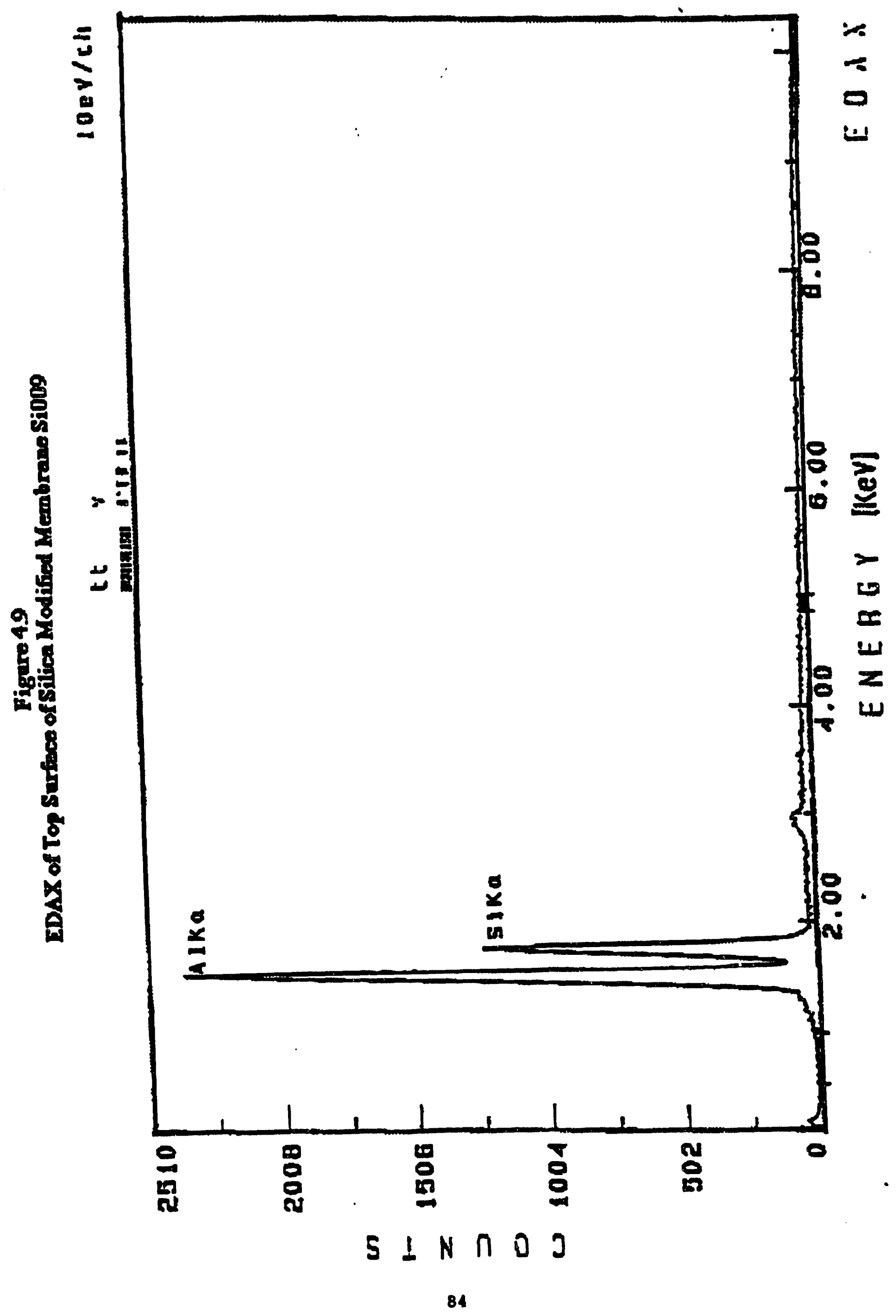




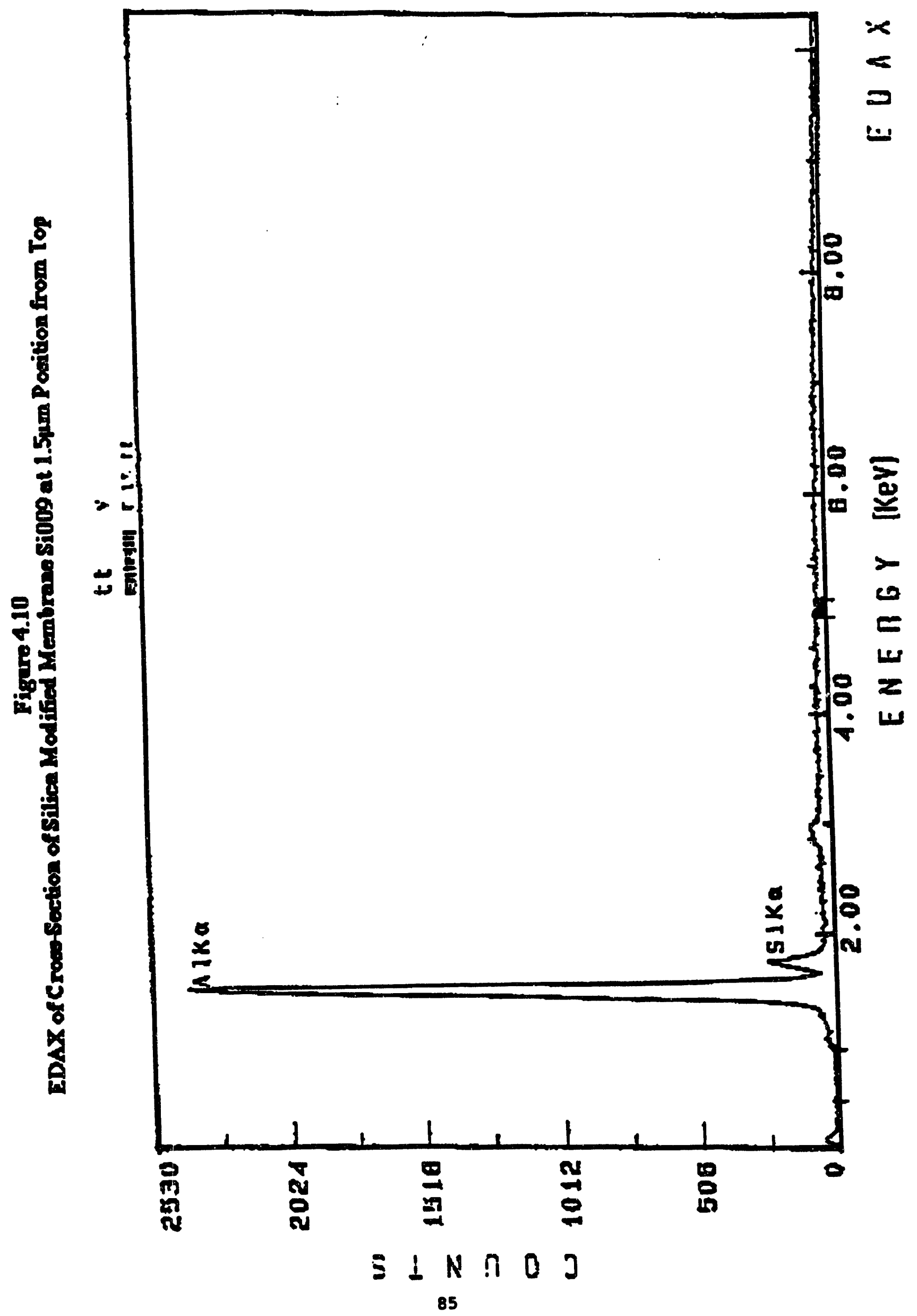


Table 4.1 Pore Size vs He/N2 Separation of Silica Modified Porous Membianes at Room Temperature

Samples Depostion Time PoreSize N2 He He/N2 He/SE6 $(\min ) \quad \frac{\mathrm{A}}{(\mathrm{M} 3 / \mathrm{M} 2 / \mathrm{hr} / \mathrm{atm})} \quad$ Selectivity

\begin{tabular}{|c|c|c|c|c|c|c|}
\hline $\mathbf{R} 1$ & & 70.00 & 244.53 & 649.22 & 2.65 & \\
\hline $\mathbf{R 2}$ & & 45.00 & 147.38 & 362.83 & 2.62 & \\
\hline Si208 & $20 \Omega$ & 31.40 & 69.55 & 169.85 & 2.44 & \\
\hline Si210 & $25 q$ & 27.60 & 48.08 & 115.66 & 2.41 & \\
\hline Si212 & $70 b$ & 24.80 & 17.62 & 36.87 & 2.09 & \\
\hline Si211 & $71 b$ & 22.80 & 18.07 & 37.79 & 2.09 & \\
\hline Si224 & $133 k$ & 22.76 & 10.24 & 21.65 & 2.12 & \\
\hline Si220 & $37 c$ & 20.00 & 8.16 & 18.90 & 2.30 & \\
\hline Si221 & 91c & - & 2.78 & 9.62 & 3.46 & \\
\hline Si209 & 302 & $<15$ & 1.010 & 3.91 & 3.86 & 2.06 \\
\hline Si207 & $35 n$ & $<5.5$ & 0.048 & 1.76 & 36.59 & 9.63 \\
\hline
\end{tabular}

He/N2 separation selectivity is based on single gas ratio.

He/SF6 separation selectivity is based on binary mixture separation.

$\boldsymbol{A b} \boldsymbol{b}$ and $\mathrm{c}$ indicated three different deposition conditions. 
Figure 4.11 Pore Size Distribution of Silica Modified Membrane Si211

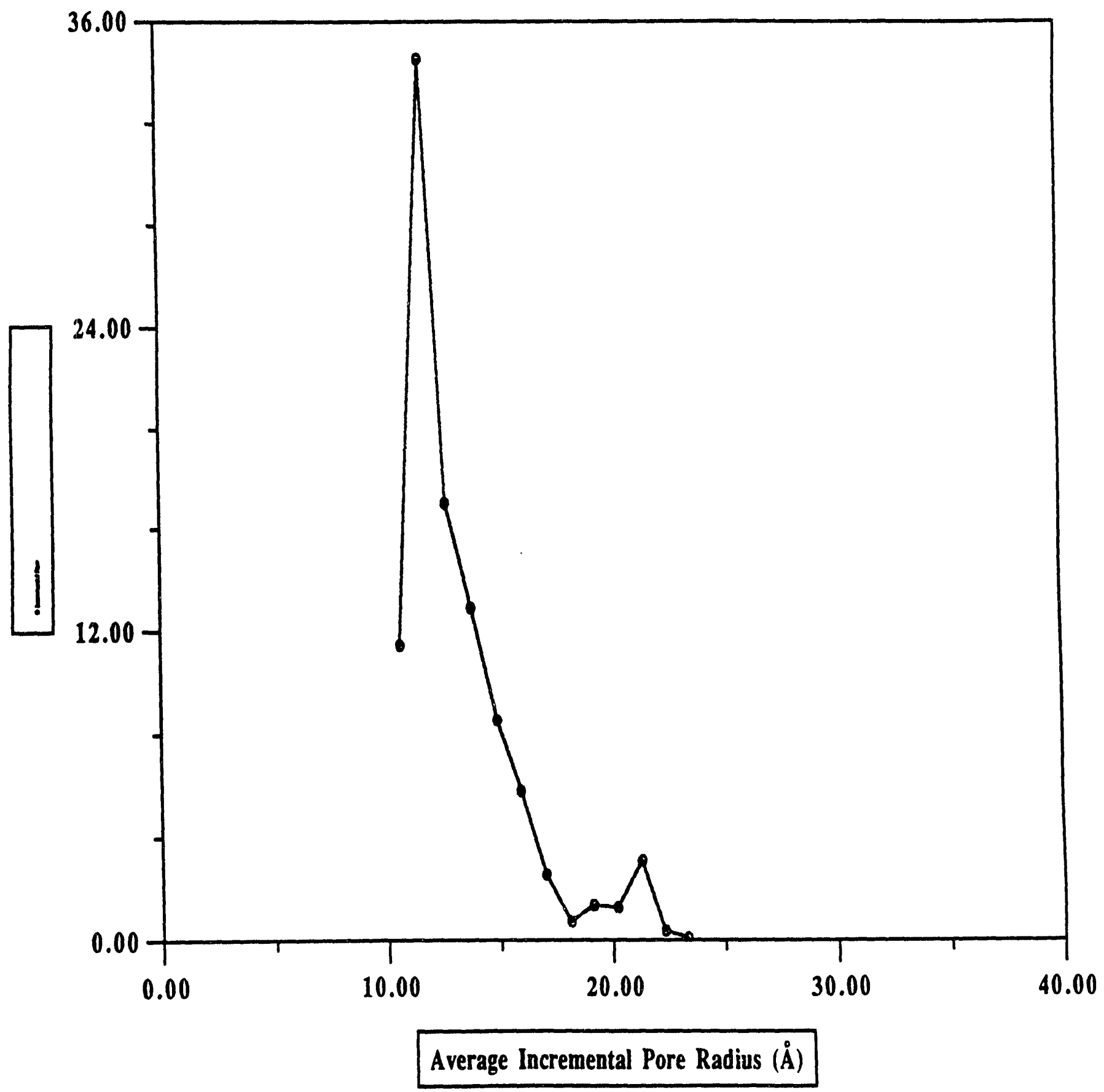


Figure 4.12 Pore Size Distribution of Silica Modified Membrane Si409

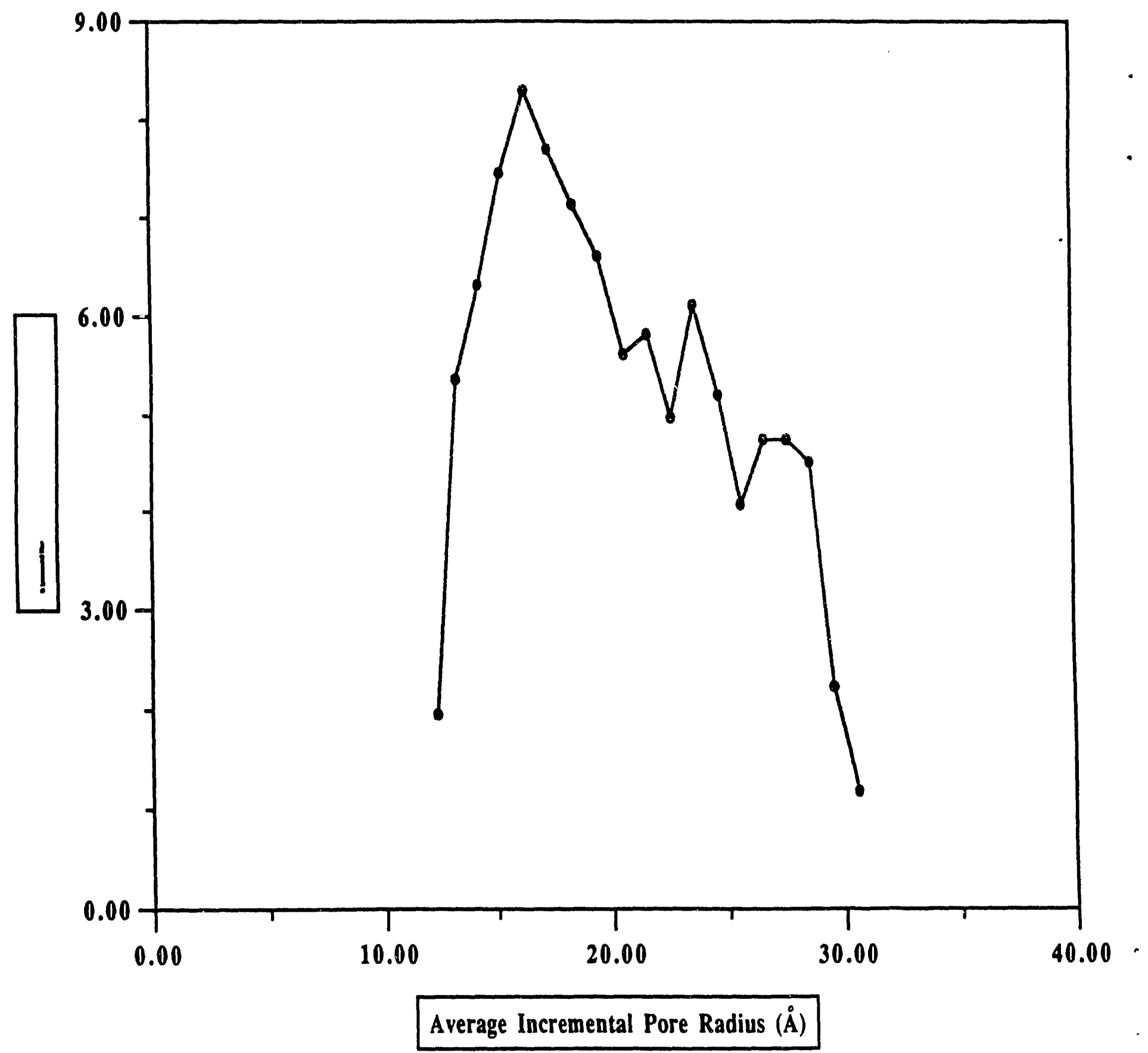


Figure 4.13 Pore Size Distribution of Silica Modified Membrane Si415

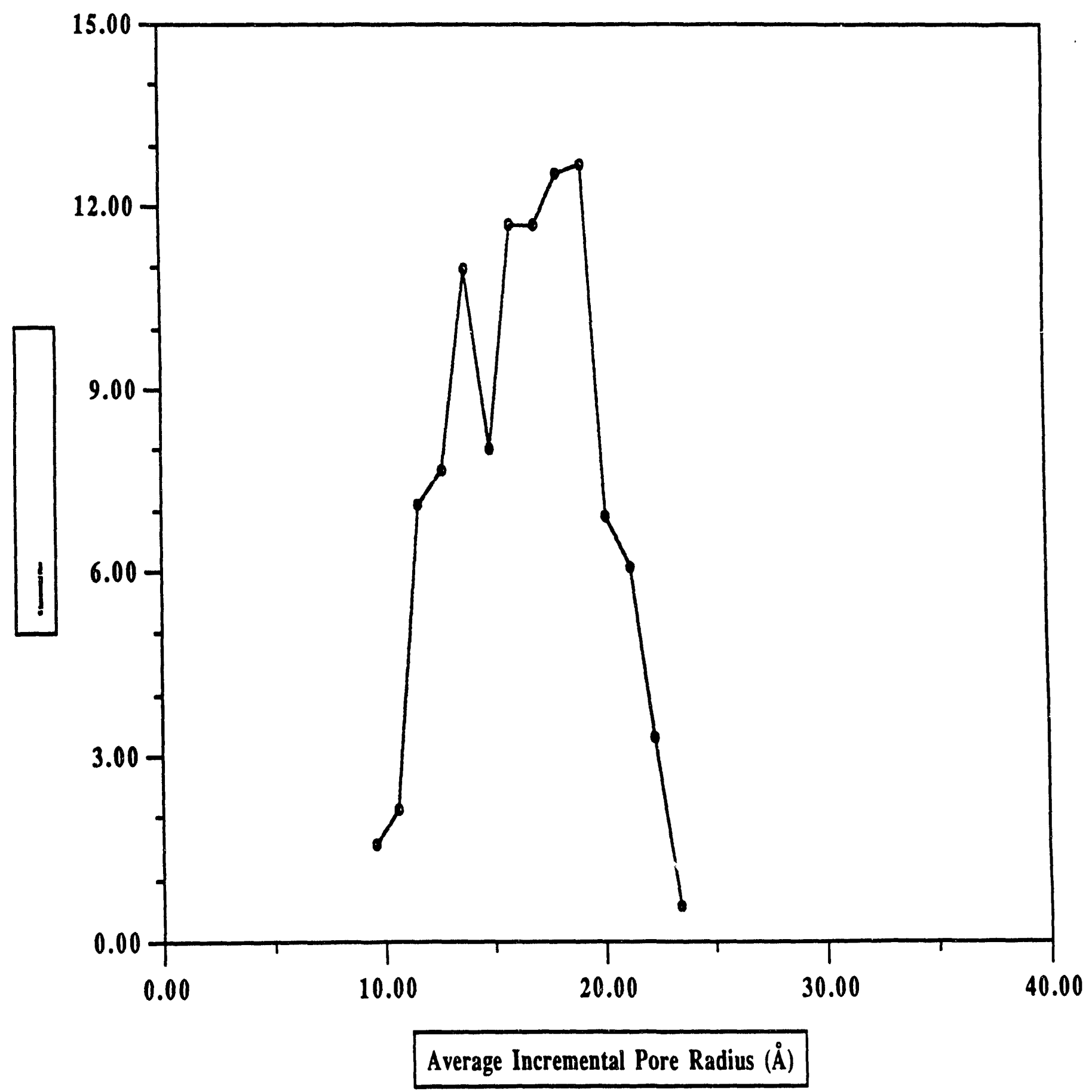


Figure 4.14 Pore Size Distribution of Silica Modified Membrane Si416

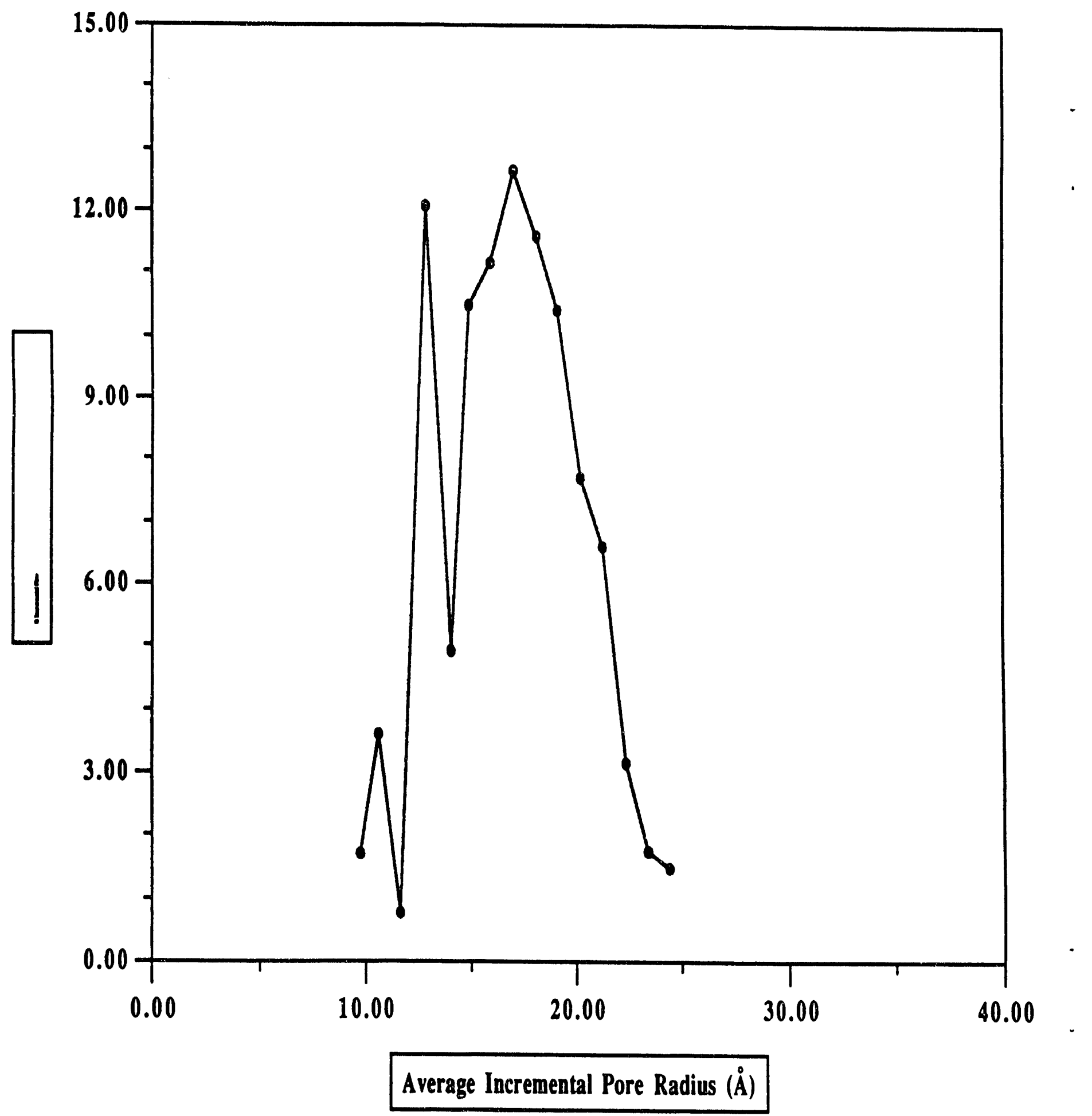


Figure 4.15 Pore Size Distribution of Silica Modified Membrane Si416

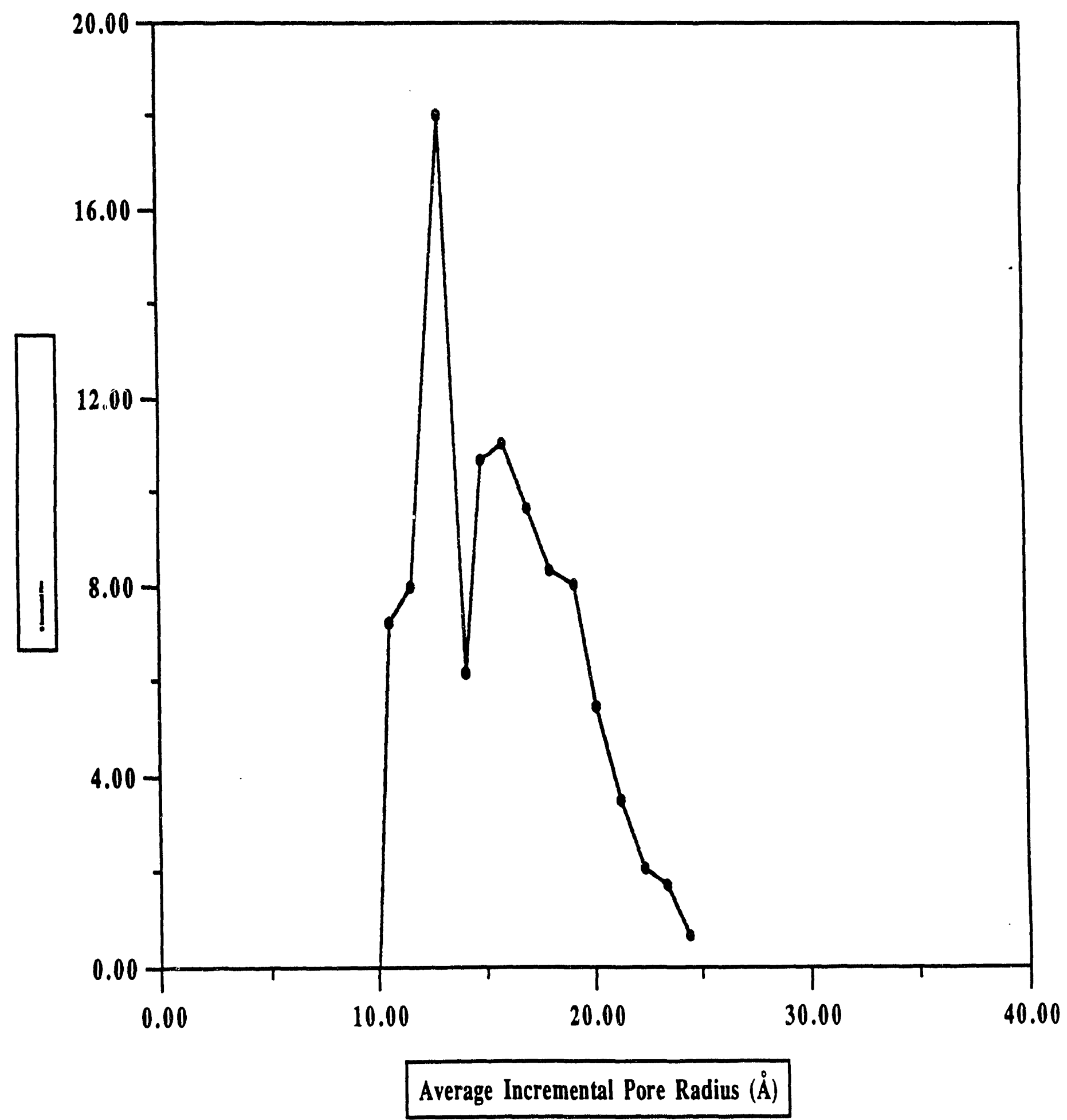


The modified membranes were first characterized by the pore size analyzer. If the modified membranes had no pore sizes larger than $15 \AA$, the membranes then were characterized by the probe gases based on size exclusion. Neopentane, $\mathrm{SF}_{6}$, nitrogen, helium and hydrogen having kinetic diameters of about $6.2 \AA, 5.5 \AA, 3.64 \AA, 2.8 \AA$ and $2.96 \AA$, respectively were used. Binary gas mixtures of $\mathrm{H}_{2} / \mathrm{N}_{2}(50: 50), \mathrm{N}_{2} /$ neopentane $(92.5: 7.5)$ and $\mathrm{He}_{\mathrm{SF}} 6$ (90.0:10.0) were selected. Mass flow meters and an on-line gas chromatography were equipped with FID and TCD to measure the composition and flow rate of the feed, reject and permeate streams.

\subsubsection{Porous Membranes}

The silica modified membrane Si018 demonstrated a selectivity in $\mathrm{N}_{2} /$ neopentane and $\mathrm{H}_{2} / \mathrm{N}_{2}$ based on Knudsen diffusion. Since hydrogen, nitrogen and neopentane can permeate through the silica modified membranes, Si018, the pore size of this membrane must be larger than the kinetic diameters of neopentane, nitrogen and hydrogen. Accordingly, the pore size of the modified membrane was assigned to $15-6 \hat{\AA}$.

It is difficult to assign the actual pore size of the membrane with pore size in the range of $15-6 \AA$. However, relative pore size can be obtained based on their gas separation selectivities and/or liquid separation selectivity. A series of modified membranes with pore size less than $15 \AA$ were prepared. The $\mathrm{N}_{2} /$ neopentane selectivity of these membranes ranges from 2.5 to 28.7 (Table 4.2). No molecular sieving separation was observed for these membranes, therefore the pore sizes of these membranes are assigned in the range of $15-6 \AA$. Since the modified membrane Si064 has the highest $\mathrm{N}_{2} /$ neopentane separation selectivity, one concludes that this membrane may have the smallest pore size. These gas separation results also are consistent with the liquid separation results.

The modified membranes with pore size less than $6 \AA$ were prepared. A $\mathrm{N}_{2}$ /neopentane separation selectivity around 405 was delivered by the modified membrane Si019 (Table 4.2). This high separation selectivity indicates that the separation is likely based on the molecular sieving effect. Since nitrogen, but not neopentane, permeated through this membrane, the pore diameter of this membrane should be smaller than the kinetic diameter of neopentane $(6.2 \AA)$ and larger than that of nitrogen $(3.6 \AA)$.

\subsubsection{Dense Phase Membranes}

Although a series of silica modified membranes with a variety of pore size distribution were synthesized, it is difficult to synthesize a porous membrane to separate hydrogen from nitrogen because of the 
Table 42 Separations of Silica Modified Porous Membranes with Pore Sine of 15 - 6 A

$\begin{array}{ccccc}\text { Samples } & \begin{array}{c}\text { Nominal } \\ \text { Pore Size (A) }\end{array} & \begin{array}{c}\mathrm{N}_{2} \text { Permeability } \\ \text { (M3/M2/hr/atm) }\end{array} & \begin{array}{c}\text { Pyrene/hezane } \\ \text { Rejection }\end{array} & \begin{array}{c}\mathbf{N}_{2} \text { Neopentane } \\ \text { Selectivitz }\end{array} \\ \text { Alumina } & 40 & 79.100 & 0 \% & 1.6(\mathrm{ca}) \\ \text { Si033 } & 15-6 & 0.972 & 30 \% & 2.5 \\ \text { Si038 } & 15-6 & 0.196 & 33 \% & 15.3 \\ \text { Si025 } & 15-6 & 0.113 & 76 \% & 24.4 \\ \text { Si064 } & 15-6 & 0.252 & 78 \% & 28.7 \\ \text { Si019 } & 6-4 & 0.130 & - & 405.0\end{array}$

1. \% rejection is based on concentration of permeated fluz/concentration of feed flur.

2. $\mathrm{N}_{2} /$ Neopentane separation was conducted by feeding $10 \%$ of neopentane in nitrogen to the membranes at room temperature and transmembrane pressure of 35 psi. 
small difference in their kinetic diameters $(0.75 \AA)$. A different separation mechanism is needed for efficient $\mathrm{H}_{2} / \mathrm{N}_{2}$ separation. Dense silica modified membranes can achieve a high selectivity in $\mathrm{H}_{2} / \mathrm{N}_{2}$ separation at high temperature based on activated diffusion.

A series of hydrogen selective membranes were synthesized, including Si009, Si024, Si187, Si195 and Si215 on 1" supports and Si403, Si404, Si412 on 10" supports. Their $\mathrm{N}_{2}$ and He permeabilities at room temperature were $.06-2.2$ and $0.13-0.35 \mathrm{M}^{3} / \mathrm{M}^{2} / \mathrm{hr} / \mathrm{atm}$ (Table 4.3) respectively. The He permeabilities increased with temperature while $\mathrm{N}_{2}$ permeabilities decreased, resulting in the enhanced selectivity for helium at a high temperature. The $\mathrm{He} / \mathrm{N}_{2}$ selectivities at $600^{\circ} \mathrm{C}$ were enhanced significantly, i.e., 10 -59.

With adjustments in our deposition procedure, several silica dense phase membranes, Si418, Si421, Si428, Si432 and Si438 with an improved selectivity were synthesized on $10^{\prime \prime}$ supports. The $\mathrm{N}_{2}$ and He permeabilities of these membranes at room temperature are 0.001 -0.006 and $0.004-0.018 \mathrm{M}^{3} / \mathrm{M}^{2} / \mathrm{hr} / \mathrm{atm}$ (Table 4.4) respectively. The $\mathrm{He} / \mathrm{N}_{2}$ separation selectivity of these modified membranes at $600^{\circ} \mathrm{C}$ ranges from 125 to 473 which is higher than the modified membranes listed in Table 4.3. The separation selectivity was probably reduced due to the leakage of the graphite packing. This small leakage attributes to $30-100 \%$ of the total $\mathrm{N}_{2}$ flow and only $1 \%$ of total He flow. The detailed evidence to prove this assumption is discussed in section 4.9. If we take this leakage into consideration, the $\mathrm{He} / \mathrm{N}_{2}$ separation selectivity of the modified membrane could reach infinity.

These He selective membranes also demonstrated a high separation selectivity in hydrogen as observed in Table 4.3. For a given modified membrane, the $\mathrm{H}_{2} \mathrm{~N}_{2}$ separation selectivity is about one half of its $\mathrm{He} / \mathrm{N}_{2}$ separation selectivity at $600^{\circ} \mathrm{C}$. Therefore, we can estimate the H2 $\mathrm{N}_{2}$ separation selectivity based on their $\mathrm{He} / \mathrm{N}_{2}$ separation. In summary, hydrogen selective membranes have been achieved. The challenge in the future is to obtain hydrogen selective membranes with high permeate flux and eliminate the small leakage from packing.

\subsection{Reproducibility and Scale-up of Chemical Vapor Deposition}

Two factors affect the reproducibility of the CVD process: variation of the precursor microporous structure and the control of the operating condition. A series of commercial ceramic membranes with an average pore size of $40 \AA$ were characterized by nitrogen permeabilities and pore size distribution before the chemical vapor deposition. The nitrogen permeabilities of these membranes range from 86 to $144 \mathrm{M}^{3} / \mathrm{m}^{2} / \mathrm{hr} / \mathrm{atm}$ (Table 4.5). Due to the slight difference in the pore size distribution, the 
Table 4.3 He, N2 and H2 Permeabilities of Modified Dense Membranes at Various Temperatures

Samoles Length Temp N2 $\frac{\text { He }}{(\mathrm{M} 3 / \mathrm{M} 2 / \mathrm{hr} / \mathrm{atm})}$ He/N2

\begin{tabular}{|c|c|c|c|c|c|c|c|}
\hline $\begin{array}{l}\text { Si009 } \\
\text { Si009 }\end{array}$ & $1^{n}$ & $\begin{array}{l}25 \\
500\end{array}$ & $\begin{array}{l}0.00970 \\
0.01000\end{array}$ & : & $\begin{array}{l}0.12300 \\
0.01250\end{array}$ & $\dot{-}$ & $\begin{array}{l}1.25 \\
12.68\end{array}$ \\
\hline Si024 & $1^{n}$ & 500 & 0.00920 & $\bullet$ & 0.23000 & - & 25.00 \\
\hline $\begin{array}{l}\text { Si187 } \\
\text { Si187 } \\
\text { Si187 } \\
\text { Si187 }\end{array}$ & $1^{n}$ & $\begin{array}{l}25 \\
300 \\
450 \\
600\end{array}$ & $\begin{array}{l}0.06198 \\
0.03922 \\
0.06032 \\
0.04061\end{array}$ & $\begin{array}{l}0.12957 \\
0.11736 \\
0.19767 \\
0.32501\end{array}$ & $\begin{array}{l}0.20871 \\
0.14915 \\
0.14314 \\
0.16842\end{array}$ & $\begin{array}{l}2.09 \\
2.74 \\
3.45 \\
9.46\end{array}$ & $\begin{array}{l}3.29 \\
3.29 \\
2.34 \\
4.65\end{array}$ \\
\hline $\begin{array}{l}\text { Si195 } \\
\text { Si195 } \\
\text { Si195 } \\
\text { Si195 }\end{array}$ & $1^{n}$ & $\begin{array}{l}25 \\
300 \\
450 \\
600\end{array}$ & $\begin{array}{l}0.22356 \\
0.09686 \\
0.05993 \\
0.049863\end{array}$ & $\begin{array}{l}0.32249 \\
0.99357 \\
0.03389 \\
2.92653\end{array}$ & $\begin{array}{l}0.55862 \\
0.52954 \\
0.98864 \\
1.39675\end{array}$ & $\begin{array}{l}1.44 \\
10.26 \\
33.94 \\
58.70\end{array}$ & $\begin{array}{l}2.50 \\
\mathbf{5 . 4 7} \\
16.50 \\
\mathbf{2 8 . 0 1}\end{array}$ \\
\hline $\begin{array}{l}\text { Si215 } \\
\text { Si215 } \\
\text { Si215 } \\
\text { Si215 } \\
\end{array}$ & $1^{n}$ & $\begin{array}{l}25 \\
300 \\
450 \\
600 \\
\end{array}$ & $\begin{array}{l}0.16000 \\
0.09300 \\
0.08100 \\
0.07500\end{array}$ & $\begin{array}{l}0.35000 \\
0.75000 \\
1.59000 \\
2.46000\end{array}$ & $:$ & $\begin{array}{l}2.11 \\
8.04 \\
19.64 \\
32.73\end{array}$ & $:$ \\
\hline $\begin{array}{l}\text { Si403 } \\
\text { Si403 } \\
\text { Si403 } \\
\text { Si403 }\end{array}$ & $10^{\prime \prime}$ & $\begin{array}{l}25 \\
300 \\
450 \\
600\end{array}$ & $\begin{array}{l}0.07678 \\
0.03858 \\
0.03283 \\
0.03021\end{array}$ & $\begin{array}{l}0.12910 \\
0.32972 \\
0.66927 \\
0.97988\end{array}$ & $\begin{array}{l}0.15362 \\
0.13011 \\
0.21643 \\
0.25511\end{array}$ & $\begin{array}{l}1.68 \\
8.55 \\
20.39 \\
31.79\end{array}$ & $\begin{array}{l}2.00 \\
3.37 \\
6.59 \\
8.28\end{array}$ \\
\hline $\begin{array}{l}\text { Si404 } \\
\text { Si404 } \\
\text { Si404 } \\
\text { Si404 }\end{array}$ & $10^{n}$ & $\begin{array}{l}25 \\
300 \\
450 \\
600\end{array}$ & $\begin{array}{l}0.05381 \\
0.03084 \\
0.02399 \\
0.02189\end{array}$ & $\begin{array}{l}0.09761 \\
0.17520 \\
0.39942 \\
0.60824\end{array}$ & $\begin{array}{l}0.14271 \\
0.09358 \\
0.12716 \\
0.15884\end{array}$ & $\begin{array}{l}1.81 \\
5.68 \\
16.65 \\
27.58\end{array}$ & $\begin{array}{l}2.65 \\
3.03 \\
5.30 \\
7.20\end{array}$ \\
\hline $\begin{array}{l}\text { Si412 } \\
\text { Si412 } \\
\text { Si412 } \\
\text { Si412 }\end{array}$ & $10^{\prime \prime}$ & $\begin{array}{l}25 \\
385 \\
450 \\
600\end{array}$ & $\begin{array}{l}0.10100 \\
0.05400 \\
0.04900 \\
0.04400\end{array}$ & $\begin{array}{l}0.21300 \\
0.51900 \\
0.86600 \\
1.26600\end{array}$ & $:$ & $\begin{array}{l}2.10 \\
8.04 \\
17.70 \\
28.71\end{array}$ & : \\
\hline
\end{tabular}


Table 4.4 He, N2 Permeabilities of Dense Silica Membranes with Improved Deposition

\begin{tabular}{|c|c|c|c|c|c|c|}
\hline Samoles & Leoeth & $\mathrm{N} 2-600^{\circ} \mathrm{C}$ & $\frac{\mathrm{He}-600^{\circ} \mathrm{O}}{(\mathrm{M} 3 / \mathrm{M2}}$ & $\frac{N 2-22^{\circ} \mathrm{C}}{\mathrm{hr} / \mathrm{atm})}$ & $\mathrm{He}-22^{\circ} \mathrm{C}$ & $\frac{\mathrm{He} / \mathrm{N2}}{600^{\circ} \mathrm{C}}$ \\
\hline S.S*1= & & 0.00011 & 0.00038 & 0.00022 & 0.00040 & 3.40 \\
\hline$S .5 * 2=$ & & 0.00000 & 0.00000 & 0.00000 & 0.00000 & - \\
\hline Si418 & $10^{\circ}$ & 0.00101 & 0.38356 & 0.00189 & 0.01160 & 380.75 \\
\hline Si 421 & $10^{\circ}$ & 0.00081 & 0.39650 & 0.00114 & 0.00838 & 473.79 \\
\hline Si 428 & $10^{\circ}$ & 0.00340 & 0.42540 & 0.00200 & 0.00400 & 125.39 \\
\hline Si 432 & $10^{\circ}$ & 0.00207 & 0.33393 & 0.00585 & 0.01769 & 160.94 \\
\hline Si 438 & $10^{\circ}$ & 0.00066 & 0.25089 & 0.00115 & 0.00791 & 381.39 \\
\hline
\end{tabular}


Sample ID

ES105.1.D \#01

ES105.1.D \#15

ES105.1.D \#20

ES105.1. \#22

ES105.1.D *25

ES105.1.D \#28

ES105.1.D \#33

ES105.1.D \#33

ES105.1.D \#33

ES105.1D \#34

ES105.1.D *34

ES105.1.D *35

ES105.1.D $\$ 36$

ESI05.1.D *37

ES105.1. $\$ 38$

ES105.1.D *39

ES105.1.D $* 40$

ES105.1D $\# 40$

ES105.1.D \#41
$\mathrm{N}_{2}$ Permeability (M3AM2/hr/atm) at $25^{\circ} \mathrm{C}$

144

138

130

137

121

120

151

151

151

117

117

139

137

156

140

145

130

130

146 
non-uniformity of the layer thickness according to SEM examination was believed to be the source of the variation. We were able to modify these membranes with such a difference in starting materials to obtain membranes with a similar pore size.

Two modified membranes, Si211 and Si212, were obtained at the same condition. The final products had a similar $\mathrm{N}_{2}$ and He permeability (Table 4.1). The pore size analysis indicated that the average pore of Si211 and Si212 were around 22.8 and $24.8 \AA$, respectively. This $2 \AA$ difference in average pore size is within the precision of the instrumentation. The consistent permeability and pore size generated from these two samples lead us to believe that the deposition process is reproducible for a 1" precursor.

We alsn investigated the reproducibility of the chemical deposition process for a 10" precursor. The modified mambranes Si 405 and Si406 were deposited under a similar condition resulting in similar $\mathrm{He}$ and $\mathrm{N}_{2}$ permeabilities as well as a similar $\mathrm{He} / \mathrm{N}_{2}$ separation selectivity (Table 4.6). Nevertheless, the deviation increased in the $1 "$ as compared to the 10". Similar results were observed in the modified membranes Si407 and Si409, which were deposited at a different condition from Si405 and Si406. This is a good indication that the large scale deposition process is also reproducible as in the small scale.

However, we discovered the presence of a nonuniform deposition. The analysis of the modified membranes $\mathrm{Si} 405$ showed that the pore size distribution of these membranes was wide, $61-24 \AA$ although a great portion of the pores in this membrane was around $50 \AA$.

We further investigated this nonuniform deposition by cutting a modified membrane Si401 into three pieces to inspect the uniformity of the membrane (Table 4.7). The first and final pieces showed similar $\mathrm{He}$ and $\mathrm{N}_{2}$ permeabilities. However, the central piece showed much higher He and $\mathrm{N}_{2}$ permeabilities. Non-uniformity like this in permeability was also present in the precursor primarily due to the different thickness along the length of existing membranes. This may cause the nonuniform deposition observed in the modified membranes.

Two corrective actions were attempted to overcome this non-uniformity deposition: increasing the deposition rate and/or controlling the permeate flux during the deposition. A modified membrane, Si409, was then synthesized at a higher deposition rate. Its average pore size decreased to about $40.9 \AA$ from $50 \AA$ (Figure 4.12). However, the pore size distribution remained wide, e.g. $60-24 \AA$.

Control of the permeate flow was attempted to narrow the pore size distribution. The permeate flow rates of the modified membranes, Si415, Si416 and Si417, were fixed at various levels during the deposition process. 
Table 4.6 He, $\mathrm{N}_{2}$ Permeabilities of 10" Modified Porous Silica Membranes

\begin{tabular}{lccc} 
Samples & \multicolumn{2}{c}{$\begin{array}{c}\text { Permeability }\left(\mathrm{m}^{3} / \mathrm{m}^{2} / \mathrm{hr} / \mathrm{atm}\right) \\
\mathrm{Ne}=22^{\circ} \mathrm{C}\end{array}$} & He $/ \mathrm{N}_{2}$ \\
Si405 & 13.32 & 32.55 & 2.44 \\
Si406 & 11.03 & 26.85 & 2.43 \\
Si407 & 6.42 & 11.43 & 1.78 \\
Si408 & 0.64 & 1.22 & 1.91 \\
Si409 & 4.66 & 10.25 & 2.49 \\
Si415 & 7.73 & 18.31 & 2.37 \\
Si416 & 17.40 & 40.90 & 2.35 \\
Si417 & 26.06 & 62.28 & 2.39
\end{tabular}


Table 4.7 He, $\mathrm{N}_{2}$ Permeabilities of 10" Modified Silica Membrane at Three Different Positions

\begin{tabular}{|c|c|c|c|}
\hline Samples & \multicolumn{2}{|c|}{$\begin{array}{l}\text { Permeability }\left(\mathrm{m}^{3} / \mathrm{m}^{2} / \mathrm{hr} / \mathrm{atm}\right) \\
\mathrm{N}_{2-22^{\circ} \mathrm{C}}\end{array}$} & $\mathrm{He} / \mathrm{N}_{2}$ \\
\hline Si401 - End \#1 & 0.094 & 0.170 & 1.87 \\
\hline Si401 - Center & 1.76 & 2.910 & 1.65 \\
\hline Si401 - End \#2 & 0.079 & 0.140 & 1.75 \\
\hline
\end{tabular}


The average pore size of Si415, Si416 and Si417 were around $33 \AA, 33.8 \AA$ and 31A, respectively. Modified membranes Si415, Si416 and Si417 showed a narrower pore size distribution, $48-21 \AA$, than unmodified membranes (Figures 4.13-4.15). The modified membrane Si417 seems more desirable for industrial applications because of a sharper pore size distribution and higher $\mathrm{He}$ and $\mathrm{N}_{2}$ permeabilities.

In summary, the deposition process was successfully scaled up from a 1 " to 10 " precursor with minor adjustment. Modified membranes with 10" length were synthesized to have a porous or dense phase structure. The reproducibility of this large scale deposition was confirmed.

\subsection{Thermal Stability of Silica Modified Membranes}

According to our previous experiment, the $\gamma-40 \AA$ alumina membranes were thermally stable up to $650^{\circ} \mathrm{C}$. These $40 \AA$ alumina membranes undergo pore growth to $60 \AA$ after being heated in $90 \%$ water in nitrogen at $650^{\circ} \mathrm{C}$ for 24 hours. The nitrogen permeabilities of these membranes increased immediately from 60 to $150 \mathrm{M}^{3} / \mathrm{M}^{2} / \mathrm{hr} / \mathrm{atm}$ at the first three hours in hydrothermal treatment. It is known that at elevated temperature $\left(800-1000^{\circ} \mathrm{C}\right), \gamma$ alumina will transfer to a alumina and results in pore size enlargement. The He permeability of existing alumina membranes rose from 295 to 1113 after being treated at $1000^{\circ} \mathrm{C}$ for $5 \mathrm{hrs}$. The average pore size of these membranes increased from $45 \AA$ to $89.6 \AA$ (Table 4.8). Under a hydrothermal condition, water will promote this transformation at an accelerated rate. Several studies indicated that foreign cations can accelerate or inhibit this transformation.

The thermal stability tests were conducted on both porous and dense modified membranes. An on-line $\mathrm{He}$ and $\mathrm{N}_{2}$ permeability measurement was used to monitor the thermal stabilities of these membranes. Silica modified 1" porous membranes Si071 was subjected to a thermal treatment at $760-800^{\circ} \mathrm{C}$ for $160 \mathrm{hrs}$. The $\mathrm{N}_{2}$ permeability of these membranes decreased from 0.19 to $0.09 \mathrm{M}^{3} / \mathrm{M}^{2} / \mathrm{hr} / \mathrm{atm}$ initially and remained constant at $760-800^{\circ} \mathrm{C}$ (Table 4.8, Figure 4.16). The decreasing of $\mathrm{N}_{2}$ permeability was due to densification of the modified membrane. It also indicated that modified porous membrane $\mathrm{Si} 071$ was thermally stable up to $760-800^{\circ} \mathrm{C}$.

Hydrogen selective membranes Si418, Si421, Si428 and Si432 were subjected to a thermal treatment at $600^{\circ} \mathrm{C}$ under $390 \mathrm{cc} / \mathrm{min} \mathrm{He}$ flow. The He permeate flows of these membranes decreased initially and became constant after 48 hours (Table $4.9-4.12$ ). However, the $\mathrm{N}_{2}$ permeate fluxes increased drastically after 48 hours with one exception, Si421 (Table 4.10). Modified membrane $\mathrm{Si} 421$ gave a $\mathrm{He} / \mathrm{N}_{2}$ separation selectivity of around 473 initially and decreased to about 320 after 75 hours (Figure 4.17), then remained constant for an additional 145 hours of thermal treatment. This result indicated that the modified membrane Si421 went through densification initially and became stable after 75 hours. 


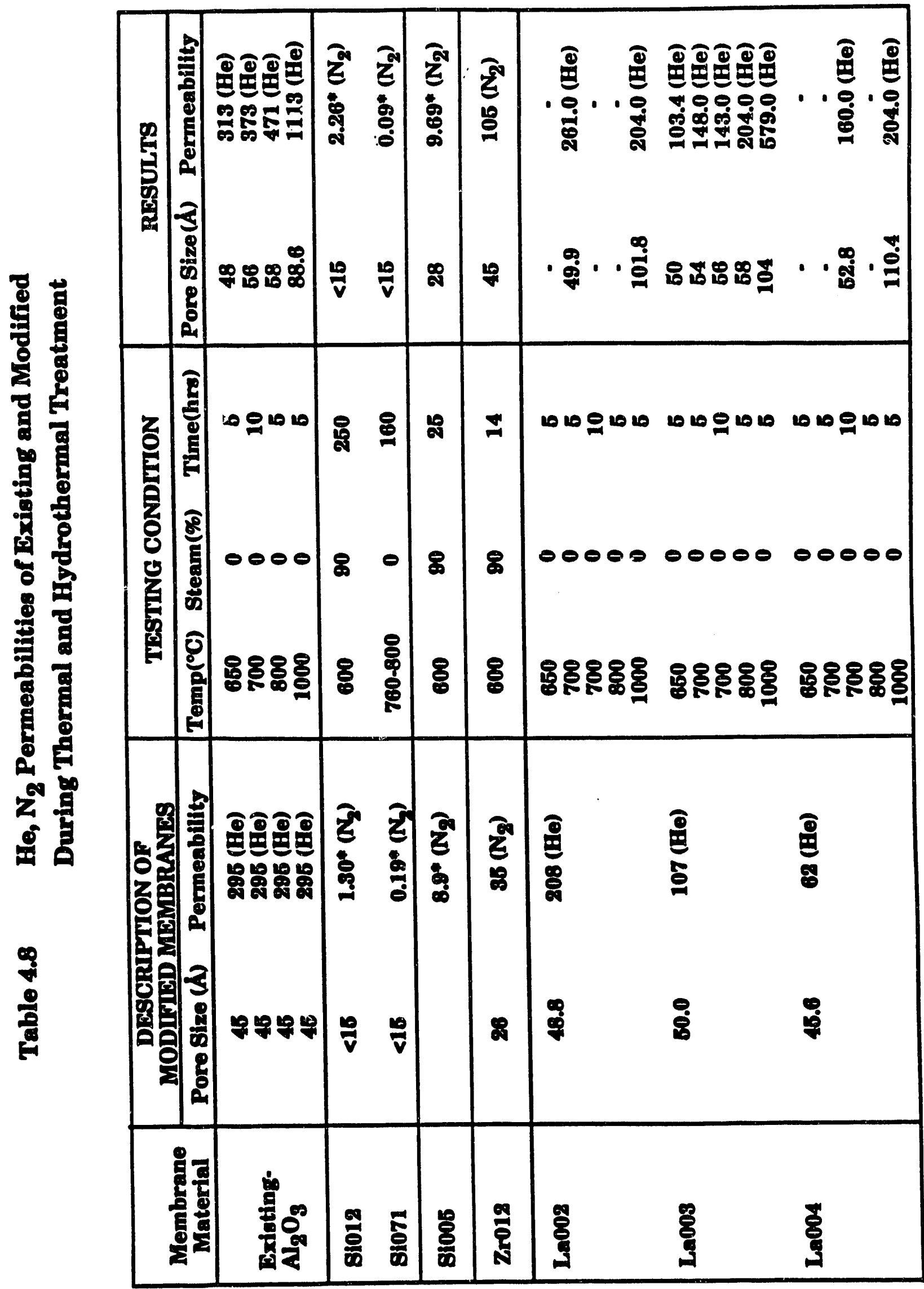



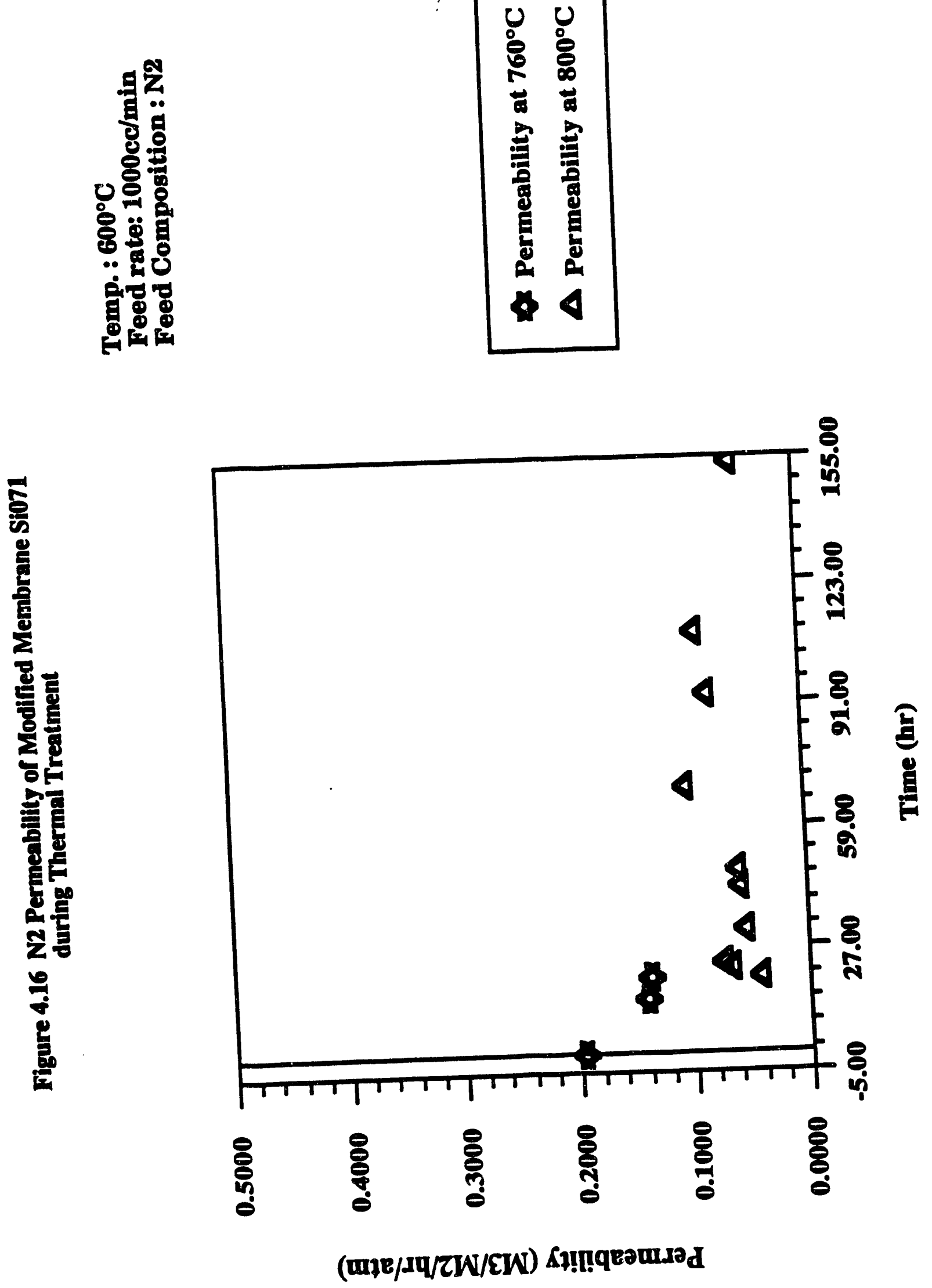
Snmole 418

\begin{tabular}{|c|c|c|c|c|c|}
\hline$\frac{\text { Irentment Time }}{(\mathrm{hr} s)}$ & $N 2-600^{\circ} C$ & $\frac{H e-600^{\circ} \mathrm{C}}{(\mathrm{M} 3 / \mathrm{M} 2}$ & $\frac{\sqrt{2}-22^{\circ} \mathrm{C}}{\mathrm{hr} / \mathrm{atm})}$ & $-22^{\circ} \mathrm{C}$ & $\frac{\mathrm{He} / \mathrm{NO} 2}{600^{\circ} \mathrm{C}}$ \\
\hline 0.0 & 0.001010 & 0.38356 & 0.00189 & 0.01160 & 380.75 \\
\hline 15.0 & 0.000980 & 0.32000 & & & 326.11 \\
\hline 23.0 & 0.000909 & 0.29511 & & & 324.65 \\
\hline 40.0 & 0.000850 & 0.28040 & & & 330.51 \\
\hline 48.0 & 0.000880 & 0.22859 & & & 260.57 \\
\hline 63.0 & 0.002120 & 0.23476 & & & 110.72 \\
\hline 69.0 & 0.003090 & 0.24116 & 0.00140 & 0.00449 & 78.07 \\
\hline
\end{tabular}


Snmple sictel

\begin{tabular}{|c|c|c|c|c|c|}
\hline$\frac{\text { Irentment Iime }}{\text { (hrs) }}$ & $N 2-600^{\circ} \mathrm{C}$ & $\frac{\mathrm{He}-600^{\circ} \mathrm{C}}{(\mathrm{M} 3 / \mathrm{M} 2}$ & $\frac{\mathrm{N} 2-22^{\circ} \mathrm{C}}{\mathrm{hr} / \mathrm{atm})}$ & He $-22^{\circ} \mathrm{C}$ & $\frac{\mathrm{He} / \mathrm{N} 2}{600^{\circ} \mathrm{C}}$ \\
\hline 0.0 & 0.000840 & 0.39650 & 0.00114 & 0.00838 & 473.79 \\
\hline 22.0 & 0.000950 & 0.40760 & & & 427.51 \\
\hline 26.0 & 0.001120 & 0.40480 & & & 362.33 \\
\hline 41.0 & 0.001090 & 0.38400 & & & 352.30 \\
\hline 47.5 & 0.000940 & 0.35980 & & & 381.46 \\
\hline 49.5 & 0.000940 & 0.36196 & & & 385.31 \\
\hline 75.5 & 0.001080 & 0.33927 & & & 313.14 \\
\hline 84.5 & 0.001080 & 0.32807 & & & 304.90 \\
\hline 99.5 & 0.001010 & 0.32570 & & & 321.25 \\
\hline 106.0 & 0.000930 & 0.32050 & & & 343.97 \\
\hline 150.5 & 0.000970 & 0.32050 & & & 330.66 \\
\hline 219.5 . & 0.001010 & 0.30930 & 0.00121 & 0.00565 & 307.64 \\
\hline
\end{tabular}


Table 411 The He anci N2 Permenbllities of Sllica Modified Dence Membranes 81428 During Thermal Treatment

Snmole Sil28

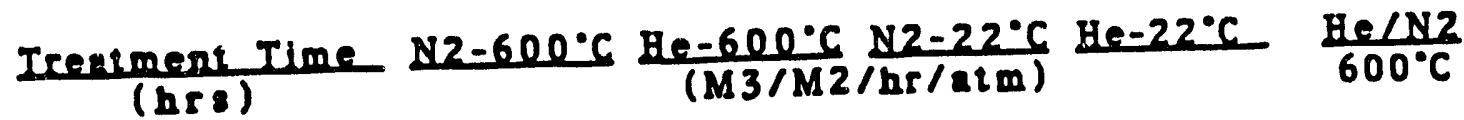

0.0

0.003400

0.42540

0.00200

0.00400

125.39

19.0

0.003290

0.42664

129.67

24.0

0.003480

0.41921

118.65

64.5

0.014190

0.42339

0.00280

0.00524

29.84 
Srmole Si432

\begin{tabular}{|c|c|c|c|c|c|}
\hline$\frac{\text { Treatment Time }}{\text { (hrs) }}$ & $N 2-600^{\circ} \mathrm{C}$ & $\begin{array}{l}\text { ermeabil } \\
\text { He }-600^{\circ} \mathrm{C} \\
(\mathrm{M} 3 / \mathrm{M} 2\end{array}$ & $\frac{\mathrm{N} 2-22^{\circ} \mathrm{C}}{\mathrm{hr} / \mathrm{atm} \mathrm{m}}$ & $\mathrm{He}-22^{\circ} \mathrm{C}$ & $\begin{array}{l}\text { Selectivity } \\
\frac{\mathrm{He} / \mathrm{N2}}{600^{\circ} \mathrm{C}}\end{array}$ \\
\hline $0.0(\mathrm{~T})$ & 0.002070 & 0.33393 & 0.00585 & 0.01769 & 160.94 \\
\hline $15.0(\mathrm{~T})$ & 0.002470 & 0.33299 & & & 134.89 \\
\hline $22.0(\mathrm{~T})$ & 0.002470 & $0 . j 2724$ & & & 132.56 \\
\hline $42.0(\mathrm{~T})$ & 0.008003 & 0.32114 & & & 40.13 \\
\hline $46.0(\mathrm{~T})$ & 0.008590 & 0.31344 & 0.00544 & 0.01351 & 36.49 \\
\hline $47.0(\mathrm{R} . \mathrm{H})$ & 0.005500 & 0.28619 & 0.00950 & 0.01825 & 52.01 \\
\hline 70.0 (H) & 0.005340 & 0.23979 & & & 44.88 \\
\hline $86.5(\mathrm{H})$ & 0.005600 & 0.24378 & & & 43.56 \\
\hline $94.0(\mathrm{H})$ & 0.005600 & 0.24045 & & & 42.16 \\
\hline $112.0(\mathrm{H})$ & 0.032548 & 0.28841 & & & 8.86 \\
\hline $112.0(R)$ & 0.006500 & 0.24996 & 0.01684 & 0.03706 & 38.48 \\
\hline $112.0(E)$ & - & - & 0.00081 & 0.03100 & - \\
\hline
\end{tabular}

T: Thermal Treatment

H: Hydrothermal Treatment

R: Membrane was repacked

E: The end seal of the membrane was fixed up with eporyl and then the membrane was repacked for determining the permeability at a low temperature 


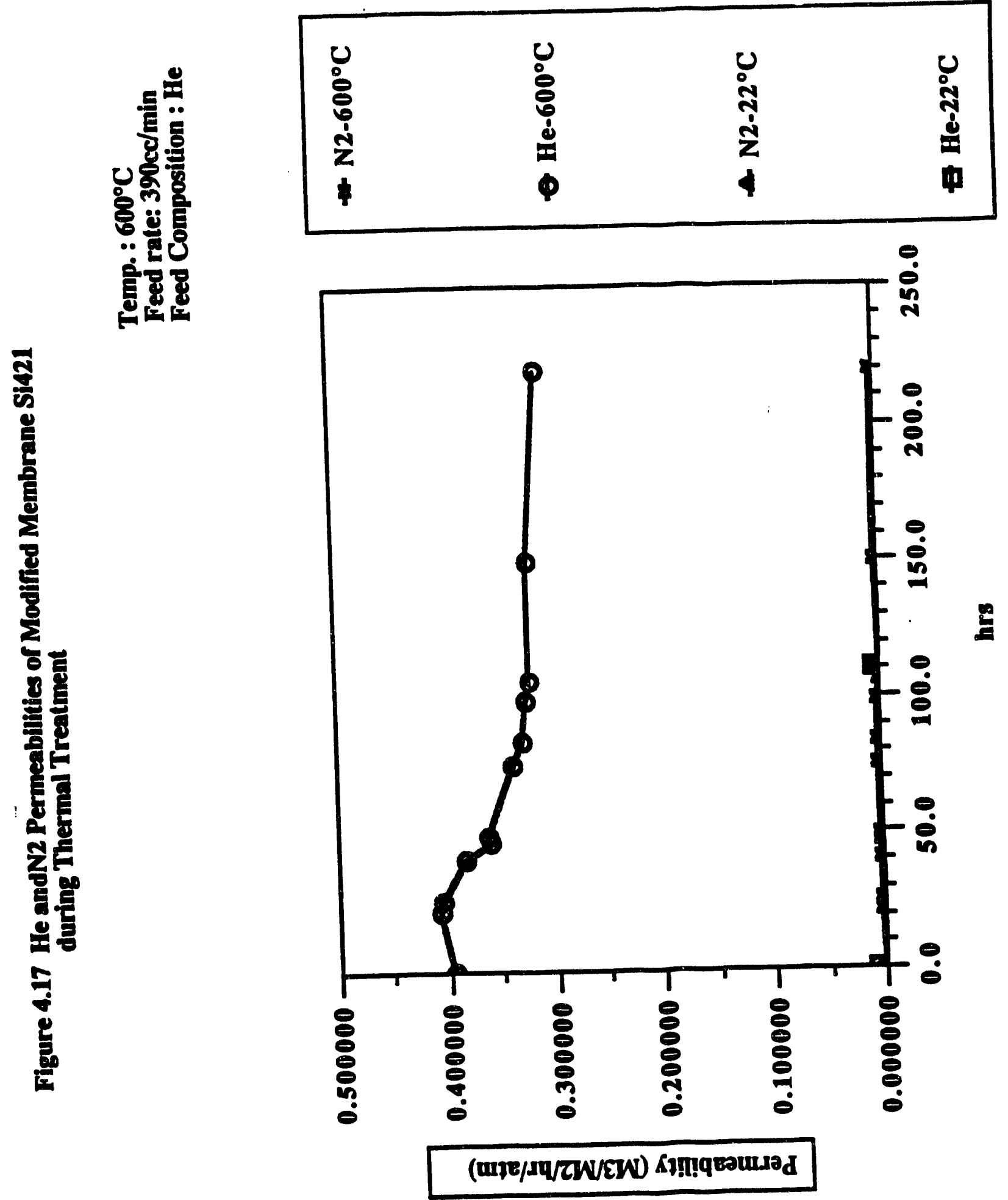


The increase of the $\mathrm{N}_{2}$ permeability of the modified membranes Si418, Si428 and Si432 after 48 hours was contradictory with the result from the modified membrane Si421. To elucidate the discrepancy, a reference run was performed, using a stainless steel tube instead of a membrane. The treatment conditions of the stainless steel tube was the same as the modified membranes. The He and $\mathrm{N}_{2}$ permeate fluxes of SS\#1 after the first 25 hours were very small and essentially negligible (Table 4.13). However, both $\mathrm{He}$ and $\mathrm{N}_{2}$ permeabilities increased drastically after 25 hours, possibly due to the leakage of the degraded packing graphite. This small leakage does not affect the separation selectivity of the large-pore-size membranes; however, this small leakage contributes to $30-100 \%$ of total $\mathrm{N}_{2}$ permeate flow and only $1 \%$ total He permeate flow of the hydrogen-selective membranes. Therefore, the decrease in $\mathrm{He} / \mathrm{N}_{2}$ selectivity after 48 hours of the thermal treatment for Si418, Si428 and Si432 was likely due to the leakage through the graphite module.

In summary, silica modified membranes went through a densification at the first 48 hours of thermal treatment at $600^{\circ} \mathrm{C}$ which resulted in the decrease of He permeability. Additional thermal treatment at the same condition did not change the permeability of the silica modified membranes. We conclude that silica modified membranes are thermally stable after the initial densification.

\subsection{Hydrothermal Stability of Silica Modified Membranes}

In the previous section, we demonstrate that both silica modified porous and dense membranes are thermally stable. The increase of the nitrogen permeability in certain instances during the thermal treatment is due to the degradation of the graphite or membrane packaging. This section focuses on the hydrothermal stability of the silica modified membranes. The $\mathrm{N}_{2}$ permeabilities of the silica modified porous membranes ( $\mathrm{Si005*}$ ), increased slightly after being heated in $90 \%$ of steam at $600^{\circ} \mathrm{C}$ for 24 hours (Table 4.8). Comparing this result with that of existing alumina membranes, it indicated that the silica modified membranes have a higher hydrothermal stability than $\gamma$-alumina membranes. The pore size analysis of $\mathrm{Si005**}$ indicated that this silica modified membrane had a pore size around $28 \AA$ after the hydrothermal treatment. The SEM cross section images of silica modified membranes Si005 also indicated that, no pinhole and pore growth occurred (Figure 4.5). Silica modified membranes Si012 with pore size less than $15 \AA$ was also subjected to a hydrothermal treatment at $600^{\circ} \mathrm{C}$ with $90 \%$ steam for 250 hours. Table 4.8 indicated that the $\mathrm{N}_{2}$ permeabilities of this modified membrane increased from 1.39 to 2.26 $\mathrm{M}^{3} / \mathrm{M}^{2} / \mathrm{hr} / \mathrm{atm}$ during the cumulative treatment. This might be due to the leakage of module, graphite or glass end seal of the membrane. We further investigated this leakage with silica modified dense membranes.

We continued studying the hydrothermal stability of silica modified dense 
Table 4.18 The He and N2 Permenbilities of Stainless Steel

Tube as Control for Thermalhydrothermal Treatment

$5.5 * 1(T)$ $\frac{\text { Trentment Time }}{(\mathrm{hrs})} \frac{\mathrm{N2}-600^{\circ} \mathrm{C}}{\mathrm{Be}-600^{\circ} \mathrm{C}} \frac{\mathrm{N2}-22^{\circ} \mathrm{C}}{(\mathrm{M} 3 / \mathrm{ML} / \mathrm{hr} / \mathrm{atm})} \mathrm{Be-22^{ \circ } \mathrm { C }} \frac{\mathrm{Be} / \mathrm{NL}}{600^{\circ} \mathrm{C}}$

0.0

17.5

25.0

41.5

49.0

$0.000110 \quad 0.00038$

$0.00022 \quad 0.00040$

3.40

0.000110

0.00040

3.84

0.000650

0.00100

$0.002820 \quad 0.00395$

0.000790 .00136

1.54

1.40

$5.5 \cdot 2(8)$

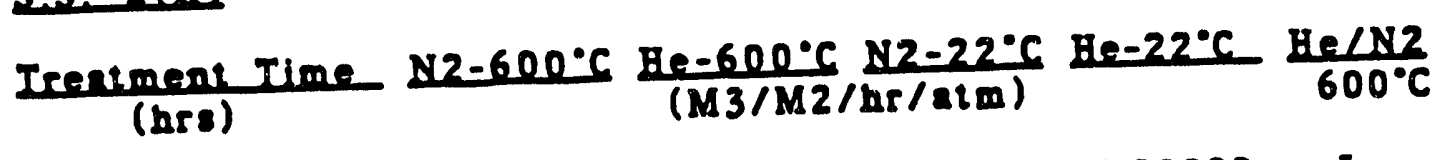

\begin{tabular}{|c|c|c|c|c|c|}
\hline 0.0 & & 0.00000 & 0.00000 & 0.00000 & 0.00000 \\
\hline 17.0 & & 0.00000 & 0.00000 & 0.00000 & 0.00000 \\
\hline 23.0 & & 0.00000 & 0.00000 & 0.00000 & 0.00000 \\
\hline 40.0 & & 0.00000 & 0.00000 & 0.00000 & 0.00000 \\
\hline 48.5 & & 0.00000 & 0.00000 & 0.00000 & 0.00000 \\
\hline 65.0 & 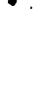 & 0.00000 & 0.00000 & 0.00000 & 0.00000 \\
\hline 70.5 & $\cdot$ & 0.00000 & 0.00000 & 0.00000 & 0.00000 \\
\hline 88.5 & & 0.00000 & 0.00000 & 0.00000 & 0.00000 \\
\hline
\end{tabular}


membranes. The modified membranes Si432 and Si438 were subjected to a thermal treatment at $600^{\circ} \mathrm{C}$ first, then a hydrothermal treatment at $600^{\circ} \mathrm{C}$ with $31 \% \mathrm{H}_{2} \mathrm{O}$ in $\mathrm{He}$. The He permeability of the modified membrane $\mathrm{Si} 432$ decreased the first 46 hours of the thermal treatment, however the nitrogen permeability increased (Table 4.12). As we discussed in the previous section, modified membranes went through a densification the first 24-48 hours of thermal treatment, therefore we observed the decrease of $\mathrm{He}$ permeability. The increase of nitrogen permeability could be due to the degradation of graphite or glass end seal of the membranes. The decrease of nitrogen permeability and the increase of $\mathrm{He} / \mathrm{N}_{2}$ separation selectivity after repacking at the 47 th hour indicated that the degradation of graphite attributed to the observed phenomenon. The nitrogen and helium permeabilities remained constant after the repacking and an additional 48 hours of hydrothermal treatment. Both $\mathrm{N}_{2}$ and He permeability increased and separation selectivity decreased to 8.86 after 112 hours of total treatment (67 hours hydrothermal treatment). The membrane resumed its permeability and separation selectivity after being repacked (Table 4.12). This indicated that loss of separation selectivity is due to the degradation of graphite. It also indicated that membranes were hydrothermally stable up to 67 hours. The end seal of the modified membrane, Si432, was fixed with epoxyl and the membrane was then repacked. The room temperature nitrogen permeability decrersed to $0.00081 \mathrm{M}^{3} / \mathrm{M}^{2} / \mathrm{hr} / \mathrm{atm}$ which is lower than the original $\mathrm{N}_{2}$ permeability. This showed that there were possibly some microcracking of the end seal of the membrane before the thermal and hydrothermal treatment. This explains why this membrane did not have high separation selectivity as other hydrogen selective modified membranes.

So far, we observed that the nitrogen permeability of the hydrogen selective membranes at $600^{\circ} \mathrm{C}$ was around $0.0005-0.00008 \mathrm{M}^{3} / \mathrm{M}^{2} / \mathrm{hr} / \mathrm{atm}$ if there was no microcracking of the end seal. The observed nitrogen mostly was due to leakage caused by graphite degradation, as evidenced in the thermal treatment of the stainless tube shown in Table 4.13. If the leakage can be eliminated, the $\mathrm{He} / \mathrm{N}_{2}$ separation selectivity can reach infinity. This is proved by thermal and hydrothermal treatment of the modified membrane Si438.

A second stainless steel tube was used in a hydrothermal test with a new membrane module. No $\mathrm{N}_{2}$ and He permeate flux was detectable at 50 psi transmembrane pressure and $600^{\circ} \mathrm{C}$ for 88 hours (Table 4.13). A similar experiment was conducted on the modified membranes Si438. The urodified membrane Si 438 was subjected to 52 hours of thermal treatment and an additional 264 hours of hydrothermal treatment at $600^{\circ} \mathrm{C}$ as illustrated in Table 4.14. The membrane went through a densification as did other hydrogen selective membranes during the first 48 hours of thermal treatment. The helium permeability then remained constant after initial densification indicated that the modified membrane was thermally and hydrothermally stable (Figure 4.18). One unexpected result was that there was no detectable permeate nitrogen flux while the helium permeate 
Table 4.14 The He and N2 Permenbilites of Bilica Modified Dense Membrnes 8 Biss During Thermal/hydrothermal Treatment

Semple sic 38

Irentment Time (hrs)

$0.0(T)$

$41.0(\mathrm{~T})$

47.0 (T)

52.0 (T)

66.0 (B)

72.0 (B)

77.0 (B)

90.0 (B)

97.0 (B)

114.0 (B)

120.5 (B)

138.0 (B)

144.5 (B)

166.0 (B)

187.5 (B)

211.0 (B)

217.5 (B)

234.5 (T)

240.5 (B)

258.5 (B)

$264.5(\mathrm{~B})$

282.0 (B)

289.0 (B)

306.0 (B)

313.0 (B)
0.00066

0.00071

0.00076

0.00076

0.00076

0.00087

0.00080

0.00083

0.00000

0.00000

0.00000

0.00000 P

0.00000 P

0.00000

0.00000

0.00000 e

0.00000

0.00000 ?

0.00000

0.00000 e

0.00000 e

0.00000

0.00000 e

0.00000 e

0.00000 e
Permeabillty

$\frac{\mathrm{He}-600^{\circ} \mathrm{C}}{(\mathrm{M} 3 / \mathrm{ML} / \mathrm{hr} / \mathrm{atm})} \mathrm{He-22^{ \circ } \mathrm { C }} \frac{\mathrm{He} / \mathrm{NL}}{600^{\circ} \mathrm{C}}$

0.25089

0.20363

0.19555

0.19195

0.16029

0.16822

0.16639

0.16205

0.16529

0.18245

0.17142

0.18245

0.17257

0.17035

0.17150

0.16981

0.16830

0.16877

0.16765

0.15549

0.16252

0.15427

0.16292

0.15604

0.15413 $\begin{array}{lll}0.00115 & 0.00791 \quad 381.39\end{array}$

288.03

267.14

252.95

211.69

192.69

207.75

194.63

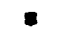

-

-

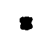

a

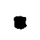

$\boldsymbol{*}$

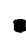

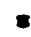

:

:

:

-

*

$0.000000 \quad 0.00592$

\section{T: Thermal Treatment}

B: Hydrothermal Treatment

- No ritrogen permeate llow was detectable at 50 psi transmembrane pressure for 1 hrs.

: The separation selectivity is inifinity 


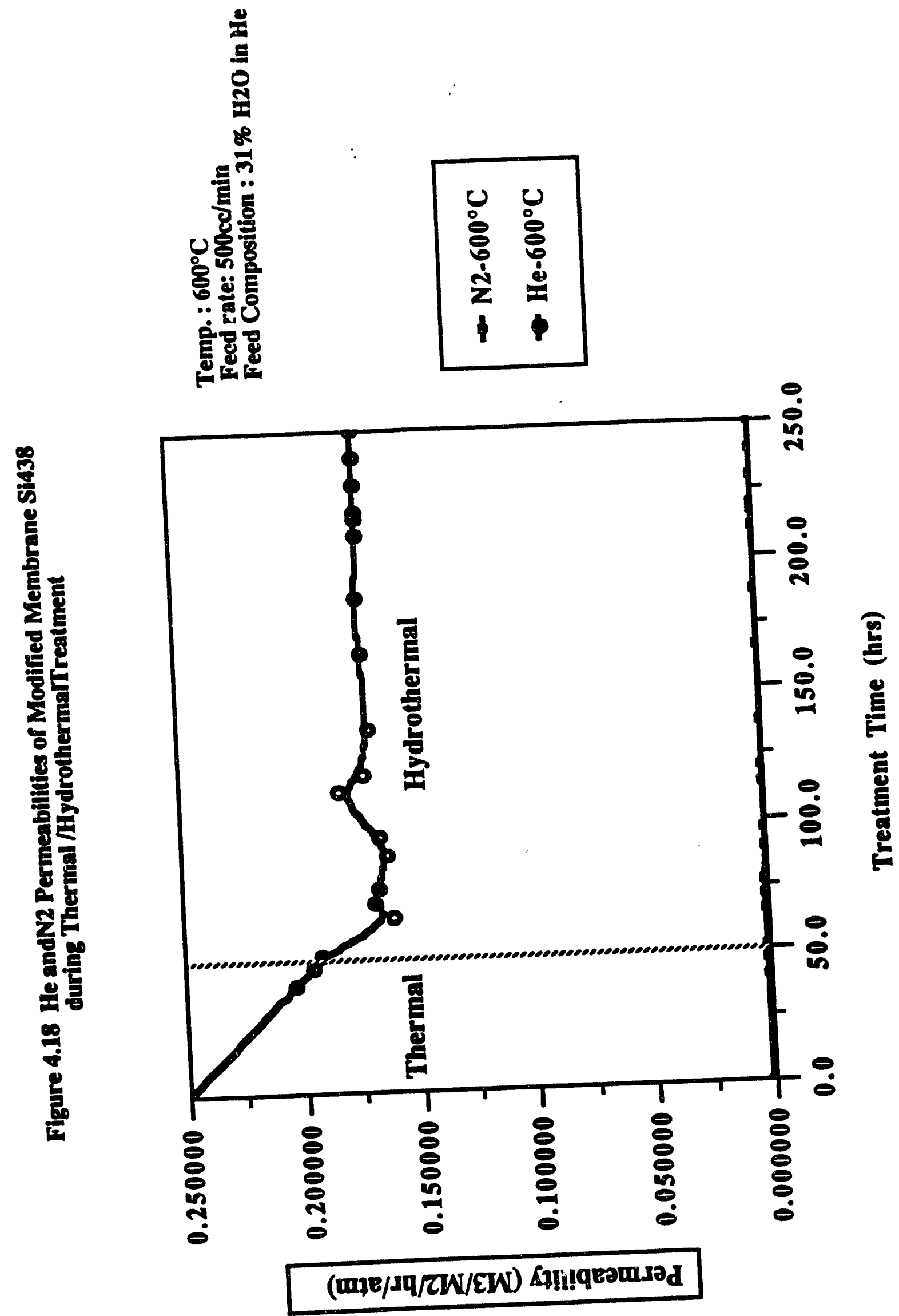


flux remained constant after 97 hours of treatment. The $\mathrm{He} / \mathrm{N}_{2}$ separation selectivity remained infinite through an additional 200 hours of hydrothermal treatment. We determined that about $.000066 \mathrm{M}^{3} / \mathrm{M}^{2} / \mathrm{hr} / \mathrm{atm}$ of the nitrogen permeability was due to the leakage of graphite. However, we did not understand what sealed the leakage after 97 hours of hydrothermal treatment.

\subsection{Thermal/Hydrothermal Stabilities of $\mathrm{La}_{2} \mathrm{O}_{3}$ Modified Membranes}

Another method to improve the thermal and hydrothermal stabilities of existing $\gamma$-alumina membranes is to impregnate other metal oxides which can retard the phase change of $\gamma$-alumina. According to Schaper, lanthanum oxide decreases the rate of sintering of $\gamma$-alumina by the formation of lanthanum aluminate surface layer (Schaper, 1983). The addition of lanthanum oxide also can postpone the phase transformation $100^{\circ} \mathrm{C}$ by decreasing the rate of nucleation.

The $\mathrm{La}_{2} \mathrm{O}_{3}$ was introduced by impregnating the existing $\gamma$-alumina membranes with an aqueous solution of $5 \%$ or $10 \%$ of $\mathrm{La}\left(\mathrm{NO}_{3}\right)_{3}$. The $\mathrm{La}_{2} \mathrm{O}_{3}$ modified membranes $\mathrm{La002}, \mathrm{La} 003$ and $\mathrm{La004}$, were calcined in the air at $600^{\circ} \mathrm{C}$ for 24 hours. In our laboratory, we observed that the pore size of alumina membranes increased $3 \AA$ after calcining in air at $650^{\circ} \mathrm{C}$ for 5 hours, while the pore size of lanthanum oxide modified membrane LA003 remained the same after the same treatment (Table 4.8).

However, the improvement of thermal stability induced by lathanium oxide only occurred at $650^{\circ} \mathrm{C}$. Both $\gamma$-alumina membranes and lanthanum oxide modified membranes showed a similar pore growth and permeability increase at 700 and $800^{\circ} \mathrm{C}$ (Table 4.8). The pore size of existing alumina membranes increased from $45 \AA$ to $54 \AA$ and $58 \AA$ after being calcined at $700^{\circ} \mathrm{C}$ and $800^{\circ} \mathrm{C}$, respectively. The permeability rose from 295 to 376 and $471 \mathrm{M}^{3} / \mathrm{M}^{2} / \mathrm{hr} / \mathrm{atm}$, respectively.

Lanthanum oxide modified membranes LA003 showed a pore size increase from $50 \AA$ to $56 \AA$ and $58 \AA$ after the same treatment. The permeability of this membrane increased from 107 to 142 and $204 \mathrm{M}^{3} / \mathrm{M}^{2} / \mathrm{hr} / \mathrm{atm}$, respectively. If the concentration of impregnation solution increased from $5 \%$ to $10 \%$, we observed the pore size of $\mathrm{La}_{2} \mathrm{O}_{3}$ modified membranes $\mathrm{La004}$ increased from $45 \AA$ to $56 \AA$ after the same treatment up to $800^{\circ} \mathrm{C}$.

According to Schaper, the influence of lanthanum oxides is substantial especially at high temperatures such as $1000-1100^{\circ} \mathrm{C}$. Further thermal treatments of lanthanum oxide modified membranes at 1000 was conducted to verify the influence of lanthanum oxides on thermal stability of existing alumina membranes at high temperature. Both existing $40 \AA$ alumina membranes and lanthanum oxides modified membranes were further treated in the air at high temperatures up to $1000^{\circ} \mathrm{C}$ for $5 \mathrm{hrs}$. The pore size 
analysis indicated that both have a similar pore growth at this temperature (Table 4.8).

In summary, the lathanium oxide modified membranes show some thermal improvement up to $650^{\circ} \mathrm{C}$. However the thermal stability of these modified membranes at $700-1000^{\circ} \mathrm{C}$ are disappointing. The silica modified membranes demonstrated a better improvement in thermal/hydrothermal stabilities than $\mathrm{La}_{2} \mathrm{O}_{3}$ modified membranes.

\subsection{Zirconia Modified Membranes}

The deposition process of $\mathrm{ZrO}_{2}$ is similar to silica deposition except $\mathrm{Zr}\left(\mathrm{OC}_{3} \mathrm{H}_{7}\right)_{4}$ and $\mathrm{Zr}\left(\mathrm{O}_{2} \mathrm{C}_{5} \mathrm{H}_{7}\right)_{4}$ were used as a chemical source. The CVD apparatus for this process was similar to the one used in $\mathrm{SiO}_{2}$ deposition (Figure 4.1 ). $\mathrm{Zr}\left(\mathrm{OC}_{3} \mathrm{H}_{7}\right)_{4}$ or $\mathrm{Zr}\left(\mathrm{O}_{2} \mathrm{C}_{5} \mathrm{H}_{7}\right)_{4}$ vapor was generated by passing $\mathrm{N}_{2}$ through the vaporizer filled with $\mathrm{Zr}\left(\mathrm{OC}_{3} \mathrm{H}_{7}\right)_{4}$ or $\mathrm{Zr}\left(\mathrm{O}_{2} \mathrm{C}_{5} \mathrm{H}_{7}\right)_{4}$. The feed gas $\mathrm{N}_{2}$ is controlled by a mass flow meter. Another stream of gas with $10-20 \%$ $\mathrm{O}_{2}$ in $\mathrm{He}$ was fed directly to the reactor and was also controlled by mass meter. The vaporize temperature, gas $1 /$ gas 2 ratio, feed, reject and permeate flow rate and deposition temperature, time and pressure have effects on the thickness and pore size of modified membranes. However, detailed effects of the experimental parameters listed above remain to be studied. $\mathrm{Zr}\left(\mathrm{OC}_{3} \mathrm{H}_{7}\right)_{4}$ and $\mathrm{Zr}\left(\mathrm{O}_{2} \mathrm{C}_{5} \mathrm{H}_{7}\right)_{4}$ react with $\mathrm{O}_{2}$ as follows and form $\mathrm{ZrO}_{2}$.

$\mathrm{Zr}\left(\mathrm{OC}_{3} \mathrm{H}_{7}\right)_{4}+\mathrm{O}_{2} \rightarrow \mathrm{ZrO}_{2}+\left(\mathrm{C}_{\mathrm{x}} \mathrm{H}_{2 \mathrm{x}}+\mathrm{CO}_{2}+\mathrm{H}_{2} \mathrm{Oetc}\right)$

$\mathrm{Zr}(\mathrm{O} 2 \mathrm{C} 5 \mathrm{H} 7)_{4}+\mathrm{O}_{2} \rightarrow \mathrm{ZrO}_{2}+\left(\mathrm{C}_{\mathrm{x}} \mathrm{H}_{2 \mathrm{x}}+\mathrm{CO}_{2}+\mathrm{H}_{2} \mathrm{Oetc}\right)$

$\mathrm{C}_{\mathrm{x}} \mathrm{H}_{2 \mathrm{x}}$ can further react with $\mathrm{O}_{2}$ to form alcohols, $\mathrm{CO}_{2}$ and $\mathrm{H}_{2} \mathrm{O}$.

Deposition was carried out with $\mathrm{Zr}\left(\mathrm{OC}_{3} \mathrm{H}_{7}\right)_{4}$ as a chemical source initially. Small pore size ( $26 \AA \dot{A})$ membranes ( $\mathrm{Zr008}$ and $\mathrm{Zr} 012$ ) were obtained through chemical vapor deposition of zirconia on existing membranes (Figures 4.19 - 4.20). However, no zirconia content can be detected by EDAX.

Since it is difficult to maintain a constant concentration of zirconia by using $\mathrm{Zr}\left(\mathrm{OC}_{3} \mathrm{H}_{7}\right)_{4}$ in propanol solution as a chemical source, a new source of zirconia was chosen. Zirconium tetraacetylactonate $\left(\mathrm{Zr}\left(\mathrm{O}_{2} \mathrm{C}_{5} \mathrm{H}_{7}\right)_{4}\right)$ was in solid form and stable up to $300^{\circ} \mathrm{C}$. The concentration of this compound in nitrogen steam can be controlled by varying the temperature of the vaporizer and feed rate of carrier gas $\left(\mathrm{N}_{2}\right)$. Balong was able to obtain a uniform zirconia film with this zirconia source at a deposition rate of $7.2 \mathrm{x}$ 10-3 mmole/min (Balong, 1977).

We experienced some difficulty in chemical deposition of zirconium tetraactylactonate. However, a zirconia modified membrane with a pore 
Figure 4.19 Pore size distribution of zirconia modified membranes Zr008

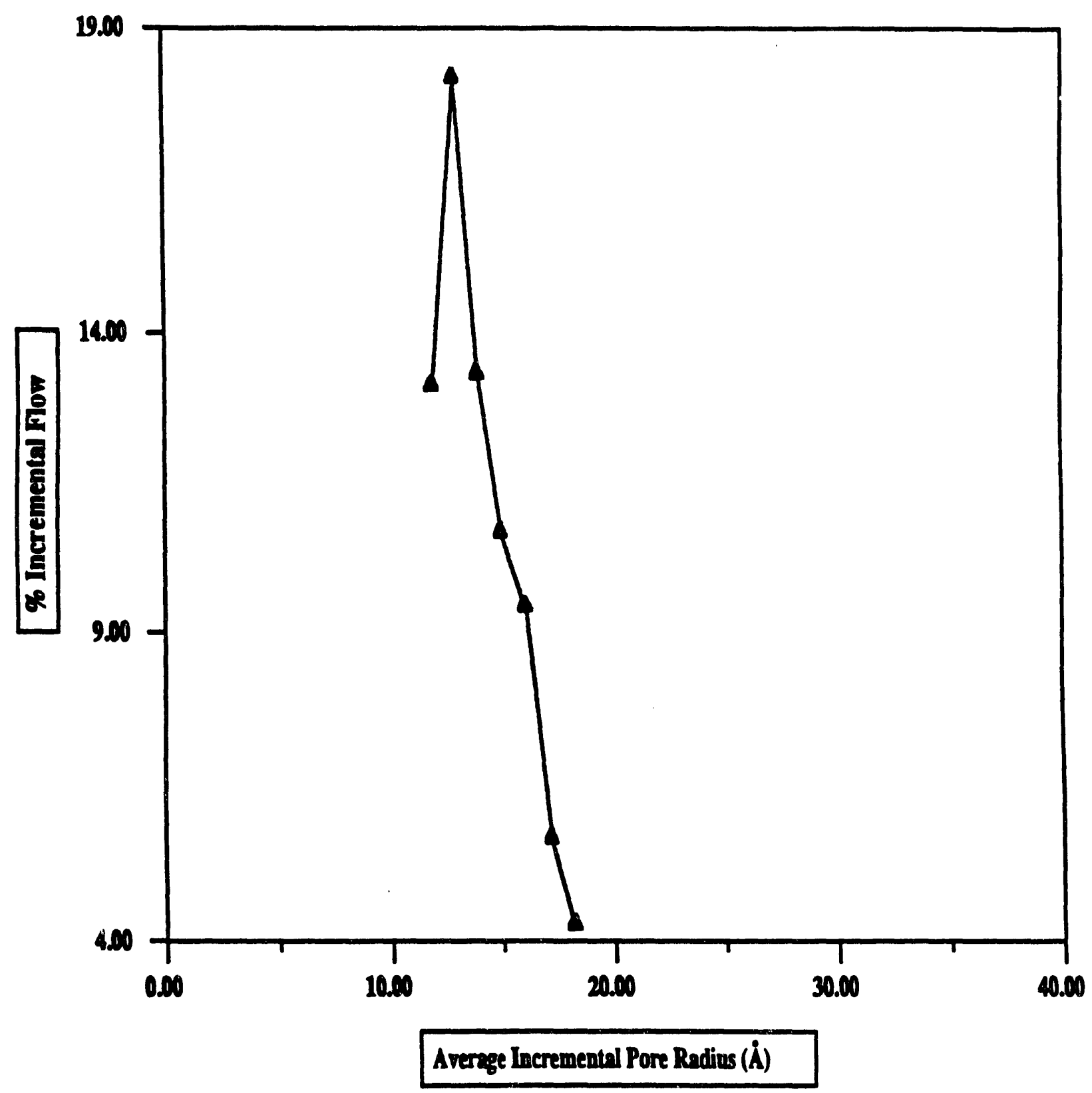


Figure 4.20 Pore size distribution of zirconia modified membranes Zr012

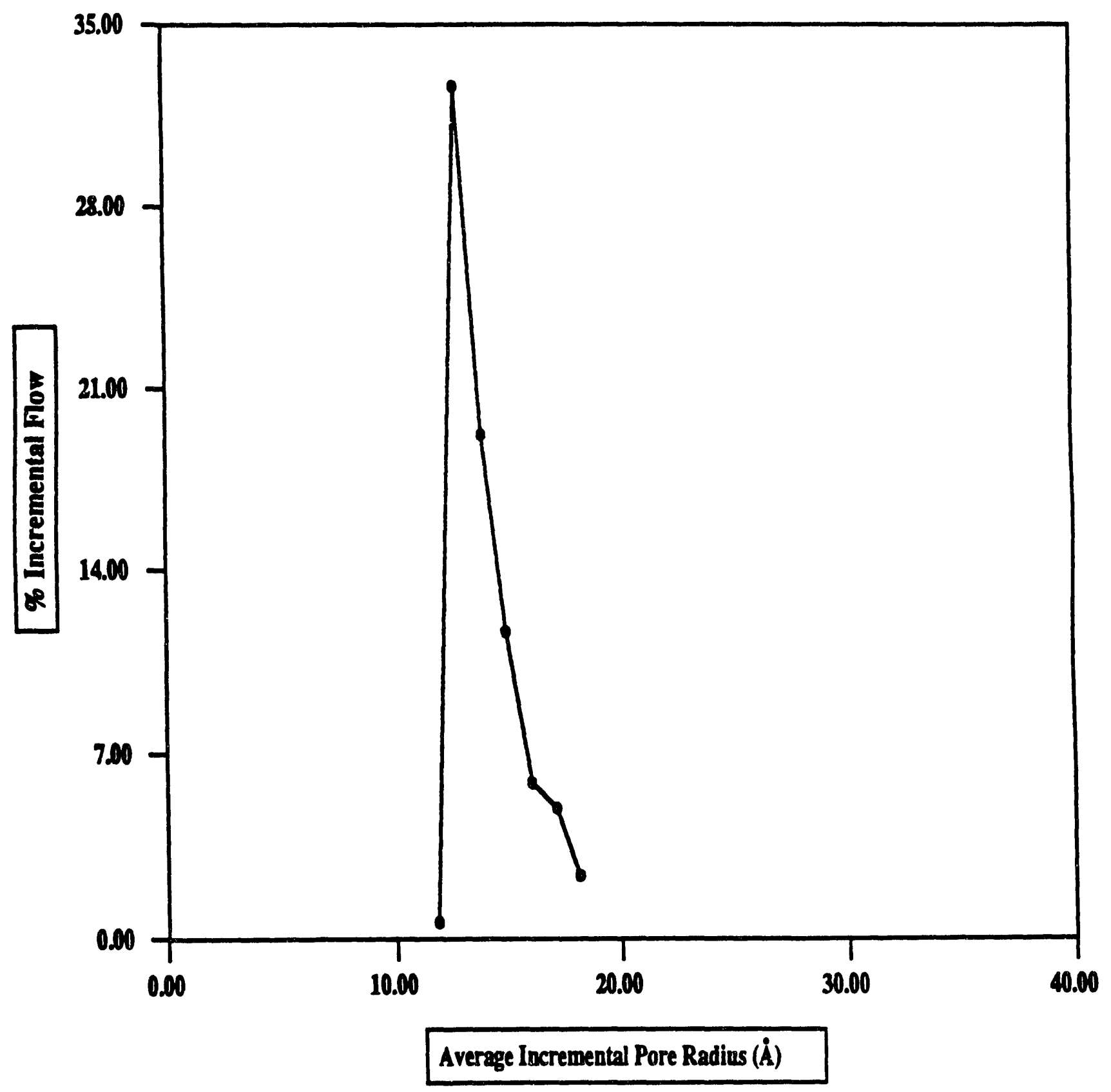


size around $34 \AA$ was obtained after several attempts. The deposition conditions are listed in the Table 4.15. A zirconia modified membrane, $\mathrm{Zr020}$, with a pore size around $24 \hat{A}$ was obtained under a similar deposition condition, except that the zirconia feeding rate was increased to $50 \mathrm{cc} / \mathrm{min}$. These membranes also showed some improvement in liquid separation. However, no zirconia content can be detected by EDAX with both zirconia modified membranes $\mathrm{ZrO} 19$ or $\mathrm{Zr020}$. The reason of this inconsistent result is unknown at the present time.

Zirconia-modified membranes $\mathrm{Zr} 019$ and $\mathrm{Zr020}$ have a similar nitrogen permeability (45 and $49 \mathrm{M}^{3} / \mathrm{M}^{2} / \mathrm{hr} / \mathrm{atm}$, respectively) but have $10 \AA$ difference in pore size according to pore size analysis. This indicated that the deposition depth of these membranes might be different. For a given pore size, high permeability is desirable. Therefore, with the combination of pore size analysis and gas permeability one can determine a better deposition procedure and conditions.

Hydrothermal stability are also studied on zirconia modified membranes The nitrogen permeability of zirconia modified membranes $\mathrm{Zr} 012$ increased from 35 to $105 \mathrm{M}^{3} / \mathrm{M}^{2} / \mathrm{hr} / \mathrm{atm}$ after $14 \mathrm{hrs}$ hydrothermal treatment at $600^{\circ} \mathrm{C}$ with $90 \%$ of stream. The pore size of this membrane increased from $26 \AA$ to $45 \AA$ (Table 4.8). At present time, it is still a question whether the low hydrothermal stability of this membrane is due to the nature of zirconia modified membranes or the failure of zirconia deposition. 
Table 4.15 The Deposition Condition for $\mathrm{ZrO}_{2}$ on Eristing Alumina Membranes

Feed gas 1

Feed gas 2

Temperature of Vaporizer

Temperature of Reactor

Reject Flux
$\mathrm{N}_{2}, 25-50 \mathrm{cc} / \mathrm{min}$

$20 \% \mathrm{O}_{2}$ in $\mathrm{He}, 400 \mathrm{cc} / \mathrm{min}$

$150-200^{\circ} \mathrm{C}$

$450-600^{\circ} \mathrm{C}$

$420 \mathrm{cc} / \mathrm{min}$ 


\section{Membrane Modification by in-situ Zoolite Crystallization}

In the past thirty years, the properties and applications of zeolites have been explored in many scientific disciplines and chemical engineering process technologies. The main commercial applications of zeolites are based on their adsorption, separation, and catalysis characterization (Rojey, 1989; Suzuki, 1989; Goldman, 1989; Kulprathiparija, 1988; Stenzel, 1985). Zeolites, in general, have respectively high thermal and hydrothermal stability $\left(550^{\circ} \mathrm{C}-800^{\circ} \mathrm{C}\right)$. Their pore size ranges from 3 to $12 \AA$, which is ideal for using in the separation of small molecules. If zeolites can be formed into membranes, they are expected to have functions both in the molecular sieve separation and catalysis. These zeolitic membranes would be able to serve as separators and reactors at the same time. Therefore, it would have a. great economic advantage over direct reaction pathway not only by combining two processes into one, but also by increasing reaction yield through the removal of the desired final or intermediate products.

Zeolitic membranes are superior than other inorganic membranes because of their diverse applications in catalysis and separation. Several polymer-zeolitic membranes demonstrate selective separation in water/ethanol and hydrogen/methane mixtures. Susuki reported the use of polymer-zeolitic membranes in catalysis (Suzuki, 1985). However, the binder, polymer, used in these membranes have low biological chemical and thermal stabilities. Inorganic-zeolitic membranes also exhibit excellent applications in separation and catalysis but have low economic feasibility because of low permeabilities (Suzuki, 1985; Matsushita, 1985; Ishikoga, 1985; Abe, 1988; Sakurada, 1989; Suzuki, 1987). Despite all the efforts in the synthesis of zeolitic membranes, there is no solid evidence of molecular sieving efficiency of those membranes. The lack of characterization technique for the membranes with small pores is the major task in the research of zeolitic membranes. The preparation and characterization of a new type of silica-ZSM-5 membrane was initiated and studied in Alcoa's Laboratory. Detailed summary of this investigation is disclosed in following sections.

\subsection{Pretreatment}

The existing polymer-zeolitic membranes as mentioned early have the similar disadvantage as polymeric membranes. Other zeolitic membranes supported on ceramics are still under development. The low permeabilities, low thermal stabilities and high brittleness are still the problems for practical applications.

Our development strategy was to overcome the deficiency of zeolitic membranes listed above. Prior to the preparation of silica-ZSM-5 membranes, several modification methods were considered. Modifications of the outside surface of the alumina supports (e.g. polymer coating) can inhibit the formation of zeolite crystals on the outside surface of the support.

Silica modification of inner surface of alumina supports can ensure that the zeolite crystal will form on the entrance or in the pores of the inside 
surface of porous support. Another pretreatment procedure is treating the inner surface of supports with zeolites/sol-gel solution.

Various concentration (2-7\%) of ZSM-5 crystals were prepared in the sol-gel solution (Table 5.1). Several supports with different pore size were dipped with the solution described. The membranes then were dried at room temperature for $24 \mathrm{hrs}$ and calcined to $450^{\circ} \mathrm{C}$. The membranes then were characterized by their nitrogen and helium permeabilities (Table $5.2-5.4$ ). Compared with their support $(0.2 \mu \mathrm{m})$, zeolitic membranes ZS129, ZS132 and ZS135 have improved in $\mathrm{He} / \mathrm{N}_{2}$ separation selectivity. This improvement indicated that the pinholes of these membranes after pretreatment were smaller than the pore size $(0.2 \mu \mathrm{m})$ of the supports. However, the $\mathrm{He} / \mathrm{N}_{2}$ separation selectivity of pretreated zeolitic membranes ZS133, ZS134, ZS138, ZS139 and ZS148 remained similar to their support $(100 \AA$ and $500 \AA)$. This indicated that the pinhole from the pretreatment is larger than 500 or $100 \AA$. Therefore, the separation selectivity is based on support material. The SEM of ZS133 (Gel\#3 on 100A) and ZS136 (Gel\#3 on $0.2 \mathrm{~mm}$ ) confirmed this speculation (Figure 5.1 -5.4). Although a few pinholes were observed on the inside surface of the membranes, a uniform layer was observed (Figure 5.5). It is unlikely to obtain a pinhole free membrane through this method. However, it is possible to narrow down the pinhole to $40 \mathrm{~A}$ by altering the zeolite/sol-gel composition. The advantage of this method is that the porosity of these membranes should be higher than those from the direct synthesis.

Once a zeolitic membrane with a small pinhole around $40 \AA$ can be achieved through this pretreatment, these pretreated membranes can be used as a starting material for direct synthesis of zeolitic membranes. The pretreatment layer can serve as a seed where the zeolite will grow in place (inside surface of starting material). The other possibility is using the chemical vapor deposition to patch up these $\sim 40 \AA$ pinholes.

\subsection{Synthesis Procedures}

A typical direct synthesis procedure of a silica-ZSM-5 membrane on a Membralox porous alumina support was as follows: prepare a solution by mixing tetraoxthorylsilica, sodium hydroxide and tetrapropryl ammonium bromide in deionized water; transfer the solution to autoclaves and place a Membralox@ porous alumina tube with a top layer pore size of $40 \AA, 100 \AA$, $500 \AA$ and $2000 \AA$ in this solution; place the autoclaves in the oven at $80-200^{\circ} \mathrm{C}$ under autogenous pressure for 1-6 days; remove the Membralox@ porous alumina tube and wash with deionized water; calcine the silica-ZSM-5-Membralox alumina tube to $300-600^{\circ} \mathrm{C}$.

Several silica-ZSM-5 membranes were synthesized on the alumina support (ZS001-ZS149). The observation of by-products in the reaction suspension from microscopic study indicated the formation of typical crystals of silica-ZSM-5. 
Table 5.1 The Concentration of the Pretreatment Sol-gel of Zeolitic Membranes

$\begin{array}{ccc}\text { Gel } & \begin{array}{c}\text { ZSM-5 } \\ \text { Concentration }\end{array} & \begin{array}{c}\text { Alumina } \\ \text { Concentration }\end{array} \\ 1 & 4.5 \% & 2.2 \% \\ 2 & 6.5 \% & 2.1 \% \\ 3 & 7.3 \% & 2.1 \% \\ 4 & 2.0 \% & 2.1 \%\end{array}$


Table 52 The Nitrogen and Helium Permeabilities of Various Pretreated Zeolitic Membranes on 0.2mm Support

$\begin{array}{lcccc}\text { Samples } & \text { Support } & \begin{array}{c}\mathrm{N}_{2} \text { Permeability } \\ \text { M3/M2/hr/atm }\end{array} & \begin{array}{c}\text { He Permeability } \\ \text { M3/M2/hr/atm }\end{array} & \begin{array}{c}\mathrm{He} / \mathrm{N}_{2} \\ \text { Selectivity }\end{array} \\ \text { Reference } & 0.2 \mu \mathrm{m} & 614.50 & 2196.51 & 1.79 \\ \text { ZS129(Gel\#1) } & 0.2 \mu \mathrm{m} & 298.22 & 598.86 & 2.10 \\ \text { ZS132(Gel\#2) } & 0.2 \mu \mathrm{m} & 462.75 & 870.19 & 1.88 \\ \text { ZS135(Gel\#3) } & 0.2 \mu \mathrm{m} & 379.11 & 741.02 & 1.95\end{array}$

Gel composition is listed on Table $\mathbf{5 . 1}$ 
Table 53 The Nitrogen and Helium Permeabilities of Pretreated Zeolitic Membranes on $500 A$ Support

$\begin{array}{lrccc}\text { Samples } & \text { Support } & \begin{array}{l}\mathrm{N}_{2} \text { Permeability } \\ \text { M3LM2/hr/atm }\end{array} & \begin{array}{l}\text { He Permeability } \\ \text { M3/M2/hr/atm }\end{array} & \begin{array}{c}\mathrm{He} / \mathrm{N}_{2} \\ \text { Selectivity }\end{array} \\ \text { Reference } & 500 \AA & 251.95 & 535.85 & 2.13 \\ \text { ZS134(Gel\#3) } & 500 \AA & 254.5 & 556.95 & 2.19\end{array}$

Gel composition is listed on Table 5.1 
Thble 54 The Nitrogen and Helium Permeabilities of Pretreated Zeolitic Membranes on 100A Support

\begin{tabular}{|c|c|c|c|c|}
\hline Samples & Support & $\begin{array}{l}N_{2} \text { Permeability } \\
\text { M } 3 \Omega \text { 2/hr/atm }\end{array}$ & $\begin{array}{l}\text { He Permeability } \\
\text { M3/M2/hr/atm }\end{array}$ & $\begin{array}{c}\mathrm{He} / \mathrm{N}_{2} \\
\text { Selectivity }\end{array}$ \\
\hline Reference & $100 \AA$ & 242 & - & 2.64(ca)a \\
\hline ZS133(Gel\#3) & $100 A$ & 190.98 & 489.8 & 2.56 \\
\hline ZS138(Gell\#) & $100 \AA$ & 195.39 & 501.76 & 2.57 \\
\hline 2S139(Gel\#3) & $100 A$ & 280.55 & 67164 & 2.40 \\
\hline ZS148(Gel\#4) & $100 A$ & 164.58 & 433.58 & 2.64 \\
\hline
\end{tabular}

Gel composition is listed on Table 5.1.

- The separation selectivity is calculated based on Knudsen diffusion. 


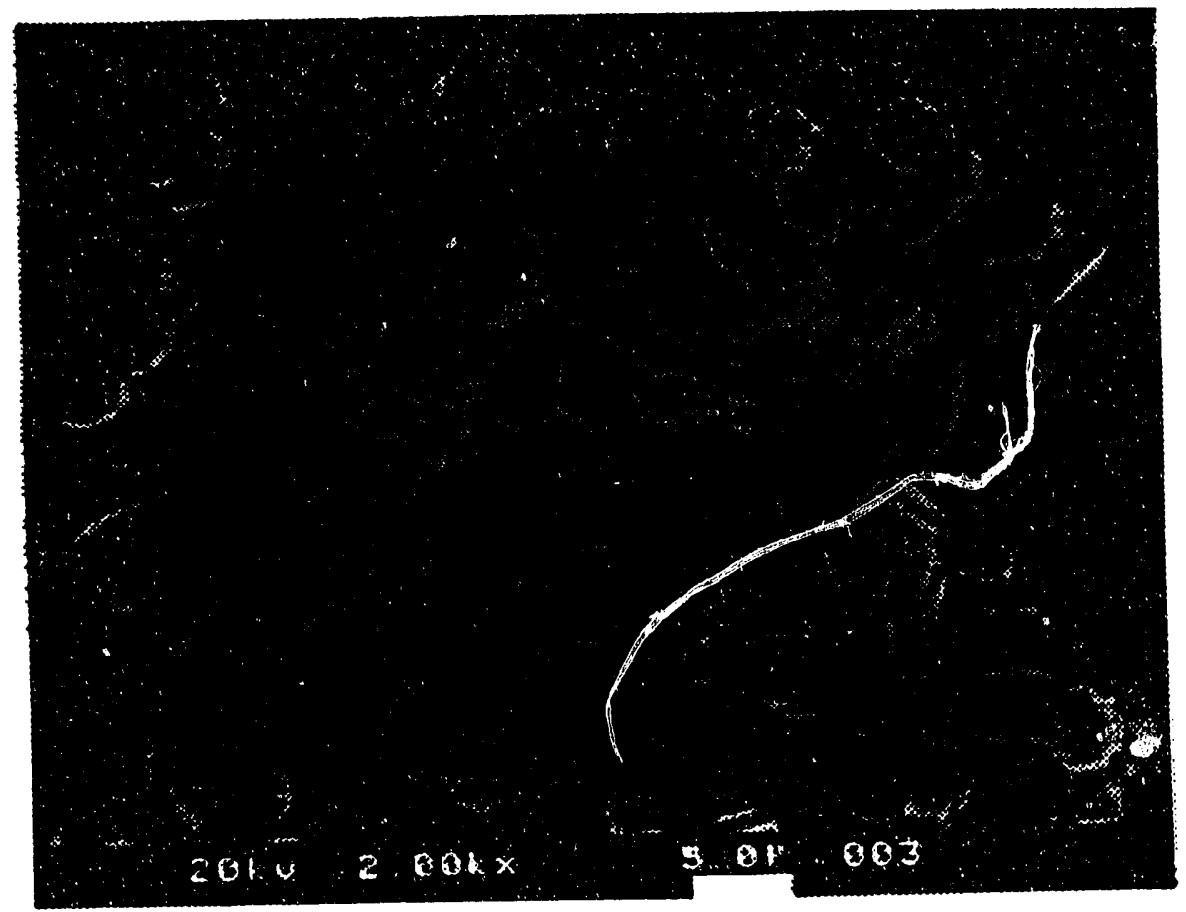

Figare 5.1

SDM of Inner Surface of Zeolitic Modified Membrane ZS 133 


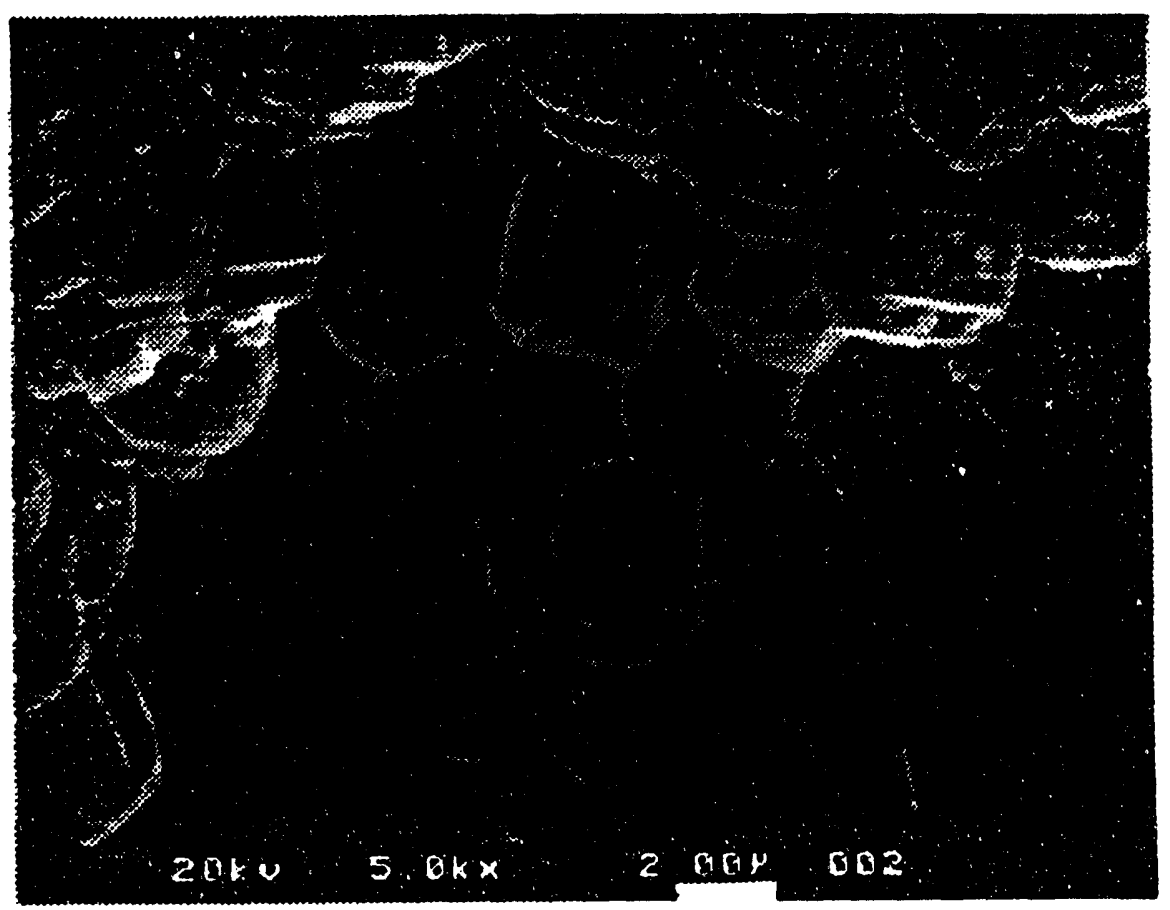

Figure 52

SDM of Inner Surface of Zoolitic Modified Membrane ZS133 


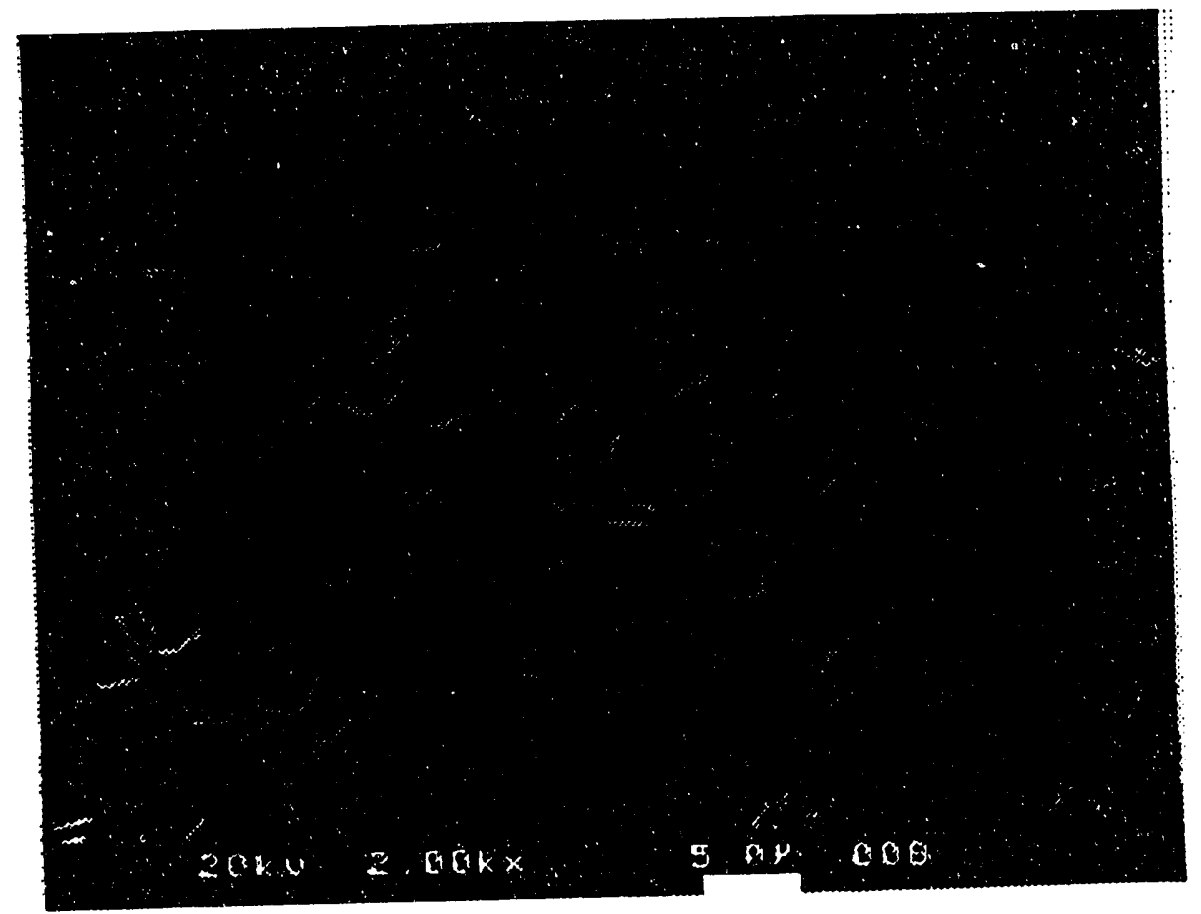

Figure 5.3

SEM of Inver Surfwee of Zeolitic Modified Membrane ZS136 


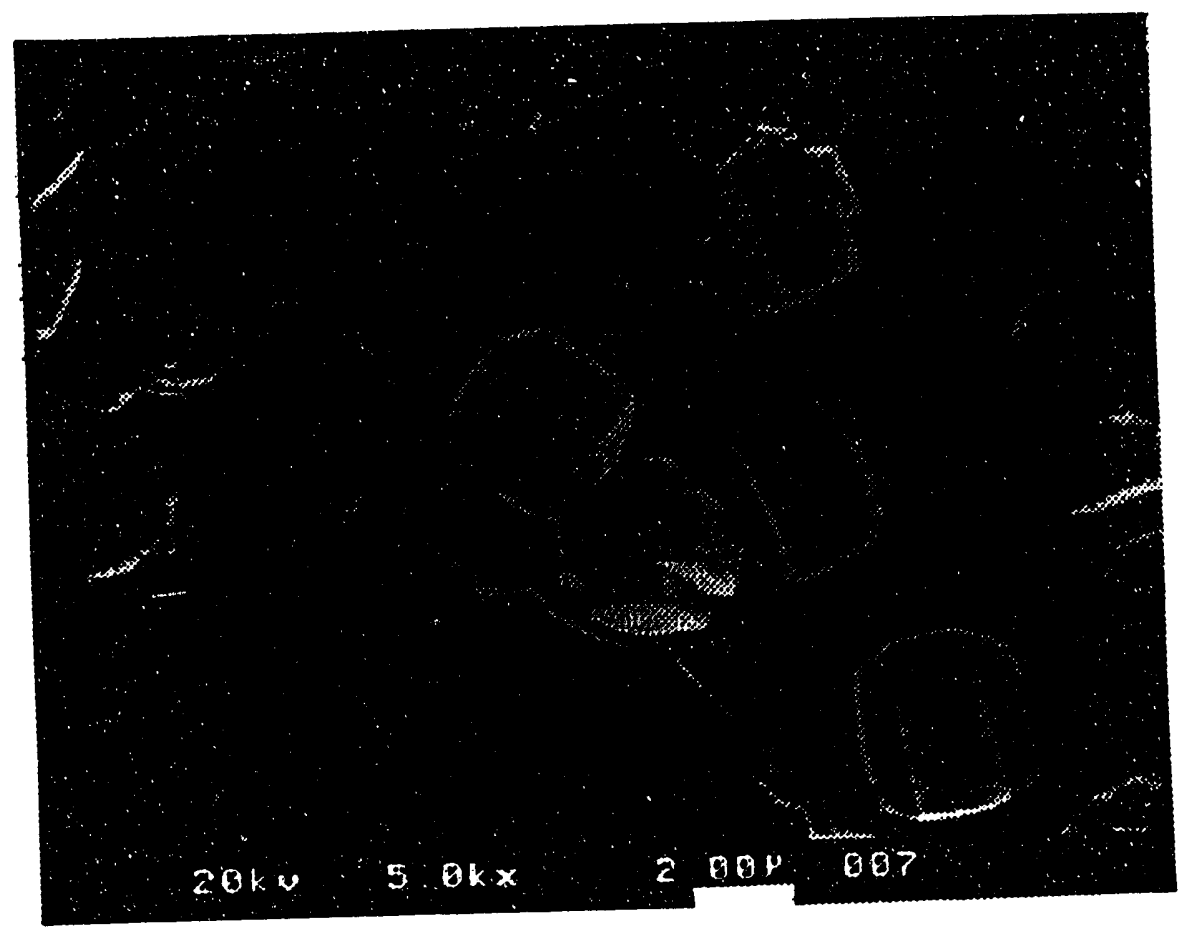

Figure 5.4

SEM of Inner Surface of Zeolitic Modified Membrane ZS136 


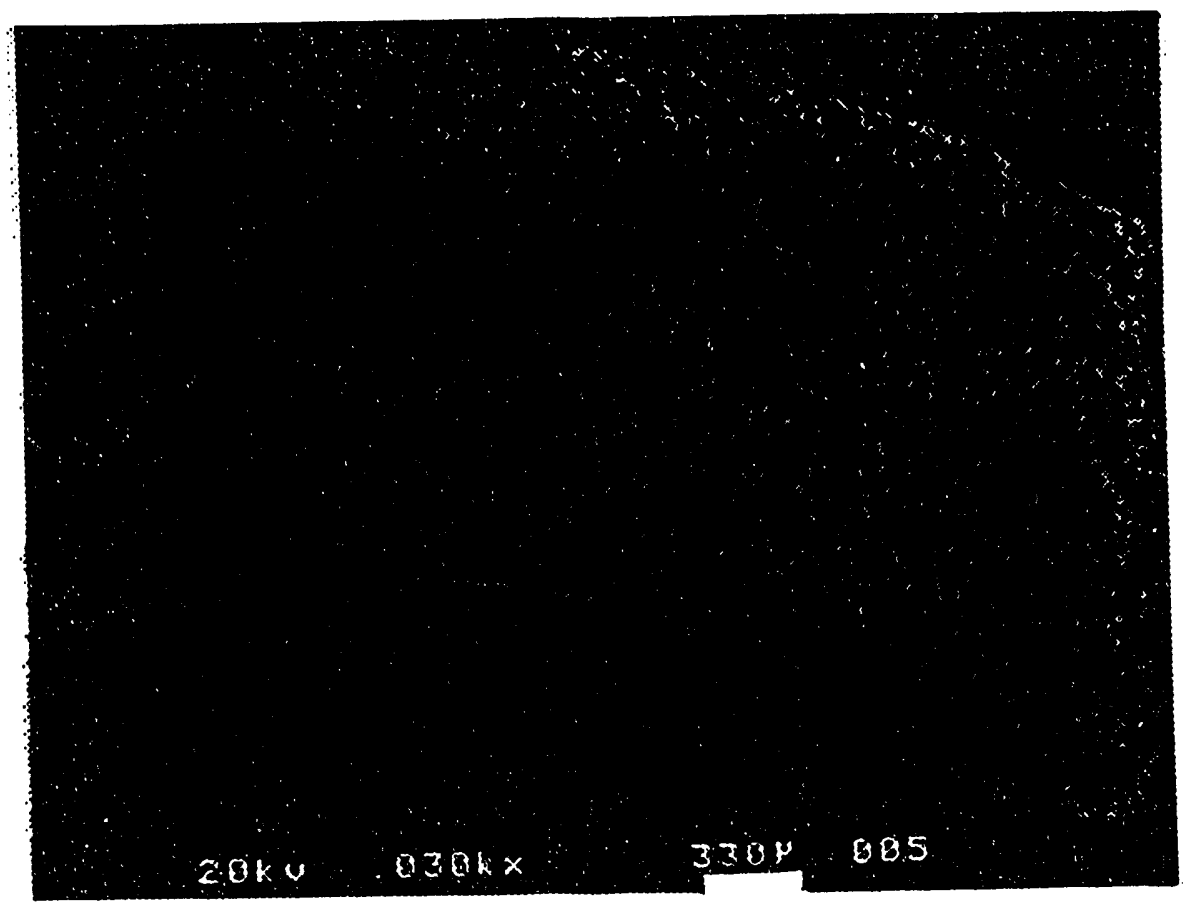

Figure 5.5

SEM of Cross-Section of Zeolitic Modified Membrane ZS136 
The scanning electron micrographs of the inner surface and cross-section of zeolitic membranes on porous alumina support indicated that their inner surface was covered with silica-ZSM-5 crystal (Figures 5.6 - 5.10). This was consistent with the EDAX analysis of the inside surface of the zeolitic membrane (Figure 5.11). The scanning electron micrographs of the outside surface of the sample tube showed that the outside surface still retained its porous structure after hydrothermal reaction (Figure 5.12).

However, not all the alumina supports are stable under the hydrothermal reaction. Efforts have been made in search of a suitable reaction condition for a particular alumina support. For example, ZS011 (40A), ZS014 (100A), ZSO05 (500A) and ZSO20 $(0.2 \mu \mathrm{m})$ were synthesized under the same conditions. However, SEM indicated that the alumina supports with a top layer of $40 \AA$ might have been damaged after a hydrothermal reaction. All of these zeolitic membranes, except ZS011, exhibited lower permeabilities than their alumina supports (Table 5.5). The increase of the nitrogen permeabilities of ZS011 from 70 to $217 \mathrm{M}^{3} / \mathrm{M}^{2} / \mathrm{hr} / \mathrm{atm}$ indicated that the $40 \AA$ $\gamma$ alumina layer was damaged during the hydrothermal reaction. Since the $40 \AA$ alumina membranes are very unstable under the hydrothermal reaction at a high pH solution, a low pH synthesis condition (pH 8-9) may be able to solve this problem. However, a low pH synthesis procedure of silica-ZSM-5 requires a long reaction time (6-24 days) and seeds which will cause a problem to control the growing position of zeolite crystals. Therefor, $\gamma$ alumina membranes with a top layer of $40 \AA$ might not be a good candidate as support in this synthesis.

Other alumina supports with a top layer of $100 \AA, 500 \AA$, and $2000 \AA$ can retain their structure under different reaction conditions. The alumina supports with a top layer of $100 \AA$ can be stable under hydrothermal reaction only when the sodium hydroxide concentration is lower than $0.125 \mathrm{M}$. When a $0.25 \mathrm{M}$ sodium hydroxide was used, the defects did not occur between the zeolitic membrane and the top layer $(100 \AA)$ of support, instead it occurred between $100 \AA$ and $0.8 \mu \mathrm{m}$ layer. These results were indicated by the scanning electron micrographs of zeolitic membrane ZSO23 (Figure 5.8).

Besides selecting a proper pretreatment procedure and synthesis conditions for a desired support, the cleaning procedure of zeolitic membranes after hydrothermal reaction was investigated. The detailed synthesis conditions of zeolitic membranes ZS104- ZS111 are listed in Table 5.6. Experimental results indicated that these zeolitic membranes have small permeabilities when calcined to $450^{\circ} \mathrm{C}$. However, further calcination up to $650^{\circ} \mathrm{C}$ usually will result in a permeability increase. EDAX analysis of the:,e membranes indicates that there was sodium residue in the alumina support (Figures 5.13 - 5.15). This sodium residue in the alumina support might have attacked support materials at a high temperature and caused the pore growth of support. The cleaning procedure before calcination to avoid such a problem was investigated. 


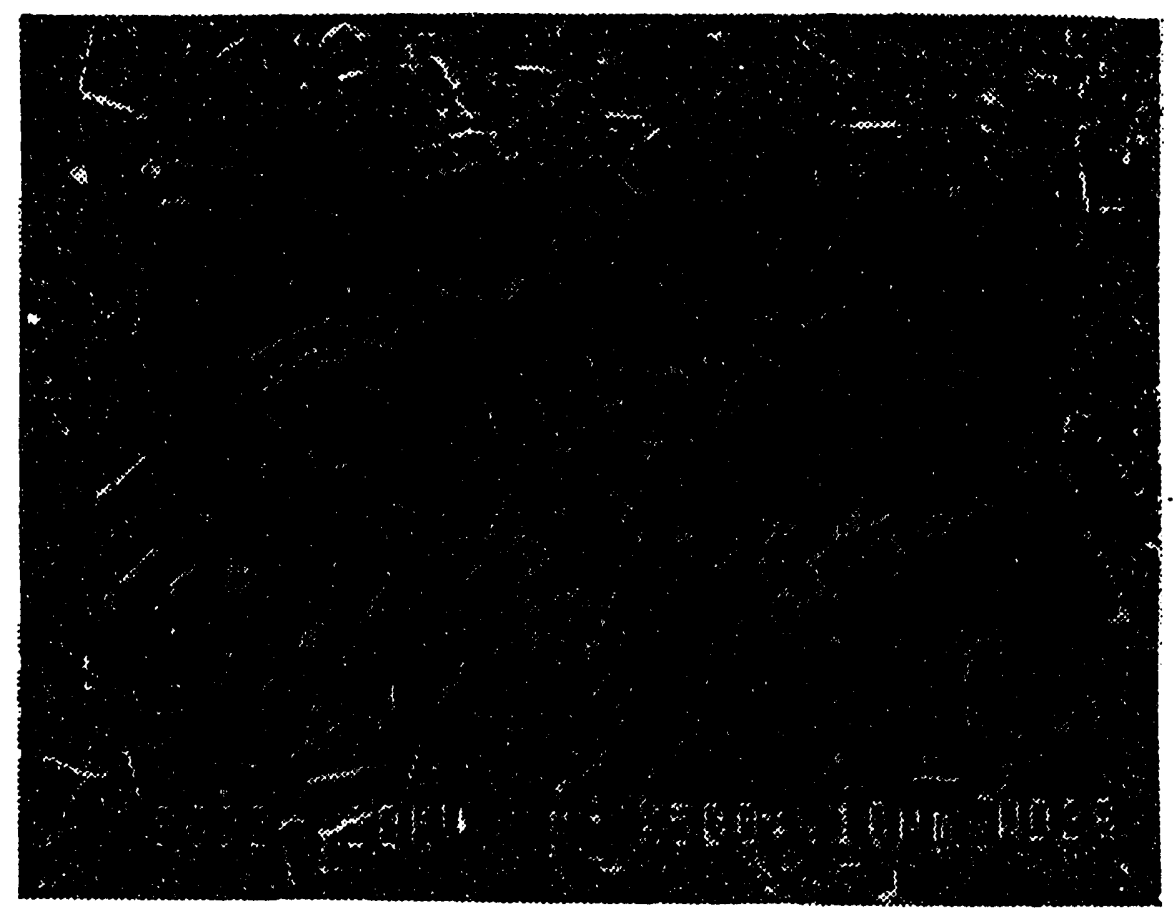

Figure 5.6

SEM of Inner Surfince of Zeolitic Modified Membrane ZS117 


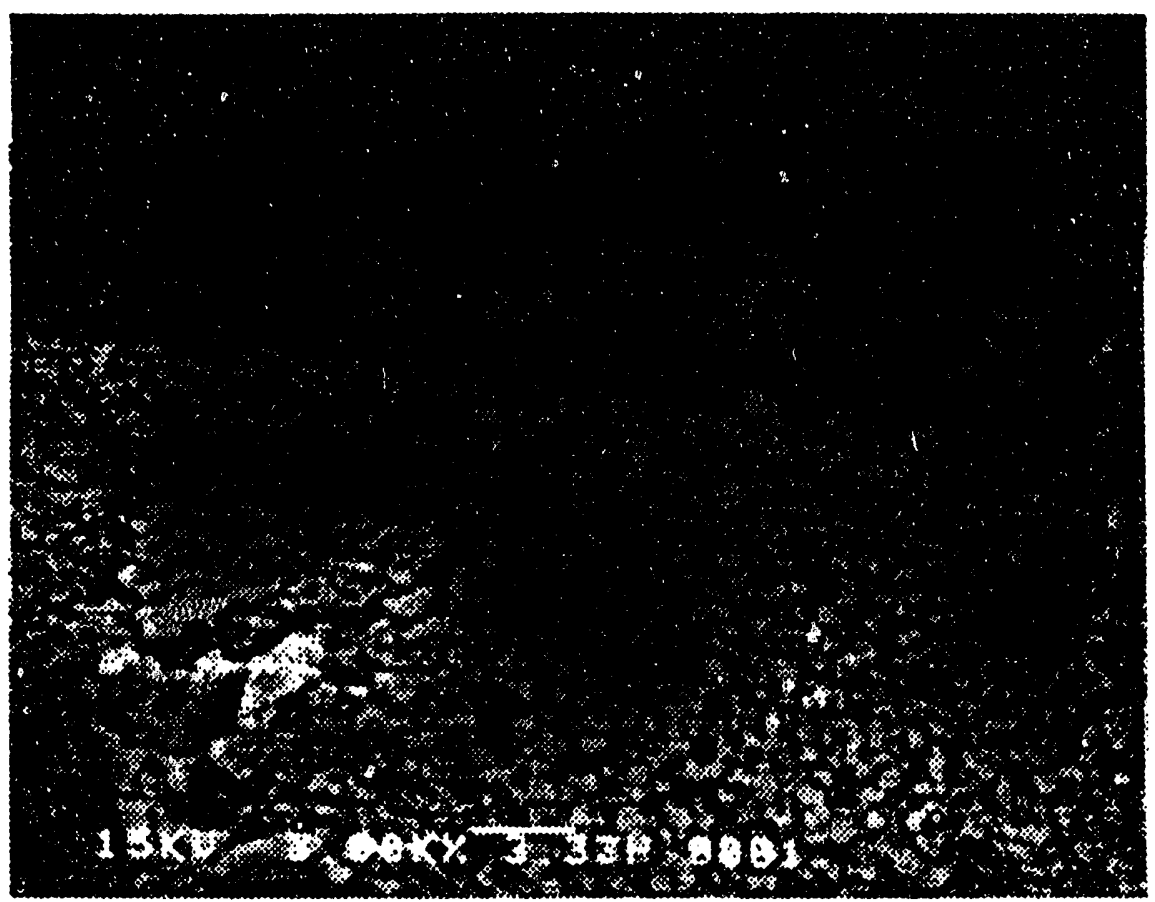

Figure 5 ?

SEM of Crowsection of Zeolitic Modified Membrane ZS014 


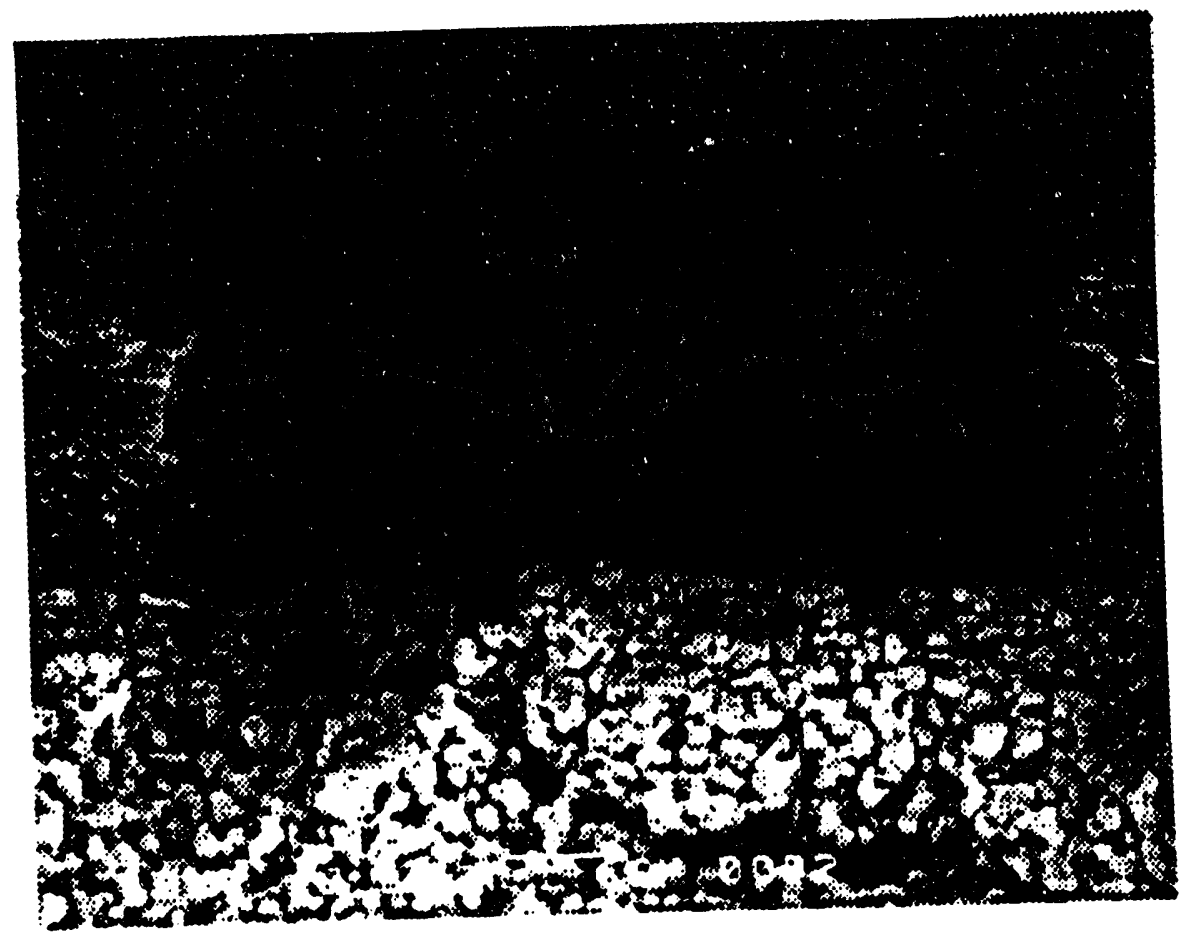

Figure 5.8

SEM of Crow Section of Zoolitic Modified Membrane ZS023 


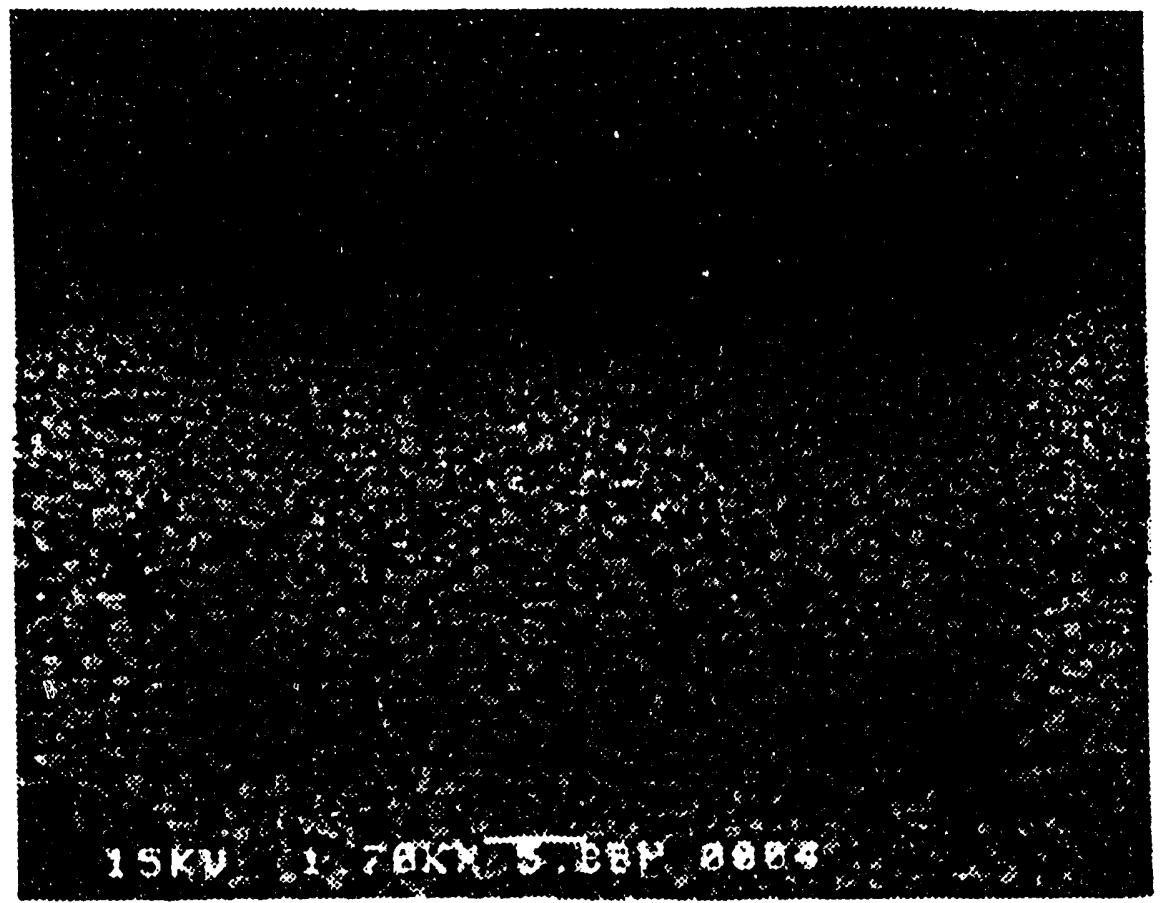

Figure 59

SDM of Crow-Section of Zoolitic Modified Membrane ZS076 


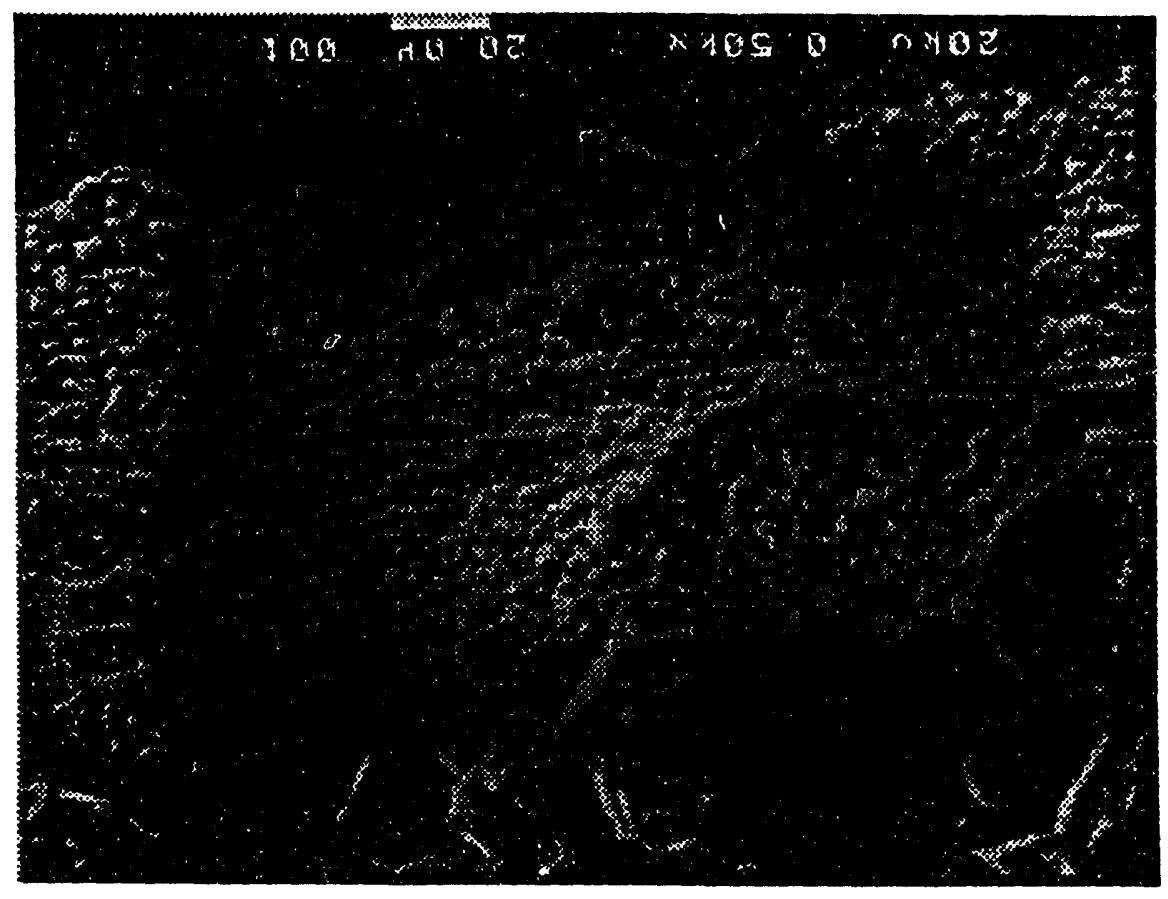

Figare 5.10

SEM of Croso-Section of Zoolitic Modified Membrane ZS 133 


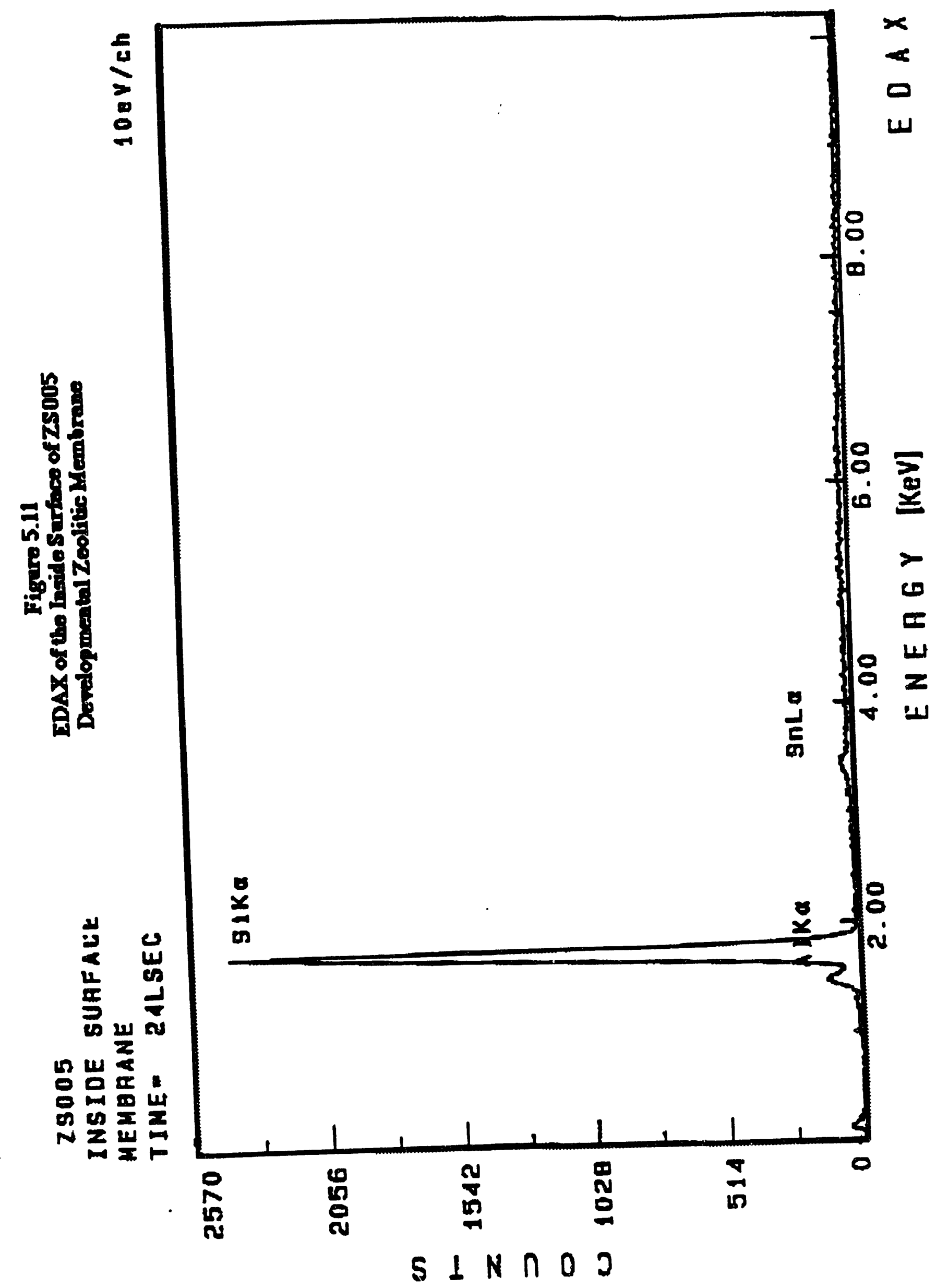




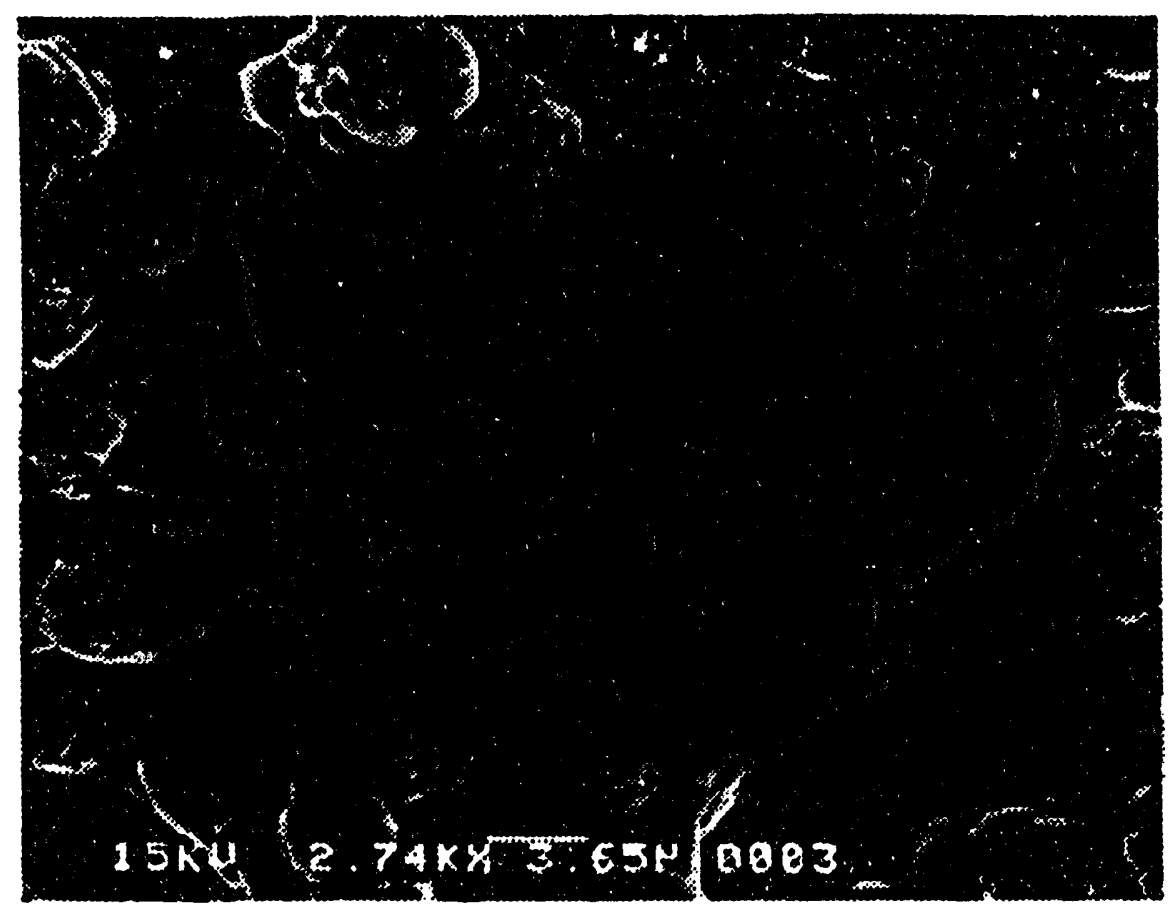

Figare 5.12

SEM of Ortiide Surface of Zeolitic Modified Membrane ZSO05 
Thble 55 The Nitrogen Permeabilities of Zeolitic Membranes on Supports Befiore and After in-eitu Synthesis

\begin{tabular}{lccc} 
& $\begin{array}{c}\text { Support } \\
\text { Pore Diameter }\end{array}$ & \multicolumn{2}{c}{$\begin{array}{c}\mathrm{N}_{2} \text { Permeability } \\
(\mathrm{M} / \mathrm{M} / \mathrm{M} / \mathrm{hr} / \mathrm{tm})\end{array}$} \\
& & Before & After \\
25011 & 40.0 & 109.0 & 108.3 \\
25014 & 100.0 & 200.0 & 72.86 \\
25005 & 500.0 & 499.0 & 108.3 \\
25020 & $0.2 \mu \mathrm{m}$ & 614.5 & 15.1
\end{tabular}


Table 26 Synthesis Conditions for ZS104-ZS110

\begin{tabular}{|c|c|c|c|c|c|}
\hline Samples & Supports & $\mathrm{NaOH}$ : & : & TPABr: & \\
\hline ZS104 & $100 \AA$ & 1 & $:$ & 2 & $:$ \\
\hline ZS1C5 & $40 \AA$ & 1 & : & 2 & $:$ \\
\hline ZS106 & $40 \AA$ & 1 & $:$ & 2 & $:$ \\
\hline ZS107 & $100 \AA$ & 1 & $:$ & 2 & $:$ \\
\hline ZS108 & $500 \AA$ & 1 & $:$ & 2 & $:$ \\
\hline ZS109 & $100 \AA$ & 1 & : & 2 & $:$ \\
\hline ZS110 & $100 \AA$ & : & $:$ & 2 & : \\
\hline
\end{tabular}

Reaction temperature: $150^{\circ} \mathrm{C}$

Reaction Time: 24 brs 
Figure 5.13

EDAX of Inner Surface of Zeolitic Membrane ZS 106

RJEE GROLP JSM EAO SEM

TUE 12-MFY-92 12119

Cursor: 0.000keV $=0$

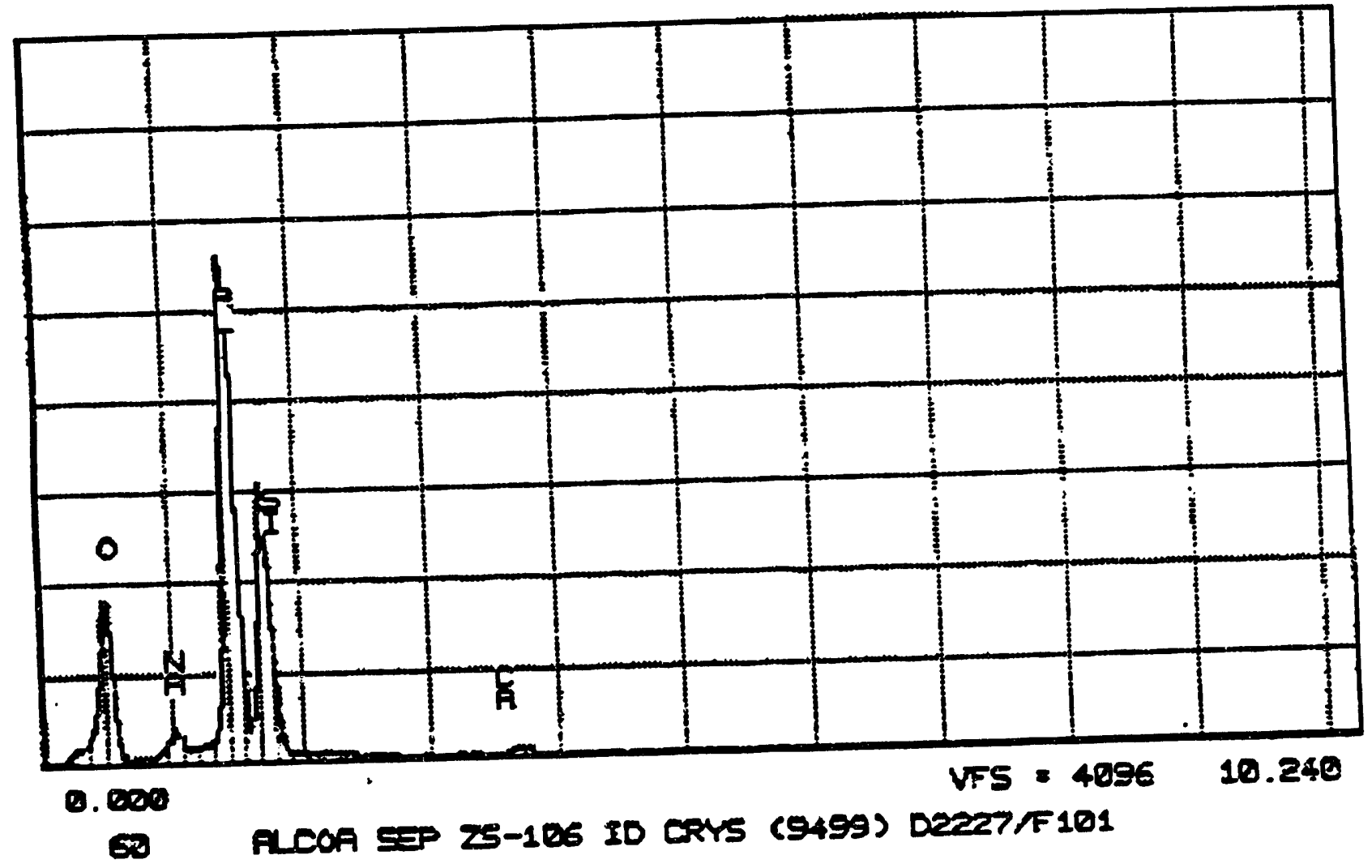


Figure 5.14

EDAX of Inner Surface of Zeolitic Membrane ZS 107

PALEE CROSP JSM 840 SEM

TUE 12-MFY-92 12:57

Cursor: D. DookeV = 0

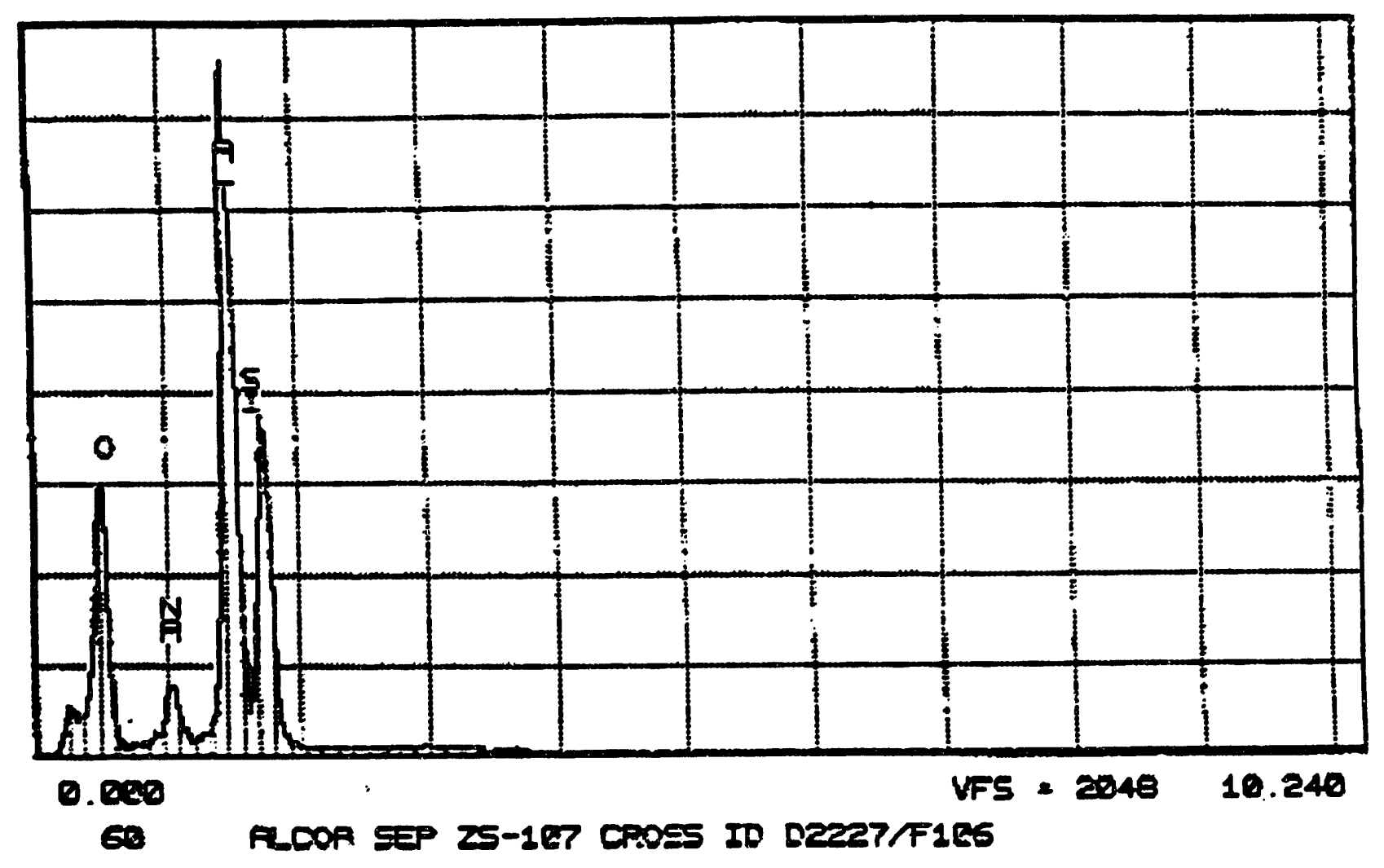


Figure 5.15

EDAX of Inner Surface of Zeolitic Membrane ZS110

RJLE GROLP JSM B40 SEM

TUE 12MPY-9Z 13:15

Cursor: D.gookeV \&

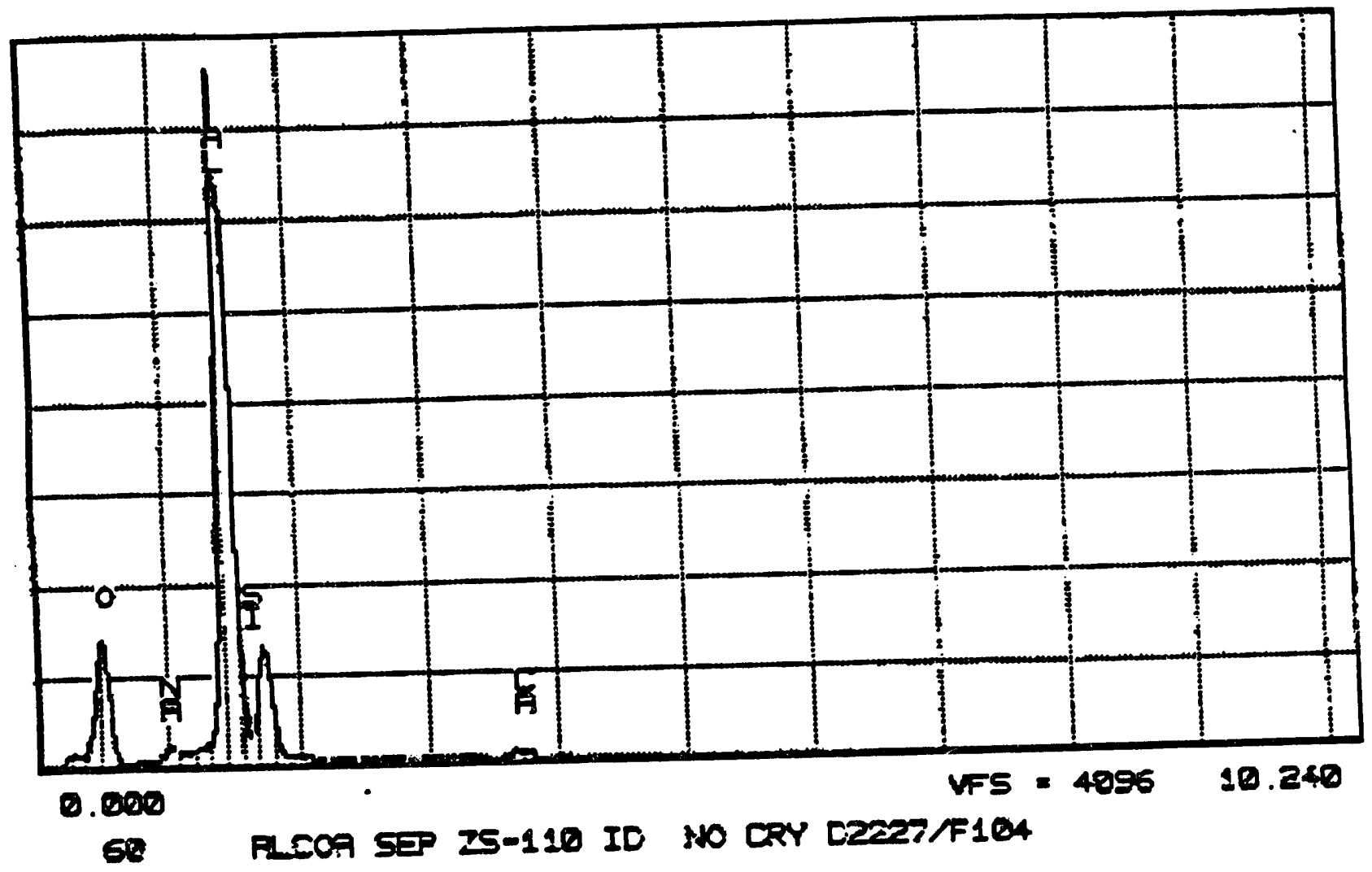


A washing procedure was developed to remove sodium residue before calcination. We discovered that zeolitic membranes are unstable under the sodium cleaning process. For example, the nitrogen permeability of zeolitic membrane ZS106 was $0.013 \mathrm{~m}^{3} / \mathrm{m}^{2} / \mathrm{hr} / \mathrm{atm}$ after the first time washed with water and calcined to $600^{\circ} \mathrm{C}$. However, further washing and calcining of this membrane up to $450^{\circ} \mathrm{C}$ caused the nitrogen permeability to increase to $7.45 \mathrm{~m}^{3} / \mathrm{m}^{2} / \mathrm{hr} / \mathrm{atm}$. This suggested that the zeolitic crystals synthesized within the porous structure may not form a strong bond with the existing alumina membrane structure.

Therefore, the synthesis conditions have been altered so zeolitic membranes can withstand this cleaning procedure. Zeolitic membranes ZS122-ZS124 were synthesized on $100 \AA$ alumina support. The detailed synthesis conditions are listed on Table 5.7. The nitrogen permeabilities of these membranes remained small and constant after the cleaning process (Table 5.8). The $\mathrm{He} / \mathrm{N}_{2}$ separation selestivity of these membranes were around 2.64.

The pore size analysis indicated that the probe gas, cyclohexane, can condense only on a certain portion of pores of these membranes. The percentage of flow contributed by noncondensable pores of zeolitic membranes ZS122, ZS123 and ZS124 was 57\%, 69\% and 71\%, respectively. The condensable portion of the pore of ZS122 has an average pore size of $36 \AA$, while ZS123 and ZS124 have a wide pore size distribution around 100-30A. (Figure 5.16 - 5.18). Further treatment with silica chemical vapor deposition can eliminate those pinholes (Table 5.9). The stability of zeolitic membranes at high temperature was improved once there was no sodium residue.

Along the concept discussed in the previous section, a $100 \AA$ alumina support was pretreated with gel $\# 3$, dried at room temperature for 24 hours and calcined to $450^{\circ} \mathrm{C}$ (ZS139*). The pretreated membrane then was placed in zeolite synthesis solution and sealed in a autoclave at $150^{\circ} \mathrm{C}$ for 20 hours. The mole ratio of $\mathrm{NaOH} / \mathrm{TPABr} / \mathrm{TEOS}$ used was $1 / 2 / 4$. The membrane was washed with deionized water until no sodium residue existed and dried at room temperature. The membrane ZS139(*2) then was dried by further calcination up to $300^{\circ} \mathrm{C}$. The permeability of $\mathrm{ZS139}\left(2^{*}\right)$ is much small after in-situ synthesis (Table 5.10). The pore size analysis indicated a $100 \AA-40 \AA$ pinhole was present in this membrane (Figure 5.19).

A similar pretreatment and in-situ synthesis were conducted on ZS143 and ZS148. The pore size distribution of these zeolitic membranes indicated that the pinholes of these membranes had a similar pore size, as that of their supported materials (Figure $5.20-5.21$ ). The He and $\mathrm{N}_{2}$ permeability of these membranes was lower than that of their supports, indicating that a great portion of inner surface was covered with zeolite crystals (Table 5.11).

In summary, the pinholes in zeolitic membranes can be minimized by combining pretreatment and in-situ synthesis. 
Table 6.7 The Synthesis Conditions for Zeolitic Membranes ZS122-ZS124

$\begin{array}{ll}\mathrm{NaOH} \text { Concentration: } & 0.25 \mathrm{M}-0.5 \mathrm{M} \\ \text { TPABr Concentration: } & 0.065-0.125 \mathrm{M} \\ \mathrm{SiO}_{2} \text { Concentration: } & 0.5-2 \mathrm{M} \\ \text { Furnace Temperature: } & 150-200^{\circ} \mathrm{C} \\ \text { Support: } & 100 \AA \\ \text { Reaction Time: } & 18-21 \mathrm{hrs}\end{array}$


Table 58 He and N2 Permeabilities of Zeolitic Membranes ZS122-ZS124

\begin{tabular}{lllllc} 
Samples & Support & Binholes & \multicolumn{2}{c}{$\begin{array}{c}\mathrm{N}_{2} \\
(\mathrm{M} 3 \Omega \mathrm{M} 2\end{array}$ (hr/atm) } & $\begin{array}{c}\mathrm{He} / \mathrm{N}_{2} \\
\text { Selectivity }\end{array}$ \\
ZS122 & $100 \AA$ & $-36 \AA$ & 19.05 & 40.06 & 2.10 \\
ZS123 & $100 \AA$ & $30-100 \AA$ & 32.93 & 77.45 & 2.34 \\
ZS124 & $100 \AA$ & $30-100 \AA$ & 28.72 & 78.14 & 2.72
\end{tabular}


Figure 5.16 Pore Size Distribution of Zeolitic Membrane ZS122

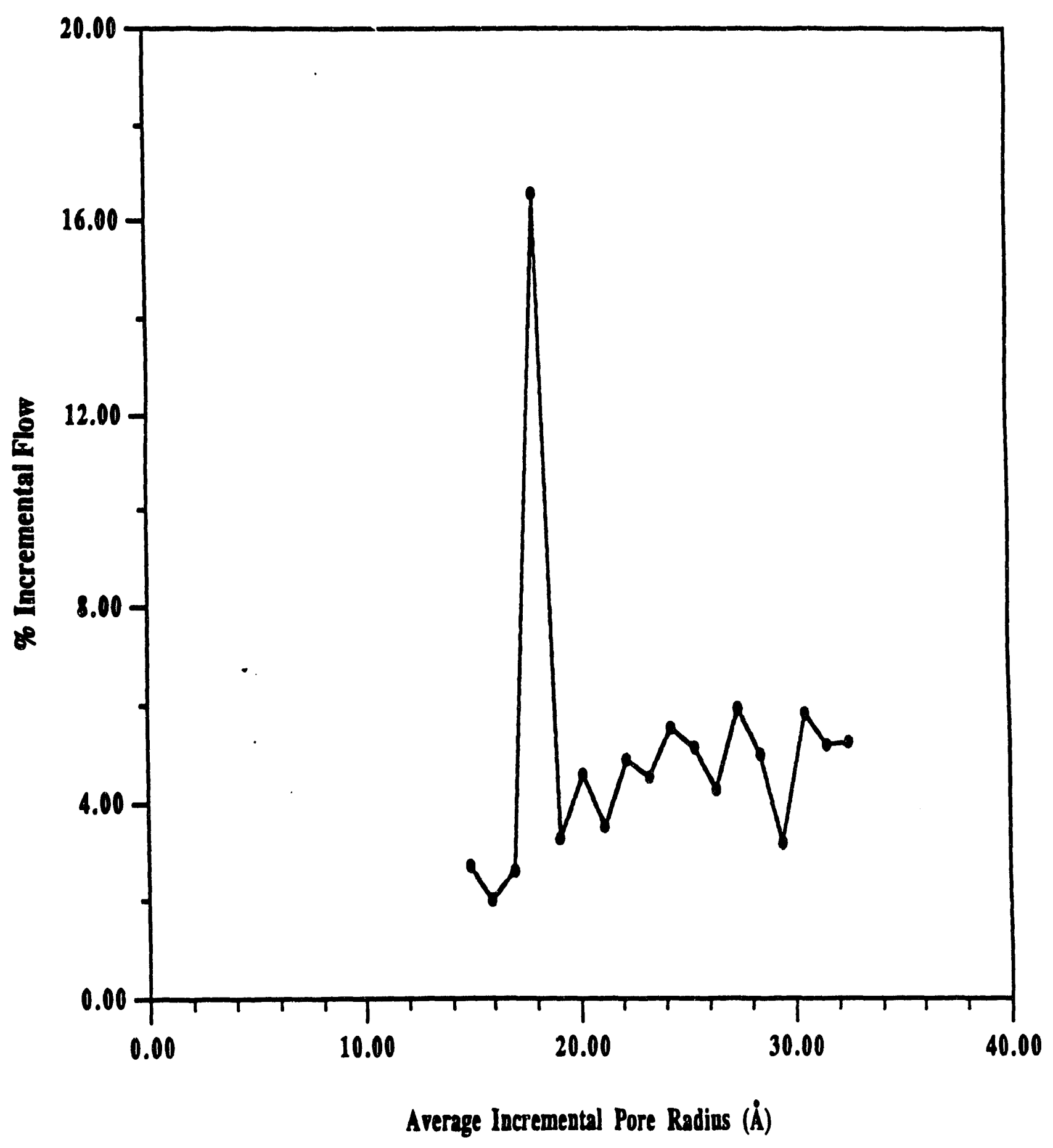


Figure 5.17 Pore Size Distribution of Zeolitic Membrane ZS123

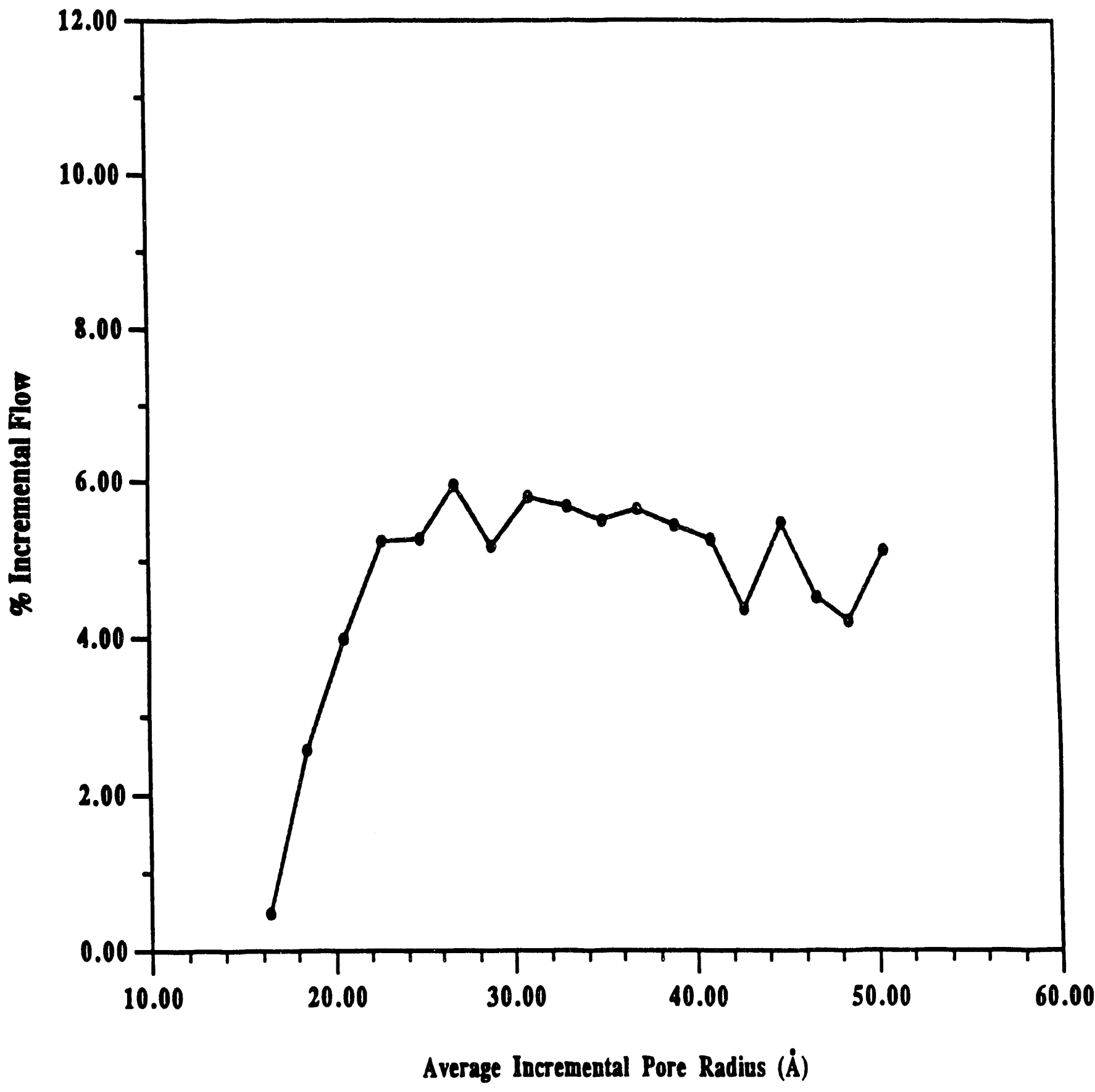


Figure 5.18 Pore Size Distribution of Zeolitic Membrane ZS124

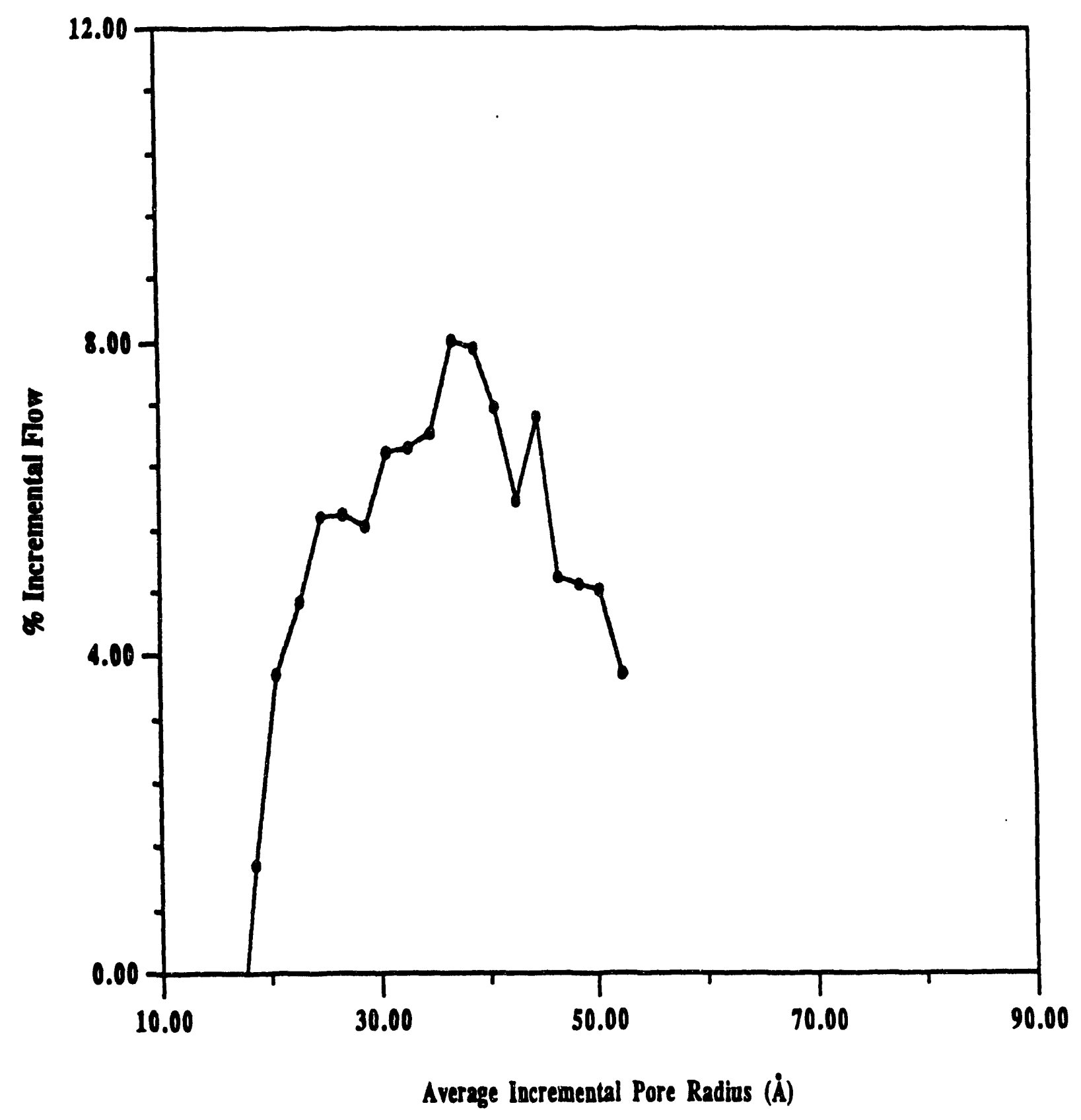


Trble 69 He and $N_{2}$ Permeabilities of Zeolitic Membranes Before and After Sillica CVD Modification

\begin{tabular}{|c|c|c|c|c|c|c|}
\hline \multirow{3}{*}{$\begin{array}{l}\text { Samples } \\
\text { ZS111 }\end{array}$} & \multicolumn{3}{|c|}{ Before } & \multicolumn{3}{|c|}{ After } \\
\hline & \multicolumn{2}{|c|}{$\begin{array}{lr}\mathrm{N}_{2} & \mathrm{He} \\
\mathrm{M} 3 \mathrm{M} & \mathrm{M} / \mathrm{hr} / \mathrm{atm}\end{array}$} & \multirow{2}{*}{$\begin{array}{c}\begin{array}{c}\mathrm{He} / \mathrm{N}_{2} \\
\text { Selectivity }\end{array} \\
2.72\end{array}$} & \multicolumn{2}{|c|}{$\begin{array}{lc}\mathrm{N}_{2} & \mathrm{He} \\
\mathrm{M} 3 / \mathrm{M} 2 / \mathrm{hr} / \mathrm{atm}\end{array}$} & \multirow{2}{*}{$\begin{array}{l}\mathrm{He} / \mathrm{N}_{2} \\
\text { Selectivity } \\
2.10\end{array}$} \\
\hline & 28.72 & 78.14 & & 0.0017 & 0.036 & \\
\hline 25123 & 32.93 & 77.45 & 2.34 & 0.0278 & 0.0140 & 1.98 \\
\hline ZS124 & 28.72 & 78.14 & 2.72 & 0.0689 & 0.0256 & 2.69 \\
\hline ZS138 & 195.39 & 501.76 & 2.57 & 4.52 & 14.49 & 3.28 \\
\hline 25148 & 8.370 & 16.100 & 1.92 & 1.9183 & 4.958 & 2.58 \\
\hline
\end{tabular}


Table 5.10 The Nitrogen and Helium Permeabilities of Zeolitic Membranes ZS139 After Pretreatment and In-situ Synthesis

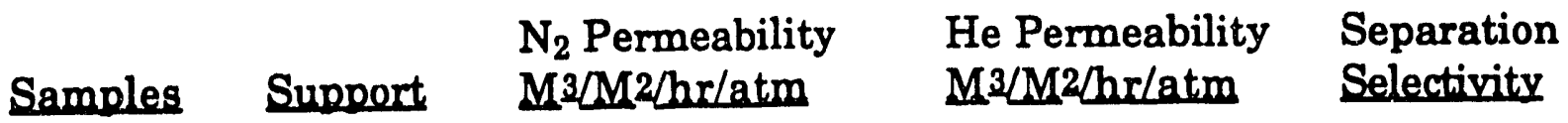

$\begin{array}{lllll}\mathrm{ZS} 139\left(1^{*}\right) & 100 \AA & 280.55 & 671.64 & 2.40 \\ \mathrm{ZS} 139\left(2^{*}\right) & 100 \AA & 15.92 & 36.63 & 2.30\end{array}$

The permeabilities of ZS139 after pretreatment with gel \#3.

The permeabilities of ZS139 after pretreatment, direct synthesis and calcined to $300^{\circ} \mathrm{C}$. 
Figure 5.19 Pore Size Distribution of Zeolitic Membrane ZS139

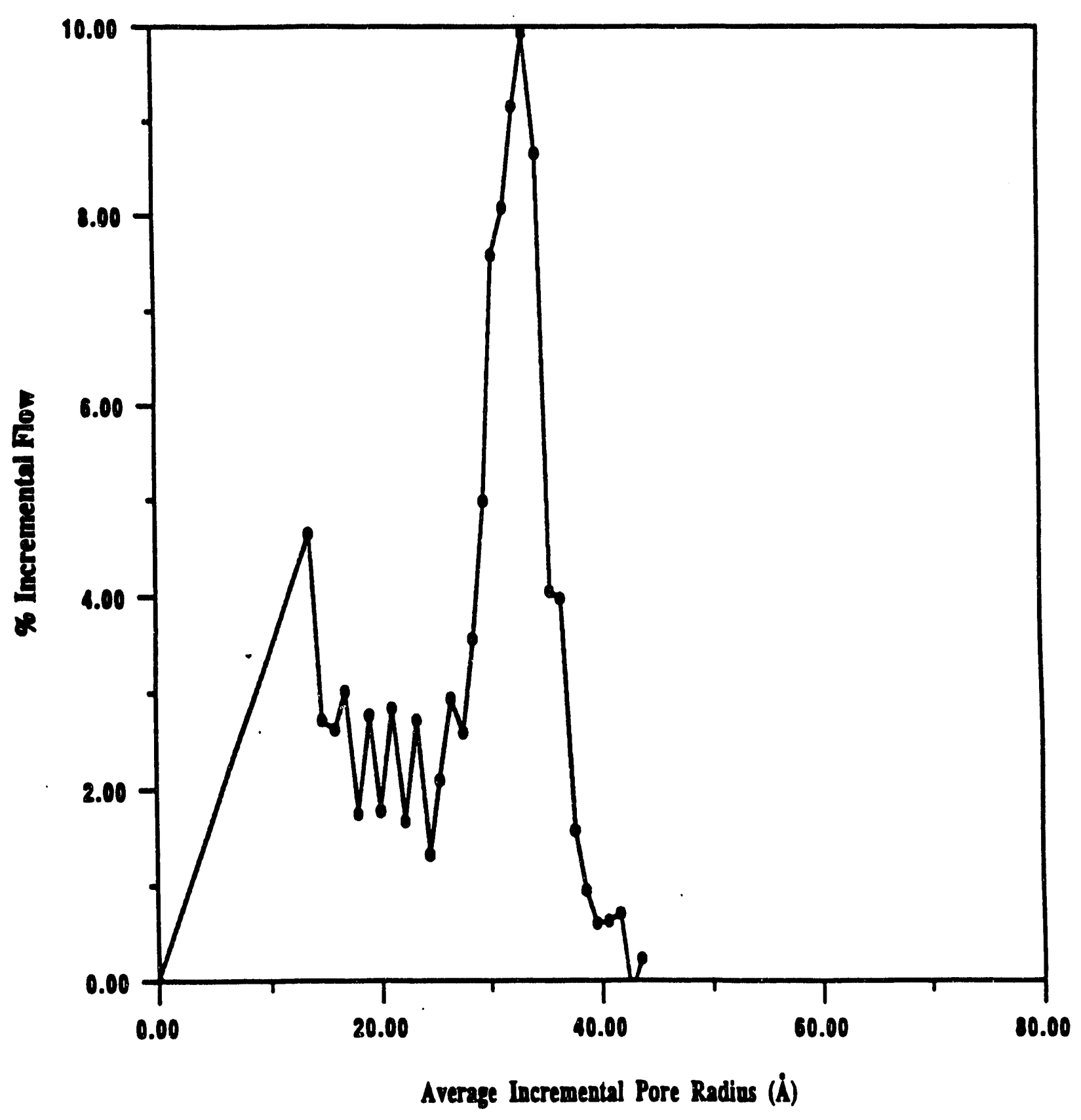


Figure 5.20 Pore Size Distribution of Zeolitic Membrane ZS143

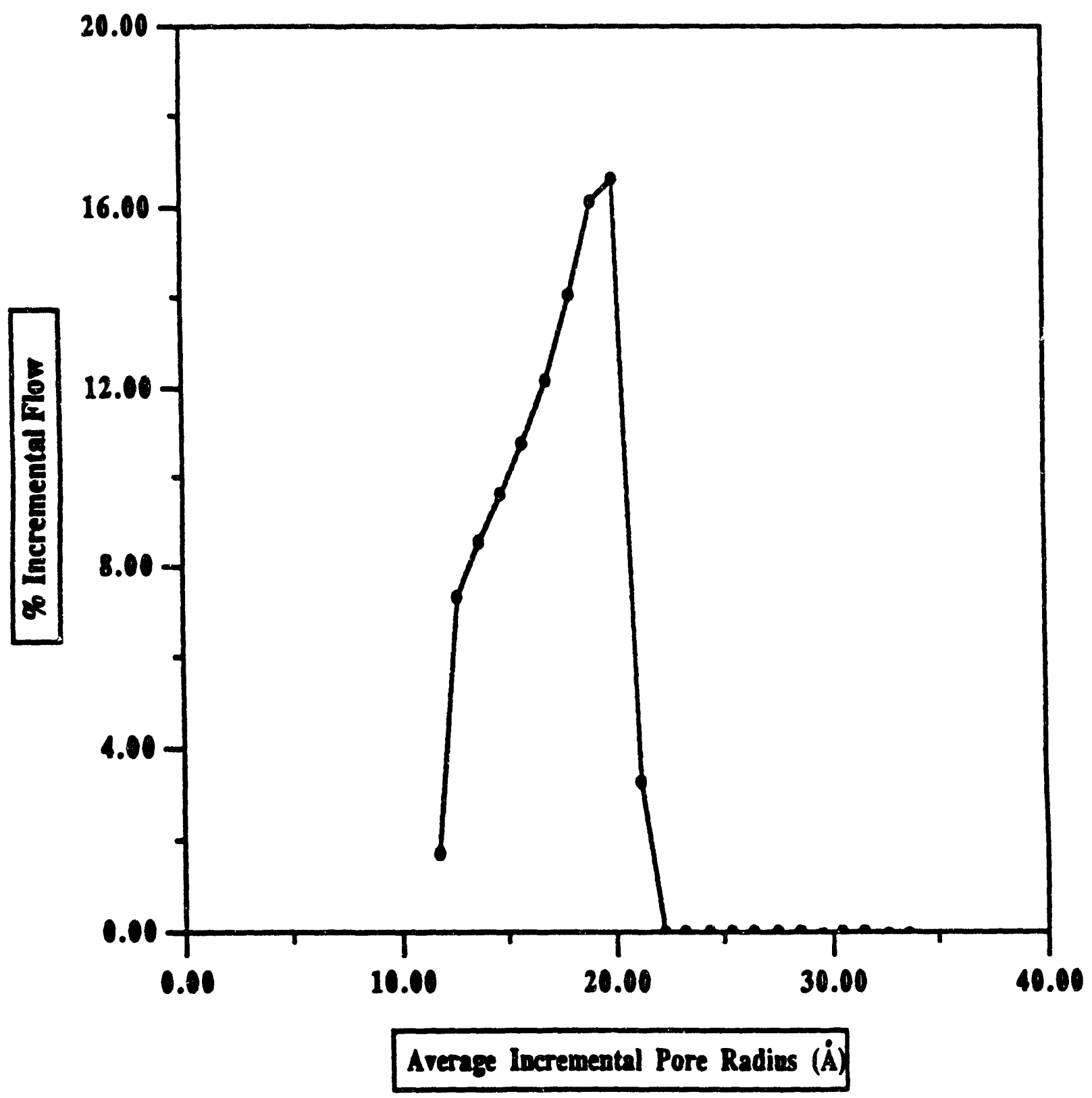


Figure 5.21 Pore Size Distribution of Zeolitic Membrane ZS148

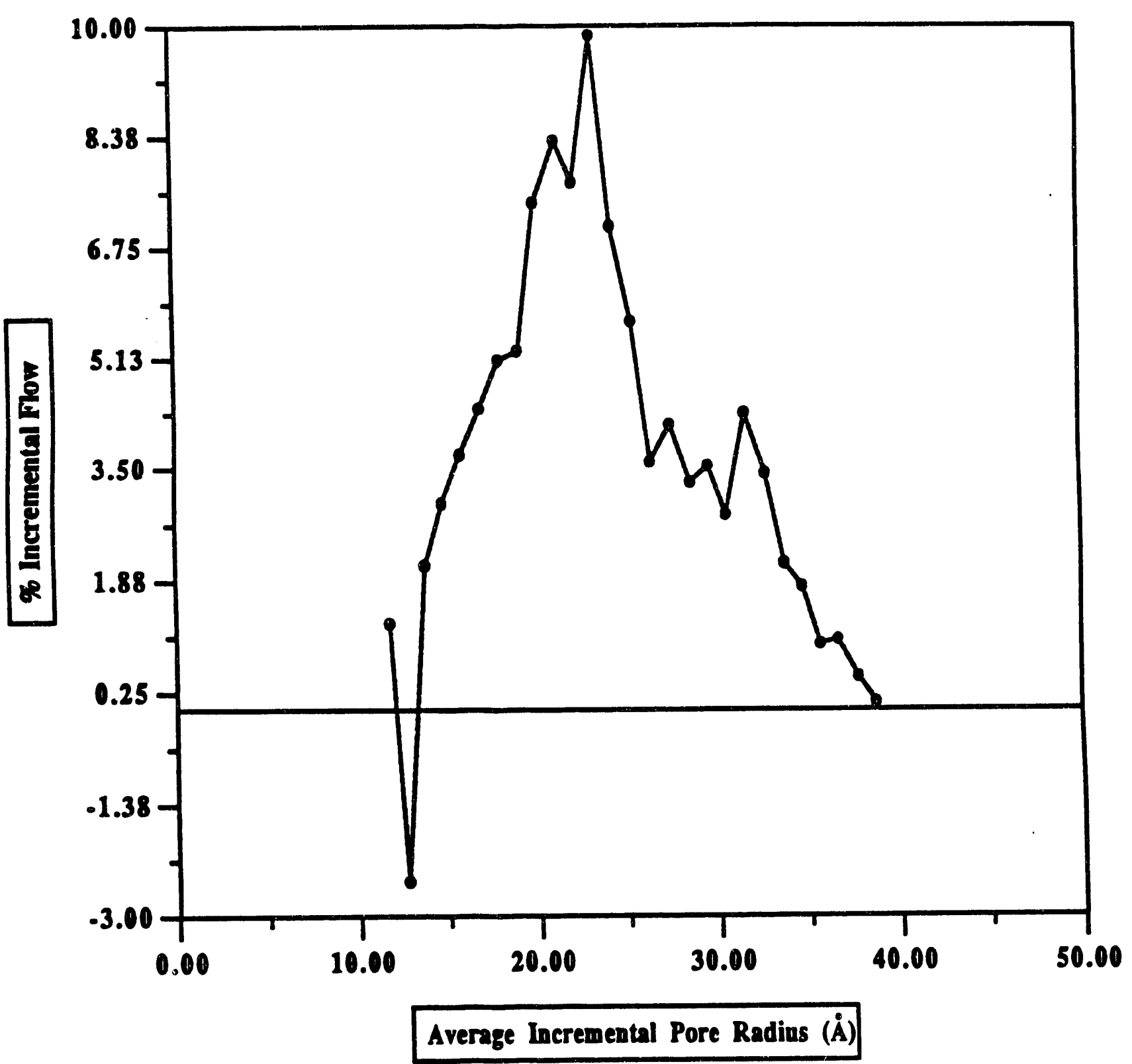


Table 5.11 He and $\mathrm{N}_{2}$ Permeability of Various Zeolitic Membranes After Pretreatment, In-situ Synthesis and/or CVD

\begin{tabular}{|c|c|c|c|c|c|}
\hline \multirow{2}{*}{$\begin{array}{l}\text { Samples } \\
\text { ZS139 }\end{array}$} & \multirow{2}{*}{$\begin{array}{l}\text { Support } \\
100 \AA\end{array}$} & \multirow{2}{*}{$\begin{array}{l}\text { Treatment } \\
\text { Sol-Gel }\end{array}$} & \multicolumn{2}{|c|}{$\begin{array}{lc}\mathrm{N}_{2} & \mathrm{He} \\
\mathrm{M}^{2} / \mathrm{M} 2 / \mathrm{hr} / \mathrm{atm}\end{array}$} & \multirow{2}{*}{$\begin{array}{c}\mathrm{He} / \mathrm{N}_{2} \\
\text { Selectivity } \\
2.40\end{array}$} \\
\hline & & & 280.05 & 671.64 & \\
\hline & & in-situ & 15.92 & 36.63 & 2.30 \\
\hline \multirow[t]{2}{*}{ 2S143 } & $50 \AA$ & Sol-Gel\#4 & 98.60 & 229.0 & 2.32 \\
\hline & & in-situ & 0.26 & 0.72 & 2.78 \\
\hline \multirow[t]{2}{*}{ ZS146 } & $100 \AA$ & Sol-Gel & 130.00 & 324.0 & .2 .49 \\
\hline & & CVD & 10.96 & 26.00 & 2.37 \\
\hline \multirow[t]{3}{*}{ ZS148 } & $100 \AA$ & Sol-Gel\#4 & 164.58 & 433.86 & 2.64 \\
\hline & & in-suite & 8.370 & 16.100 & 1.92 \\
\hline & & CVD & 1.9183 & 4.958 & 2.58 \\
\hline
\end{tabular}




\section{Modification}

Chemical vapor deposition can be used in the modification of zeolitic membranes to eliminate the pinholes and defects of these membranes. Zeolitic membranes ZS111, ZS123 and ZS124 were modified by silica CVD method. The $\mathrm{N}_{2}$ and He permeabilities of these membranes decreased drastically after deposition (Table 5.9). The $\mathrm{He} / \mathrm{N}_{2}$ separation selectivity of ZS124 remained the same while ZS123 decreased. As discussed in Section 6 , the $\mathrm{He} / \mathrm{N}_{2}$ separation selectivity decreased with the pore size of membranes until an optimum pore size was reached which was around 5.5A. Therefore, the decrease of the separation selectivity in ZS124 might indicate that the pore size of pinholes was less than $40 \mathrm{~A}$ but larger than $5.5 \AA$.

This silica modified zeolitic membrane, ZS111, demonstrates a high separation selectivity in the $\mathrm{He}_{\mathrm{SF}} 6$ separation which indicated that a great portion of the pinholes have been eliminated. A silica modified membrane, Si172, with an average pore size of about $22 \AA$ showed a separation selectivity of 1.57 in $\mathrm{He}^{-} \mathrm{SF}_{6}$ separation while zeolitic membrane ZS111 demonstrated a separation selectivity of around 4.8. Therefore, we concluded that the pinholes in ZS111 were smaller than 22A. Since ZMS-5 crystals have a pore opening of around $5.2 \AA \times 5.6 \AA$ and the kinetic diameter of $\mathrm{SF}_{6}$ is around $5.5 \AA$, we are not sure that the total molecular sieving separation can be achieved by ZSM-5 zeolitic membranes.

It is possible to block the open pore of zeolitic membranes while trying to patch up the pinholes with chemical vapor deposition. The other possible route of modification is to patch up the pinhole before removing the template of zeolitic membranes. Since the template inside the pores of ZSM-5 will decompose at $450^{\circ} \mathrm{C}$, a low temperature chemical vapor deposition should be employed. Zeolitic membranes ZS146 and ZS148 were synthesized and further modified with such a method. The $\mathrm{He} / \mathrm{N}_{2}$ separation selectivities of ZS146 and ZS148 after chemical vapor deposition and calcination at $520^{\circ} \mathrm{C}$ were slightly higher than their supports $(-2.46)$. This result is similar to the results reported by other ZSM-5 zeolitic membranes.

ZSM-5 zeolitic membranes showed a separation selectivity slightly higher than Knudsen diffusion for the gas molecules which have a kinetic diameter smaller than the pore opening of ZSM-5 crystals (5.6A). For the

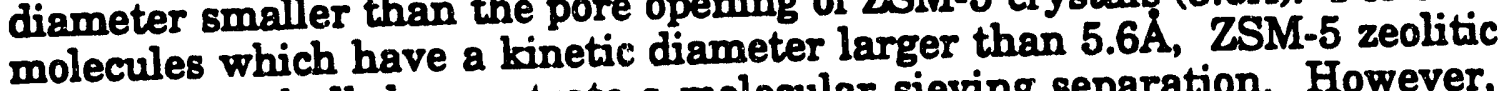
membranes shall demonstrate a molecular sieving separation. However, so far, the reported zeolitic membranes demonstrate a combined transport mechanism. Gas molecules transport partially through zeolite channels and partially through the microporous defects. Therefore, a separation selectivity higher than Knudsen but lower than molecular sieving separation was observed. 
Although it is encouraging that our zeolitic membranes showed a similar or higher $\mathrm{He} / \mathrm{N}_{2}$ separation selectivity than other reported zeolitic

membranes, the analytical results can not prove the separation is due to a true zeolitic membrane. In the past, because of the unsteady supply of neopentane, we used $\mathrm{SF}_{6}$ as 8 probe gas molecule. However, since the kinetic diameter of $\mathrm{SF}_{6}$ is $5.5 \AA$, no molecular sieving separation was observed by our zeolitic membrane. Therefore, using probe gas molecules which have a kinetic diameter larger than a ZSM-5 crystal opening is the only way to identify the true zeolitic membranes. 


\subsection{Introduction}

Gas separation mechanisms through a ceramic membrane can be classified in five categories: (a) Knudsen diffusion or free molecular flow requires the pore size of the membrane is ten times less than the mean free path of gas molecules. The pore size is usually in the range of 40 to $100 \AA$ which is still much larger than molecular size. The separation efficiency is based on the gas molecular weight. The ideal selectivity is the inverse of the square-root of molecular weight ratio. (b) Molecular sieving or micropore diffusion is based on the size of molecule vs. the pore diameter of a membrane. The pore size required is usually near the molecular size, which ranges from 3 to $10 \AA$. The separation mechanism is simply dependent on the size exclusion. (c) Solid-solution diffusion is based on the gas molecule solubility and mobility in a dense-film of the membrane. The separation mechanism involves three steps, ie., dissolution, migration, and evolution. (d) Surface diffusion is controlled by the product of molecular adsorb-ability and migration rate on the surface. The separation is dependent on the chemical and physical interaction between gas molecules and membrane surface. (e) pore condensation is determined by the vapor pressure of the gas component, pore size and temperature. The last four mechanisms usually can provide a very high selectivity in certain gas separations. However, the mechanisms d \& e are diminished at high temperature $\left(>200^{\circ} \mathrm{C}\right)$.

\section{Pore Sive ve Gas Separations}

According to Present \& deBethune's theory, the separation efficiency of the membrane increases with the decrease of the pore size of the membrane (Present, 1949). However, as the pore size decreases, the surface flow through the membranes become important. As a result, the inverse relationship is not obeyed for a certain range of the pore size. Fain incorporated gas molecule adsorption, surface flow and surface momentum accommodation (Fain, 1991) in addition to Knudsen flow into a transport equation. The equation thus developed can predict the unexpected anomaly.

For a given class of membrane materials, the separation selectivity decreases with the pore size reduction of the membrane until a critical pore size is reached. Then the separation selectivity increases drastically as the pore size of the membranes further decreases (Figure 6.1).

This phenomena was observed in $\mathrm{He} \mathbb{N}_{2}$ separation with our modified porous membranes. The modified membranes Si208 and Si210 with a pore size around 31-27 $\AA$ showed a Knudsen separation in $\mathrm{He} / \mathrm{N}_{2}$ with a selectivity of 2.4-2.5. However, as the pore size of the modified membrane decreased to 22-24A (Si211 and Si212), the $\mathrm{He} / \mathrm{N}_{2}$ separation selectivity decreased to 2.09 (Table 4.1). The He/N2 separation selectivity started 
Figure 6.1 The He/N2 Separation Selectiviey Vs Pore Size

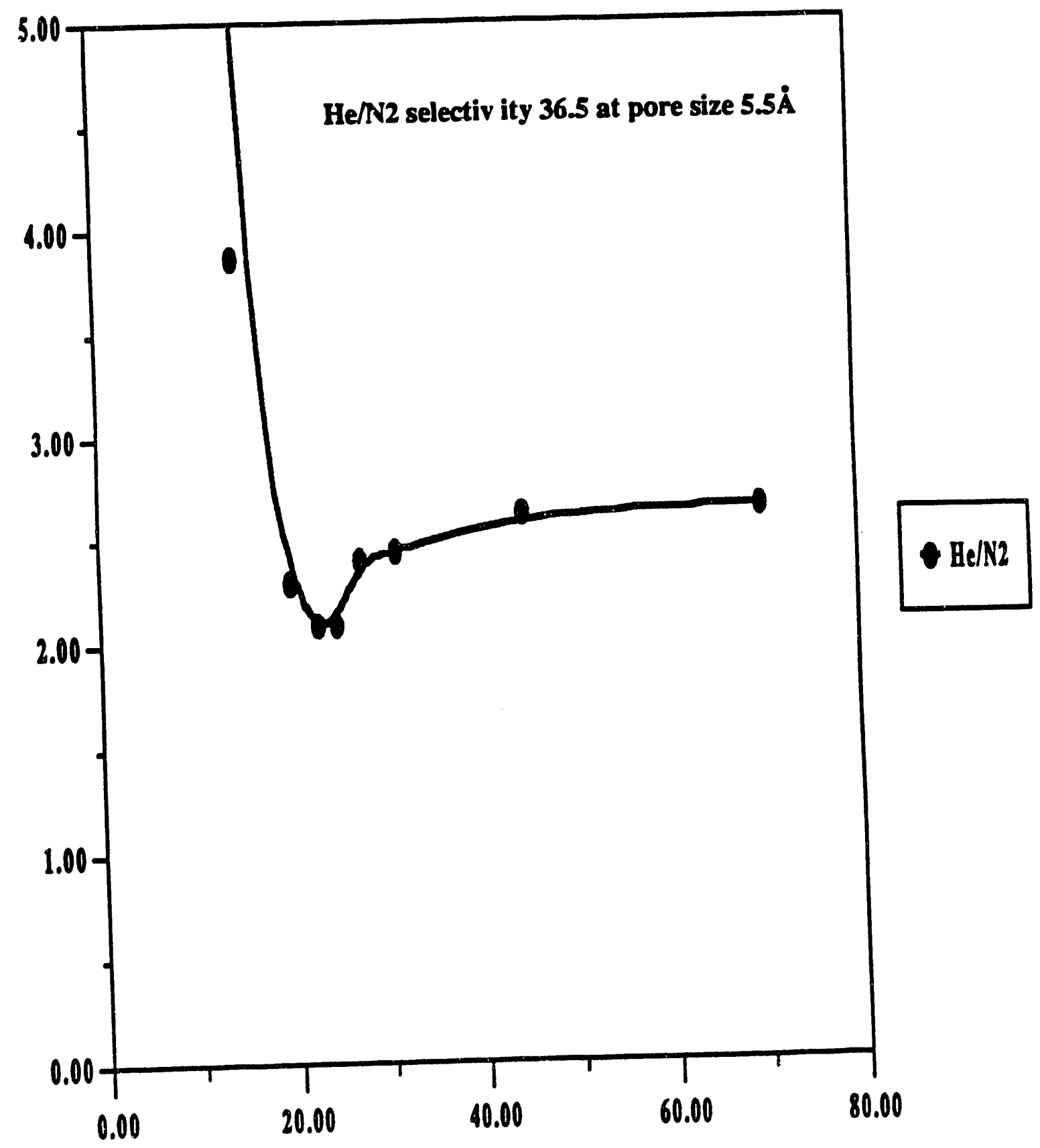


increasing as the pore size of the modified membrane is less than $15 \AA$. For example, according to pore size distribution, both modified membranes ZS209 and ZS207 did not have a pore size larger than $15 \AA$. A high $\mathrm{He} / \mathrm{N}_{2}$ separation selectivity was observed in these two modified membranes (e.g., 3.86 and 36.59). These two modified membranes were further characterized with $\mathrm{He}_{\mathrm{SSF}} 6$ mixture separation. The $\mathrm{He} / \mathrm{SF}_{6}$ separation selectivity of the modified membranes Si209 is around 2.06 which is slightly higher than that of existing $40 \AA$ alumina membranes (Table 4.1). Since there is no molecular sieving separation, we conclude that both $\mathrm{He}$ and $\mathrm{SF}_{6}$ can permeate through this membrane. The kinetic diameter of $\mathrm{He}$ and $\mathrm{SF}_{6}$ are 2.89 and 5.5A, respectively. Therefore, we concluded that the modified membrane Si209 has a pore size larger than $5.5 \AA$ and smaller than $15 \AA$. The modified membrane Si207, on the other hand, demonstrated a He/SF 6 separation selectivity around 9.06 which is much higher than Knudsen separation. Although there is no molecular sieving separation, the high separation selectivity indicates that the pore size of this membrane is close to kinetic diameter of $\mathrm{SF}_{6}$ which is $5.5 \AA$. This also indicated that in order to obtain a high $\mathrm{He} / \mathrm{N}_{2}$ separation selectivity at room temperature, the pore size of these silica modified membranes should be $-5 \AA$. In this section, we will focus on the separation of hydrogen-containing gas mixtures with membranes of a pore size $<5 \AA$ or close to dense phase.

\section{Literature Review on Si-Modified Membranes}

$\mathrm{SiO}_{2}$-modified membranes provide a very high selectivity of hydrogen. It potentially offers a new energy-efficient process to recover hydrogen. Table 6.1 summarizes the permeabilities of the hydrogen-selective membranes discussed in the literature. The separation mechanism, although was explained by those authors, was still not very clear.

Goldsmith et al. (1992) reported the permeation tests of $\mathrm{He}, \mathrm{CO}_{2}, \mathrm{Ar}$ and $\mathrm{N}_{2}$ using $\mathrm{SiO}_{2}$-modified membranes. The permeability of $\mathrm{He}$ obtained was 0.155

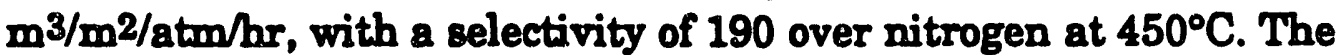
separation mechanism was explained by molecular sieving. The pore size was estimated in the range of 5 to $10 \AA$.

Megiris and Glezer (1992), and Gavalas et al. (1990 and 1989) suggested that a non-porous $\mathrm{SiO}_{2}$ film was deposited on the porous support of their hydrogen-selective membranes. The gas separation mechanism was "solid solution diffusion" through the dense film. Hydrogen is dissolved and diffused through the dense $\mathrm{SiO}_{2}$ membrane. The permeation was a function of temperature. Since the $\mathrm{H}_{2}$ mobility in the $\mathrm{SiO}_{2}$ film increases with the temperature increase, the hydrogen permeability is significantly increased at a higher temperature. The permeation ratio of $\mathrm{H}_{2}$ to $\mathrm{N}_{2}$ was reported from 200 to 3000 at $450 \sim 750^{\circ} \mathrm{C}$ depending on the permeation rate. In general, the higher the permeation rate is, the lower the selectivity is. They also investigated the hydrothermal stability of their membranes 


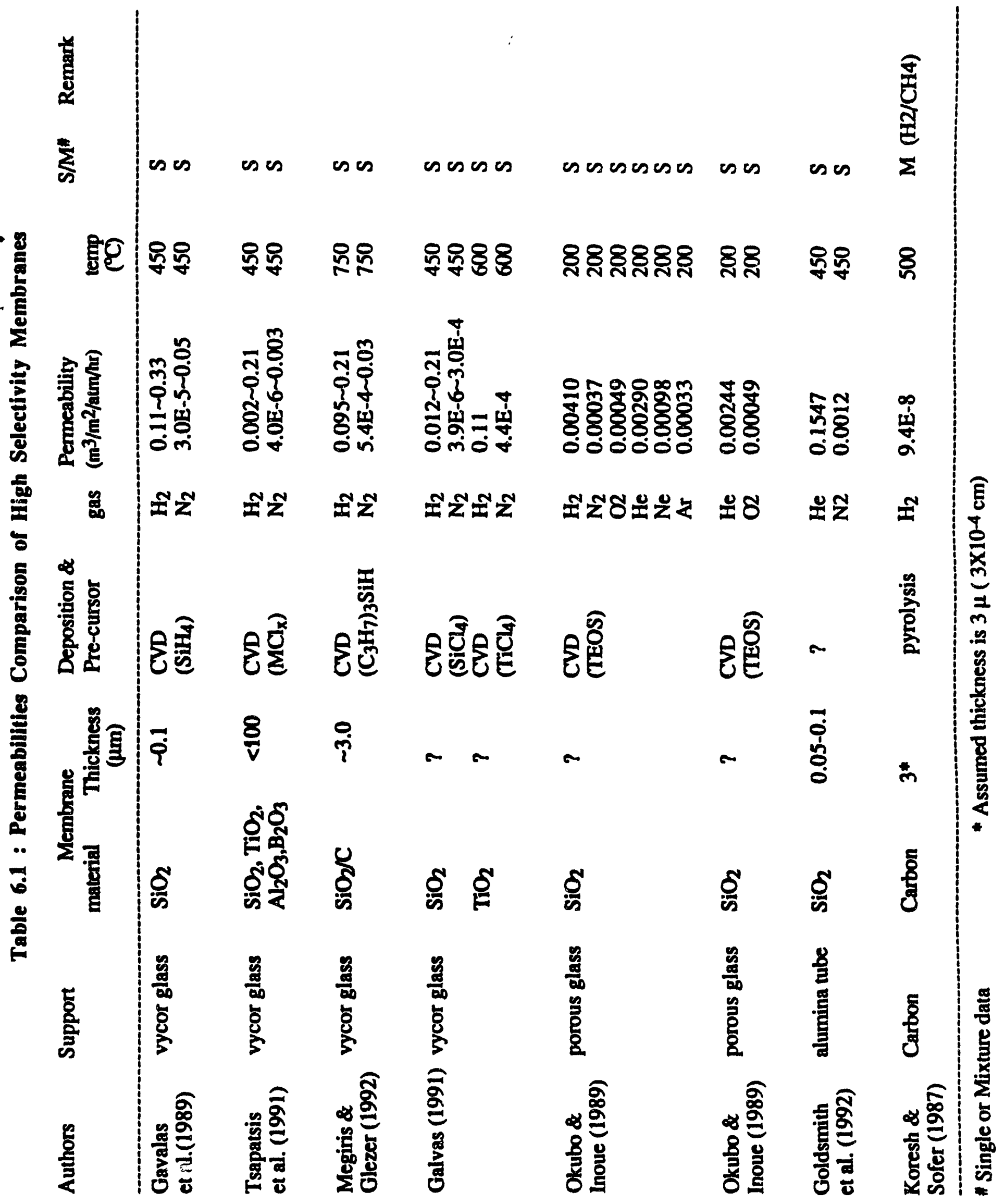


(Gavalas, 1991). The test was carried out in an environment that contained $23 \% \mathrm{H}_{2}, 27 \% \mathrm{CO}, 32 \% \mathrm{H}_{2} \mathrm{O}$ and $18 \% \mathrm{CO}_{2}$ at $600^{\circ} \mathrm{C}$ for up to 3 days. The permeation rate of $\mathrm{H}_{2}$ decreased from 0.31 to 0.075 ( $\left.\mathrm{cm}^{3} / \mathrm{cm}^{2} / \mathrm{min} / \mathrm{atm}\right)$, while that of $\mathrm{N}_{2}$ dropped from 0.0003 to 0.0001 ( $\left.\mathrm{cm}^{3} / \mathrm{cm}^{3} / \mathrm{min} / \mathrm{atm}\right)$. The separation selectivity slightly decreased after the 3 days of the hydrothermal treatment.

Okubo and Inoue (1989 a,b) reduced the pore size by $\mathrm{SiO}_{2}$ through a CVD process. Gas permeation was suggested through "micropore diffusion", thus, gas with a smaller molecular size gave a higher permeability. The permeation mechanism was estimated to be diffusion through the pores small enough to deviate from Knudsen diffusion. The permeation was also a function of temperature, which follows the Arrehnius equation. The solution-diffusion mechanism was ruled out by comparing the apparent activation energies of He permeation in glass and fused silica. The He apparent activation energy of diffusion in their membrane was $3.9 \mathrm{KJ} / \mathrm{mole}$, while that of vycor glass (non-porous) and fused silica were $21 \mathrm{KJ} / \mathrm{mole} . \mathrm{N}_{2}$ with a kinetic diameter of $3.64 \AA$ might be larger than the pore diameter, thus no permeation of nitrogen was observed. However, the small $\mathrm{N}_{2}$ permeation observed was attributed to the minor defect of the membrane. As a result, the permeability of $\mathrm{N}_{2}$ followed Knudsen diffusion, i.e., decreased with temperature increase.

Based on the above review, the $\mathrm{SiO}_{2}$-modified membrane was believed to be microporous layer with pore size within the micropore diffusion range or molecular sieving. Goldsmith et al. and Okubo et al. came to the same conclusion. The dissolution process suggested by Gavalas et al. failed to explain the high permeation rate of He reported by Okubo and Goldsmith. He was an inert gas and should not have interaction with the silica surface. In addition, the diffusion activation energies of $\mathrm{He}$ in the membrane was far smaller than that of the dense glass film. The molecule of $\mathrm{He}$ is so small that it could penetrate the microporous structure of the $\mathrm{SiO}_{2}$ film, thus it delivers high permeability. The penetration of He through the network of $\mathrm{SiO}_{2}$ structure is possible but rather unlikely. The He permeation rate (Boyd and Thompson, 1980) in the dense glass was almost 5 to 6 orders of magnitude less than the $\mathrm{H}_{2}$ permeation rate reported by Gavalas.

\subsection{Separations of Gas Mixtures using Si-Modified Membranes}

The method of $\mathrm{SiO}_{2}$-modified membrane was discussed in Section 4. A one inch tube was first synthesized, later a $10^{n}$ tube was also synthesized. The silica content of modified membranes was determined with electron microprobe (or EDAX) throughout the permselective layer of the alumina membrane. The layer structure was also examined by scanning electron microscopy (SEM). 
Single gas permeation test was used to evaluate the separation performance of the $1^{n} \mathrm{SiO}_{2}$-modified membrane. The membrane was housed in a stainless steel module. Permeabilities of $\mathrm{N}_{2}, \mathrm{H}_{2}, \mathrm{He}$ and $\mathrm{Ne}$, were measured at 300,450 and $600^{\circ} \mathrm{C}$. Feed flow at $\sim 10 \mathrm{l} / \mathrm{min}$, and feed pressure from 20 to 80 psig were selected by adjusting the back pressure regulator of the reject stream. Permeate was open to atmosphere and flow rate was measured by a bubble meter.

\subsubsection{Single Gas Permeation}

Figure 6.2 presents the permeability at elevated temperatures. He and $\mathrm{H}_{2}$ permeabilities increased with the temperature increase while the $\mathrm{N}_{2}$ permeability decreased. In addition, Ne permeability slightly decreased along with the temperature increase. Some of the phenomena were also reported by Gavalas et al. (1989) and Okubo and Inoue (1989) with modified vycor glass membranes. At $600^{\circ} \mathrm{C}$, the ratio of $\mathrm{He}$ to $\mathrm{N}_{2}$ is 59 and $\mathrm{H}_{2}$ to $\mathrm{N}_{2}$ is 28 , which is much higher than the theoretical Knudsen separation. Under the Knudsen regime, the permeability ratio of $\mathrm{He}$ to $\mathrm{N}_{2}$ is 2.6 and that of $\mathrm{H}_{2}$ to $\mathrm{N}_{2}$ is 3.7 for a $50 \AA$ membrane.

The kinetic diameter of $\mathrm{He}$ is the smallest one $(2.6 \AA)$, followed with $\mathrm{H}_{2}(2.89 \AA)$ and $\mathrm{Ne}(2.75 \AA) . \mathrm{N}_{2}$ has the largest kinetic diameter, 3.64 $\AA$. It is believed that membrane pores were reduced by $\mathrm{SiO}_{2}$ deposition. Gas permeation is through "micropore diffusion", thus, gas with a smaller molecular size gave a higher permeability.

\subsubsection{Mixture Separation}

A gas mixture of $69 \% \mathrm{~N}_{2}$ and $30 \% \mathrm{H}_{2}$, was used to simulate the composition of syn-gas provided by METC. Separation was carried out at $538^{\circ} \mathrm{C}$ and $7 \mathrm{~atm}$ at a total flow rate of about $1.0 \mathrm{~V} / \mathrm{min}$. Table 6.2 lists the separation results of $\mathrm{H}_{2}$ and $\mathrm{N}_{2}$. The $\mathrm{H}_{2}$ concentration increased from $31 \%$ to $73 \%$. The separation factor is 6.1 which is higher than Knudsen (3.74). However, the separation factor is still smaller than the permeability ratio (ca. $\sim 22$ ) of $\mathrm{H}_{2}$ to $\mathrm{N}_{2}$ of this modified membrane. This phenomenon was also observed in other modified membranes (Table 6.3). Silica modified membranes Si009, $\mathrm{Si018}, \mathrm{Si019}, \mathrm{Si022}$ and $\mathrm{Si} 024$ were investigated. $\mathrm{A} 47 \% \mathrm{~N}_{2}$ in $\mathrm{H}_{2}$ mixture was used in this binary mixture separation. In general, the separation selectivity observed in binary mixture separation is smaller than that which was based on single gas ratio. The permeated stream of modified membranes Si009 and Si024 show a great enrichment in $\mathrm{H}_{2}(92 \%)$. However, the separation selectivity remained around 10.6 and 11.3 , respectively. One should note that the permeability ratio of two gases can only present the ideal separation factor. The practical separation factor is determined not 


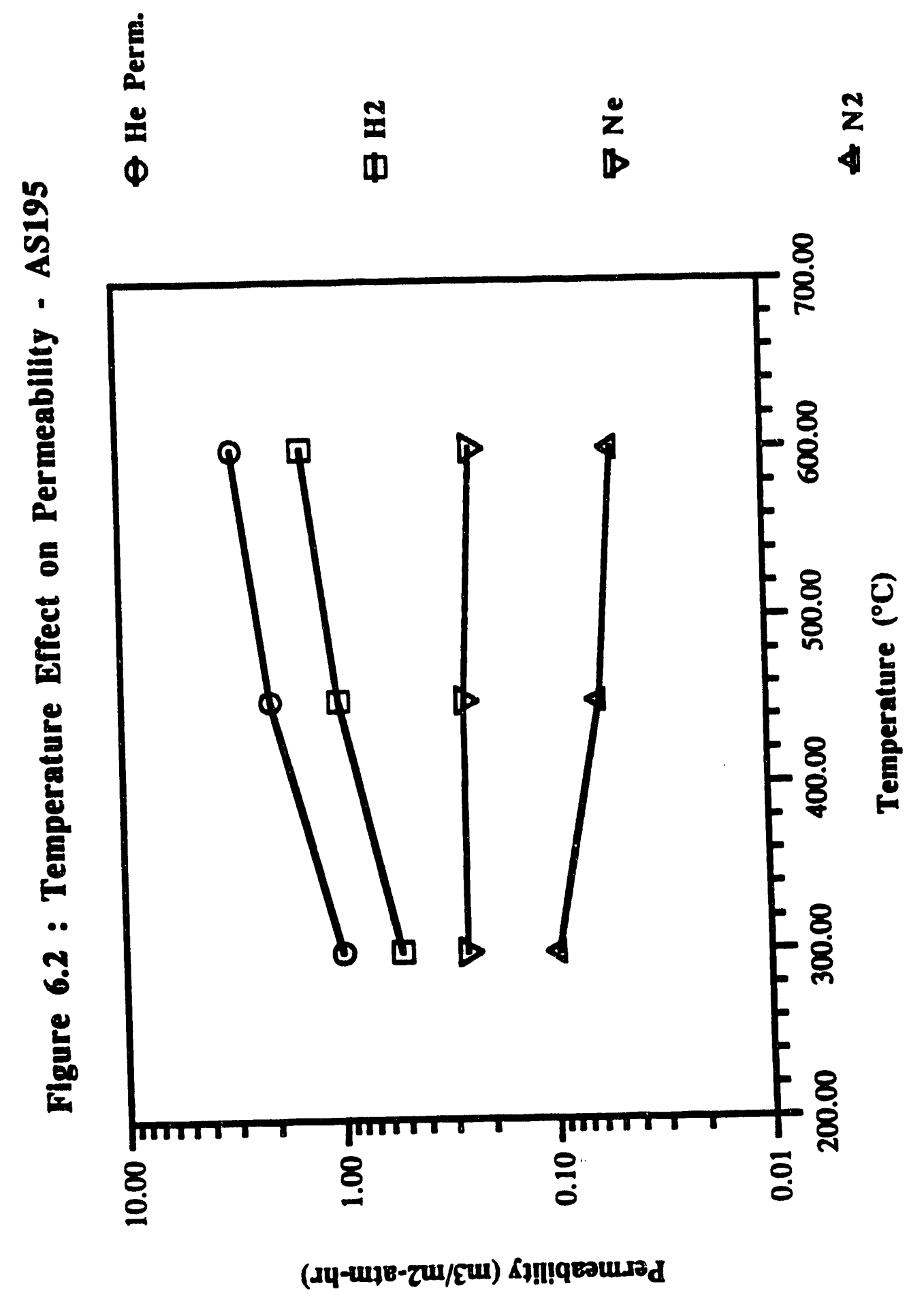


Table $6.2 \mathrm{H}_{2} / \mathrm{N}_{2}$ Separation in Modified Membrane - AS195

\begin{tabular}{|c|c|}
\hline \multicolumn{2}{|l|}{ Temperature: } \\
\hline $\begin{array}{l}\text { Feed Flow } \\
\text { Pressure }\end{array}$ & $\begin{array}{l}0.97 \mathrm{~V} / \mathrm{min} \\
7 \mathrm{~atm}\end{array}$ \\
\hline $\begin{array}{c}\text { Composition } \\
\mathrm{H}_{2} \\
\mathrm{~N}_{2}\end{array}$ & $\begin{array}{l}31.4 \% \\
68.6 \%\end{array}$ \\
\hline $\begin{array}{l}\text { Reiect } \\
\text { Flow } \\
\text { Pressure }\end{array}$ & $\begin{array}{l}0.95 \mathrm{~V} / \mathrm{min} \\
6.97 \mathrm{~atm}\end{array}$ \\
\hline $\begin{array}{c}\text { Composition } \\
\mathrm{H}_{2} \\
\mathrm{~N}_{2}\end{array}$ & $\begin{array}{l}30.9 \% \\
69.1 \%\end{array}$ \\
\hline $\begin{array}{l}\text { Permeate } \\
\text { Flow } \\
\text { Pressure }\end{array}$ & $\begin{array}{l}0.018 \mathrm{l} / \mathrm{min} \\
1 \mathrm{~atm}\end{array}$ \\
\hline $\begin{array}{c}\text { Composition } \\
\mathrm{H}_{2} \\
\mathrm{~N}_{2}\end{array}$ & $\begin{array}{l}73.5 \% \\
26.5 \%\end{array}$ \\
\hline Bressure ratio & 0.143 \\
\hline Stage cut & 0.019 \\
\hline Separation factor $\left(\mathrm{H}_{2} \mathrm{~N}_{2}\right)$ & 6.1 \\
\hline (Permeate $\left.\mathrm{H}_{2} \%\right) /($ Per & $\left.\mathrm{T}_{2} \%\right)$ \\
\hline
\end{tabular}


Table $6.3 \mathrm{H} 2 / \mathrm{N} 2$ Separation Selectivity of Silica ModifiedMembranes

\begin{tabular}{|c|c|c|}
\hline Somples & $\frac{\text { Temp }}{C}$ & $\mathrm{H} 2 / \mathrm{N}_{2}$ \\
\hline $\begin{array}{l}51009 \\
\text { S1009 }\end{array}$ & $\begin{array}{l}500 \\
500\end{array}$ & $\begin{array}{l}12.68 \mathrm{R} \\
10.59\end{array}$ \\
\hline $\begin{array}{l}\text { SiO } 18 \\
\text { SiO } 18 \\
\text { SiO } 18 \\
\text { S1O } 18\end{array}$ & $\begin{array}{r}20 \\
20 \\
500 \\
500\end{array}$ & $\begin{array}{l}1.86 \mathrm{~d} \\
0.91 \mathrm{~b} \\
2.66 \mathrm{a} \\
1.69 \mathrm{~b}\end{array}$ \\
\hline $\begin{array}{l}\text { SiO } 19 \\
\text { SiO } 19\end{array}$ & $\begin{array}{l}500 \\
500\end{array}$ & $\begin{array}{l}3.12 \mathrm{R} \\
1.27 \mathrm{~b}\end{array}$ \\
\hline $\begin{array}{l}\text { SiO22 } \\
\text { SiO22 } \\
\text { SiO22 } \\
\text { SiO22 }\end{array}$ & $\begin{array}{l}500 \\
500 \\
600 \\
600\end{array}$ & $\begin{array}{l}2.91 \mathrm{a} \\
1.23 \mathrm{~b} \\
3.72 \mathrm{~g} \\
1.54 \mathrm{~b}\end{array}$ \\
\hline $\begin{array}{l}\text { SiO24 } \\
\text { SiO24 }\end{array}$ & $\begin{array}{l}500 \\
500\end{array}$ & $\begin{array}{l}25.00 \mathrm{R} \\
11.34 \mathrm{~B}\end{array}$ \\
\hline
\end{tabular}


only by the membrane property but also by the pressure difference across the membrane. From the viewpoint of gas mixture separation, there is always a limitation in separation factor. Since pressure is the only driving force, the partial pressures of each component in permeate can never be larger than that of the reject. In practice, permeate pressure always exists, so the real separation factor is never equal to the ideal separation factor. Unless a membrane has infinite selectivity, the separation factor never reaches infinity.

As discussed in Sec. 4, a modified membrane with a nearly infinite selectivity of hydrogen over nitrogen was developed via a chemical vapor deposicion. Gaseous mixture separations with a membrane like this failed due to the leak of nitrogen through the graphite packing. It is believed that a nearly pure hydrogen stream could be obtained provided a perfect seal could be developed.

\subsection{Removal of Trace Contaminants}

$\mathrm{H}_{2} \mathrm{~S}$ and $\mathrm{NH}_{3}$ are the two trace contaminants which may be removed via decomposition. Ceramic membranes with a selectivity to hydrogen may facilitate the decomposition of these contaminants via the catalytic membrane reactor approach. The concept has been demonstrated experimentally and analyzed mathematically for several key chemical production processes. A mathematical analysis was performed to assess the feasibility of the trace contaminants removal under the coal gasifications environment.

To simplify the analysis, a feed containing $\mathrm{H}_{2}, \mathrm{~N}_{2}, \mathrm{H}_{2} \mathrm{~S}$ and $\mathrm{NH}_{3}$ was shown in Figure 6.3. Other contaminants, e.g., $\mathrm{CO}$ may be present and are ignored without compromising the feasibility analysis. Our analysis selected the extreme temperatures and pressures encountered in the coal conversion environment. That is, temperatures were at 538 and $1093^{\circ} \mathrm{C}$ and pressures were at 6 and 32 atm, respectively. The simulation conditions are also summarized in Figure 6.3.

The effluent composition is listed in Table 6.4 and summarized in Figure 6.4 for the most favorable condition, i.e., no limitation and reactor kinetics. At $1100^{\circ} \mathrm{C}$, the effluent ammonia in the feed should be decomposed nearly completely even without the removal of hydrogen by the membrane. It indicates that the thermodynamics for the decomposition of ammonia is favorable. However, at a lower temperature and a lower pressure, i.e., $540^{\circ} \mathrm{C}$ and $6 \mathrm{~atm}$, the membrane reactor could enhance the conversion of $\mathrm{NH}_{3}$ from $50 \%$ at equilibrium to $70 \%$. No $\mathrm{H}_{2} \mathrm{~S}$ decomposition was found for the system with or without the catalytic membrane reactor. The potential pressure of hydrogen required from $\mathrm{H}_{2} \mathrm{~S}$ decomposition is too low to be practical, (i.e., low equilibrium conversion coupled with low concentration of $\mathrm{H}_{2} \mathrm{~S}$ ). However, the above analysis does not account for the enhancement through reaction rate due to the removal of hydrogen. No simulation was 
Figure 6.3 : Simulation Conditions of Catalytic Membrane Reactor

5 Components System - H2, N2, S2, NH3, H2S

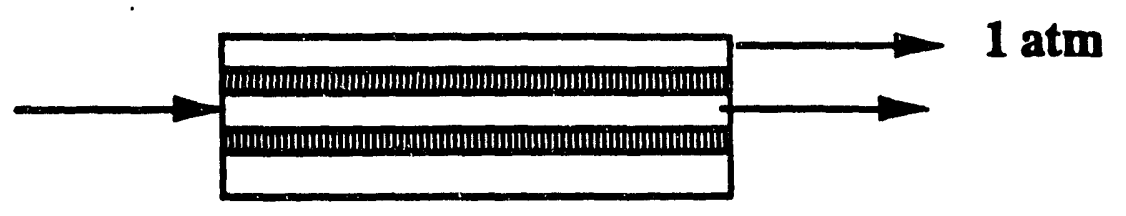

Plug flow @ Fast reaction rates

Feed conditions : $\quad \mathrm{N} 2 \quad 70.5 \%$

$\mathrm{H} 2 \quad 29.4 \%$

H2S $0.73 \%$

NH3 $0.44 \%$

Couversion $=\frac{\text { Feed NH3 }-(\text { reject NH3 }+ \text { Permeate NH3) }}{\text { Feed NH3 }} \times 100$

Case 1: $\mathrm{T}=811 \mathrm{~K} \quad \mathrm{P}=6.0 \mathrm{~atm}$

Case 2: $\mathrm{T}=811 \mathrm{~K} \quad \mathrm{P}=32.0 \mathrm{~atm}$

Case 3: $T=1366 \mathrm{~K} \quad P=6.0 \mathrm{~atm}$

Case 4: $T=1366 \mathrm{~K} \quad P=32.0 \mathrm{~atm}$

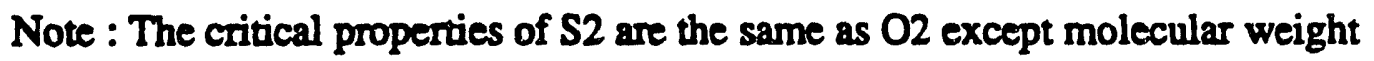


Table 6.4 The Simulated Decompositions of $\mathrm{NH}_{3}$ and $\mathrm{H}_{2} \mathrm{~S}$ in Reducing Conditions

Based on Ideal Knudsen Separations

\begin{tabular}{ccccccccc}
$\begin{array}{c}\text { Temperature } \\
\left({ }^{\circ} \mathrm{C}\right)\end{array}$ & $\begin{array}{c}\text { Total pressure } \\
\text { (atm) }\end{array}$ & \multicolumn{3}{c}{$\begin{array}{c}\mathrm{NH}_{3} \\
\text { (mole \%) }\end{array}$} & \multicolumn{3}{c}{$\begin{array}{c}\mathrm{H}_{2} \mathrm{~S} \\
\text { (mole \%) }\end{array}$} \\
\hline & & In & Out & E.Q. & In & Out & E.Q. \\
\hline 538 & 6.0 & 0.44 & 0.13 & 0.22 & 0.73 & 0.73 & 0.73 \\
538 & 32.0 & 0.44 & 0.54 & 0.64 & 0.73 & 0.73 & 0.73 \\
& & & & & & & \\
1093 & 6.0 & 0.44 & 0.01 & 0.01 & 0.73 & 0.73 & 0.73 \\
1093 & 32.0 & 0.44 & 0.04 & 0.04 & 0.73 & 0.73 & 0.73 \\
\hline
\end{tabular}




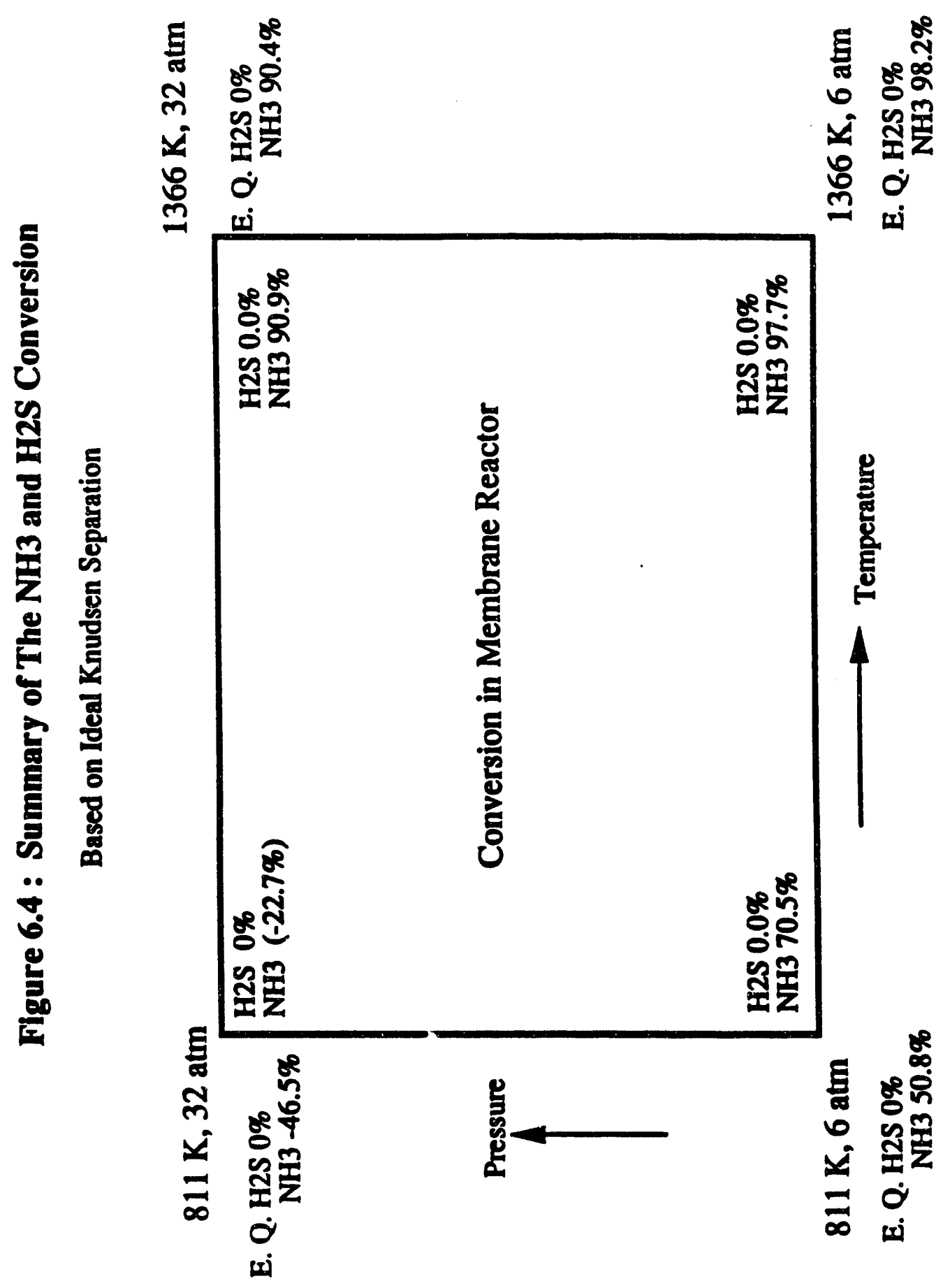


performed due to the lack of the reaction kinetic information.

The above analysis was further explored using a hydrogen selective membrane, i.e., selectivity of $\mathrm{H}_{2} / \mathrm{N}_{2}=-25$. The results are summarized in Table 6.5 and Figure 6.5). At high temperature side $\left(1093^{\circ} \mathrm{C}\right)$, this membrane showed no significant improvement for $\mathrm{NH}_{3}$ decomposition because the equilibrium conversion is high under such conditions. At low temperature side $(811 \mathrm{~K})$, the $\mathrm{NH}_{3}$ decomposition is greatly increased to $70.5 \%$ at $32 \mathrm{~atm}$ and $88.6 \%$ at $6 \mathrm{~atm}$. This indicated that the $\mathrm{H}_{2}$-selective membrane is superior to the existing membrane for $\mathrm{NH}_{3}$ decomposition. However, there is still no $\mathrm{H}_{2} \mathrm{~S}$ decomposition using such a membrane due to very small equilibrium constant of $\mathrm{H}_{2} \mathrm{~S}$. It is concluded that a hydrogen selective membrane, as those described in Section 4, is promising in removing $\mathrm{NH}_{3}$ at the lower temperatures of the coal conversion process through the coupling of the hydrogen production enrichment. Further economic analysis is suggested to determine the viability of the proposed process. 


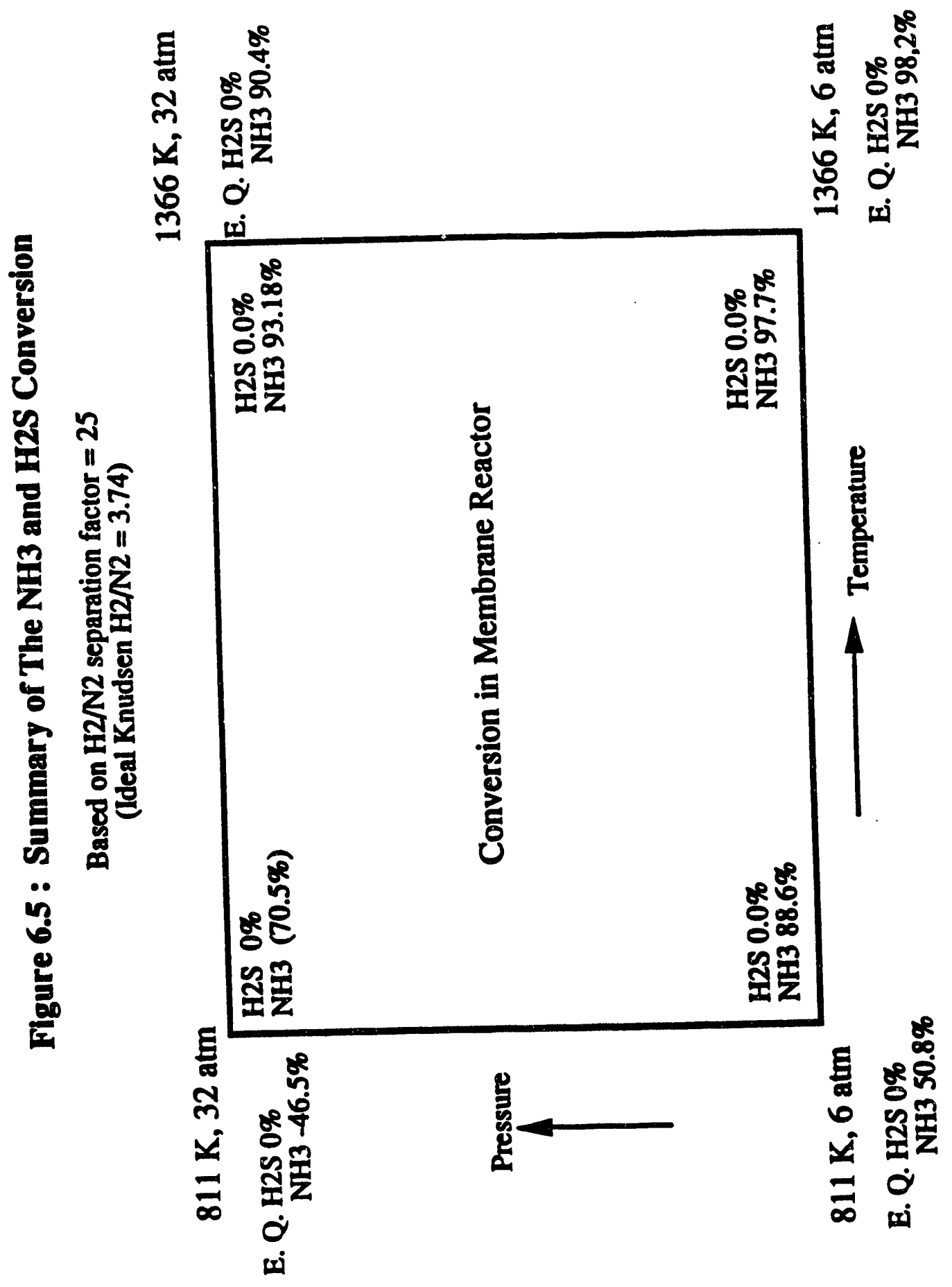




\section{Canclusion}

1. A pore size distribution analysis was established to determine the flowweighted pore size of an asymmetric membrane. It provides an effective tool for synthesis and characterization of microporous membranes.

2. The smallest pore size of the existing membrane available was confirmed with the pore size distribution analyzer to be $40 \AA$. It shows excellent thermal and moderate hydrothermal stability at ${ }^{-} 600^{\circ} \mathrm{C}$. Deterioration of the microporous structure was observed under an alkali environment.

3. Existing membranes demonstrate gas separation following Knudsen diffusion. A mathematical model has been developed to predict the gas separation efficiency at a high temperature environment.

4. Pore size of the existing membranes was reduced to $<10 \AA$ and dense phase via chenical vapor deposition of silica and zirconia. Silica dense-phase membranes show a unique selectivity for hydrogen at a high temperature. Further, the dense membranes demonstrate thermal and hydrothermal stability at $600^{\circ} \mathrm{C}$ after initial densification.

5. In-situ crystalization was pursued to develop a zeolitic membrane. Our result shows inclusion of zeolitic structure with existing membranes; however, minor cracks exist. Several post-treatment studies show promising results to remedy the cracks.

6. Decomposition of trace ammonia contaminant via catalytic membrane reactor was explored. The hydrogen selective membrane provides a viable avenue for amrnonia removal via decomposition. Further economic analysis is required to assess its commercial viability. 


\section{List of symbols}

A : coefficient defined in eq. 8

$A^{\prime} \quad$ : modified A coefficient defined in eq. 16

$B$ : coefficient defined in eq. 11

B $\quad$ : modified B coefficient defined in eq. 17

Cp : permeability of single gas [mole-m/(s-m $\left.\left.\mathrm{m}^{2}-\mathrm{Pa}\right)\right]$

$\mathrm{D}_{12}$ : diffusion coefficient $\left[\mathrm{m}^{2 / \mathrm{s}}\right]$

fo : coefficient defined in eq. 9

g : coefficient defined in eq. 8

$g^{\prime} \quad:$ coefficient defined in eq.15

k : Boltrmann constant $=1.381 \times 10-23[\mathrm{~J} / \mathrm{K}]$

L : Avogadro number $=6.023 \times 1023[1 / \mathrm{mole}]$

$\mathrm{m} \quad$ : mass of one molecule [Kg]

$\mathrm{m}+\quad$ : mass defined in eq. $13[\mathrm{Kg}]$

$\mathrm{m}_{1}$ : mass of one molecule of light component [Kg]

$\mathrm{m}_{2}$ : mass of one molecule of heavy component [Kg]

$m_{x} \quad$ : mass defined in eq $12[\mathrm{Kg}]$

n : molar flux [mole/s/m $\left.\mathbf{m}^{2}\right]$

n1 : molar flux of light component [mole/s/m

n2 : molar flux of heavy component [mole/s/m

$n_{k} \quad$ : pore number per unit area of membrane [1/m2]

$\overline{\mathrm{p}} \quad$ : average pressure across the membrane $[\mathrm{Pa}]$

p : pressure [Pa]

$\mathrm{P}_{\mathrm{h}} \quad$ : feed pressure $[\mathrm{Pa}]$

$\mathrm{P}_{1} \quad$ : permeate pressure $[\mathrm{Pa}]$

Pr : pressure ratio of permeate to feed [-]

QF : Feed molar flow [mole/s]

$Q_{P} \quad:$ Permeate molar flow [mole/s] 


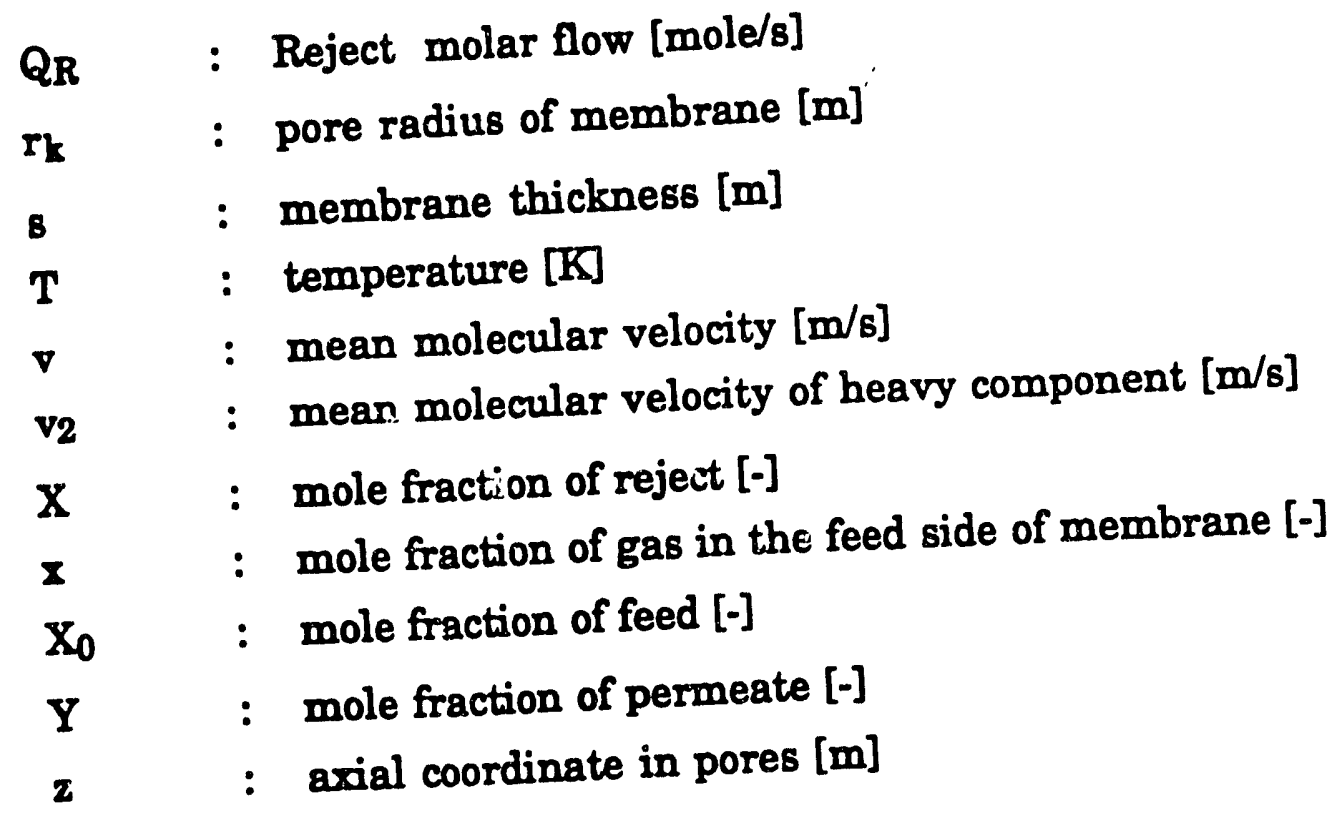

\section{Greek Symbols}

$\alpha \quad:$ separation factor defined in eq. $24[-]$

$\alpha_{0}:$ theoretical Knudsen separation factor $=\left(\mathrm{m}_{2} / \mathrm{m}_{1}\right)^{1 / 2}$

B : reflection coefficient in eq. $22[-]$

$\eta \quad$ : gas viscosity $[\mathrm{Pa} \cdot \mathrm{s}]$

$\lambda \quad:$ mean free path of molecule [m]

$\theta$ : stage cut, the ratio of permeate flow to feed flow [-]

$\sigma \quad:$ collision diameter [m]

$\sigma^{*}$

: mean collision diameter [m] 


\section{Refierences}

Abe, F.; Y. Fujita, JP 63287504 A2 24 Nov (1988).

Balog, M.; M. Schieber; M. Michman; Patai, S.,Thin Solid Films, 47, 109, (1977).

Bird, R. B., W. E. Stewart, and E. N. Lightfoot, "Transport Phenomenon", John Wiley and Sons, New York 510 (1960).

Boyd, D. C. and D.A. Thompson, "Glass," Encyclopedia of Chemical Technology, 3rd ed., vol. 11 John Wiley and Sons, New York, 807-880 (1980).

Eickmann, U. and U. Werner, German. Chem. Eng. 8, 186 (1985).

Fain, D. E. and W. K. Brown, "Neon Isotope Separation by Gaseous Diffusion Transport in the 'Transition Flow Regime with Regular Geometries", DOE repcrt, Union Carbide Cor., Nuclear Division, Oak Ridge Gaseous Diffusion Plant, Rpt. \# K-1863, unclassified, Sept. (1974).

Fain, D.E., G. E. Roettger, and D. E. White, "Development of Ceramic Membranes for Gas Separation", FY1990 Development Activities, K/QT-413, Martin Marietta Energy Systems, Inc., Oak Ridge K-25 Site, Oak Ridge, Tennessee, June (1991).

Gallaher, G. R. Jr., J. C. S.Wu, M. P. Pagano, T. E. Gerdes, R. Bhave, and P. K. T. Liu, The Stability of a Commercial Ceramic Membrane used as a Dehydrogenation Reactor, International Congress on Membranes and Membrane Processes, August 1990, Chicago, U. S. A. Paper 30F and unpublished Alcoa internal reports.

Gavalas, G. R., C. E. Megiris, and S. W. Nam, Chemical Engineering Science, vol. 44(9), 1829, (1989).

Gavalas G. R.; Altadena, Calif.; Megiria, C. E., Eemnes, N.; U. S. Patent 4,902,307, Feb., (1990).

Gavalas, G. R., Hydrogen Separation by Ceramic Membranes in Coal Gasification, Proceedings of the Eleventh Annual Gasification and Gas Stream Cleanup Systems Contractor Review Meeting, Morgantown, WV, DOE, August (1991).

Goldman, M; D. Fraemle; G. Levin, J. Appl. Polm., 37, 179, (1989).

Goldsmith, R. L., R. J. Higgins, and B. A. Bishop, "Low-Cost Ceramic Membranes and Supports for Gas Separation," DOE Contract Review Meeting (1992).

Haraya, K, Y. Shindo, T.Hakuta, and H. Yoshitome, J. Chem Eng. Japan, 19(3), 186 (1986a). 
Haraya, K., Y. Shindo, T. Hakuta, and H. Yoshitome, J. Chem. Eng. Japan, 19 (5), 461 (1986b).

Haraya, K. T. Hakuta, H.Yoshitome, and S. Kimura, Separation Science \& Tech., 22(5), 1425 (1987).

Huckins, H. E. and K. Kammermeyer, Chem. Eng. Prog., 49(6), 294 (1953).

Hwang, S.-T. and K. Kammermeyer, Can. J. Chem. Eng., 44, 82 (1966).

Ishikaqa, A.; T. H. Chiang; F. Toda, J. Chem. Soc., Chem. Commun., 765, (1989).

Kao, Y.-K., M.-M.Qiu, and S. -T.Hwang, Ind. Eng. Chem. Res., 28, 1514 (1989).

Keizer, K., R. J. R. Uhlhorn, R. J. van Vuren and A. J. Burggraaf, J. Mem. Sci., 39,285 (1988).

Kirshnamoorthy,P.R.; P. Ramaswamy; B. H. Narayana, "Modified Interphases in Composite Materials", Elsevier Science Co., 1579, 1990.

Kulprathipanja, S. ; R. W. Neuzil; N. N. Li; U.S. 4740219 A26 Apr. (1988).

Larson, J. W., “ Modern Power System,” 39, January (1981).

Leenaars, A. F. M., K. Keizer and A. J. Burggraaf, J. Mem. Sci., 19, 1077 (1984) .

Li, K, D. R. Acharya, and R. Hughes, Gas Separation \& Purification, 4, 81 (1990).

Matsushita Electric Industrial Co., Ltd. Jpn. Kokai Tokkyo Koho, 2pp JP 60129119 A2 10 Jul (1985).

Megiris, C. E. and J. H. E. Glezer, Ind. Eng. Chem. Res. vol. 31, 1293 (1992).

Murrell, L.L., N. C. Dispenziere, J. of Çatal.,111, 450, (1988).

Nam, S. W.; G. R. Gavalas; AIChE Symposium Series, 85 (268), 68, (1989).

Niewa, M, S. Kato, T. Hattori and Y Murakami J. Chem. Soc., Farad. Trans. I, 80, 3135, (1984).

Niewa, M.; Y. Murakami;Materials Chemistry and Physics, 17, 73, (1987).

Niewa, M.; Y. Murakami; J. Phys. Chem. Solids 50, 487, (1989).

Okubo, T. and H. Inoue, J. Membrane Science, vol. 42, 109 (1989a).

Okubo T. and H. Inoue, AIChE Journal, Vol. 35(5), 845 (1989b).

Pan, C. Y. and H. W. Habgood, Ind. Eng. Chem., Fundam., 13(4), 323 (1974). 
Pan, C. Y. and H. W. Habgood, Can. J. Chem. Eng., 56, 197 (1978).

Present, R. D. and A. J. DeBethune, Physical Review, 75 (7), 1050 April 1 (1949).

Reed, G.P., Filteration \& Separation, 106, March/April (1985).

Reid, R. C., J. M. Prausnitz, and B. E. Poling, "The Properties of Gases and Liquids", 4th edition, McGraw-Hill, New York, 397 (1987).

Rojey, A.; A. Deschamps; A. Grehier; E. Robert, Eur. Pat. appl.,(EP 324675), (1989).

Sakurada, S.; N. Tagaya; T. Maoshima; T. Isoda, Canadian Patent 1235684, (1989).

Sasaki, T. JP 01110541 A2 (1989).

Schaper, H., E. B. M. Doesburg, L. L.Van Reijen, Applied Catalysis, 7, 211, (1983).

Schmitt, R. W., J. Inst. Energy, vol 54, 63 (1980).

Shindo,Y., T. Hakuta, H. Yoshitome, H. and Inoue, J. of Chem. Eng. Japan, 6(2), 120 (1983).

Shindo, Y., T. Hakuta, H. Yoshitome, and H. Inoue, J. of Chem. Eng. Japan, 17(6), 650 (1984).

Shindo, Y., N.Itoh, and K. Haraya, Separation Science \& Tech.,24 (7\&8), 599 (1989).

Somiya, Yoshimura, Kurita, Ryuichi, and Hori; Report of the Research Laboratory of Engineering Materials, Tokyo Institute of Technology, Nov., (1985).

Sterzel, H. J.; A. Sanner, DE 3407149 A1 29 Aug (1985).

Suruki, H., J P 60028826 (1985).

Suzuki, H., Eupr. Patent 135069, (1985).

Suruki, H., US Pat.4699892 (1987).

Tock, R. W. and K. Kammermeyer, AIChE Journal, 15 (5), 715, Sept. (1969).

Tranchino, L., R. Santarossa, F. Carta, C. Fabiani, and L. Bimbi, Separation Science \& Tech. 24 (14), 1207 (1989).

Uhlhorn, R. J. R., K. Keizer, and A. J. Burggraaf, J. Membrane Science, 46, 225 (1989). 
Wu, J. C. S. and P. K. T. Liu, Ind. Eng. Chem. Res., 31, 322 (1992).

Yang, R.T., Butterworths, 109 (1987). 


\section{APPENDIX}

\section{FORTRAN Program:}

Binary Mixture Separation 
Notes of the Program for Gas Separations using Ceramic Membrane

This program is used to predict the separation of a binary gas mixture in ceramic membranes at high temperature. Basically it followed the method of Eickmann and Werner's paper (1985). The separation mechanism included Knudsen diffusion, viscous flow, and Poiseulle flow. Two modifications are added in our calculation. When calculating the mole fraction of permeate stream, the stage cut $(\theta)$ is introduced to reflect the real membrane separation. The fitting narameters, $n_{k}$ and $\beta$, are averaged by mole fractions of binary mixture in the feed.

The surface diffusion is not considered in the calculation. Pore size growth due to elevated temperatures is considered in the program. However, if the operating temperature is exceeded $811^{\circ} \mathrm{C}$, the calculation will based on the internal data at $811^{\circ} \mathrm{C}$. In addition, the $n_{k}$ and $\beta$ of $\mathrm{H}_{2}$ and $\mathrm{N}_{2}$ are corrected according to the operating temperatures. The rest of components are not corrected by temperatures.

Only binary mixture can be calculated in this program at the present time. There are 13 components listed in the program, and the program can calculated the separation factor of any combination of two components. However, due to the lack of experimental data $n_{k}$ and $\beta$, only 4 components, $\mathrm{H}_{2}, \mathrm{CO}, \mathrm{N}_{2}$, and $\mathrm{CH}_{4}$ can be calculated. The calculated results from the rest of components are meaningless unless the $n_{\mathbf{k}}$ and $\beta$ are supplied.

The program runs at interactive mode. At the prompt, users need to input the names of components (either lower or upper cases), the pressures of feed and permeate side, the mole fraction of light components in feed, the operating temperature, and the stage cut (the ratio of permeate to feed).

An example to run this program in VAX computer is following;

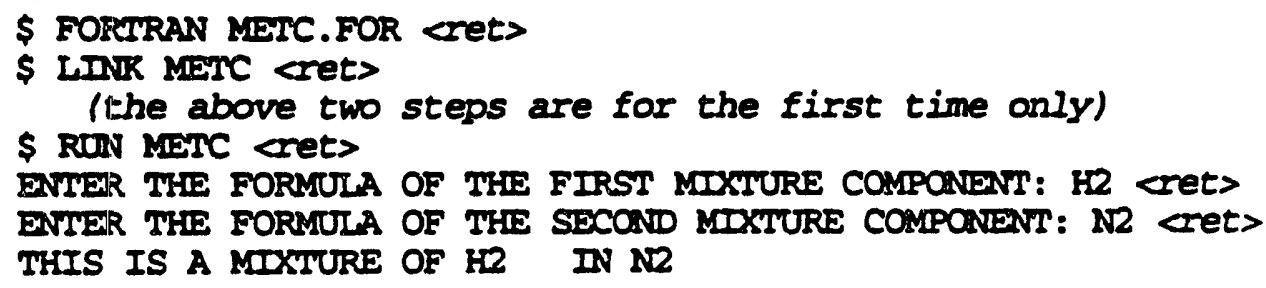


* of iteration is 10

The pressure at which ALPKA MAX can be obtained is $2.507 \mathrm{~atm}$.

\begin{tabular}{lcccr} 
Permeability & $\begin{array}{c}\mathrm{H} 2 \\
(\mathrm{~m} 3 / \mathrm{m} 2 / \mathrm{atm} / \mathrm{hr})\end{array}$ & $\begin{array}{c}\mathrm{N} 2 \\
(z)\end{array}$ & $(\mathrm{m} 3 / \mathrm{m} 2 / \mathrm{atm} / \mathrm{hr})$ & \multicolumn{1}{c}{$(z)$} \\
Knudsen & 173.8 & 49.5 & 27.7 & 20.8 \\
Poiseulle & 2.0 & 0.6 & 1.2 & 0.9 \\
Viscous & 175.4 & 49.9 & 104.2 & 78.3 \\
Total & 351.2 & & 133.1 & \\
FORIRAN STOP & & & &
\end{tabular}

The program is written in FORTRAN code, and is machine-independent. With the proper compilation, it should run in any computer although it has not been tested yet.

In the notation, some variables are defined in the Eickmann and Werner's paper. The equations' number in the notation are matched with those in the paper. 
Notation used in FORTRAN program

Name

Symbol

Unit

A

ALPHA

AMU, AMUP

APRIME

B

B1, B2

BETA

BETAVG

BPRIME

BY

C3, C4

D12

DIP

DP

EPP

F

G

GPRIME

I, J, K, ICOUNT, TRY

KNUD

L

LAMBDA

MPLUS

MX

NK

NKAVG

NU

NUBAR

PC

PH

PHI

PL

POIS

POPT

Q

QP

$\mathbf{R}$

RG

RHOC

RK
A $\quad$ Coefficient in eqn. 7

$\alpha$

$A^{\prime}$

B

$\beta$

Bave

B'

b'y)

$D_{12}$

$\varepsilon_{p}$
$f_{0}$

g,

$\lambda$

$\mathrm{m}^{+}$

$\mathbf{m}_{\mathbf{x}}$

$n_{k}$

$\mathbf{n}_{\mathbf{k}}$

$\underline{\mu}$

$\mu$

$\phi$

Coefficients in eqn. 19

Permeate side pressure

Poiseulle flow

$p_{h} \mid \alpha_{\max }$

Feed pressure at $\alpha_{\max }$ number of components

Total permeability

$\begin{array}{ll}r & \text { Pore radius } \\ \mathbf{R} & \text { Gas constant }\end{array}$

Pc Critical density

k
Boltzmann's constant
Separation factor

$A / \beta$ in eqn. 26

Dummy variables

$B \beta$ in eqn. 27

Diffusion coefficient

Dipole moment

Porosity of membrane

Coefficient in eqn. 6

Coefficient in eqn. 25

Knudsen permeability

Avogadro's number

path
Coefficient in eqn. 8

Fitting parameter in eqn. 25

.12

Fitting coefficient in eqn. 25

-

$\mathrm{m}^{2 / \mathrm{s}}$

debye

$\mathrm{Pa}$

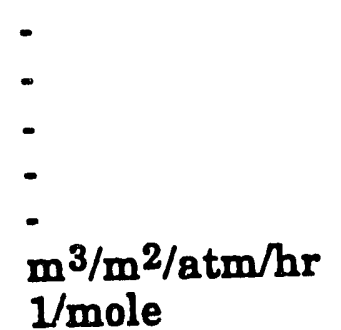

m

g/mole

g/mole

-

Pa-8

Pa-s

atm

atm

atm

$\mathrm{m}^{3} / \mathrm{m}^{2} / \mathrm{atm} / \mathrm{hr}$

atm

-

$\mathrm{m}^{3 / \mathrm{m}^{2} / \mathrm{atm} / \mathrm{hr}}$

$\mathrm{m}$

$\mathrm{J} / \mathrm{mole} / \mathrm{K}$

$\mathrm{g} / \mathrm{cm}^{3}$

J/K 
SIGMA

T1, T2, T3, T4, T5, T6

T1A, T6A

TC

THETA

TL

TR

UK

V2BAR

VBAR

VC

VISC

$\mathrm{X} 1$

$\mathrm{XM}$

XNMAE

$\mathrm{Y}$ $\theta$

$\sigma$

$\mathrm{v}_{12}$

$\bar{v}$

$\mathbf{y}$
Collision diameter

Dummy variables

Dummy variables

Critical temperature

Stage cut

Thickness of membrane

Reduced temperature

Shape factor, $1 /$ tortuosity

Mean molecule velocity

Mean molecule velocity

Critical volume

Viscous flow

Mole fraction of feed

molecular weight

molecule name (e.g. H2)

Mole fraction of permeate m

-

$\mathrm{K}$

m

-

$\mathrm{m} / \mathrm{s}$

$\mathrm{m} / \mathrm{s}$

$\mathrm{cm}^{3} / \mathrm{mole}$

$\mathrm{m}^{3 / \mathrm{m}^{2} / \mathrm{atm} / \mathrm{hr}}$

g/mole 
THIS PROGRAY TAKES INTO ACCOUNT THREE TRANSPORT MRCHANISMS, KNUDSEN DIFFUSION, VISCOUS FLOW, AND NON-SEPARATIVE DIFFUSION CAUSED BY INTER-MOLECULES MONENTUM TRANSFER.

THE PORE SIZES OF MEMBRANE ARE CORRECTED WITH TEMPERATURE.

CHARACTER*5 XNAME (13), NAME

INTEGER TRY

RENL INABDA, NU, NUBAR, NK, MX, MPLUS, PHI , KNUD, L, NKAVG

DIMIENSION XY(13),TC (13), PC (13), RHOC (13), VC (13), DP (13),

c DIP (13), SIGA (13),NU (13), NK (13), BETA (13).

C KANUd (2), POIS (2), VISC (2), QP (2), PHI (13,13),

c X_NK $(13,4), X_{\text {BETA }}(13,4)$

SEQUENCE OF GAS MOLECULES: NH3, CO2, CO, HE, H2, H2S, NO, N2, $\mathrm{NO} 2, \mathrm{O} 2, \mathrm{SO} 2, \mathrm{H} 2 \mathrm{O}, \mathrm{CH} 4$.

DATAI : CHARACTERISTICS OF GASES

XM, MOLECULAR WEIGIT, G/GSOLE

DIP, DIPOLE YOMENT, DEBYE

SIGYA, COLLISION DIANETER, WETER

TC, CRITICAI TEMTPEATURE, KELVIN

PC, CRITICAI PRESSURE, ATY

RHOC, CRITICAL DENISITY, G/CC

DATA2 : CHARACTERISITCS OF YEQBRANES

EP, POROSITY, -

UK, SHAPE PACTOR, OR 1/TORTUOSITY, -

$R$, PORE RADIUS, $Y$

TL, THICKNESS OF THE MERGRANE LAYER, M

DATA 3 : X_NK, 1/42

DATA 4 : X_BETA, -

c

PL, PERYEATE pRESSURE, ATY

PH, FEED PRESSURE, ATM

T, OPERATING TEAPERATURE, KELVIN

X1. HOLE PRACTION OR LIGHTER COAPONENT IN FEED, -

$Y$, YOLE FRACTION OF LIGHTER COAPONENT IN PERAEATE, THETA, STAGE COT (PERYEATE FLOW/FEED FLOW). -

c

NAYDISTS /DATAI/ XX,DIP,SIGA,TC, PC, RHOC

/DATA2/ EP, UK, R, TI

OPEN (UNIT=1, FILE ' MIX1 .DAT', STATUS= ' OLD') OPEN (UNIT =2, PIIE= 'MIX2 . DAT' , STATUS=' OLD') OPEN (UNIT=3, PILE= 'MIX3 .DAT' , STATUS= ' OLD') OPEN (UNIT=4, FILE= 'MIX4 . DAT' , STATUS= 'OLD') $\operatorname{READ}(1$, DATA1)

$\operatorname{READ}(2, \mathrm{DATA} 2)$

DO $1 \quad I=1,13$

$\operatorname{READ}(3, *) \quad(X \operatorname{NK}(I, J), J=1,4)$

DO $2 I=1,13$

$2 \operatorname{READ}(4, *) \quad\left(X \_B E T A(I, J), J=1,4\right)$

$T R Y=0$

402 WRITE $(6,400)$

400 FORYAT(' ENTER THE FORMULA OF THE FIRST MIXTURE COMPONENT: ',\$)

10 REND $(5,450)$ NME

450 PORMAT(A5) 


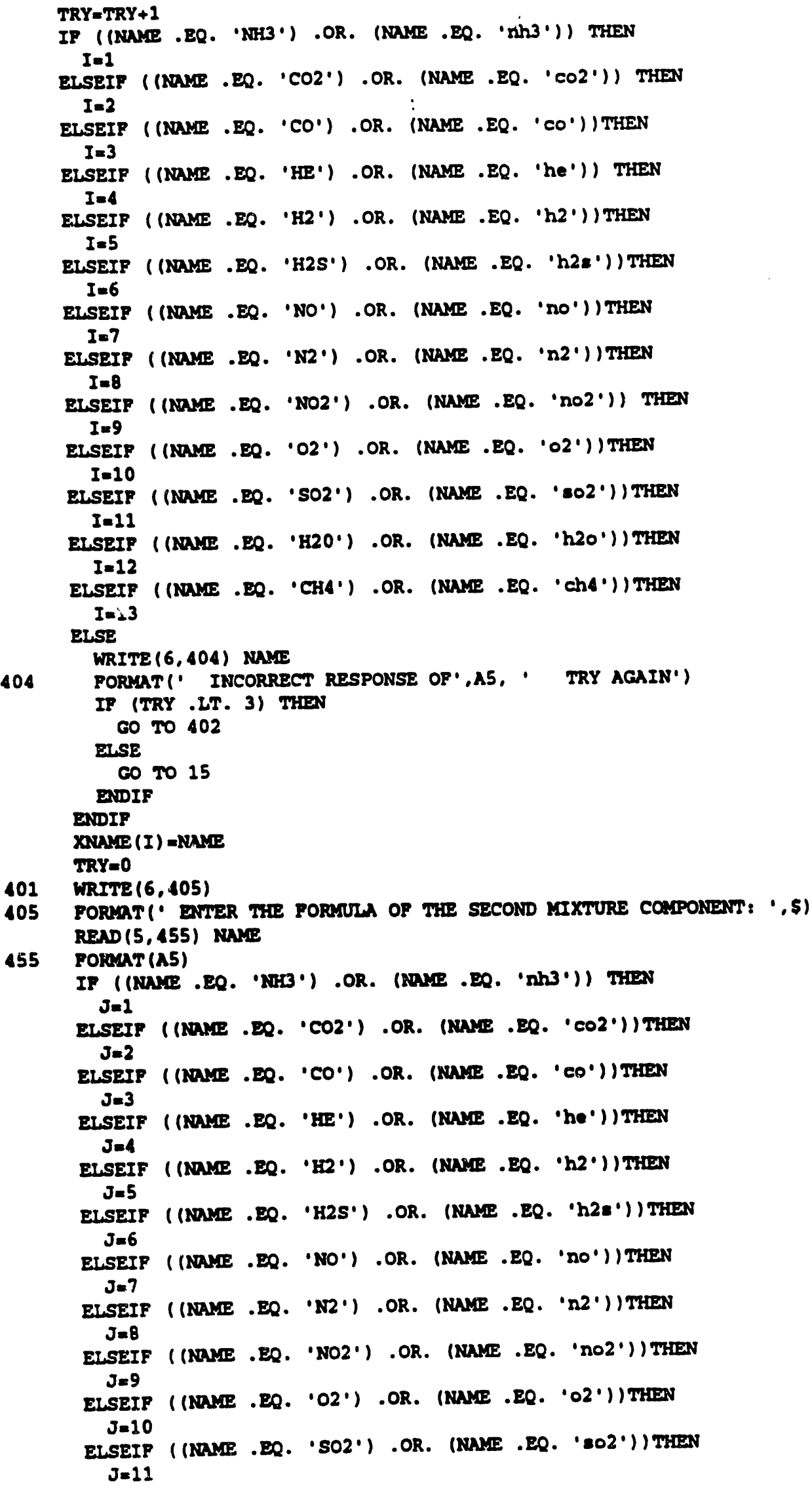




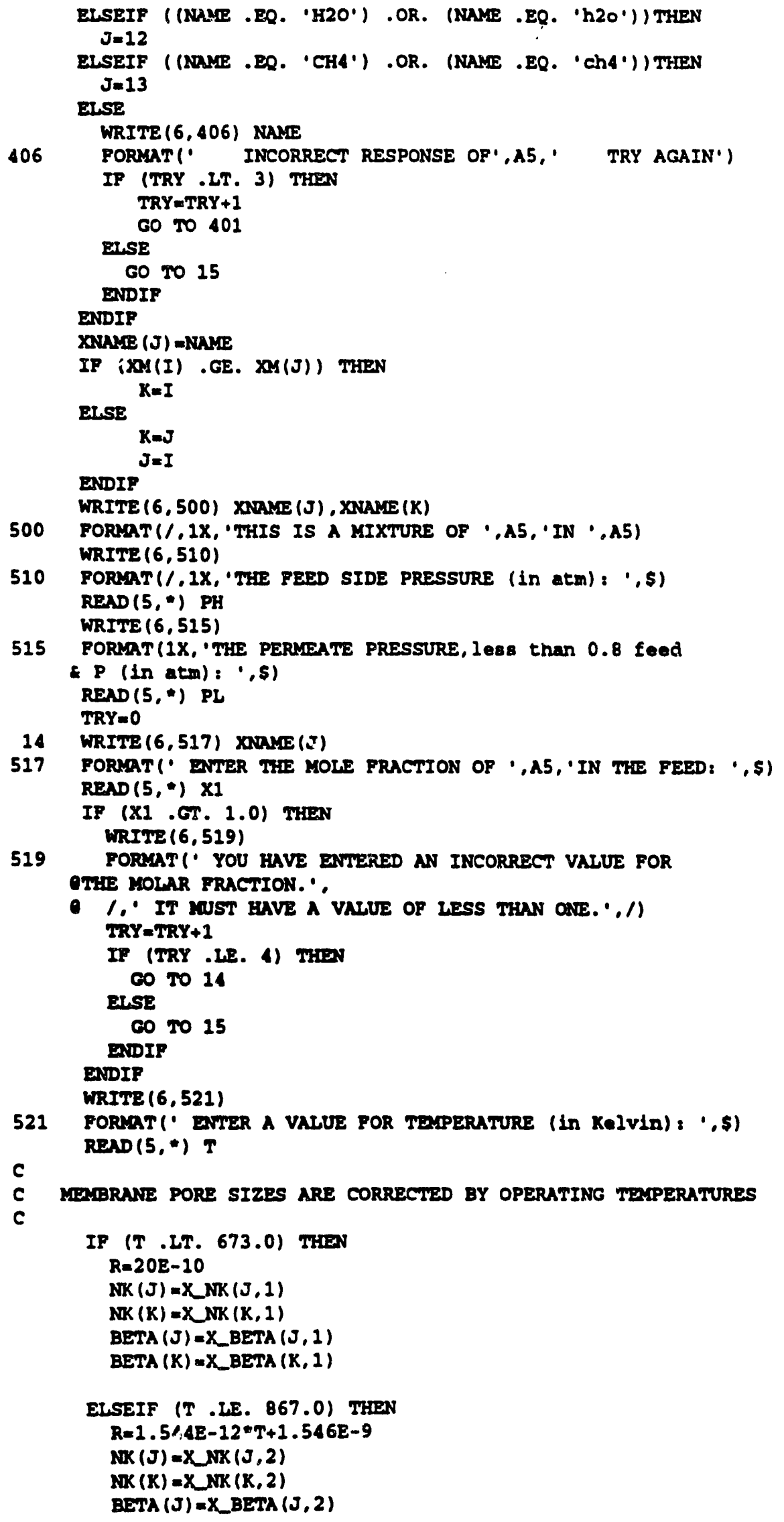


$\operatorname{BETA}(K)=X \_B E T A(K, 2)$

EUSEIF (T . LE. 1005.0) THEN

$R=2.679 \mathrm{E}-12 * T+6.272 \mathrm{E}-10$

$\operatorname{NK}(J)=X \operatorname{NK}(J, 3)$

$\operatorname{NK}(K)=X \operatorname{NKK}(X, 3)$

$\operatorname{BETA}(J)=X \_\operatorname{BETA}(J, 3)$

$\operatorname{BETA}(\mathrm{K})=\mathrm{X} \_$BETA $(K, 3)$

ELSEIF (T .LE. 1088.0) THEN

$R=4.243 E-12=T-8.167 E-10$

$\operatorname{NK}(J)=X \operatorname{NR}(J, 4)$

$\operatorname{NK}(K)=X \operatorname{NK}(K, 4)$

BETA $(J)=X \quad \operatorname{BETA}(J, 4)$

$\operatorname{BETA}(\mathrm{X})=\mathrm{X}$ BETA $(\mathrm{K}, 4)$

ELSE

WRITE $(6,502)$

502

FORYAT(' THE TEAPERATURE VALUE ENTERED IS OUT OP THE RANGE',

$R=38 \mathrm{~B}-10$

$1.0^{\circ}$ OF OUR STUDY BUT WILL BE RUN USING 815 C DATA.',/)

$\operatorname{NK}(J)=X \operatorname{NK}(J, 4)$

$\operatorname{MK}(K)=\mathrm{X} \operatorname{NKK}(K, 4)$

$\operatorname{BETA}(J)=X$ _BETA $(J, 4)$

BETA $(K)=X \_B E T A(K, 4)$

ENDIP

WRITE (6,504)

504 PORAST(' ENTER THE STMGE CUT VALUE (MUSE lese than 0.5):,$\$$ )

READ $(5, *)$ THETA

C CONSTANTS - RG : GAS CONSThNT, JMOLE-K

C RK : BOLTZWhNS'S CONSTANT, J/K

I : AVOCADRO NULBER, 1/MOLE

C

RG=8.314

$R K=1.38062 \mathrm{E}-23$

$I=6.022169 E+23$

$P I=3.1415926$

PH=PH*1.013E+05

PLEPL $1.013 E+05$

$P=(P H+P L) / 2.0$

C CaICULATE VISCOSITY, NU

TR=T/TC (J)

$\operatorname{VC}(2)=\operatorname{xar}(\tau) / R H O C(J)$

$P R=P /(P C(J) * 1.013 E 5)$

$P T R=1.058 *(T R * 0.645)-0.261 /((1.9 * T R) *(0.9 * 20610(1.9 * T R)))$

AYU-33.3*SORT (XAT (J) *TC (J)) *PIR/ (VC (J)*0.667)*1.08-07

NO $(J)=$ MUUP $(T R, P R, D I P(J), T C(J), P C(J), N \times U)$

TR=T/TC (K)

$\mathrm{VC}(\mathrm{K})=\mathrm{XY}(\mathrm{K}) / \mathrm{RHOC}(\mathrm{K})$

$P R=P /(P C(K) * 1.01385)$

$P T R=1.058 *(T R * 0.645)-0.261 /((1.9 * T R) *(0.9 * 20610(1.9 * T R)))$

$A X U=33.3 *$ SQRT $(X Y(X) * T C(K)) *$ FIR $/(V C(K) * 0.667) * 1.0 E-07$

NU $(X)=A Y U P(T R, P R, D I P(K), T C(K), P C(K), A M U)$

PHII $=(S O R T(1 / 8)$.

PHI $=((1+($ SQRT $(\mathrm{NU}(J) / \mathrm{NU}(\mathrm{K}))) *((\operatorname{XO}(\mathrm{K}) / \mathrm{XY}(J)) * 0.25)) * * 2)$

PHI $3=(\operatorname{SQRT}(1+(\operatorname{XOS}(\mathrm{J}) /$ XNA (K) $)))$

PHI $=((1+(\operatorname{SQRT}(N U(K) / N U(J))) *((\operatorname{XaS}(J) / \operatorname{XQ}(K)) * 0.25)) * 2)$

PHI5 $=(\operatorname{SORT}(1+(\operatorname{XOS}(\mathrm{K}) / \operatorname{XOX}(\mathrm{J}))))$

PHI $(J, K)=$ PHI 1 PHI $2 /$ PHI 3

PHI $(K, J)=$ PHI 1 * PHI $4 /$ PHI 5

WRITE $(6,950)$

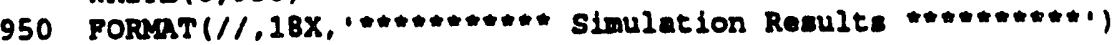

WRITE $(6,101)$ XNAYE $(J)$, NU (J), XNAYE $(K), N U(K)$ 


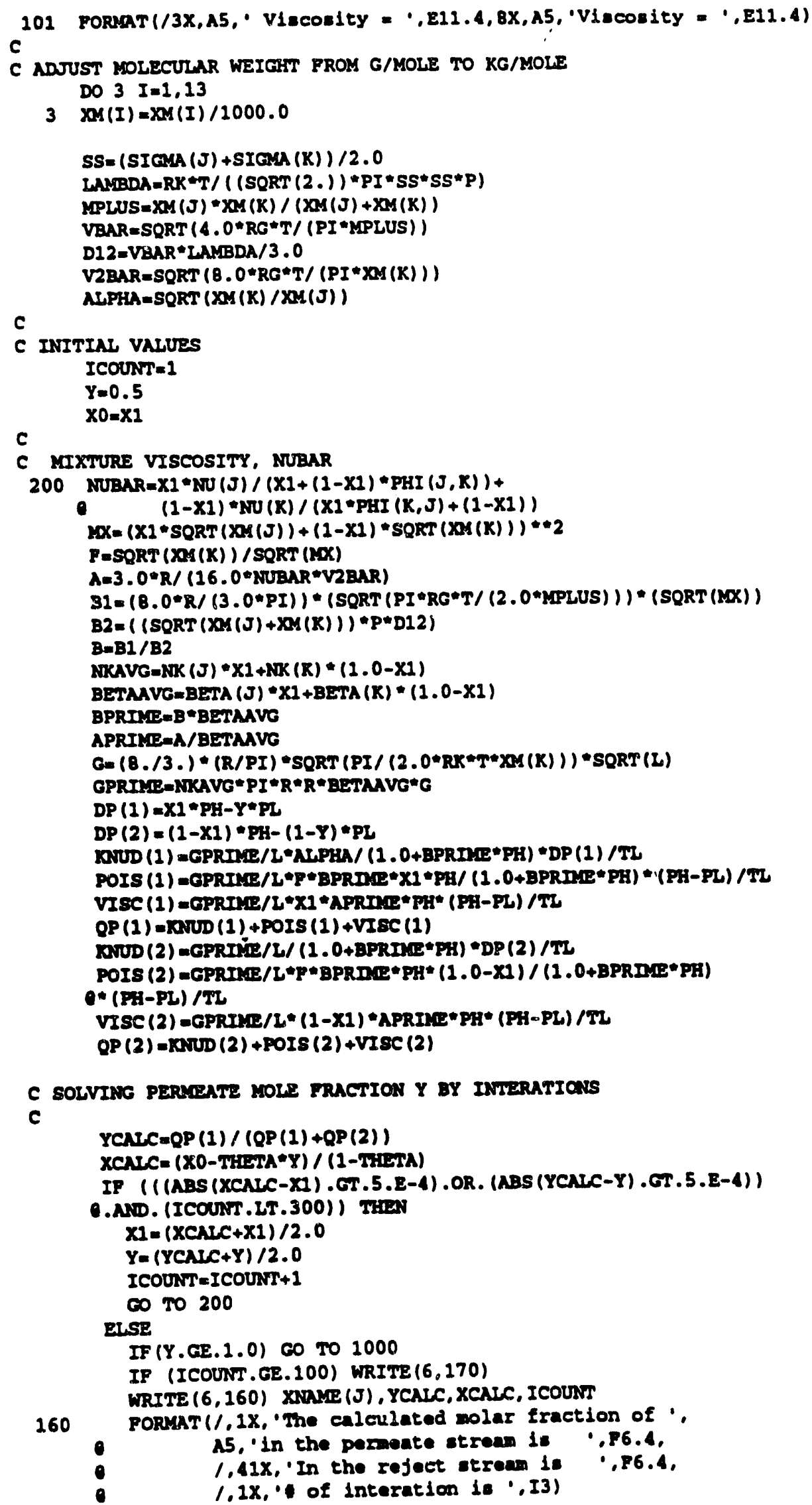


170 FORAT $(/ / .10 x, " 11$ WARNING $\mid 1$ The anewer may not be correct $)$ BNDIP

SEP FACTOR =YCALC/ $(1,0-Y C A L C) *(1-X 0) / \times 0$

WRITE $(6,960)$ SEP_PACTOR

WRITE $(6,900)$ XNANE (J), XNANE (K) :

MRITE $(6,910) \operatorname{KNUD}(1), \operatorname{KNUD}(1) / Q P(1) * 100, \operatorname{KNUD}(2)$.

0 $\operatorname{KNUD}(2) / Q P(2) * 100$.

WRITE (6,920) POIS(1), POIS (1)/QP(1)*100 .,POIS (2),

○ POIS (2)/QP (2)*100.

WRITE (6,930) VISC(1),VISC (1)/OP (1)*100, VISC (2),

0 $\operatorname{VISC}(2) / O P(2) * 100$

WRITE (6,940) QP(1), QP (2)

60 TO 15

1000 WRITE $(6,970)$

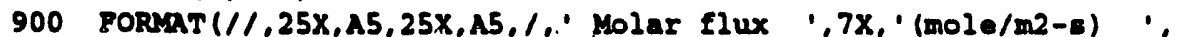
96x, '(\$)', 10X, (mole/m2-s)', 11X, '(s)')

910 Forapt (/,1X, 'Knuden diffusion', 4X, E9.2,7X,F5.1,9X, E9.2, 11X, F5.1)

920 FORXAT (/.1X, 'Momentum transfer'.4X,B9.2,7X,F5.1,9X,E9.2,11X, P5.1)

930 PORART (/, 1X, 'Viscous Elow', 9X, E9.2,7X, F5.1,9X, E9.2,11X, F5.1)

940 PORnT (/, 1X, 'Total'.16X, E9.2,21X, 29.2)

960 FORAT $(/ /, 10 x$, 'SEPARATION FACTOR $=\cdot, \mathbf{P 6 . 2})$

970 PORMT $(/ /, 1 X$, THE CAICUIATIONS FAILS.',/.1X, 'THE PRESSURE

- DIFPERENCE OP FESD AND PERUEATE MA BE TOO SMLL")

CLOSE (UNTT=1, STATUS='SAVE')

CLOSE (UNIT $=2$, STATUS=' SAVE')

CLOSE (UNIT-3, STATUS=' SAVE')

CLOSE (UNIT-4, STATUS" 'SAVE')

STOP

END

C - H-

C FUNCTION TO CNCUIATE PURE CAS VISCOSITY AT DIFPERENT PRESSURES

FUNCTION AXUP (TR, PR, DIP, TC, PC, AYU)

$A=1.9824 E-03 / T R * \operatorname{EXP}\left(5.2683 * T_{R} *(-0.5767)\right)$

$B=A *(1.6552 *$ IRR -1.2760$)$

$\mathrm{C}=0.1319 / \mathrm{IR}+\operatorname{EXP}(3.7035-\mathrm{IR} *(-79.8678))$

De2.9496/TR*EXP $\left(2.9190+\mathrm{TR}^{*} *(-16.6169)\right)$

DIPR=52.46*DIP*DIP*PC/ (TC*TC)

$0=1 .-5.655 * \mathrm{DIPR}$

$N Y U P=B * P R+1 . /(1 .+C \oplus P R * D)$

AIUP $=0 * A=P R * 1.5 /$ NIUP

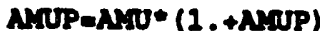

RETURN

END 
(xox1.dat)

SDATAI

$x y=17.03,44.01,28.01,4.00,2.016,34.08,30.01,28.02,46.01,32.0,64.06$, $18.016,16.04$

$D I P=1.5,0.0,0.1,0.0,0.0,0.9,0.2,0.0,0.4,0.0,1.6,1.8,0.0$

SIGEA $=2.624 E-10,3.996 \mathrm{E}-10,3.59 \mathrm{E}-10,2.7 \mathrm{E}-10,2.968 \mathrm{E}-10$, $2.655 \mathrm{E}-10,3.47 \mathrm{E}-10,3.681 \mathrm{E}-10,4.29 \mathrm{E}-10,3.433 \mathrm{E}-10,4.29 \mathrm{E}-10$, $2.655 \mathrm{E}-10,3.882 \mathrm{E}-10$

TC $=405.6,304.2,134.2,5.25,33.2,373.6,179.2,126.2,431.0$, $154.6,430.4,647.3,90.65$

$P C=113.5,73,35,2.26,12.8,88.9,65,33.5,100,49.7,77.7$, $218.4,45.8$

(MIX2. dat)

SDATA2

$\mathrm{EP}=0.5$

UK=0.339

$R=20.0 \mathrm{E}-10$

TLE $=0 \mathrm{E}-6$ SEAD

(200x3.dat)

$6.5 \mathrm{E} 15,6.5 \mathrm{E} 15,6.5 \mathrm{E} 15,6.5 \mathrm{E} 15$

2.5E15,2.5E15, 2.5E15,2.3E15

$6.5 E 15,6.5 E 15,6.5 E 15,6.5 E 15$

$2.1815,2.9815,2.9815,4.1815$

$6.5 \mathrm{E} 15,6.5 \mathrm{E} 15,6.5 \mathrm{E} 15,6.5 \mathrm{E} 15$

$6.5 E 15,6.5 E 15,6.5 E 15,6.5 E 15$

$6.5 \mathrm{E} 15,6.5 \mathrm{E} 15,6.5 \mathrm{E} 15,6.5 \mathrm{E} 15$

$6.5 \mathrm{E} 15,6.5 \mathrm{E} 15,6.5 \mathrm{E} 15,6.5 \mathrm{E} 15$

$6.5 \mathrm{E} 15,6.5 \mathrm{E} 15,6.5 \mathrm{E} 15,6.5 \mathrm{E} 15$

$6.5 E 15,6.5 E 15,6.5 E 15,6.5 E 15$

$6.5 \mathrm{E} 15,6.5 \mathrm{E} 15,6.5 \mathrm{E} 15,6.5 \mathrm{E} 15$

6.5E15,6.5E15,6.5E15,6.5E15

$3.4 E 15,8.5 E 15,8.8 E 15,8.8 E 15$

\section{(200x4. dnt)}

$0.5000,0.5000,0.5000,0.5000$ $0.5000,0.5637,0.5637,0.3857$ $0.5328,0.0873,0.0840,0.0793$ $0.9593,0.5383,0.5383,0.2540$ $1.3191,0.6332,0.6332,0.1529$ $0.5000,0.5000,0.5000,0.5000$ $0.5000,0.5000,0.5000,0.5000$ $0.7522,1.1109,1.1109,0.4643$ $0.5000,0.5000,0.5000,0.5000$ $0.5000,0.5000,0.5000,0.5000$ $0.5000,0.5000,0.5000,0.5000$ $0.5000,0.5000,0.5000,0.5000$ $0.3481,0.0580,0.0588,0.0944$ 

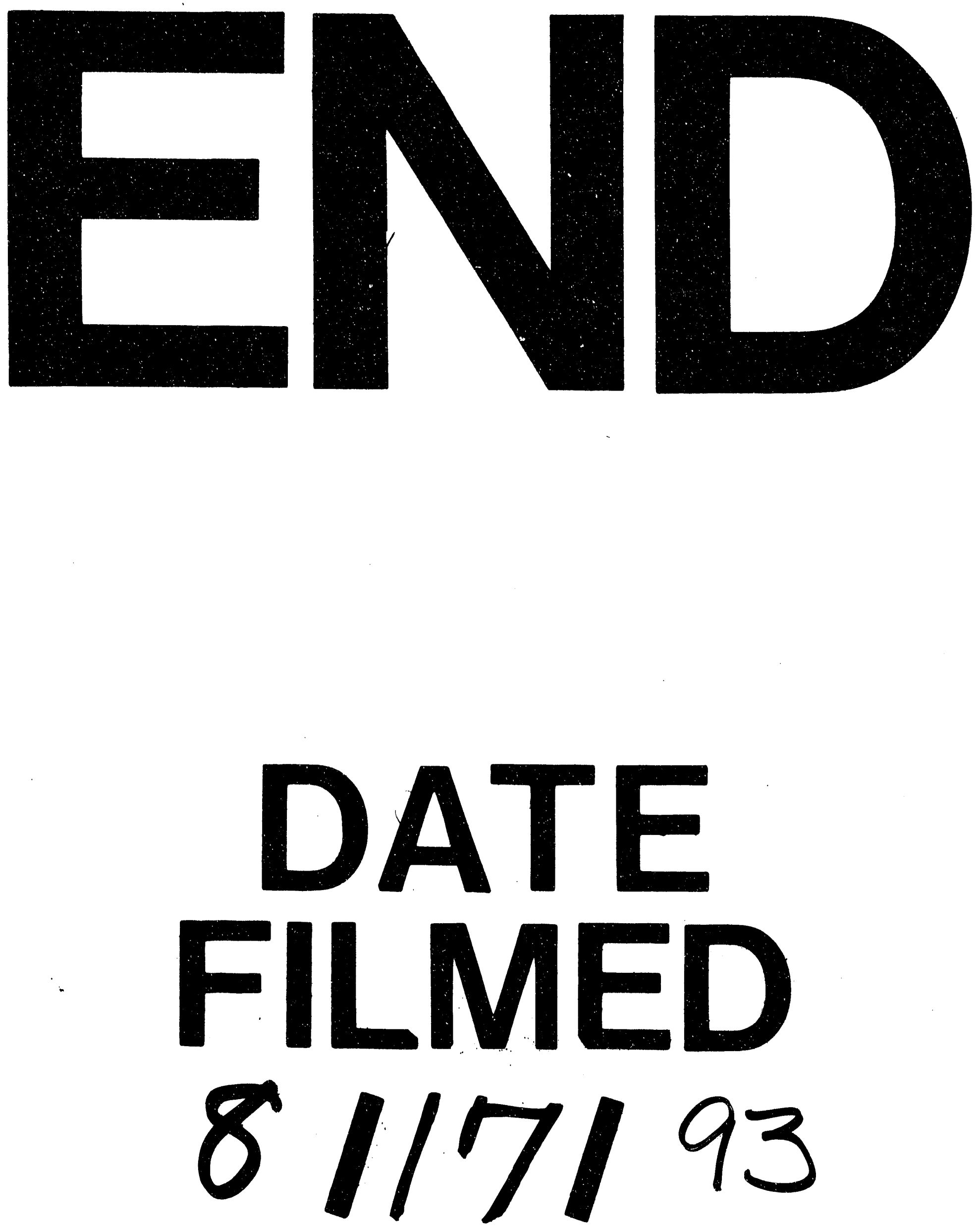